Portland State University

PDXScholar

Summer 9-10-2019

\title{
Concrete Bridge Deck Performance Data and Metrics for the State of Oregon
}

Jael Wettach-Glosser

Portland State University

Follow this and additional works at: https://pdxscholar.library.pdx.edu/open_access_etds

Part of the Civil Engineering Commons

Let us know how access to this document benefits you.

\section{Recommended Citation}

Wettach-Glosser, Jael, "Concrete Bridge Deck Performance Data and Metrics for the State of Oregon" (2019). Dissertations and Theses. Paper 5271.

https://doi.org/10.15760/etd.7144

This Thesis is brought to you for free and open access. It has been accepted for inclusion in Dissertations and Theses by an authorized administrator of PDXScholar. Please contact us if we can make this document more accessible: pdxscholar@pdx.edu. 
Concrete Bridge Deck Performance Data and Metrics for the State of Oregon

by

Jael Wettach-Glosser

A thesis submitted in partial fulfillment of the requirements for the degree of

Master of Science

in

Civil and Environmental Engineering

Thesis Committee:

Thomas Schumacher, Chair

Avinash Unnikrishnan

Jason C. Anderson

Portland State University

2019 
C2019 Jael Wettach-Glosser 


\begin{abstract}
Bridge decks are a critical element of a bridge that support and distribute vehicle loads to the superstructure. Because of the requirements of this role, bridge decks are exposed to severe conditions that typically lead to structural deficiency in bridges which is both costly and disruptive. Therefore, to keep bridges and highways in good repair, developing optimal preservation decisions for concrete bridge decks is key. In order to develop effective performance monitoring and preservation schedules, the parameters affecting bridge deck deterioration need to be better understood.
\end{abstract}

With guidance from the literature and Oregon Department of Transportation (ODOT) personnel, two datasets were created with data currently available through ODOT and the National Bridge Inventory (NBI). Using these datasets, a survival analysis utilizing Kaplan-Meier survival curves and Cox proportional hazards regression was performed to predict concrete bridge deck performance and identify the parameters that drive bridge deck deterioration. To compliment these findings, a survey was developed to identify information that should be collected on concrete bridge decks to improve performance monitoring. This survey was distributed to all Departments of Transportation's (DOT's) in the United States and to a few select non-destructive evaluation (NDE) contractors. Using the results from the survival analysis and the survey, a list of parameters that ODOT can use to improve concrete bridge deck performance monitoring in the future was compiled. 


\section{ACKNOWLEDGEMENTS}

This thesis would not be possible without the generous support and assistance I have received during my time at Portland State University.

First I would like to thank my advisors Thomas Schumacher and Avinash Unnikrishnan for sharing their knowledge and guiding this research. It truly has been a joy to work with them and I am forever grateful for their belief in my abilities and the opportunities they have given me.

I would also like to thank ODOT for funding this project and providing data analyzed in this thesis. Specifically, I would like to thank Bruce Johnson, Mathew Mabey, Bruce Novakovich, Andrew Blower, Ray Bottenberg, and Liz Hunt for sharing their expertise and providing valuables insights. I would also like to thank Liantao Xu and Charlotte Davidson for their assistance in gathering data.

In addition, I would like to thank the Dwight David Eisenhower Transportation Fellowship Program and ACI for their generous financial support during my master's degree program. 


\section{TABLE OF CONTENTS}

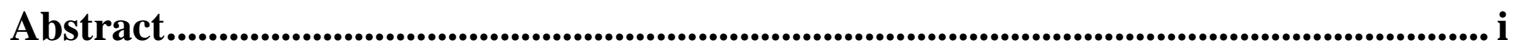

Acknowledgements .................................................................................................................. ii

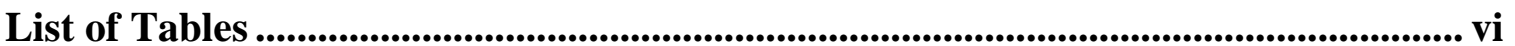

List of Figures............................................................................................................. vii

$1.0 \quad$ Introduction .............................................................................................................. 1

$2.0 \quad$ Literature Review ........................................................................................................... 3

$2.1 \quad$ Bridge Deck Deterioration ............................................................................ 3

2.1.1 Steel Reinforcement Corrosion.................................................................. 4

2.1.2 Concrete Cracking …………............................................................... 7

2.2 Parameters Affecting Deck Deterioration....................................................... 11

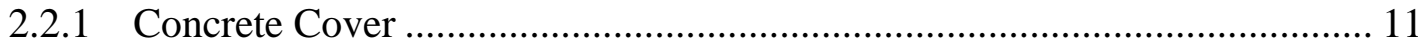

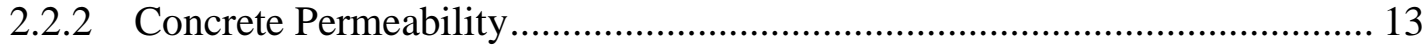

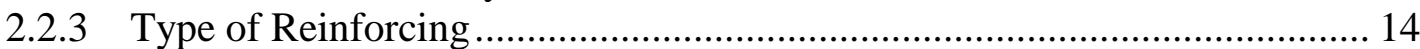

2.2.4 Exposure to Chlorides and Deicers........................................................ 16

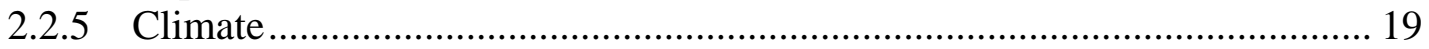

2.2.6 Average Daily Truck Traffic (ADTT) ……………................................... 22

2.3 Data Collection and Asset Management Practices ……………………......... 24

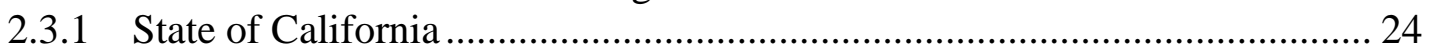

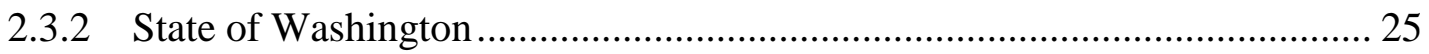

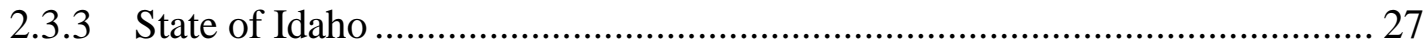

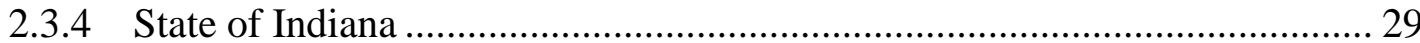

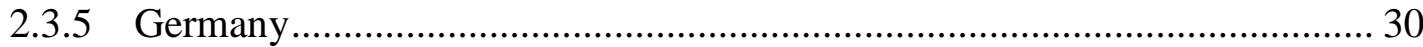

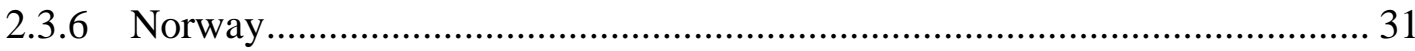

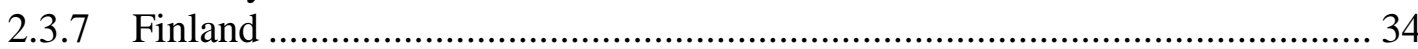

2.4 Service Life Prediction Models …………………......................................... 35

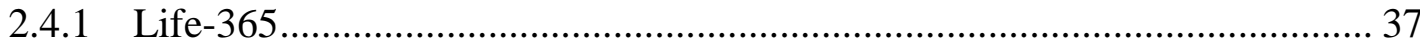

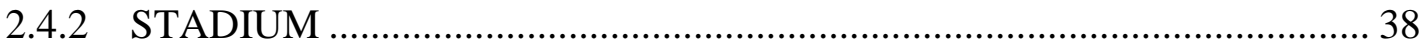

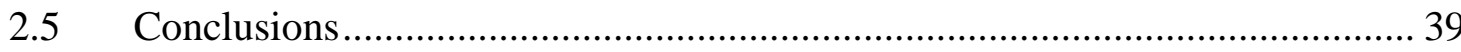

3.0 Dataset Assembly ................................................................................................... 42

3.1 Oregon-specific Datasets and performance metrics ........................................... 42

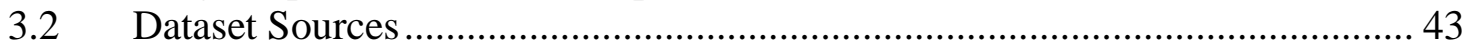

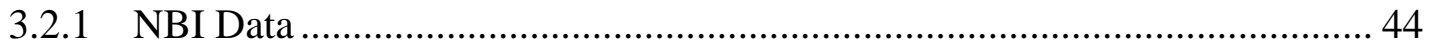

3.2.2 Element-Level Data and Health Index......................................................... 45

3.2.3 OTIA III Construction Data........................................................................... 47

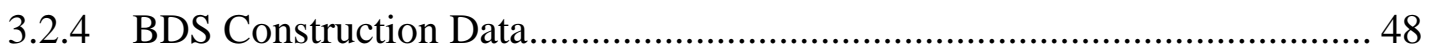

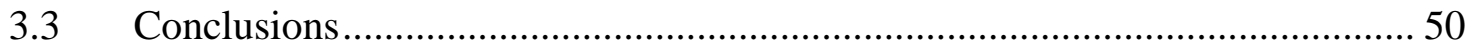

4.0 Descriptive Analysis of the NBI and refined Datasets........................................ 52

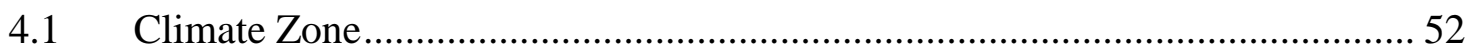

4.2 Design Period ........................................................................................... 57 


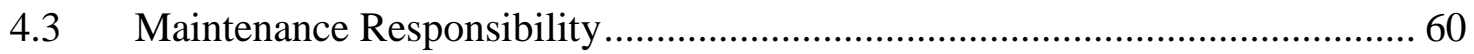

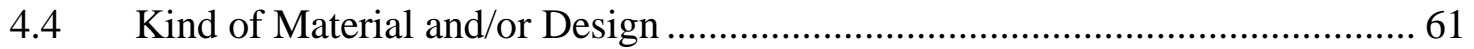

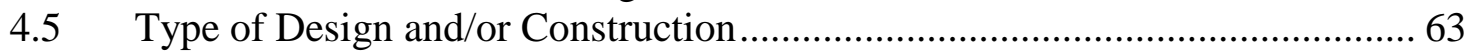

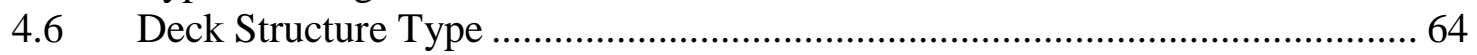

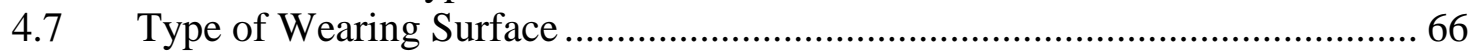

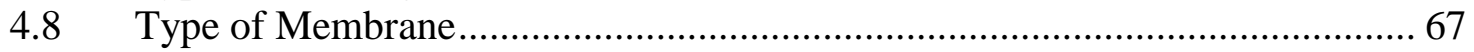

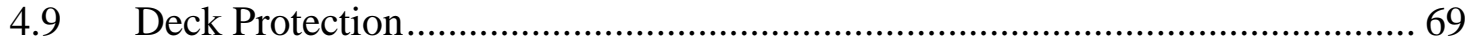

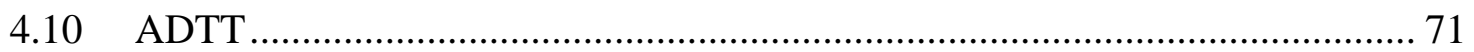

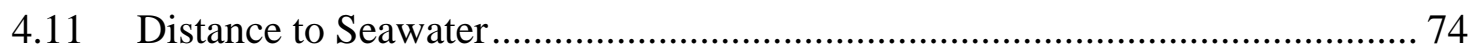

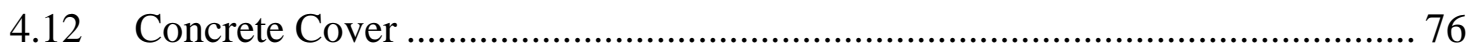

4.13 Transverse Rebar Spacing.................................................................. 78

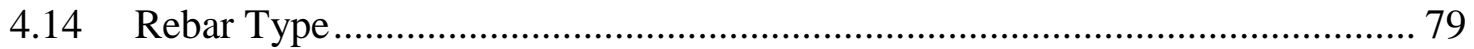

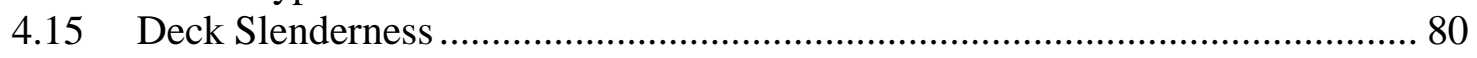

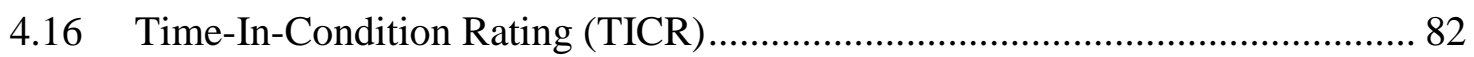

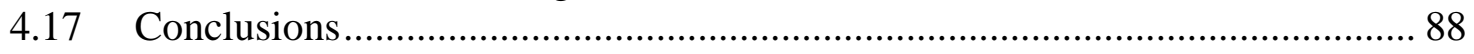

5.0 Survival Analysis................................................................................................... 92

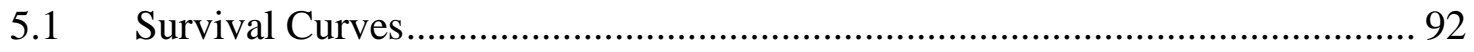

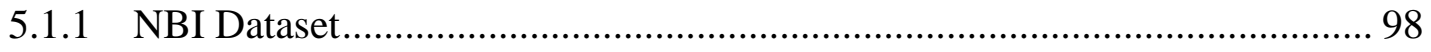

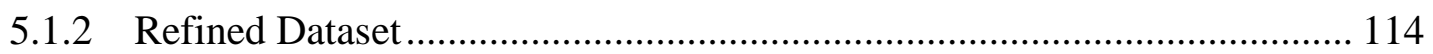

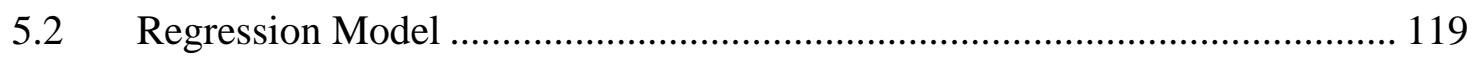

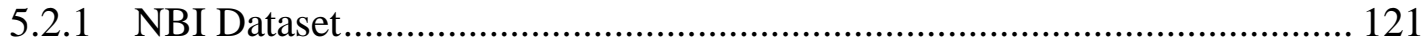

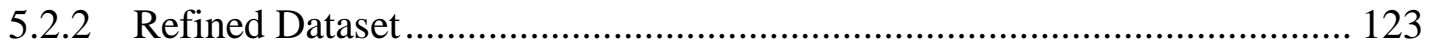

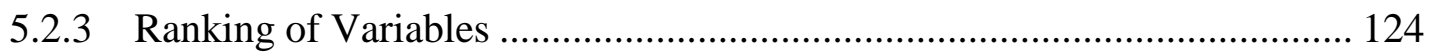

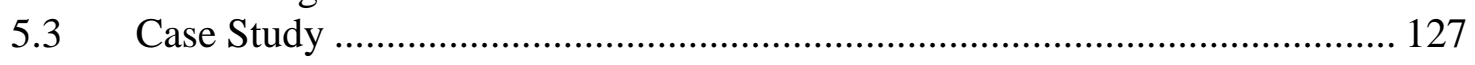

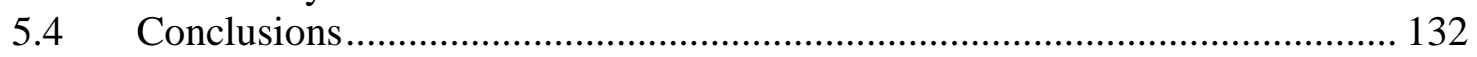

6.0 Survey ............................................................................................................... 134

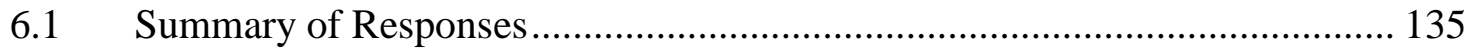

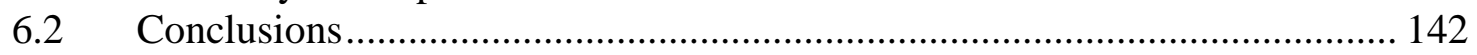

7.0 Summary and Conclusions ......................................................................... 143

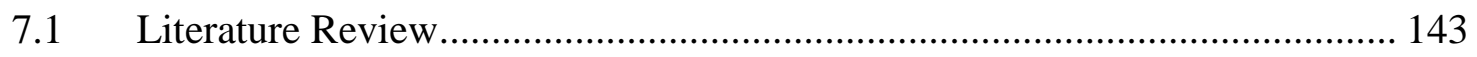

7.2 Data Assembly and Descriptive Analysis …………..................................... 144

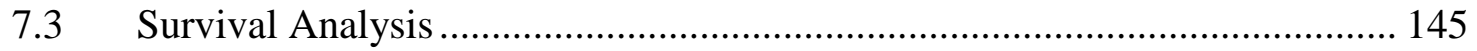

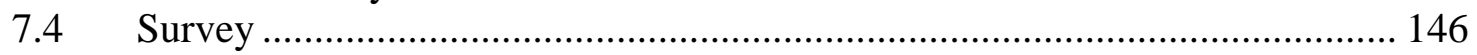

$7.5 \quad$ Recommendations .............................................................................. 147

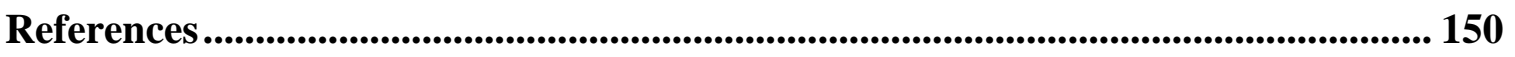

Appendix A: Survey Responses ............................................................................... 161

A.1 Survey Response from BDI ................................................................ 162

A.2 Survey Response from E2CHEM ……………....................................... 164

A.3 Survey Response from AIDPE ………………….................................... 166

A.4 Survey Response from Idaho DOT ............................................................. 168

A.5 Survey Response from Kentucky DOT …………...................................... 170 
A.6 Survey Response from Missouri DOT....................................................... 172

A.7 Survey Response from New Hampshire DOT …………………………...... 174

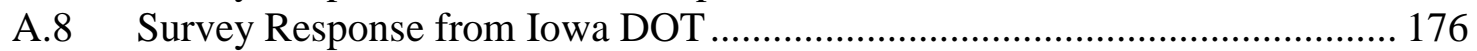

A.9 Survey Response from Mississippi DOT....................................................... 178

A.10 Survey Response from Tennessee DOT …………........................................ 180

A.11 Survey Response from Vermont DOT...................................................... 182

A.12 Survey Response from Florida DOT …………..................................... 184

A.13 Survey Response from Texas DOT ……................................................. 186

A.14 Survey Response from Maine DOT ........................................................ 188

A.15 Survey Response from Arkansas DOT ………………………………....... 190

A.16 Survey Response from Massachusetts DOT ………..................................... 192

A.17 Survey Response from North Carolina …………............................................ 194

A.18 Survey Response from Michigan DOT.................................................... 196

A.19 Survey Response from Connecticut.......................................................... 198

A.20 Surey Response from Georgia DOT …………........................................ 200

A.21 Survey Response from North Dakota DOT ………...................................... 202

A.22 Survey Response from Alaska ................................................................. 204

A.23 Survey Response from Californai DOT ......................................................... 206

A.24 Survey Response from New Jersey DOT ……………………………….... 208

A.25 Survey Response from Delaware DOT...................................................... 210

A.26 Survey Response from Colorado DOT ……….......................................... 212

A.27 Survey Response from Virginia DOT....................................................... 214

A.28 Survey Response from Montana DOT ........................................................... 216

A.29 Survey Response from Illinois DOT....................................................... 218

A.30 Survey Response from Minnesota DOT ………...................................... 220

A.31 Survey Response from South Dakota DOT …………………………......... 222

A.32 Survey Response from Washington DOT ...................................................... 224 


\section{LIST OF TABLES}

Table 2-1: Environment Type Based on Primary and Secondary Variables (McConnell,

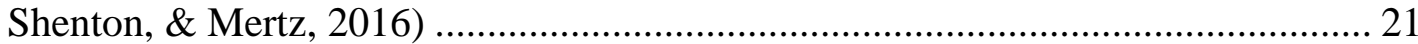

Table 2-2: Parameters Affecting Bridge Deck Deterioration .......................................... 40

Table 3-1: Variables Gathered and Derived from the NBI............................................ 45

Table 3-2: Percentage of Replacement Bridges with Available Construction Information

in FileNet .............................................................................................. 48

Table 3-3: Number of NBI Bridge Decks in Each Climate Zone/Design Period Group.. 50

Table 3-4: Number of Bridges in Each Climate Zone/Design Period Group with

Complete Construction Information ................................................................... 50

Table 4-1: Select Parameters Affecting Concrete Bridge Deck Deterioration .................. 52

Table 5-1: Survival Object Elements and Survival Probabilities for Bridge Decks in

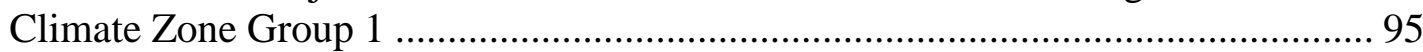

Table 5-2: Regression Results for the NBI Dataset ................................................ 122

Table 5-3: Regression Results for the Refined Dataset ................................................. 123

Table 5-4: Ranking of Variables Depending on CR Group for the NBI Dataset ............ 125

Table 5-5: Ranking of Variables Depending on CR Group for the Refined Dataset ..... 126

Table 5-6: Relative Hazard Ratios for the NBI Dataset ................................................ 129

Table 5-7: Relative Hazard Ratios for the Refined Dataset......................................... 129

Table 5-8: Characteristics of Concrete Bridge Deck on Bridge 00511 .......................... 129

Table 6-1 Survey Questions.................................................................................... 135

Table 7-1: Recommended Factors to Be Collected by ODOT ……………………........ 149 


\section{LIST OF FIGURES}

Figure 1-1: Bridges Addressed by Work Type. Example for the State of Oregon (ODOT, 2017) ...................................................................................................... 2

Figure 2-1: Photo of Deteriorated Bridge Deck in Branchport, NJ. Photo Courtesy by

Thomas Schumacher........................................................................................ 3

Figure 2-2: Illustration of Corrosion Propagation of a Steel Reinforcing Bar Submersed in

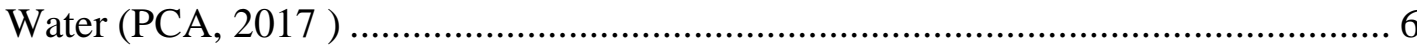

Figure 2-3: Illustration of Cracking in Concrete due to Steel Reinforcement Corrosion

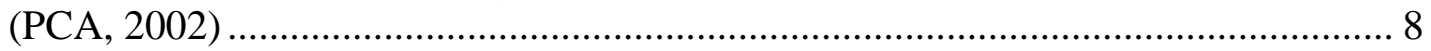

Figure 2-4: Time to Corrosion Initiation as a Function of Cover Depth and Chloride Concentration (Kassir \& Ghosn, 2001) ................................................................ 12

Figure 2-5: Survival Probability Curves by Deck Protection Measure (Fleischhacker, Ghonima, \& Schumacher, (In review))................................................................ 16

Figure 2-6: Survival Probability Curves by Climatic Region (Fleischhacker, Ghonima, \& Schumacher, (In review))............................................................................... 21

Figure 2-7: Survival Probability Curves by ADTT (Fleischhacker, Ghonima, \& Schumacher, (In review))............................................................................... 23

Figure 2-8: Bridge Deck Deterioration with Preservation Action (The vertical upward jumps represent bridge preservation action) (Azizinamini, Power, Myers, \&

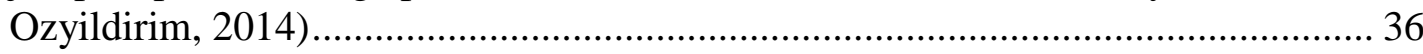

Figure 3-1: Element-level Condition State Quantities for a Sample Bridge Deck ........... 46

Figure 3-2: Health Indices for a Sample Bridge from 1998 to 2017 ............................... 47

Figure 4-1: Oregon Climate Zones .............................................................................. 54

Figure 4-2: Frequency Plot of Climate Zones in NBI Dataset.......................................... 54

Figure 4-3: Frequency Plot of Climate Zones in Refined Dataset..................................... 55

Figure 4-4: Frequency Plot of Climate Groups in NBI Dataset....................................... 55

Figure 4-5: Frequency Plot of Climate Groups in Refined Dataset................................. 56

Figure 4-6: Frequency Plot of Bridge Deck Effective Year Built in NBI Dataset ........... 58

Figure 4-7: Frequency Plot of Bridge Deck Effective Year Built in Refined Dataset ..... 58

Figure 4-8: Frequency Plot of Design Period in NBI Dataset ........................................ 59

Figure 4-9: Frequency Plot of Design Period in Refined Dataset ................................... 59

Figure 4-10: Frequency Plot of Maintenance Responsibility in NBI Dataset ................... 60

Figure 4-11: Frequency Plot of Maintenance Responsibility in Refined Dataset ............. 61

Figure 4-12: Frequency Plot of Bridge Material/Design in NBI Dataset ......................... 62

Figure 4-13: Frequency Plot of Bridge Material/Design in Refined Dataset ................... 62

Figure 4-14: Frequency Plot of Bridge Design/Construction in NBI Dataset ................... 63

Figure 4-15: Frequency Plot of Bridge Design/Construction in Refined Dataset ............ 64

Figure 4-16: Frequency Plot of Deck Structure Type in NBI Dataset............................... 65

Figure 4-17: Frequency Plot of Deck Structure Type in Refined Dataset......................... 65

Figure 4-18: Frequency Plot of Wearing Surface Types in NBI Dataset .......................... 66

Figure 4-19: Frequency Plot of Wearing Surface Types in Refined Dataset ................... 67

Figure 4-20: Frequency Plot of Membrane Types in NBI Dataset................................... 68

Figure 4-21: Frequency Plot of Membrane Types in Refined Dataset .............................. 68

Figure 4-22: Frequency Plot of Deck Protection Method in NBI Dataset......................... 69 
Figure 4-23: Frequency Plot Deck Protection Method in Refined Dataset ..................... 70

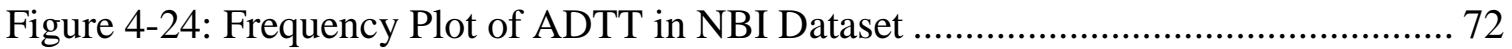

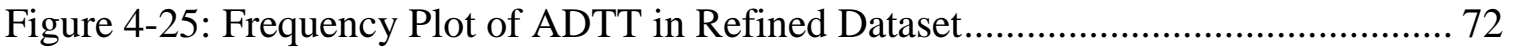

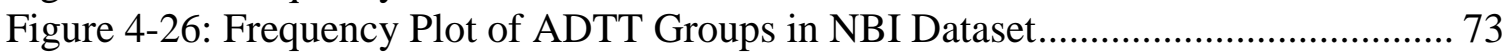

Figure 4-27: Frequency Plot of ADTT Groups in Refined Dataset............................... 73

Figure 4-28: Frequency Plot of Distance to Seawater in NBI Dataset ........................... 74

Figure 4-29: Frequency Plot of Distance to Seawater in Refined Dataset ...................... 75

Figure 4-30: Frequency Plot of Distance to Seawater Groups in NBI Dataset ............... 75

Figure 4-31: Frequency Plot of Distance to Seawater Groups in Refined Dataset.......... 76

Figure 4-32: Frequency Plot of Bridge Deck Concrete Cover in Refined Dataset.......... 77

Figure 4-33: Frequency Plot of Concrete Cover Groups in Refined Dataset ................... 77

Figure 4-34: Frequency Plot of Rebar Spacing in Refined Dataset................................ 78

Figure 4-35: Frequency Plot of Rebar Spacing Groups in Refined Dataset .................... 79

Figure 4-36: Frequency Plot of Rebar Type in Refined Dataset .................................. 80

Figure 4-37: Frequency Plot of Deck Slenderness in Refined Dataset.......................... 81

Figure 4-38: Frequency Plot of Deck Slenderness Groups in Refined Dataset............... 81

Figure 4-39: Three sample cases of CR records for 23 years of NBI data, 1992-2014.

Source: (Ghonima, Schumacher, Unnikrishnan, \& Fleischhacker, 2018) ............... 85

Figure 4-40: Bar Plot of Mean TICR from Refined Dataset ....................................... 85

Figure 4-41: Survival Curves of TICR from Refined Dataset ....................................... 86

Figure 4-42: Bar Plot of Mean TICR from Refined Dataset by Climate Group.............. 86

Figure 4-43: Survival Curves of Censored TICR from Refined Dataset by Climate Group

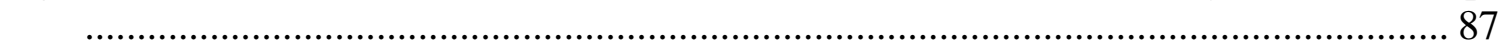

Figure 4-44: Bar Plot of Mean TICR from Refined Dataset by Design Period................ 87

Figure 4-45: Survival Curves of Censored TICR from Refined Dataset by Design Period

Figure 5-1: Survival Curve for Bridge Decks in Climate Zone Group 1........................ 96

Figure 5-2: Survival Curves for Bridge Decks in Climate Zone Group 1 and 3 ............. 97

Figure 5-3: Survival Curves of TICR Depending on CR ............................................ 99

Figure 5-4: Survival Curves of TICR Depending on Grouped Climate Zone ................ 100

Figure 5-5: Survival Curves of TICR Depending on Design Period ............................. 101

Figure 5-6: Survival Curves of TICR Depending on NBI Item 21 Maintenance

Responsibility ............................................................................................ 102

Figure 5-7: Survival Curves of TICR Depending on Prestressed Concrete Bridges from

NBI Item 43A Kind of Material and/or Design .................................................... 104

Figure 5-8: Survival Curves of TICR Depending on Continous Bridges from NBI Item

43A Kind of Material and/or Design ............................................................ 105

Figure 5-9: Survival Curves of TICR Depending on Prestressed, Steel, and Continuous

Bridges from NBI Item 43A Kind of Material and/or Design.............................. 106

Figure 5-10: Survival Curves of TICR Depending on NBI Item 43B Type of Design

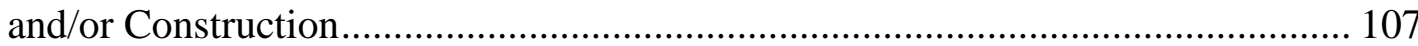

Figure 5-11: Survival Curves of TICR Depending on NBI Item 107 Deck Structure Type 
Figure 5-12: Survival Curves of TICR Depending on NBI Item 108A Type of Wearing

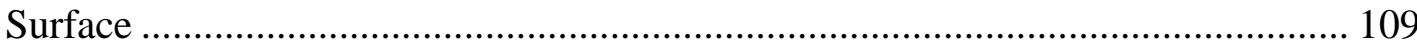

Figure 5-13: Survival Curves of TICR Depending on NBI Item 108B Type of Membrane

Figure 5-14: Survival Curves of TICR Depending on NBI Item 108C Deck Protection 111

Figure 5-15: Survival Curves of TICR Depending on ADTT ..................................... 112

Figure 5-16: Survival Curves of TICR Depending on Distance to Seawater .................. 113

Figure 5-17: Survival Curves of TICR Depending on Concrete Cover........................... 115

Figure 5-18: Survival Curves of TICR Depending on Transverse Rebar Spacing ......... 116

Figure 5-19: Survival Curves of TICR Depending on Rebar Type ................................ 117

Figure 5-20: Survival Curves of TICR Depending on Deck Slenderness ....................... 118

Figure 5-21: Relative Hazard of Bridge 00511........................................................ 130

Figure 5-22: Normalized Relative Hazards of Bridge Decks in Oregon ......................... 131

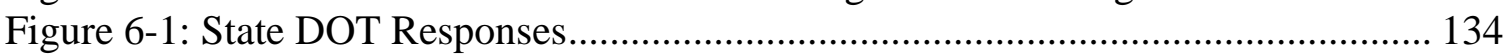

Figure 6-2: DOT Responses to Question 1.1 (Most Important Parameter Controlling Concrete Bridge Deck Performance) Grouped by Region in the United States ..... 136

Figure 6-3: DOT Responses to Question 1.2 (Second Most Important Parameter Controlling Concrete Bridge Deck Performance) Grouped by Region in the United States

Figure 6-4: DOT Responses to Question 1.3 (Third Most Important Parameter Controlling Concrete Bridge Deck Performance) Grouped by Region in the United States 138

Figure 6-5: Agency Responses to Question 3 .......................................................... 140 


\subsection{INTRODUCTION}

Bridges represent crucial components of the infrastructure in the United States. They allow for the transportation of people, materials, and goods over geographic obstacles that would otherwise be impassable. As of 2017, nearly $10 \%$ of all the bridges in the United States were categorized as structurally deficient (ASCE, 2017). This means that load carrying elements on the bridge were found to be in poor condition due to deterioration, damage, or a combination of both (FHWA, 2011). This is a serious issue considering that "on average there are 188 million trips across structurally deficient bridges each day" (ASCE, 2017). In addition, the average age of bridges in the U.S. is constantly increasing. Of the 614,387 bridges in the National Bridge Inventory (NBI), more than 30 percent have exceeded their 50-year design life, which means they are most likely in need of some form of repair, rehabilitation, or replacement (FHWA, 2011). To make matters worse, travel demands and the costs of bridge rehabilitation work will continue to increase while the availability of funding is limited (Koch, Brongers, Thompson, Virmani, \& Payer, 2003). As a result, the federal government estimates that there is a backlog of bridge rehabilitation and replacement costs totaling $\$ 123$ billion (ASCE, 2017). This emphasizes that the condition of bridges throughout the United States is a very important topic and the development of optimal preservation decisions is paramount. 


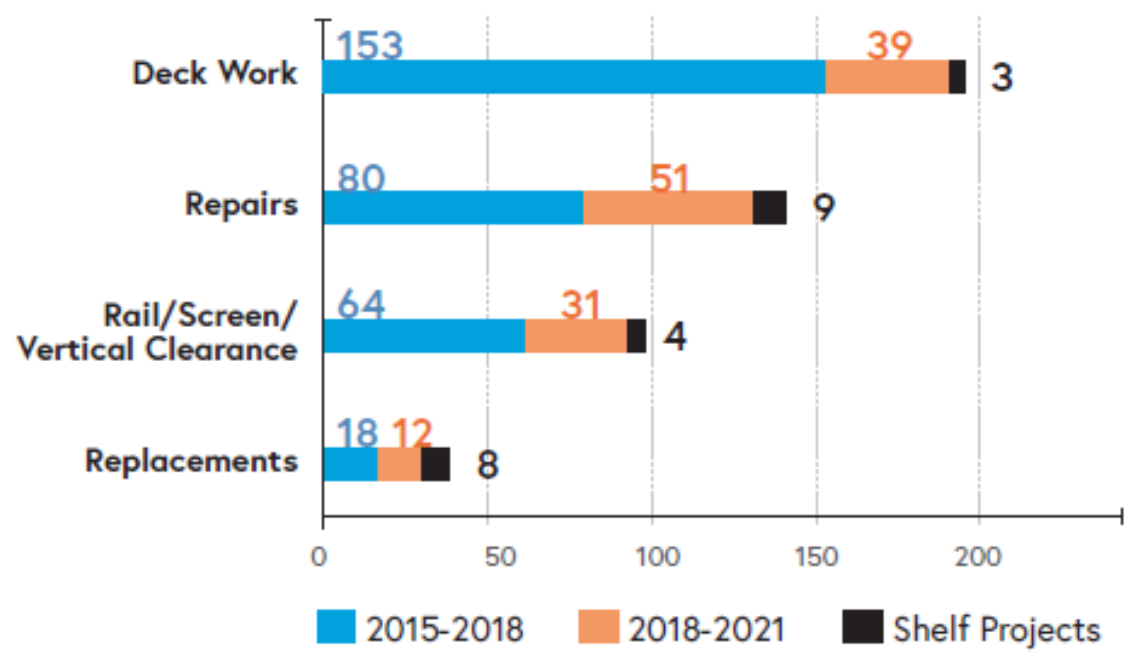

Figure 1-1: Bridges Addressed by Work Type. Example for the State of Oregon (ODOT, 2017)

Bridge decks are a critical element of a bridge as they support and distribute vehicle loads to the superstructure. However, because of the requirements of this role, bridge decks are exposed to "severe exposure conditions" (Williamson, Weyers, Brown, \& Sprinkel, 2007). According to the National Cooperative Highway Research Program (NCHRP) Synthesis 333, concrete bridge deck deterioration is one of the leading causes of structural deficiency in bridges. In addition, the preservation of concrete bridge decks is both costly and disruptive to highway systems (Koch, Brongers, Thompson, Virmani, \& Payer, 2003). Figure 1-1 shows an example of the number of work types performed on bridges, highlighting that the majority of ODOT bridge work focuses on preserving bridge decks (ODOT, 2017). Therefore, developing optimal preservation decisions for concrete bridge decks is key in keeping bridges and highways in good repair. In order to develop effective preservation schedules, the factors affecting bridge deck deterioration need to be understood. 


\subsection{LITERATURE REVIEW}

This literature review aims to identify parameters that influence deck deterioration so that condition monitoring and service-life prediction can be performed effectively. In addition, performance metrics and guidelines were gathered from select European countries and other State DOT's in an attempt to identify best practice.

\subsection{Bridge Deck Deterioration}

Concrete bridge deck deterioration is one of the main causes affecting the structural integrity of bridges in the National Bridge Inventory (NBI) (Russell, et al., 2004). This deterioration takes the form of concrete distress and corrosion of the reinforcement and can occur from freeze-thaw damage, abrasion damage, alkali-aggregate reactivity, excessive cracking, or spalling (Russell, et al., 2004; Li \& Zhang, 2001; Gucunski, et al., 2013; Agrawal, Kawaguchi, \& Chen, 2008). Figure 2-1 shows a bridge deck that required significant rehabilitation work after having been in service for only about 25 years.

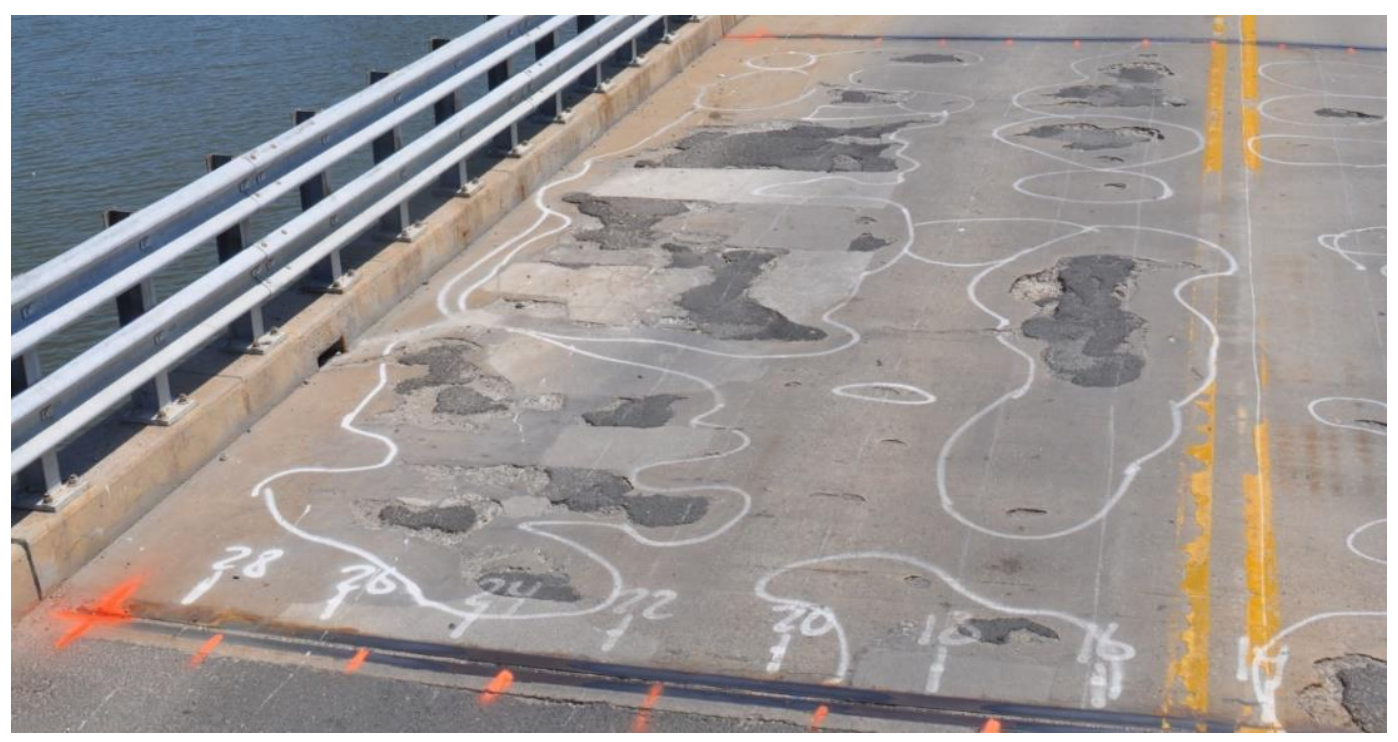

Figure 2-1: Photo of Deteriorated Bridge Deck in Branchport, NJ. Photo Courtesy by Thomas Schumacher. 
Despite there being a plethora of processes that cause deck deterioration, two main processes stand out: steel reinforcement corrosion and cracking of concrete (Li \& Zhang, 2001; Gucunski, et al., 2013; Agrawal, Kawaguchi, \& Chen, 2008). These are subsequently discussed in more detail, ordered by importance, according to the author's best judgment.

\subsubsection{Steel Reinforcement Corrosion}

Corrosion of steel reinforcing bars is the primary cause of concrete bridge deck deterioration (Stewart \& Rosowsky, 1998; Shi, et al., 2015; Shi, Cross, Liu, Fortune, \& Ewan, 2011). Bridge deck corrosion, through the corrosion of reinforcing steel, typically results from chloride contamination, and often is associated with low quality concrete, poor cover, and the use of deicers ( $\mathrm{Vu} \&$ Stewart, 2000; Koch, Brongers, Thompson, Virmani, \& Payer, 2003; Gucunski, et al., 2013). In 2002, a federal study estimated the annual cost of corrosion in the United States to be $\$ 276$ billion. Of that total, $\$ 2$ billion were associated with the cost of corrosion on bridge decks (Koch, Brongers, Thompson, Virmani, \& Payer, 2003). This cost is expected to increase in the future due to the trend that as bridges get older the rate of structural deterioration increases (Covino Jr., et al., 2002). This increase in the rate of deterioration is caused by the increase in legal load standards as well as the increase of chloride concentrations from the use of deicers (Stewart \& Rosowsky, 1998; Morcous, Lounis, \& Mirza, 2003). As the costs associated with corrosion increase, the impact of corrosion on optimal resource allocation becomes

more obvious. Understanding the process of corrosion in concrete bridge decks is vital in 
identifying parameters that drive deterioration. The process of corrosion in bridge decks is composed of two stages: initiation and propagation.

First, initiation, or the time it takes reinforcement to start corroding, begins with chloride contamination. Factors that affect contamination are characteristics of the concrete such as rebar cover, quality, compaction, and curing (Vu \& Stewart, 2000; Yu, Francois, Dang, L'Hostis, \& Gagne, 2015). These factors reflect the suitability of concrete to its exposure environment. Chlorides contaminate concrete by diffusing through the protective cover. Once the concentration of chlorides exceeds a critical threshold value, initiation takes place. Typically, bridge owners assume a critical corrosion threshold value in order to interpret chloride content data. However, it should be noted that no reliable range of chloride threshold values exists due to the uncertainty introduced by test procedures (Angst, Elsener, Larsen, \& Vennesland, 2009). Reported values of chloride threshold vary significantly and range from $0.04 \%$ to $8.34 \%$ total chloride by weight of cement (Angst, Elsener, Larsen, \& Vennesland, 2009). ODOT has seen widespread corrosion, with concentrations of $0.04 \%$, of bridge decks built between 1950 and 1970 with their typical Class A - 3000 psi mix design (Blower, 2019). Besides direct diffusion through the cover, corrosion can be initiated if chlorides, oxygen, and moisture are able to penetrate through cracks. These cracks can be formed from drying shrinkage, overloading, thermal expansion, or other processes (Vu \& Stewart, 2000). Corrosion can also be initiated when the passive layer around the reinforcing bar, which is provided by the concrete's inherent alkaline environment, is destroyed (PCA, 2017). 


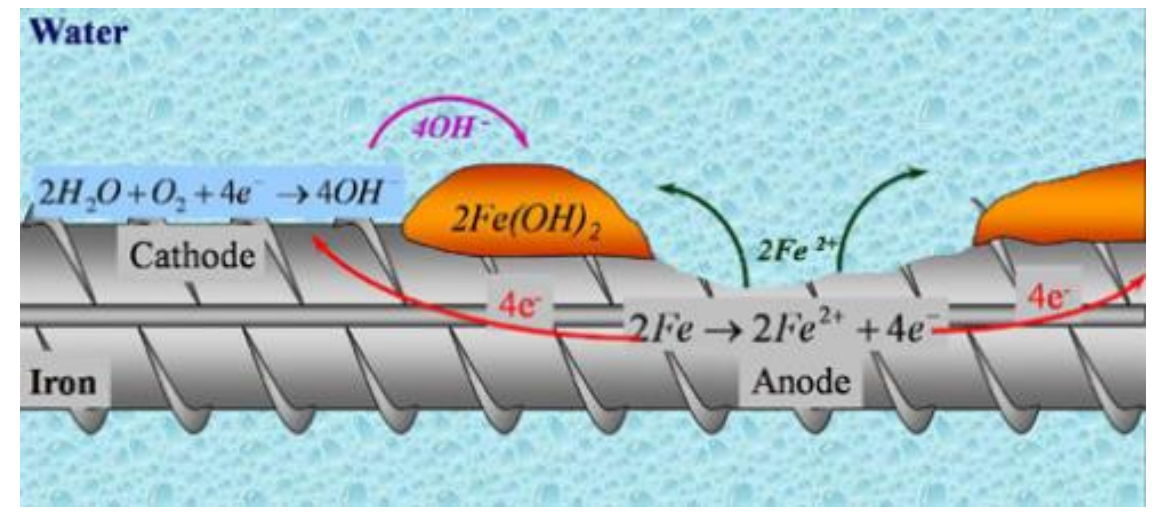

Figure 2-2: Illustration of Corrosion Propagation of a Steel Reinforcing Bar Submersed in Water (PCA, 2017)

Second, propagation takes place, as illustrated in Figure 2-2. Propagation is the loss of area associated with corrosion of the reinforcing steel. When reinforcement corrodes, metal area is decreased, and a byproduct is produced (rust) (PCA, 2017). This rust expands and creates tensile stresses inside the concrete that cause internal microcracking, external longitudinal cracking, and eventually spalling (Shi, Cross, Liu, Fortune, \& Ewan, 2011; Vu \& Stewart, 2000). When these events occur, the rate of corrosion is likely to increase and bond may be reduced, causing significant damage to the structural integrity of the bridge deck (Vu \& Stewart, 2000; Gucunski, et al., 2013).

Steel reinforcement corrosion is a significant contributor to the deterioration of concrete bridge decks. By understanding this process, it is apparent that the main factors contributing to deck corrosion are concrete cover, concrete permeability, and chloride concentration. 


\subsubsection{Concrete Cracking}

Li and Zhang (2001) describe the process of concrete bridge deck failure as a five-step process highlighting the role of cracking in bridge deck deterioration. First, early-age cracks develop transverse to the direction of traffic on the underside of the bridge deck (Li \& Zhang, 2001; Ideker \& Banuelos, 2014; Ideker, Deboodt, \& Fu, 2013). Despite primarily being caused by shrinkage and temperature changes, these cracks can be influenced heavily by traffic loading as well as the initial curing conditions (Li \& Zhang, 2001; Gucunski, et al., 2013; Anderson \& DiBrito, 2012; Lin, Zhao, \& Tabatabai, 2012). Second, as loading progresses, transverse cracks develop on the top of the deck while longitudinal cracks develop on the bottom of the deck. The transverse cracks on the top develop at weak areas and then progress through the deck. Eventually, these cracks connect with the transverse cracks on the bottom, producing through cracks. Third, water penetrates through the cracks which further wears out the concrete and accelerates crack growth. Fourth, traffic loading continues which further degrades through cracks, resulting in a loss of aggregate connection and load transfer. Finally, once the through cracks develop enough, the concrete deck fails in shear, which leads to spalling and depression of the slab (Li \& Zhang, 2001; Covino Jr., et al., 2002; Ideker, Deboodt, \& Fu, 2013). 


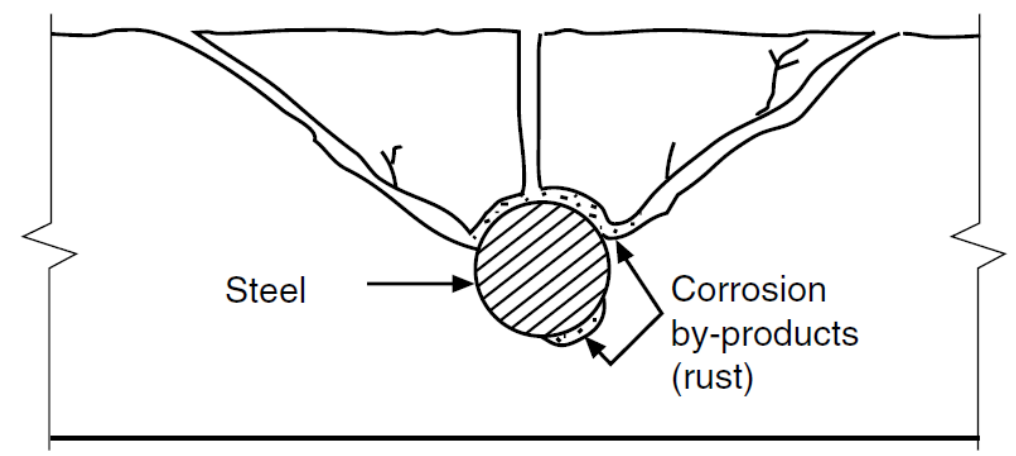

Figure 2-3: Illustration of Cracking in Concrete due to Steel Reinforcement Corrosion (PCA, 2002)

The first cracks that develop in concrete are typically the result of plastic shrinkage and drying shrinkage (PCA, 2002). These cracks, although small in scale, can have a large impact on deterioration as they expand and allow for the movement of chlorides (Vu \& Stewart, 2000). Plastic shrinkage cracks develop when the surface of fresh concrete shrinks due to rapid water loss through evaporation. The concrete below the drying surface restrains the shrinkage and tensile stresses develop, resulting in wide, shallow cracks. Drying shrinkage cracks develop as a result of restraint to shrinkage and are the most common cracks that occur in concrete. As fresh concrete dries, excess water evaporates, causing shrinkage. As the volume of concrete decreases, reinforcement and other structural components restrain the concrete, inducing tensile stresses which result in cracks through the hardened concrete (PCA, 2002). Proper curing can be achieved by providing the concrete with excess water and covering the surface to prevent evaporation. While effective, this process is time-consuming and can pose a considerable challenge for projects with significant time constraints. A potential solution to this challenge is the use 
of self-curing admixtures that reduce shrinkage and thus prevent early-age cracking (Anderson \& DiBrito, 2012; Ideker, Deboodt, \& Fu, 2013).

Similar to shrinkage cracks, thermal cracks develop when the expansion of concrete due to temperature change is restrained. Thermal cracks can develop when concrete is either heated or cooled and can vary depending on aggregate type, cement content, watercement ratio, temperature range, concrete age, and relative humidity (PCA, 2002). Although thermal cracking is a common issue, properly designing for thermal movement by using sliding bearings and expansion joints can minimize cracking.

For bridges in the northern regions of the United States, deterioration as a result of freeze-thaw is a significant consideration. When water freezes, the volume of the liquid increases by $9 \%$. When this occurs to the water inside moist concrete, pressures develop in the capillaries and pores that result in tensile stresses (PCA, 2002; Guthrie, Waters, \& Reese, 2015). If the tensile strength of the concrete is exceeded, cracking, scaling, and crumbling can take place. To minimize this form of deterioration, concrete should be designed to contain entrained air to allow for the expansion of water and, simultaneously, have reduced permeability to limit water penetration (PCA, 2002). In addition, the effect of certain deicers should be kept in mind. Studies have shown that deicers that contain the cations magnesium/calcium or the anions formate/acetate increase permeability and decrease the strength of concrete which can result in further cracking (Shi, et al., 2009). 
Deterioration is also influenced by fatigue cracking (Li \& Zhang, 2001; Gucunski, et al., 2013). Fatigue cracking on bridge decks is due to the significant fatigue loads that bridges experience from traffic. An indication of the loads a bridge endures is average daily truck traffic (ADTT), which can result in up to 2 million trucks a year (Li \& Zhang, 2001). Hence, a bridge can experience millions of load cycles throughout its life span, which contributes to the propagation of fatigue cracks and further deterioration. According to Li and Zhang, the ability of concrete bridge decks to resist fatigue cracking is as important as its ability to resist corrosion (Li \& Zhang, 2001). Fatigue loads contribute to the development of through cracks, which reduce aggregate connection and load transfer.

As the number and size of cracks increase, so does the potential for chloride initiation (Gucunski, et al., 2013; Yu, Francois, Dang, L'Hostis, \& Gagne, 2015; Guthrie, Waters, $\&$ Reese, 2015; Dong, et al., 2017). Once chlorides reach the reinforcing steel, propagation takes place and the steel corrodes (see section 2.2.1). As a result, tensile stresses develop in the concrete creating severe cracking and spalling (Shi, Cross, Liu, Fortune, \& Ewan, 2011; Vu \& Stewart, 2000).

From these processes, it is apparent that cracking in concrete plays a significant role in the deterioration of concrete bridge decks. Cracks develop throughout a bridge decks life and increase the speed at which deterioration occurs. Therefore, understanding the factors 
that increase resistance to cracking is crucial. Factors that influence cracking are steel reinforcement corrosion, traffic loads, climate, and the quality of the concrete.

\subsection{Parameters Affecting Deck Deterioration}

In the previous section, the main deterioration processes and their contributing factors were identified and summarized. Of the many ways deterioration occurs, corrosion of the reinforcing steel and cracking of the concrete were found to be the two most influential processes affecting bridge deck performance. These two processes interact with each other making deterioration more damaging and costly as time progresses. In order to provide more effective bridge preservation, the factors affecting deterioration need to be understood and observed. To do this, parameters that can be measured in the field were identified and are explained in further detail.

\subsubsection{Concrete Cover}

Corrosion of steel reinforcing bars is the most prominent process in the deterioration of concrete bridge decks, and therefore reducing chloride contamination is of the utmost importance. One parameter that affects chloride concentration is concrete cover thickness (Russell, et al., 2004; Shi, Cross, Liu, Fortune, \& Ewan, 2011; Yu, Francois, Dang, L'Hostis, \& Gagne, 2015). Concrete cover is the layer of concrete that deters chloride ingress by protecting reinforcing steel from water and salts. In a study on chloride core measurements from 15 bridge decks in the snow belt region, a positive correlation between cover depth and corrosion initiation was found (Figure 2-4) (Kassir \& Ghosn, 2001). 


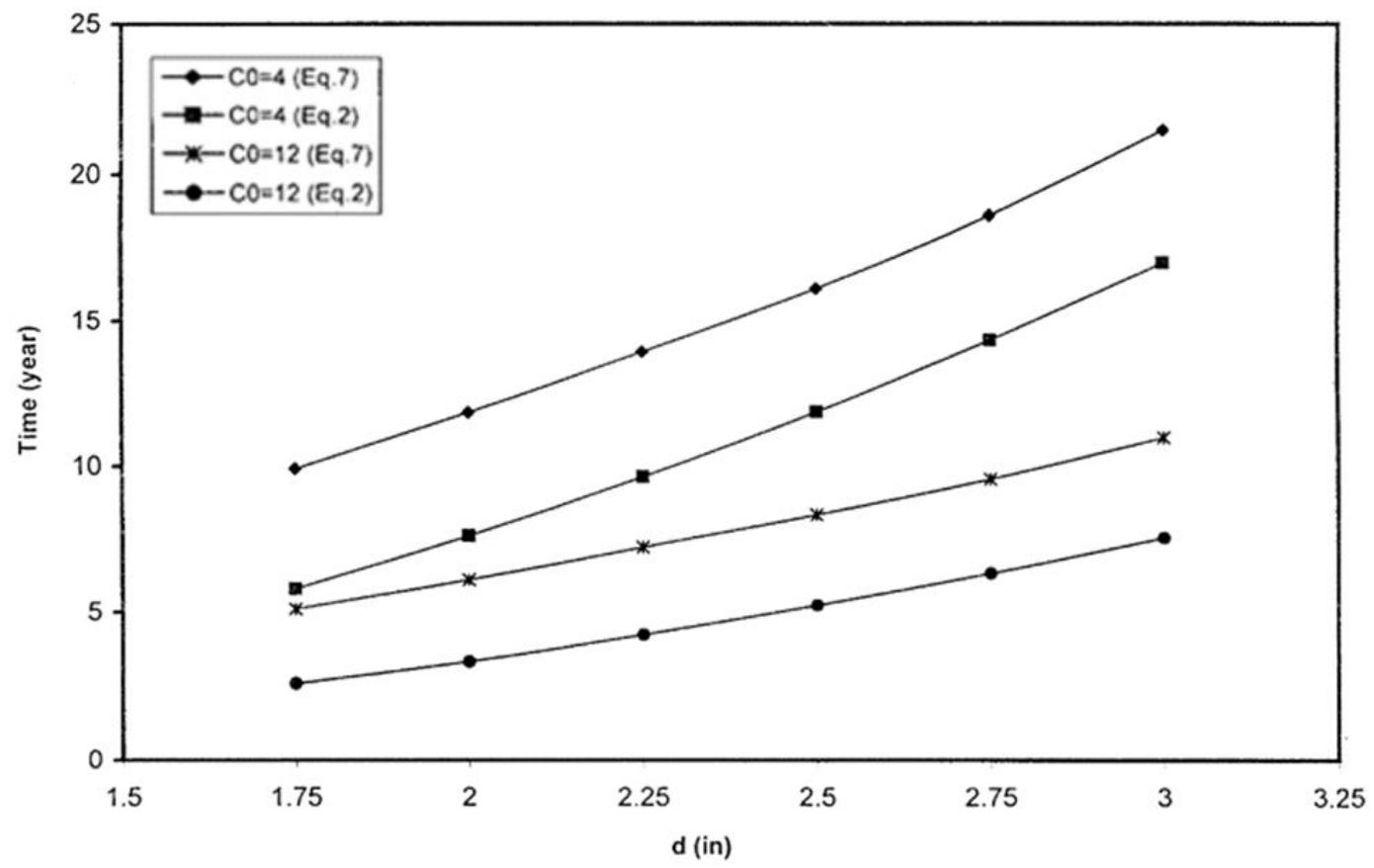

Figure 2-4: Time to Corrosion Initiation as a Function of Cover Depth and Chloride Concentration (Kassir \& Ghosn, 2001)

This suggests that increasing concrete cover slows down the corrosion process by increasing the time for chlorides to reach the reinforcement (Kirkpatrick, Weyers, Anderson-Cook, \& Sprinkel, 2002; Shi, Xie, Fortune, \& Gong, 2012 ). Therefore, deterioration of bridge decks can be reduced by an increase in cover thickness. However, while increasing cover thickness increases the time to corrosion initiation, existing crack width models suggest that thicker cover results in wider surface cracks (Stewart \& Rosowsky, 1998; Russell, et al., 2004; Shi, Xie, Fortune, \& Gong, 2012 ). This presents a dilemma, once cracks develop, chloride ingress accelerates. Therefore, concrete cover of bridge decks must be in a range that effectively deters chloride ingress but at the same time reduces crack width. Concrete cover is a parameter that has been proven to effect deterioration and is valuable in predicting the service life of bridge decks. 


\subsubsection{Concrete Permeability}

Although increased cover creates a barrier between the environment and reinforcement, chloride contamination can still occur through un-cracked concrete by the transport of chloride ions in water. The primary way in which chloride ions move through un-cracked concrete is via the pore structure of the cement paste and the interfaces between aggregates and cement matrix (Clifton, et al., 2000; Dong, et al., 2017; Achal, Mukherjee, \& Reddy, 2011). Therefore, the main parameter influencing the movement of chlorides in bridge decks is concrete permeability. Concrete permeability is mainly a function of the water-cement ratio and maximum aggregate size but can be substantially affected by additives and proper compaction/curing procedures (Clifton, et al., 2000; Shi, Xie, Fortune, \& Gong, 2012 ). In a study focused on the behavior of a "typical" reinforced concrete bridge, it was determined that an increase in permeability due to an increase in water-cement ratio had a greater effect on chloride ingress than concrete cover (Vu \& Stewart, 2000). This highlights the fact that although proper cover can exist, chloride contamination is almost guaranteed for permeable concrete. The water-cement ratio is widely considered to have a significant influence on concrete permeability due to its effect on capillary porosity (Vu \& Stewart, 2000; Clifton, et al., 2000). However, studies have shown that the use of low water-cement ratio's in concrete results in higher compressive strengths, higher moduli of elasticity, and lower creep, which promote cracking (Russell, et al., 2004). Once cracking occurs, the permeability of concrete matters little since a more effective path to the reinforcement has been created $(\mathrm{Yu}$, Francois, Dang, L'Hostis, \& Gagne, 2015). Therefore, concrete water-cement ratios must be contained in a range that encourages low permeability and cracking. Permeability in 
concrete decks should be reduced by the addition of fly ash, silica fume, and groundgranulated blast furnace slag to reduce chloride ingress (Russell, et al., 2004; Williamson, Weyers, Brown, \& Sprinkel, 2007). Studies have shown that the addition of admixtures decreases the $\mathrm{pH}$ of concrete which in turn decreases the threshold chloride level. Although this accelerates chloride initiation, steel reinforcement is still better protected due to increased resistance to chloride ion penetration (Thomas, 1996).

\subsubsection{Type of Reinforcing}

While increased concrete cover and reduced concrete permeability aim to slow the ingress of chlorides, changing the reinforcement type can be effective in reducing bridge deck corrosion. Over the last 40 years the most popular corrosion resistant reinforcement alternative has been epoxy-coated rebar (Phares, Fanous, Wipf, Lee, \& Jolley, 2006; Russell, et al., 2004; Kirkpatrick, Weyers, Anderson-Cook, \& Sprinkel, 2002; Eamon, Jensen, Grace, \& Shi, 2012). Epoxy-coated rebar effectively limits steel contact with oxygen, chlorides, and moisture while keeping costs relatively low. Based on test data, epoxy-coated rebar takes 12 times longer to corrode then standard rebar (Russell, et al., 2004). However, a major drawback in epoxy-coated rebar is the potential for chips and cracks during installation. If the rebar coating becomes damaged, localized corrosion of the steel reinforcement can take place (Phares, Fanous, Wipf, Lee, \& Jolley, 2006; Liu, Zhao, Liu, Cen, \& Xue, 2016). In addition, in conditions where epoxy-coated rebar is continuously wet, the adhesive between the steel and coating can wear out over time reducing the chloride protection (Russell, et al., 2004). Because of these issues, other alternatives have been suggested such as rebar made of stainless steel, galvanized steel, 
and microcomposite steel (Clifton, et al., 2000; Williamson, Weyers, Brown, \& Sprinkel, 2007). These reinforcement alternatives use different alloys to raise the chloride threshold before corrosion initiates. The chloride threshold for galvanized steel is approximately 2.5 times greater than the threshold for carbon steel. In comparison, the chloride threshold for stainless steel is approximately 10.5 times greater than the threshold for carbon steel, while the threshold for microcomposite steel is around 3.5 times higher (Williamson, Weyers, Brown, \& Sprinkel, 2007). Figure 2-5 shows the survival probability curves for commonly used reinforcements as described in NBI Item 108C (FHWA, 1995) computed by Fleischhacker, Ghonima, \& Schumacher (In review). Higher curves indicate better performance. In addition, although only used in a small number of bridges in the United States, interest in fiber reinforced polymer (FRP) rebars have grown as a potential replacement for steel rebars. FRP reinforcement is noncorrosive and is considered a cost-effective alternative despite large initial costs (Eamon, Jensen, Grace, \& Shi, 2012). These alternatives provide a lot of promise in terms of how much chloride they can withstand. However, due to limited field data and the cost of materials, these alternatives have seen limited use. Overall, reinforcement type influences deck deterioration and with the development of alternatives should be even more influential in the future. 


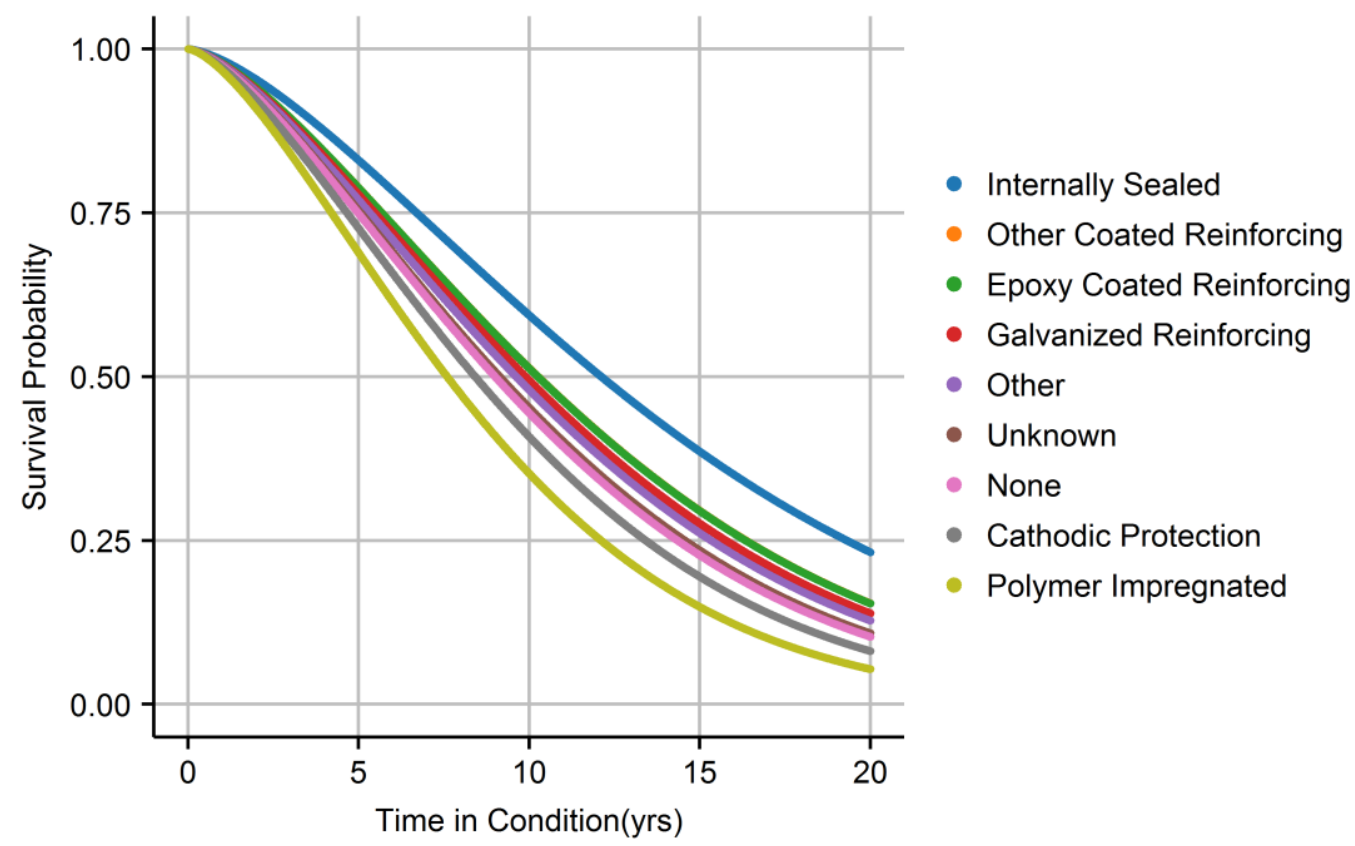

Figure 2-5: Survival Probability Curves by Deck Protection Measure (Fleischhacker, Ghonima, \& Schumacher, (In review)).

\subsubsection{Exposure to Chlorides and Deicers}

According to the literature, concrete bridge decks are exposed to chlorides from two main sources, deicing salts from winter maintenance and salt spray from the ocean (Kassir \& Ghosn, 2001; Koch, Brongers, Thompson, Virmani, \& Payer, 2003; Covino Jr., et al., 2002; Shi, Cross, Liu, Fortune, \& Ewan, 2011; Yu, Francois, Dang, L'Hostis, \& Gagne, 2015; Shi, Xie, Fortune, \& Gong, 2012 ). Of these sources, deicing salts have garnered the most attention due to the large increase of use in the last 60 years. In the 1950s the United States used 1,000,000 tons of deicing salts which gradually increased to $15,000,000$ tons in the 1990s (Stewart \& Rosowsky, 1998). The amount of chloride ions present on a bridge deck is determined by how often deicing salts are applied and the 
number of cycles of wetting and drying that occur (Kassir \& Ghosn, 2001). The more deicing salts that are applied, the more likely deterioration will take place (Russell, et al., 2004; Houska, 2007). For example, bridges on interstates are of greater concern than bridges on rural roads because more deicing salt is applied (Kirkpatrick, Weyers, Anderson-Cook, \& Sprinkel, 2002). The amount of deicing salts applied to a bridge combined with information on wetting and drying cycles gives a good estimate of the amount of chlorides a bridge is exposed too. This information is vital for determining the likelihood a bridge will deteriorate in a certain region. Therefore, deicing salt quantity is an important parameter to consider. In addition, certain other deicers have been also found to damage concrete. Compared to sodium chloride, magnesium chloride, magnesium acetate, magnesium nitrate, and calcium chloride can damage concrete, while ammonium nitrate and ammonium sulfate are extremely damaging (PCA, 2002). Therefore, choosing the right deicer is important in reducing deterioration.

Besides the application of deicing salts, bridges are exposed to chlorides from sea water. In a survey of 52 different agencies to determine what types of environments cause the most corrosion, coastal regions were identified as the worst, specifically for bridges with uncoated weathering steel (McConnell, Shenton, \& Mertz, 2016). Even bridges that are not directly on the coast can experience chloride contamination from the ocean. It is commonly understood that winds can carry salt spray over $3 \mathrm{~km}$ and areas within 1 to 2 $\mathrm{km}$ of the ocean are considered aggressive chloride environments (Stewart \& Rosowsky, 1998; Vu \& Stewart, 2000). In a study by McGhee on 1158 Australian bridges, surface 
chloride concentration was found to be a function of a bridges distance to the coast ( Vu \& Stewart, 2000). The equations relating surface chloride concentration to distance to seawater can be modeled as follows (Vu \& Stewart, 2000):

$$
\begin{gathered}
C_{0}(d)=2.95 \frac{\mathrm{kg}}{\mathrm{m}^{3}} d<0.1 \mathrm{~km} \\
C_{0}(d)=1.15-1.81 * \log (d) 0.1 \mathrm{~km}<d<2.84 \mathrm{~km} \\
C_{0}(d)=0.03 \frac{\mathrm{kg}}{\mathrm{m}^{3}} d>2.84 \mathrm{~km}
\end{gathered}
$$

As salt spray continues to build upon bridges, chloride concentrations increase, thus increasing the chances for deterioration processes such as rebar corrosion to take place. In areas such as the northwestern United States, the combination of deicing salt application and proximity to the ocean can substantially influence the deterioration of bridges (Shi, et al., 2015; Covino Jr., et al., 2002; Yu, Francois, Dang, L'Hostis, \& Gagne, 2015). Therefore, the distance of a bridge to the ocean is a valuable parameter that can approximate the amount of chloride a bridge is exposed to.

Since corrosion of reinforcing steel is so important to the deterioration of concrete bridge decks, it is important to be able to provide a quantitative measurement of the deterioration risk. The most common way of determining chloride exposure in concrete is through chloride depth profiling in which chloride concentrations are determined from pulverized samples of bridge decks. Since this method involves the gathering of samples and associated lab work, nondestructive alternatives have been developed for increased accessibility and speed. For example, the rapid chloride permeability test (RCPT) measures the resistance of concrete to ionic movement (Isgor, et al., 2017; Shi, Xie, 
Fortune, \& Gong, 2012 ). This measurement, also known as concrete resistivity, is strongly influenced by concrete characteristics such as permeability and chloride content (Isgor, et al., 2017). Resistivity measurements have been shown to correlate with the corrosion rate of steel reinforcement and the transport properties of concrete (Song \& Saraswathy, 2006). Because of this relationship, resistivity is considered a useful quantitative indicator of the corrosion risk (Morris, Vico, \& Vazquez, 2004). Over the last few years, surface resistivity (SR) measurements have taken the place of RCPT measurements because of the speed at which measurements can be acquired. Compared to hours with RCPT, SR measurements can be taken in seconds (Isgor, et al., 2017). By using resistivity data from SR measurements that relate concrete properties with chloride ingress, chloride profiles can be estimated. This can help create an understanding of the deterioration potential of concrete bridge decks and allow for more effective preservation. However, caution should be used when interpreting resistivity measurements. Depending on the density and saturation of concrete being tested, resistivity measurements can vary. In addition, there is no current consensus on appropriate resistivity threshold values to reliably link measurements to corrosion potential (Guthrie \& Tuttle, 2006).

\subsubsection{Climate}

In addition to the amount of chlorides present on bridges from deicers and salt spray, understanding the climatic conditions that exist is important in estimating the movement of those chlorides. The concentration of chloride ions at the surface of concrete bridge decks can vary depending on the amount of chlorides present in the environment and the number of wetting and drying cycles (Kassir \& Ghosn, 2001; Russell, et al., 2004). In 
regions that freeze and thaw often, this can be an important factor in the ingress of chlorides in concrete (Kim \& Yoon, 2010; Lin, Zhao, \& Tabatabai, 2012). When ice exposed to deicing salt melts, that water migrates through cracks in the concrete to the reinforcing steel. The more often that melting occurs, the more likely chlorides will permeate the concrete. Also, the expansion of freezing water has the potential to create micro cracks and increase the size of already present cracks. In addition to melting in cold regions, the amount of moisture present in an environment is influential to the movement of chlorides. Precipitation and humidity are parameters that should be considered for all bridges. In a 2016 study on 10,000 uncoated weathering steel bridges, it was determined that distance to seawater and relative humidity were the two most influential parameters affecting bridge corrosion (McConnell, Shenton, \& Mertz, 2016). In this study, climate was quantified for hundreds of bridges and assessed with bridge performance data. The identified climate parameters were combined into a methodology that effectively described corrosion performance by consistently inferior environment (CSE) type (Table 2-1). Therefore, collecting information on climate can be a valuable parameter in predicting where bridge deck deterioration is most likely to occur (Agrawal, Kawaguchi, \& Chen, 2008). Figure 2-6 shows the survival probability curves for different climatic regions computed by Fleischhacker, et al. (In review). Higher curves indicate better performance. 
Table 2-1: Environment Type Based on Primary and Secondary Variables (McConnell, Shenton, \& Mertz, 2016)

\begin{tabular}{|c|c|c|c|c|}
\hline Parameter & $\begin{array}{l}\text { Consistently inferior } \\
\text { environment }\end{array}$ & CSE 1 & CSE 2 & CSE 3 \\
\hline $\begin{array}{l}\text { Distance to } \\
\text { coast }(\mathrm{km})\end{array}$ & $<0.15$ & $>0.15$ & $>0.15$ & $>0.15$ \\
\hline and & and & and & and & and \\
\hline Humidity score & $\geq 0.65$ & $\leq 0.65$ & $\leq 0.63$ & $\leq 0.62$ \\
\hline and & and & and & and & and \\
\hline $\mathrm{Cl}^{-}(\mathrm{mg} / \mathrm{L})$ & 0.565 & $\leq 0.372$ & $\leq 0.565$ & $<=0.565$ \\
\hline and & and & and & and & and \\
\hline $\mathrm{SO}_{4}(\mathrm{mg} / \mathrm{L})$ & 0.793 & $\leq 0.663$ & $\leq 0.793$ & $\leq 0.793$ \\
\hline and & and & and & and & and \\
\hline $\mathrm{NO}_{3}(\mathrm{mg} / \mathrm{L})$ & 0.611 & $\leq 0.572$ & $\leq 0.611$ & $\leq 0.611$ \\
\hline and & and & and & and & and \\
\hline Crossing type & Waterway & Highway & Highway & Any \\
\hline
\end{tabular}

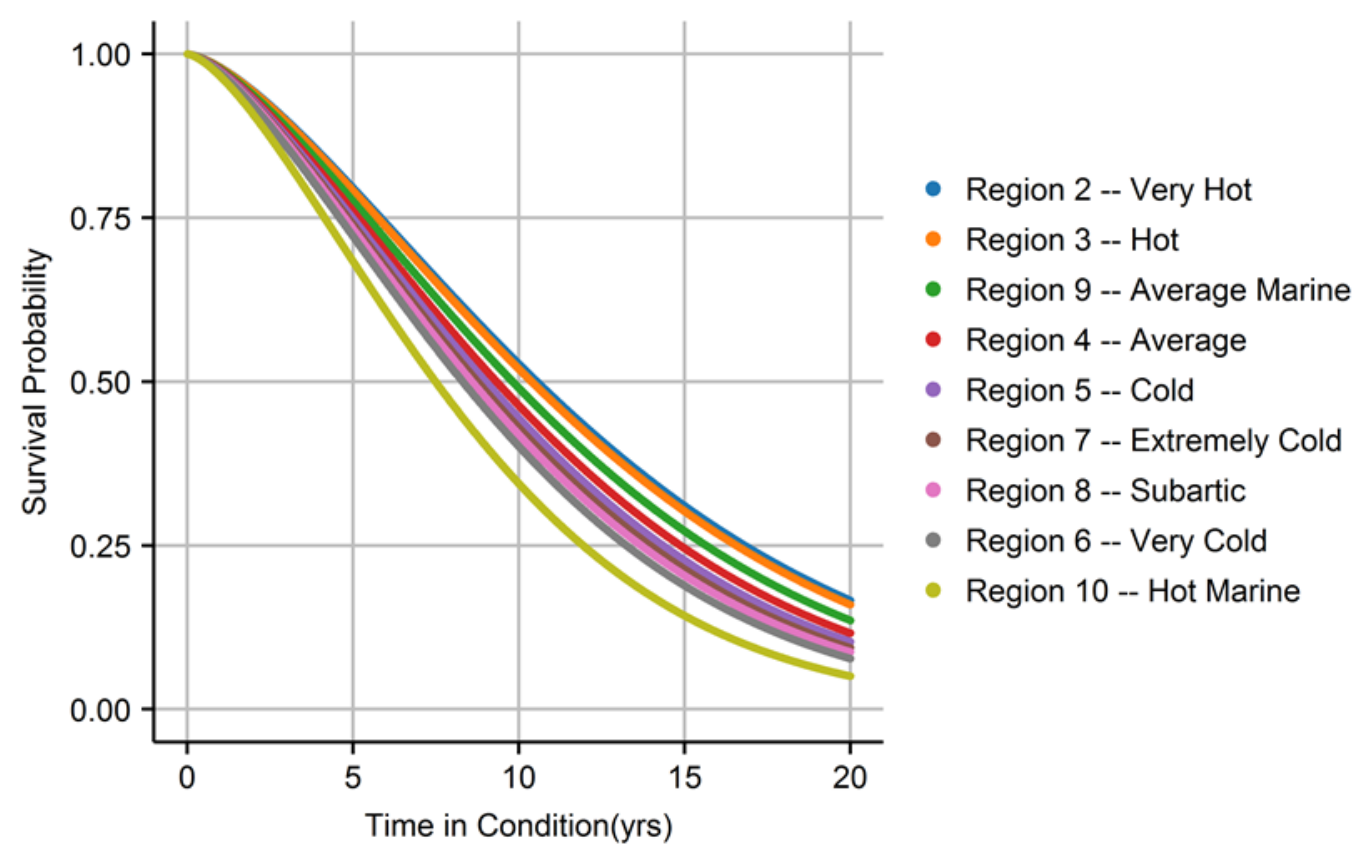

Figure 2-6: Survival Probability Curves by Climatic Region (Fleischhacker, Ghonima, \& Schumacher, (In review)) 


\subsubsection{Average Daily Truck Traffic (ADTT)}

Most of the parameters mentioned previously relate to corrosion of the reinforcing steel in concrete bridge decks. However, studies have shown that fatigue cracking can contribute substantially to deterioration and is controlled by a different set of parameters. The most prominent of these parameters is average daily truck traffic (ADTT), which is essentially a measure of how much a bridge is loaded (Morcous, Lounis, \& Mirza, 2003; Lin, Zhao, \& Tabatabai, 2012). As a result of repeated traffic loads, through cracks may develop in concrete decks, which results in faster chloride contamination (Li \& Zhang, 2001). Figure 2-5 shows the survival probability curves for different select ADTT values computed by Fleischhacker, et al. (In review). It can be observed that higher ADTT values lead to lower bridge deck performance. Therefore, bridges with less traffic experience less deterioration than bridges with more traffic (Ghonima, Schumacher, \& Unnikrishnan, In review; Hatami \& Morcous, 2011; Agrawal, Kawaguchi, \& Chen, 2008; Kim \& Yoon, 2010). This highlights the importance of truck traffic on the deterioration of bridge decks. With more truck traffic, the potential for crack development increases, resulting in accelerated chloride contamination. 


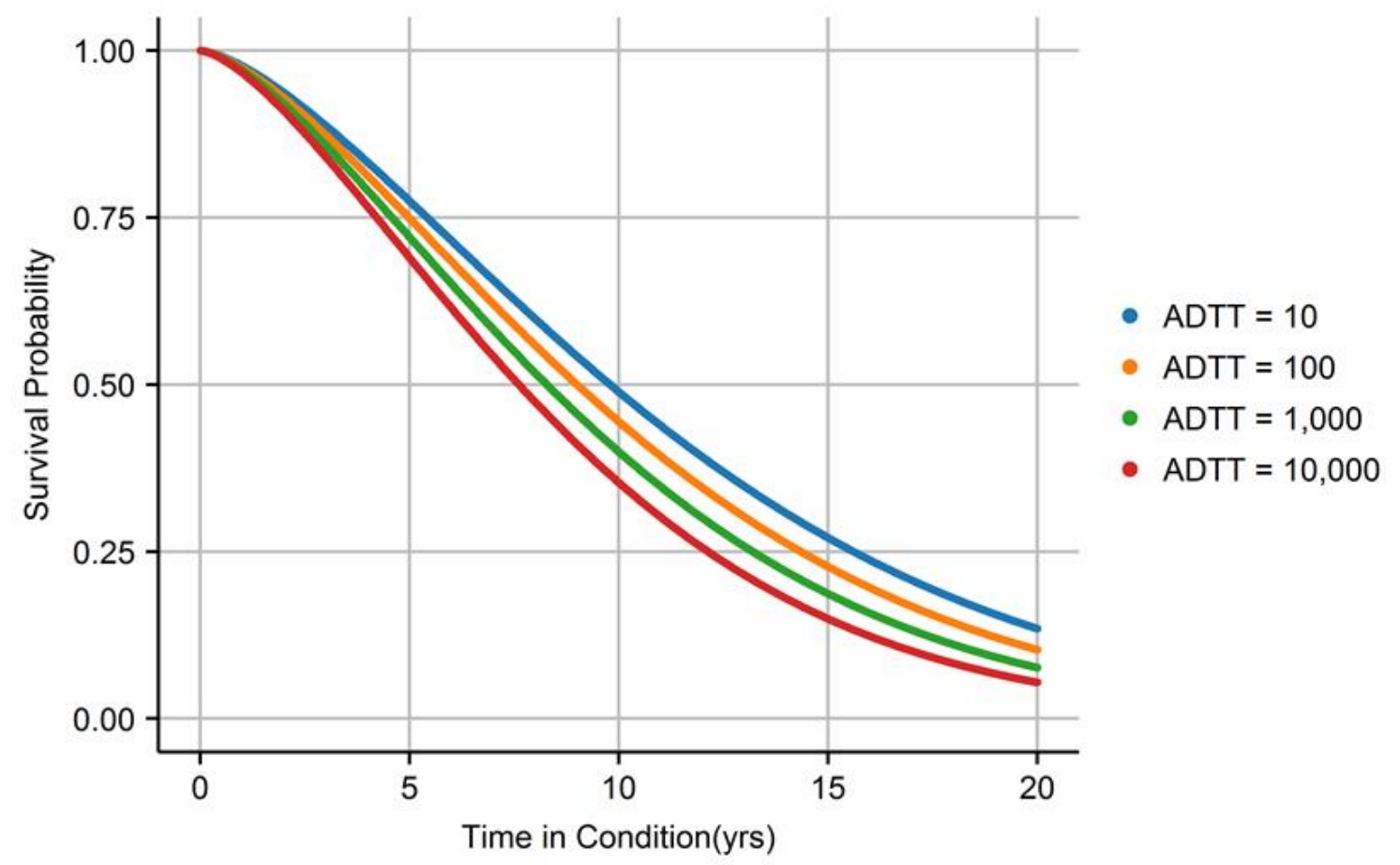

Figure 2-7: Survival Probability Curves by ADTT (Fleischhacker, Ghonima, \& Schumacher, (In review)) 


\subsection{Data Collection and Asset Management Practices}

Outside of the United States, other countries have developed unique asset management systems and inspection procedures to cope with the deterioration of bridges. The goal of this section is to identify key performance metrics and procedures that foreign countries and other DOT's use in an effort to develop improvements for ODOT's data collection and asset management practices.

\subsubsection{State of California}

Across all of California's 12 districts, there are approximately 24,500 bridges that are inspected and preserved by The California Department of Transportation (Caltrans) Division of Maintenance Office. This office, composed of 140 inspectors and engineers, is responsible for the inspection and maintenance of all these bridges. To take on this task, Caltrans relies on a single system that combines bridge inspection, project prioritization, and project archiving into an interoperable database (FHWA, 2005).

In California, bridge inspections take place every two years and are performed by Statelicensed civil engineers. Inspectors are also responsible for fracture critical and underwater inspections when required (FHWA, 2005). Data collected by inspectors is based on

the AASHTO Guide for Commonly Recognized (CoRe) Structural Elements and includes information on bridge element condition, fracture critical findings, and load rating findings. Once inspections are completed, the information is gathered in the centralized bridge management database using a collection and report generating software called 
SMART (FHWA, 2005). Once the data is entered, a bridge inspection report is generated that documents current condition and recommends preservation actions.

From the information provided by the inspectors, bridge management engineers review and prioritize maintenance actions using the AASHTOWare Bridge Management (BrM) system (AASHTO, 2018). This system runs deterioration models to recommend project prioritization based on the scope identified by the Caltrans Division of Maintenance Office. Priority is given to projects that minimize traffic impact and maximize costeffectiveness (FHWA, 2005). Once a project is complete, all reports, plans, photos, and significant correspondence are archived in the bridge database using the BIRIS web application.

\subsubsection{State of Washington}

The Washington State Department of Transportation (WSDOT) has developed a series of inspection types to address the variety of needs related to bridge management. All inspection information is recorded in BridgeWork (WSDOT, 2018) and used to update data in the inventory database. In addition, each bridge has its own unique file containing all inspection reports and inspection photographs. Inspections are carried out following the AASHTO Manual for Bridge Evaluation (MBE) (AASHTO, 2011) and the FHWA NHI 12-049 Bridge Inspectors Reference Manual (BIRM) (FHWA, 2012).

The first inspection taking place after completion of construction or rehabilitation work is an initial routine inspection. These inspections establish and verify the baseline 
information about the bridge and take into account any new observations. For example, this type of inspection requires inspectors to note the location and extent of surface cracks in newly-poured bridge decks (WSDOT, 2018 ). After the initial inspection, routine inspections are scheduled every two years throughout the life of the bridge unless specific criteria are met to allow for a longer inspection interval. These inspections consist of observations and measurements required to determine the physical and functional condition of the bridge. Specifically, any changes from the initial or previous condition are observed to make sure the bridge satisfies service requirements (WSDOT, 2018 ). For all bridges over water, routine inspections require the assessment of existing scour conditions. Once a routine inspection has been completed, a bridge inspection report is completed that records all findings and reports on bridge condition. Bridge inspection reports are submitted and entered into BridgeWork in order to maintain up-to-date and accurate records.

Interim inspections are used for the monitoring of a known or suspected deficiency between routine inspections (WSDOT, 2018 ). For example, the rapid deterioration of a specific member would require the scheduling of an interim inspection. Depending on the issue, measurements and tests can be performed to determine the degree of deterioration.

Damage inspections take place only when structural damage occurs due to environmental or human events (WSDOT, 2018 ). These inspections are designed to determine the need for emergency measures or the scheduling of an interim inspection. 
When further details on the condition of bridge elements are required, in-depth inspections are utilized. These inspections involve the testing, monitoring, and analysis of specific bridge components and usually take place on a one-time basis (WSDOT, 2018 ). In-depth inspections can vary in the extent of analysis and so no standard set of procedures exist.

\subsubsection{State of Idaho}

The Idaho Transportation Department's (ITD) method for bridge management relies on the combination of structural condition data and expert-mediation. To make asset management decisions, condition, age, and service information are examined by expert engineers to identify maintenance, repair, and replacement actions (FHWA, 2012). Because ITD has a funding program specifically for preservation and restoration, bridge projects that contribute to overall network health are prioritized (ITD, 2016). In order to keep bridges in a state of good repair, while minimizing costs, ITD directs $20 \%$ of funding to preservation projects and $80 \%$ to restoration projects.

For the 4200 highway structures in Idaho, the ITD Bridge Asset Management Unit is responsible for inspection, load rating, and data management of inventory and condition information. To manage this data, ITD utilizes the AASHTOWare Bridge Management (BrM) system (AASHTO, 2018). Bridge inspections are divided into four main types: inventory inspections, routine inspections, special inspections, and in-depth inspections. 
Inventory inspections take place after the construction and are designed to accurately document the base condition of a bridge. Inventory inspections gather the required elements and items for the BrM system and the NBI (ITD, 2016). When information is missing, field teams are expected to take measurements of bridge components.

Routine inspections gather information on structure inventory, safety, and condition through visual assessment of the bridge elements (ITD, 2016). These inspections take place every 24 months unless conditions suggest a shorter or longer interval. Depending on bridge complexity, design, and condition, routine inspections can vary in detail. After a routine inspection is completed, an inspection report is required that includes detailed photographs of all structural issues.

In-depth inspections are performed on elements that require further assessment to determine condition (ITD, 2016). These inspections can include the testing, monitoring, or analysis of specific bridge elements. In-depth inspections occur on a 48-month interval that can be reduced depending on the severity of deterioration

Special inspections are used for the monitoring of known or suspected bridge defects. This type of inspection is commonly used to monitor fatigue-prone details on steel girder bridges but can be utilized for any defect identified by an inspection team (ITD, 2016). 


\subsubsection{State of Indiana}

In an effort to provide efficient asset management, bridge management systems (BMS) are key in identifying future conditions and effective treatment interventions for bridges (Ruck \& Francis, 2017). However, as new data and technology become available, outdated BMS become less reliable. This highlights the need for better prediction models that take into account the factors that influence bridge deterioration. This issue is specifically important to the Indiana Department of Transportation (INDOT) because its BMS is 36 years old, and with the recent changes in bridge inspection standards no longer considered dependable (Ruck \& Francis, 2017). To correct this issue, INDOT commissioned a research project to develop new deterioration models for main bridge components. Undertaken by Purdue University, this project was completed in 2016 and resulted in six deterioration models that identified 10 influential variables (Moomen, Qiao, Agbelie, Labi, \& Sinha, 2016 ). The variables affecting bridge deterioration are assumed to be as follows:

- Deck age in years

- Interstate location

- Angle of skew

- Bridge length

- Type of service under bridge

- Number of spans in main unit

- Freeze index in 1,000 s of degree-days

- Average annual number of freeze-thaw cycles 
- Average annual daily truck traffic (ADTT)

- Deck protection

To validate the deterioration models, the 2010-2016 condition ratings for every bridge in the network was predicted and compared with the actual condition. Even though predicted condition rating was consistently less than actual condition rating, good correlations were observed (Ruck \& Francis, 2017). According to INDOT, validating deterioration models is important in increasing the credibility of BMS, which results in increased effectiveness.

\subsubsection{Germany}

Due to Germany's central location in Europe and the development of the European market, traffic loads have increased substantially along the federal road network. In addition, the majority of bridges in Germany were built between 1960 and 1980 and have been shown to contain severe design flaws (Haardt \& Holst, 2008). This combination of increased traffic with poor bridge condition has resulted in substantial maintenance demands that require an effective management system. The German BMS aims to establish cost-effective and sustainable maintenance practice through the acquisition of condition data, damage analysis, deterioration forecasting, and priority ranking.

According to the German Standard DIN 1076 (DIN, 2011), bridge inspections are split up into four categories: main inspections, simple inspections, inspections on special occasions, and inspections according to special regulations and regular observations 
(Beuth Verlag, 1999). Main inspections, composed of visual examinations of the complete structure, are performed every six years (Haardt \& Holst, 2008). Field tests are also utilized for deeper examinations when deemed necessary. These examinations include non-destructive tests to determine concrete strength, cover, level of corrosion, and extent of deck delamination. Simple inspections, which are less detailed than main inspections are performed three years after every main inspection. Inspections on special occasions and inspections according to special regulations and regular observations are required only after a special event or claim has been submitted. In those cases, investigations are used to gather more precise information on damage size and cause while identifying maintenance measures.

Information from inspections is collected in the Road Information Database-Structures, which also includes information on bridge construction, characteristics, damage, and suggested maintenance (BMVBS, 2004). Damage, reported from inspections, is evaluated on a scale of 1 to 4 based on the effect it has on stability, traffic safety, and durability (Haardt \& Holst, 2008). This information, combined with additional data such as geographic location and traffic volume, forms the basis of maintenance planning and helps German decision-makers fund key bridge projects.

\subsubsection{Norway}

Norway is a unique country for bridge development because of its geography. Mountains interlaced with fjords compose a landscape that demands bridge development and 
maintenance to be excellent. In Norway, the inspection and management of the nation's 18,000 national and county bridges are detailed in five main handbooks:

- Handbook V441 - Inspection Manual for Bridges (Norwegian Public Roads Administration, 2000)

- Handbook R211 - Field Surveys (Norwegian Public Roads Administration, 1997)

- Handbook R411 - Bridge Management (Norwegian Public Roads Administration, 1997)

- Handbook N401 - Bridge Management for County Roads (Norwegian Public Roads Administration, 2017)

- Handbook R610 - Standard for Operation and Maintenance of National Roads (Norwegian Public Roads Administration, 2012)

After a bridge is completed, inspection responsibility is given to the Norwegian Public Roads Administration (NPRA) for the remainder of the bridges' lives. Each bridge allocated to NPRA is required to undergo a routine inspection program composed of three inspection types: simple, main, and special. Simple inspections are designed to be general assessments that determine if damage affecting the environment, carrying capacity, traffic safety, maintenance, or aesthetics has occurred. Simple inspections are visual assessments and are performed on an annual basis. Main inspections focus on general bridge performance and highlight the need for operational and maintenance measures. These inspections include detailed visual assessments of all structural elements 
augmented by material tests and surveys when deemed necessary. Due to the complexity of main inspections, these inspections are only required every five years for bridges and three years for ferry piers. Unlike simple and main inspections, special inspections are not required periodically. Instead, special inspections are performed on demand and exist to investigate previously detected damage, movement, and degradation mechanisms. In addition, special inspections also exist to detail costly and complicated maintenance measures. Special inspections usually consist of visual assessment, surveys, and material tests of either the whole bridge or specific elements.

Depending on the inspection type, all elements of a bridge are checked for damage defects, and faults by the implementation of visual assessments, surveys, and material tests. In general, visual assessments examine settling, cracks, damaged cover, spalling, reinforcement corrosion, and weathering. Surveys include leveling, horizontal displacement, joint thickness, tracking, wear layer smoothness, and free height. Material tests include cover depth, carbonation depth, chloride content, electrochemical potential, compressive strength, structural analysis, and tension cable control.

After bridge inspections are completed, the data is combined with technical and administrative information for each bridge in the Norwegian IT system BRUTUS (Norwegian Public Roads Administration, 2014). BRUTUS is used to cost-effectively administer, operate, and maintain bridges throughout the country. Once inspection data is compiled, damage information is ranked to prioritize repair and maintenance measures. 
This ranking system is composed of two parts, damage severity and damage impact. Damage severity ranks from 1 (small damage) to 4 (critical damage). Damage impact is split into groups (B - carrying capacity, T - road safety, V - maintenance costs, $\mathrm{M}$ environmental/aesthetics) and ranked on consequence from 1 (no consequence) to 4 (serious consequence). After a bridge is ranked, the two parts are multiplied together to produce a priority index that dictates bridge rehabilitation work.

\subsubsection{Finland}

In Finland, guidelines for the inspection of bridges are provided by the Finnish Road Administration (Finnra) and include information on classifying and entering data (Everett, et al., 2008). In addition, Finnra also provides bridge repair directives to standardize and guide repair work on damage identified in inspections. Standard inspection reports include inspection type, overall bridge condition, condition of structural elements, data from physical testing, and bridge repair recommendations (Everett, et al., 2008). Data on bridge damage includes type, cause, class, extent, effect on bearing capacity, and location. In addition to providing bridge repair recommendations, inspectors also provide information on repair urgency, measure, cost, and extent. With direct contact with Finnra, inspectors effectively address critical needs for bridge maintenance.

Bridge inspections in Finland are carried out through five different types: acceptance inspections, safety inspections, general inspections, basic inspections, and special inspections (Everett, et al., 2008). Acceptance inspections take place after the completion 
of construction or repair work and are usually completed by the contractor, owner, bridge designer, and other stakeholders. Safety inspections take place on an annual basis to ensure safety compliance. General inspections are commonly performed on a five-year basis and are the primary inspection reported by Finnra certified bridge inspectors. Basic inspections are supplemented general inspections that include tests and core samples for improving service-life models and quality control. Special inspections take place when information gathered from general inspections is not enough, specifically when cause of damage is undetermined.

In addition to a variety of different inspections, Finland utilizes NDT and material sampling to understand bridge deterioration. Tests outlined in Finnra's inspection guidelines are: concrete cover, carbonation depth, chloride content, electrode potential, rebound hammer testing, microstructural analysis of concrete, tensile bond pull-off testing, moisture of concrete cover, opening of surface structures, and coating depth of steel parapets (Everett, et al., 2008). Overall, Finland has a multidimensional bridge evaluation program heavily centered on bridge inspection. This allows for quick identification and communication of management information.

\subsection{Service Life Prediction Models}

Understanding the factors that govern bride deck deterioration is key in anticipating what types of bridges will need preservation action. However, in order to quantitatively

understand how long a bridge remains functional, service life prediction is required. According to the Design Guide for Bridges for Service Life report, service life is defined 
as the duration in which bridge elements or systems provide the desired level of performance or functionality, considering proper maintenance and repair (Azizinamini, Power, Myers, \& Ozyildirim, 2014). The service life of a bridge deck can be defined as the time it takes for a bridge deck to go from an initial (new) condition $C_{0}$ to an unacceptable condition $C_{f}$ the period of time between $T_{0}$ and $T_{f}$ respectively (Azizinamini, Power, Myers, \& Ozyildirim, 2014). During the service life, repair and rehabilitation occur, which restore bridge condition and increase the service life of a bridge deck, as illustrated in Figure 2-8. To estimate service life, software packages are used that take into account sources of deterioration, deterioration mechanisms, deterioration models, and failure modes (Azizinamini, Power, Myers, \& Ozyildirim, 2014). Two popular service life software packages are Life-365 and STADIUM, but other models exist such as BridgeLCC, BEES, Duracrete, CONlife, and MACSI (Mitchell \& Frohnsdorff, 2004).

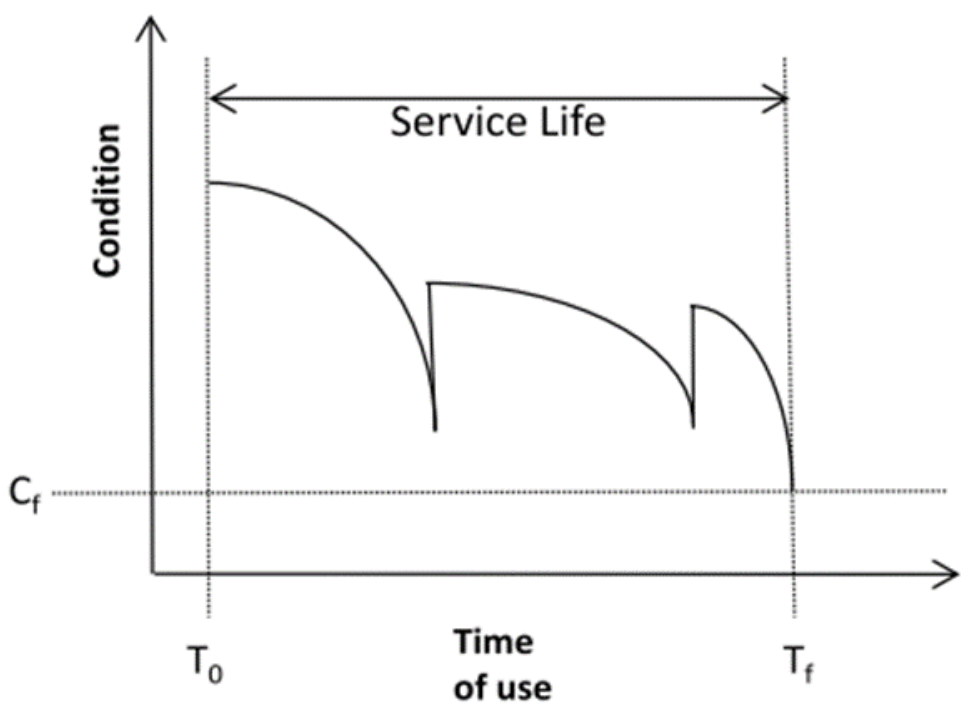

Figure 2-8: Bridge Deck Deterioration with Preservation Action (The vertical upward jumps represent bridge preservation action) (Azizinamini, Power, Myers, \& Ozyildirim, 2014) 


\subsubsection{Life-365}

Developed by the American Concrete Institute (ACI), Life-365 is a service life program that can be used to model marine structures, parking garages, bridge decks, and transportation infrastructure. Life-365 was developed by a consortium consisting of ACI Committee 365 and companies from the concrete industry and is available for free. Service life in this program is defined as the initiation time to corrosion summed with the time it takes corrosion to reach an unacceptable level (Ehlen, Bentz, \& Thomas, 2008 ). To model deterioration, Life-365 assumes that corrosion of the reinforcing steel is the main source of deterioration and that ionic diffusion is the only method of chloride transport. In addition, the initiation period is calculated using Fick's second law of diffusion, while the propagation period is assumed to be 6 years for uncoated steel and 20 years for stainless steel (Ehlen, Bentz, \& Thomas, 2008 ). The required inputs for Life365 are:

- $\quad$ Diffusion rate at 28 days, $D_{\text {ref }}$

- Maximum surface chloride level, $C_{s}$

- Chloride threshold to initiate corrosion of steel, $C_{t}$

- Clear cover to reinforcement, $c_{c}$

- Propagation period, $t_{p}$

- Geographic location and general exposure

- Type and dimensions of concrete structural members

- Depth of clear concrete cover to the reinforcing steel

- Details of each alternative corrosion protection strategy 
- Costs of the concrete constituent material

- Details and costs of the concrete repair strategy

\subsubsection{STADIUM}

Developed by SIMCO Technologies, STADIUM is an advanced commercial service life program. Although mainly used for chloride diffusion modeling, STADIUM can model multiple mechanisms and account for the effect of cement and supplementary cementing materials on transport properties (Marchand, 2001). Instead of using Fick's equation, the diffusion of all ions in the system is modeled by solving the extended NernstPlanck/Poisson equation set. Due to the complexity of deterioration processes and the necessary expertise to use STADIUM correctly, the company has moved away from directly selling the program and now offers service life prediction as a service they provide to a client. The required inputs for STADIUM are:

- Material density

- Paste content

- Diffusion coefficients

- Water diffusivity

- Total porosity

- Capillary porosity

- Initial values and boundary conditions for ion concentration, volumetric water content in the pores, and electrical potential

- Initial amount of solid phases 
- Equilibrium constants

- Temperature

\subsection{Conclusions}

This literature review focused on gathering information on concrete bridge deck condition assessment/monitoring and service-life prediction. The review found that the deterioration of concrete bridge decks is a complex topic that requires understanding of the processes and parameters that drive deterioration. Of the many ways deterioration occurs, corrosion of the reinforcing steel and cracking of the concrete were found to be the two governing processes affecting bridge deck performance. These two processes interact with each other making deterioration more damaging and costly as time progresses. From these processes, the parameters that drive deck deterioration were identified to show what information could help inform asset management decisions in the future. Table 2-2 lists the parameters that past studies have found to drive bridge deck deterioration and some related references. In addition, to show different methodologies for data collection and asset management practices, different states and countries were researched. Finally, service life prediction was explored, and the main prediction models were identified to outline the important inputs in deterioration modeling. 
Table 2-2: Parameters Affecting Bridge Deck Deterioration

\begin{tabular}{|c|c|c|c|}
\hline PARAMETER & DESCRIPTION & $\begin{array}{l}\text { EFFECT ON } \\
\text { DETERIORATION }\end{array}$ & MEASUREMENT \\
\hline $\begin{array}{l}\text { Depth of concrete } \\
\text { cover }\end{array}$ & $\begin{array}{l}\text { Layer of concrete that } \\
\text { protects the reinforcement } \\
\text { from surface } \\
\text { contamination. }\end{array}$ & $\begin{array}{l}\text { Effective concrete cover } \\
\text { delays chloride ingress by } \\
\text { acting as a barrier between } \\
\text { reinforcement and water. }\end{array}$ & $\begin{array}{l}\text { Eddy-current-based } \\
\text { cover meter or } \\
\text { ground penetrating } \\
\text { radar (GPR). }\end{array}$ \\
\hline $\begin{array}{l}\text { Concrete } \\
\text { permeability }\end{array}$ & $\begin{array}{l}\text { Concrete characteristic that } \\
\text { influences the flow of } \\
\text { liquids through the pore } \\
\text { structure of the concrete. }\end{array}$ & $\begin{array}{l}\text { Low concrete permeability } \\
\text { reduces chloride ingress by } \\
\text { slowing down the transport } \\
\text { of chloride ions. }\end{array}$ & $\begin{array}{l}\text { Hydraulic } \\
\text { permeability test or } \\
\text { air-permeability } \\
\text { measurement } \\
\text { (Torrent } \\
\text { Permeability Test). }\end{array}$ \\
\hline $\begin{array}{l}\text { Type of } \\
\text { reinforcement }\end{array}$ & $\begin{array}{l}\text { Material of reinforcement } \\
\text { and, if present, any } \\
\text { protective layers. }\end{array}$ & $\begin{array}{l}\text { Less reactive materials } \\
\text { increase the time to } \\
\text { corrosion initiation. }\end{array}$ & $\begin{array}{l}\text { From design and as- } \\
\text { built drawings. }\end{array}$ \\
\hline Chloride exposure & $\begin{array}{l}\text { Amount of chlorides a } \\
\text { bridge deck is exposed to } \\
\text { from deicing salts or } \\
\text { seawater. }\end{array}$ & $\begin{array}{l}\text { Increased deicer use and } \\
\text { close proximity to the } \\
\text { ocean results in increased } \\
\text { chloride content on the } \\
\text { surface of bridge decks. }\end{array}$ & $\begin{array}{l}\text { Chloride } \\
\text { concentration } \\
\text { destructive test, } \\
\text { rapid chloride } \\
\text { penetration test, } \\
\text { surface resistivity } \\
\text { using Wenner probe. }\end{array}$ \\
\hline Climate & $\begin{array}{l}\text { Combination of } \\
\text { temperature, precipitation, } \\
\text { humidity, and other } \\
\text { characteristics that define a } \\
\text { region. }\end{array}$ & $\begin{array}{l}\text { High humidity, } \\
\text { precipitation, and freeze- } \\
\text { thaw action increase the } \\
\text { ingress of chlorides. }\end{array}$ & $\begin{array}{l}\text { Obtained from } \\
\text { NOAA or local } \\
\text { climate databases. }\end{array}$ \\
\hline Truck traffic & $\begin{array}{l}\text { Average daily truck traffic } \\
\text { (ADTT) }\end{array}$ & $\begin{array}{l}\text { High ADTT increases the } \\
\text { chances of cracking, which } \\
\text { accelerates corrosion. }\end{array}$ & $\begin{array}{l}\text { From traffic } \\
\text { monitoring stations, } \\
\text { weigh in motion } \\
\text { (WIM) stations, } \\
\text { ODOT TransGIS } \\
\text { Database. }\end{array}$ \\
\hline
\end{tabular}

To conclude, Table 2-2 presents an initial list of parameters to be collected in addition to ODOT's current bridge deck condition data consisting of element-level inspection information. In particular, the data analysis portion of the research will shed additional light on what parameters are influential in concrete bridge deck deterioration. The researchers are also interested in identifying the pertinent information already collected by the different departments within ODOT. By identifying information such as construction data that can influence concrete bridge deck deterioration, the researchers 
hope to utilize all of the useful information that is collected by the agency. The overall goal is to identify the factors that can be collected and are collected so that ODOT can improve concrete bridge deck monitoring in the future. 


\subsection{DATASET ASSEMBLY}

To evaluate concrete bridge deck performance, an Oregon-specific dataset that combines ODOT information with data from the National Bridge Inventory (NBI) needed to be created. After consulting with ODOT personnel, the research team decided to create a more quantitative and reliable dataset and to add information on various construction parameters and element-level condition states. By adding additional construction information to the new dataset, important variables that were not previously considered could be explored. In addition, by adding element-level data, a more detailed performance metric could be used to quantify concrete bridge deck performance.

\subsection{Oregon-specific Datasets and performance metrics}

Due to the large number of concrete bridge decks in Oregon, the research team decided it was necessary to create a more manageable subset for the gathering of construction data. However, by creating a refined dataset with fewer bridge decks, the team was worried that information on the performance metrics would be lost. Therefore, to retain all the information gathered, the research team decided that two datasets would be analyzed. The first dataset is composed of Oregon NBI bridge decks while the second dataset is refined to 400 bridge decks with construction information. To create this refined dataset, bridges were grouped based on climate zone (defined in Section 3.1) and design period (defined in Section 3.2). In total, the refined dataset contains 400 bridge decks across all climate zones and design periods. In comparison, the NBI dataset contains information for 5242 bridge decks. 
To quantify deterioration in bridge decks, two performance metrics were chosen. The first metric, the time-in-condition-rating (TICR), is simply the number of years an NBI bridge deck is assigned the same condition rating (CR). This metric is valuable because it gives a measure of how bridge deck condition changes throughout 25 years of available NBI inspection data. The second performance metric is composed of the element-level condition states provided by ODOT. Although this metric has fewer years of information, there is more detail since each bridge deck element can have quantities in four different condition states. In order to compare the NBI TICRs with the element-level condition states, a proposed health index can be calculated using the element-level information (TRB, 2001). Both of these performance metrics will be analyzed with the independent variables in the two datasets to better understand what drives deterioration in bridge decks.

\subsection{Dataset Sources}

In order to develop the two datasets mentioned in Section 3.1, data was gathered from multiple sources. NBI data was gathered from the FHWA website (FHWA, 2018). Element-level data was collected directly through ODOT's bridge inspection database. Construction data was gathered from two locations. First, data from the OTIA III program was explored. Second, after determining that more complete data needed to be gathered, construction information was extracted from ODOT's bridge data system (BDS). 


\subsubsection{NBI Data}

The NBI is a comprehensive source of bridge information for the whole United States (FHWA, 2018). Defined as a public highway bridge with a span length of more than 20 $\mathrm{ft}$, each NBI bridge has 116 data items that describe the various characteristics and condition ratings (CRs) associated with each structure. Before the commencement of this project, researchers at Portland State University had created and analyzed a nationwide dataset based on NBI records (Ghonima, Schumacher, Unnikrishnan, \& Fleischhacker, 2018). This dataset, focused on concrete highway bridge decks, reduced the number of NBI items to 15 variables considered influential to bridge deck deterioration. In addition, parameters such as deck area and distance to seawater were added. The nationwide dataset also included information on bridge deck CR for the years 1992-2014, which were used to calculate the performance metric TICR.

For this project, an NBI dataset needed to be created that was specific to Oregon. Using the nationwide dataset as a guide, NBI concrete bridge decks in Oregon were selected and variables considered influential to bridge deck deterioration were included. Although there are 6949 NBI bridges with concrete decks in Oregon, the dataset that was created only includes information for 5242 bridge decks. This reduced number is a result of an inability to match NBI records with ODOT records. Instead of 15 variables, the Oregonspecific NBI dataset reduces the NBI items that are expected to affect bridge deck deterioration to seven and includes four additional parameters, as listed in Table 3-1. Also, the Oregon-specific NBI dataset includes CR information for the years 1992-2016. Note that the names of the NBI variables and groups follow FHWA (1995). 
Table 3-1: Variables Gathered and Derived from the NBI

\begin{tabular}{|l|l|}
\hline \multicolumn{1}{|c|}{ NBI VARIABLES } & \multicolumn{1}{|c|}{ DERIVED FROM NBI } \\
\hline Maintenance Responsibility (Item 21) & ADTT \\
\hline Kind of Material and/or Design (Item 43A) & Distance from Seawater \\
\hline Type of Design and/or Construction (Item 43B) & Design Period \\
\hline Deck Structure Type (Item 107) & Climate Zone \\
\hline Type of Wearing Surface (Item 108A) & \\
\hline Type of Membrane (Item 108B) & \\
\hline Deck Protection (Item 108C) & \\
\hline
\end{tabular}

\subsubsection{Element-Level Data and Health Index}

The element-level condition states gathered by ODOT inspectors are detailed quantities that reflect the condition of bridge elements. For the element-level data provided by ODOT, there are four different condition states for each deck element, defect, and protective measure. Each one of these components can have different quantities in different states. For example, Figure 3-1 shows the change in condition state quantity as time progresses for a randomly selected concrete bridge deck. Condition state 1 is "good" while condition state 4 is "severe". In order to gather the element-level data, a request was made to ODOT personnel to query information for specific elements that represent concrete bridge decks in the ODOT system. These elements include: 12-concrete deck, 15-precast concrete top flange, 16-concrete top flange, 38-concrete slab, 39-precast concrete slab. For each one of these elements, all the available years of condition state quantities for all defects and protective measures were gathered. In total there are 166,133 rows of information for inspections in the years 1997 through 2018. 
Using the element-level data, an alternative performance metric called the bridge deck health index was calculated. This performance metric, which is based on the California Bridge Health Index developed by Caltrans, takes into consideration varying bridge deck condition quantities to determine an overall health index (Shepard \& Johnson, 2001). In the California Bridge Health Index formula, bridge element condition state quantities and element value are combined to determine bridge condition based on economic worth (Chase, Adu-Gyamfi, Aktan, \& Minaie, 2016). Since this project only focuses on bridge deck condition, the economic component of the health index calculation was excluded.

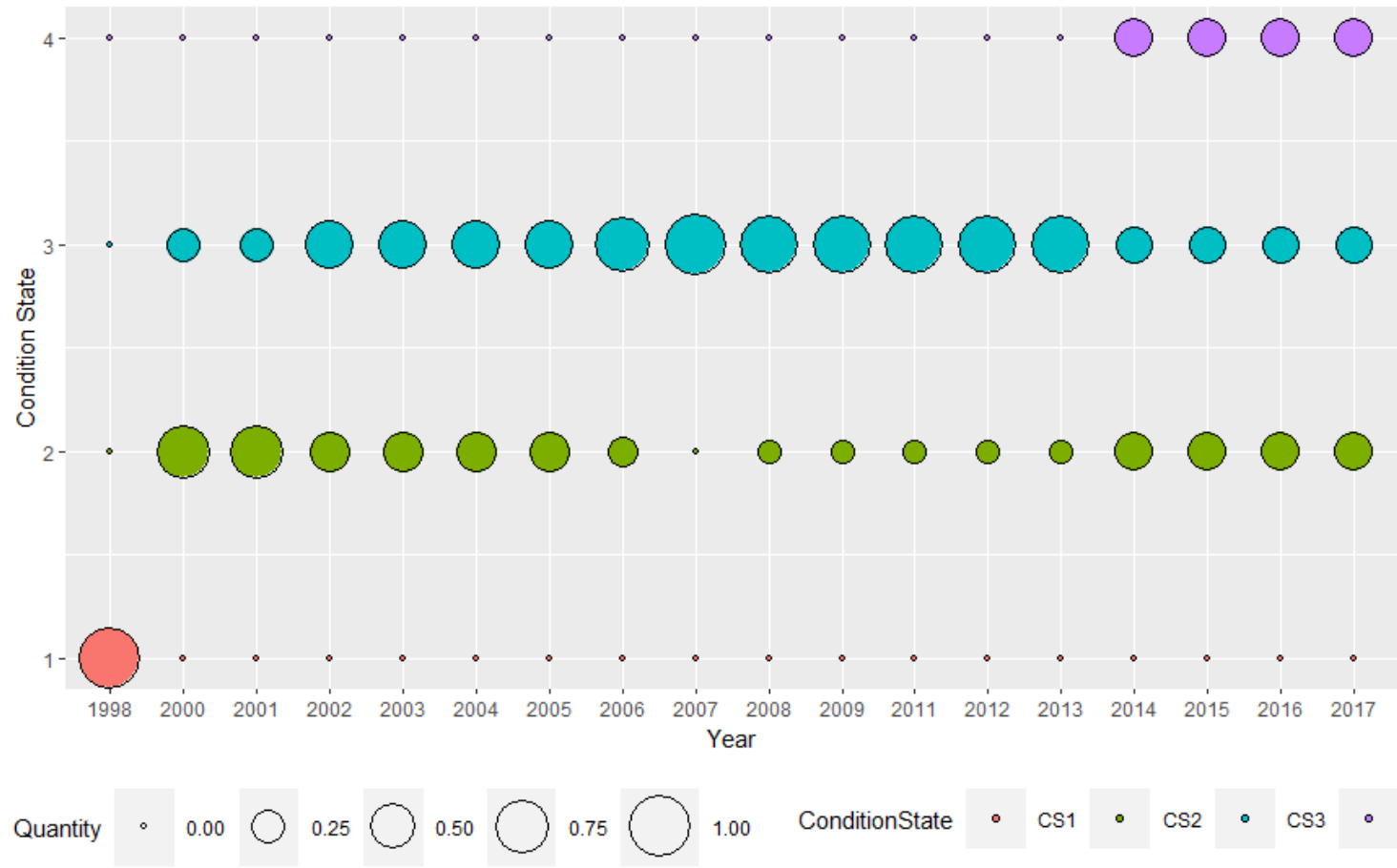

Figure 3-1: Element-level Condition State Quantities for a Sample Bridge Deck

To calculate health indices from the element-level data, the sum of the weighted deck condition quantities was divided by the total deck quantity. Bridge deck quantities in the 
different condition states were weighted to reflect their influence on bridge deck health. The weight for condition state one is 1 , the weight for condition state two is $2 / 3$, the weight for condition state three is $1 / 3$, and the weight for condition state four is 0 . An example of the calculated health indices for a bridge deck can be seen in Figure 3-2. A bridge deck with a health index of 1 is in the best condition while a bridge deck with a health index of 0 is in the worst condition.

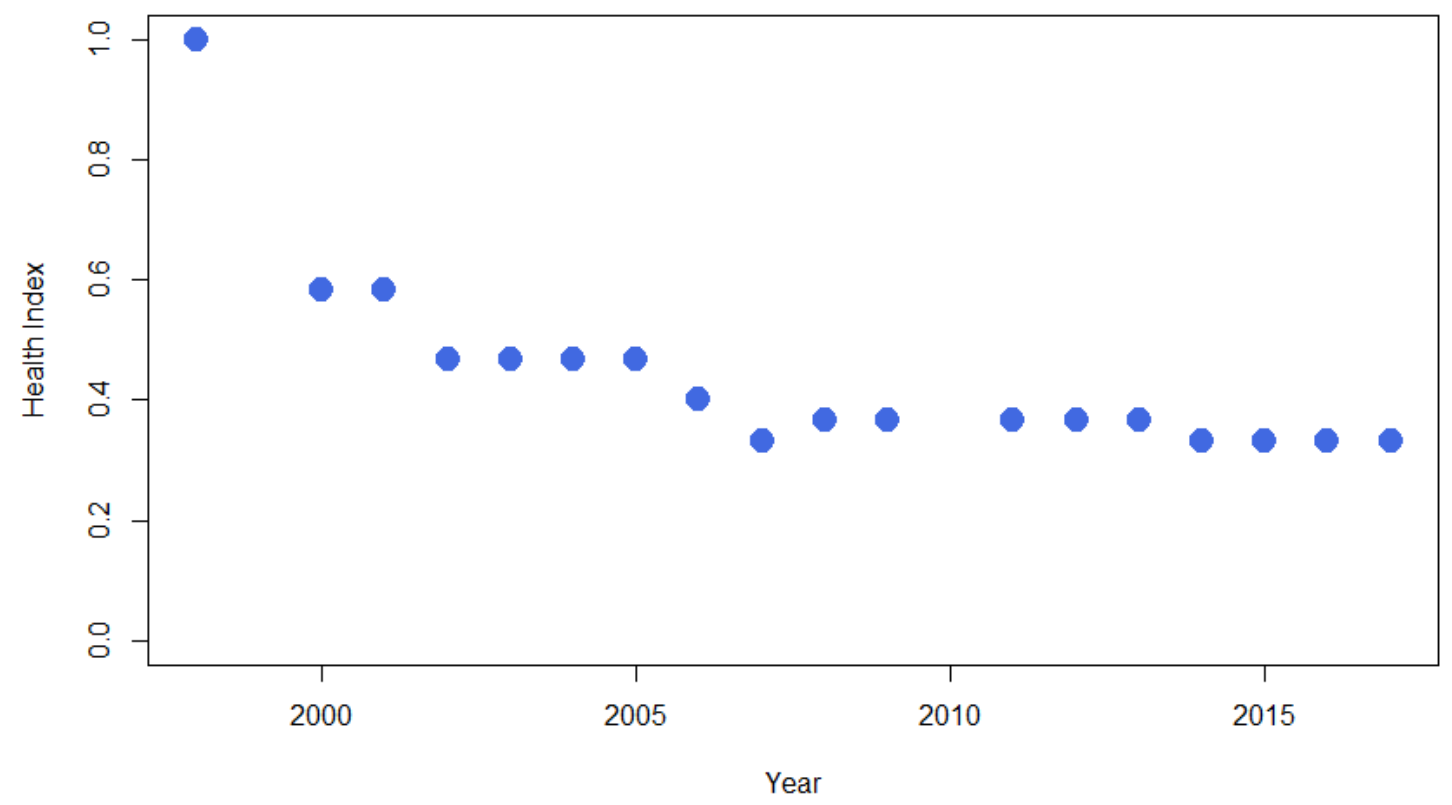

Figure 3-2: Health Indices for a Sample Bridge from 1998 to 2017

\subsubsection{OTIA III Construction Data}

The primary goal of searching through FileNet and the data from the OTIA III program was to identify what construction information is available for bridges within ODOT. After examining the available information and the limitations of the database, the research team determined that in order to gather information on bridge decks within a 
reasonable time frame, a subset needed to be created looking at only replacement bridges. Replacement bridges were chosen over repaired bridges because of data availability. To simplify the gathering process, 100 replacement bridges were randomly selected from the OTIA III program. For each of these bridges, information believed to relate to concrete bridge deck deterioration was gathered. This information included: lab concrete strength, field concrete strength, concrete cover, rebar spacing, rebar type, w/c ratio, air content, and deck slenderness. In addition, notes related to nonconformance during construction were included. After looking at the available construction data, it quickly became apparent that data availability was significantly limited (Table 3-2).

Table 3-2: Percentage of Replacement Bridges with Available Construction Information in FileNet

\begin{tabular}{|l|l|}
\hline \multicolumn{1}{|c|}{ VARIABLE } & \multicolumn{1}{c|}{ PERCENT AVAILABLE } \\
\hline Lab Concrete Strength (psi) & $15 \%$ \\
\hline Field Concrete Strength & $1 \%$ \\
\hline Concrete Cover (in) & $44 \%$ \\
\hline Rebar Spacing (in) & $44 \%$ \\
\hline Rebar Type & $47 \%$ \\
\hline W/C Ratio & $13 \%$ \\
\hline Air Content (\%) & $13 \%$ \\
\hline Deck Thickness (in) & $45 \%$ \\
\hline Approx. deck spacing & $43 \%$ \\
\hline Notes & $43 \%$ \\
\hline
\end{tabular}

\subsubsection{BDS Construction Data}

Once the data was gathered from the OTIA III program, the research group realized that there was simply too much missing information and a new source of construction data needed to be found. After consultation with ODOT personnel, the research team determined that ODOT's BDS would be able to provide adequate data. In comparison to 
the OTIA III database, the BDS only contains bridge drawings, which reduced the type of information that could be gathered. Only specified information such as concrete cover, rebar spacing, rebar type, and deck slenderness could be obtained. After determining that the BDS could provide enough construction data, the research group decided that a subset of 400 bridges should be created. This subset would be split up into groups by nine climate zones and three design periods (see Table 3-3), which are described in detail in Sections 3.1 and 3.2, respectively. In order to have enough information in each group for statistical analysis, 10 randomly selected NBI bridges were assigned to each group. Although data availability in the BDS database was better than in the OTIA III database, missing information was still present. Some drawing sets simply did not have deck drawings and so over 500 bridges had to be reviewed to gather information for the 27 groups. In addition to having missing information, some groups did not have enough bridge decks to gather data from. To compensate for these shortcomings, data from bridge decks in other groups were added. The goal was to have at least 40 bridge decks in each climate zone with complete data. The complete breakdown of gathered data based on climate zone and design period can be seen in Table 3-4. 
Table 3-3: Number of NBI Bridge Decks in Each Climate Zone/Design Period Group

\begin{tabular}{|c|l|l|l|}
\hline \multirow{2}{*}{ CLIMATE ZONE } & \multicolumn{3}{|c|}{ DESIGN PERIOD } \\
\cline { 2 - 4 } & \multicolumn{1}{|c|}{$\mathbf{1}$} & \multicolumn{1}{|c|}{$\mathbf{2}$} & $\mathbf{3}$ \\
\hline $\mathbf{1}$ & 90 & 219 & 648 \\
\hline $\mathbf{2}$ & 175 & 729 & 719 \\
\hline $\mathbf{3}$ & 46 & 357 & 288 \\
\hline $\mathbf{4}$ & 12 & 23 & 27 \\
\hline $\mathbf{5}$ & 3 & 10 & 32 \\
\hline $\mathbf{6}$ & 46 & 191 & 203 \\
\hline $\mathbf{7}$ & 25 & 105 & 257 \\
\hline $\mathbf{8}$ & 29 & 104 & 219 \\
\hline $\mathbf{9}$ & 5 & 44 & 125 \\
\hline
\end{tabular}

Table 3-4: Number of Bridges in Each Climate Zone/Design Period Group with Complete Construction Information

\begin{tabular}{|c|l|l|l|}
\hline \multirow{2}{*}{ CLIMATE ZONE } & \multicolumn{3}{|c|}{ DESIGN PERIOD } \\
\cline { 2 - 4 } & $\mathbf{1}$ & $\mathbf{2}$ & $\mathbf{3}$ \\
\hline $\mathbf{1}$ & 15 & 15 & 20 \\
\hline $\mathbf{2}$ & 15 & 14 & 23 \\
\hline $\mathbf{3}$ & 15 & 18 & 17 \\
\hline $\mathbf{4}$ & 8 & 14 & 18 \\
\hline $\mathbf{5}$ & 3 & 7 & 13 \\
\hline $\mathbf{6}$ & 15 & 15 & 18 \\
\hline $\mathbf{7}$ & 14 & 16 & 20 \\
\hline $\mathbf{8}$ & 13 & 17 & 16 \\
\hline $\mathbf{9}$ & 3 & 17 & 21 \\
\hline
\end{tabular}

\subsection{Conclusions}

In order to evaluate the performance of concrete bridge decks, two Oregon-specific datasets were created. The first dataset or "NBI dataset" is composed of all NBI concrete highway bridge decks in Oregon and contains variables gathered and calculated from the NBI. The second dataset or "refined dataset" is a subset of 400 bridge decks in which NBI related variables are supplemented by construction data. The construction data added 
to the refined dataset was gathered from ODOT's BDS. In addition to the independent variables included in the datasets, both datasets contain performance metrics that can be used to quantify concrete bridge deck deterioration. The first performance metric is TICR, which is based on NBI CRs for the years 1992-2016. The second performance metric is composed of element-level health indices, which are determined for each bridge deck element for the years 1997-2018. The element-level data was queried through ODOT's bridge inspection database. Although the datasets contain both performance metrics, only TICR was used for the survival analysis because the data associated with this metric is more consistent and easier to apply for analysis. 


\subsection{DESCRIPTIVE ANALYSIS OF THE NBI AND REFINED DATASETS}

In order to better understand the Oregon-specific datasets, descriptive statistical analysis was performed on the parameters suspected of affecting concrete bridge deck performance. The parameters that were analyzed were gathered from the NBI and construction databases and can be seen in Table 4-1. To gain a better understanding of these variables and their relationship with concrete bridge deck deterioration, plots showing frequency for both the full NBI dataset and the refined dataset containing 400 bridge decks were created and analyzed. In order to compare these two datasets, the resulting plots are shown next to each other. For some variable frequency plots there are fewer counts than the total for each dataset, which is a result of missing data.

Table 4-1: Select Parameters Affecting Concrete Bridge Deck D
\begin{tabular}{|l|l|}
\hline NBI & REFINED \\
\hline Climate Zone & Concrete Cover \\
\hline Design Period & Rebar Spacing \\
\hline Maintenance Responsibility & Rebar Type \\
\hline Kind of Material and/or Design & Deck Slenderness \\
\hline Type of Design and/or Construction & \\
\hline Deck Structure Type & \\
\hline Type of Wearing Surface & \\
\hline Type of Membrane & \\
\hline Deck Protection & \\
\hline ADTT & \\
\hline Distance to Seawater & \\
\hline
\end{tabular}

\subsection{Climate Zone}

The climate zone variable describes the climate that each bridge deck is exposed to.

These climate zones take into account humidity, precipitation, and temperature and split 
Oregon into nine distinct regions. The climate zones that were utilized were based on the book "The climate of Oregon: from rain forest to desert" (Taylor \& Hannan, 1999). The Oregon climate zones can be seen in Figure 4-1. However, because of the reconstruction of older bridges and the absence of infrastructure in remote climate zones, some groups did not have enough bridge decks. In order to compensate for these shortcomings, more bridge decks from later design periods were included to ensure that there were at least 40 bridges in each climate zone. To understand the distribution of bridge decks within these zones, frequency plots were created for both the NBI and the refined dataset (Figure 4-2 \& Figure 4-3). The NBI plot shows that most bridges exist in climate zone 2 while climate zone 4 and 5 have the least amount of bridge decks. The plot for the refined dataset shows how bridges were selected based on availability. All climate zones contain at least 40 bridges except for climate zone 5 . Despite having distinctively different characteristics, each climate zone may not show obvious differences when describing the performance metrics. In order to simplify this variable, the research group decided to group similar climate zones together. Specifically, climate zones west of the cascades were assigned to group 1 (i.e. climate zones 1 and 2), climate zones along the cascades with higher elevation were assigned to group 2 (i.e. climate zones 3 and 4), and climate zones east of the cascades were assigned to group 3 (i.e. climate zones 5 to 9). The NBI frequency plot shows that group 1 contains the most bridge decks followed by group 3 (Figure 4-4). In comparison, the frequency plot for the refined dataset shows that group 3 has almost twice as many bridges as group 1 and group 2 (Figure 4-5). 


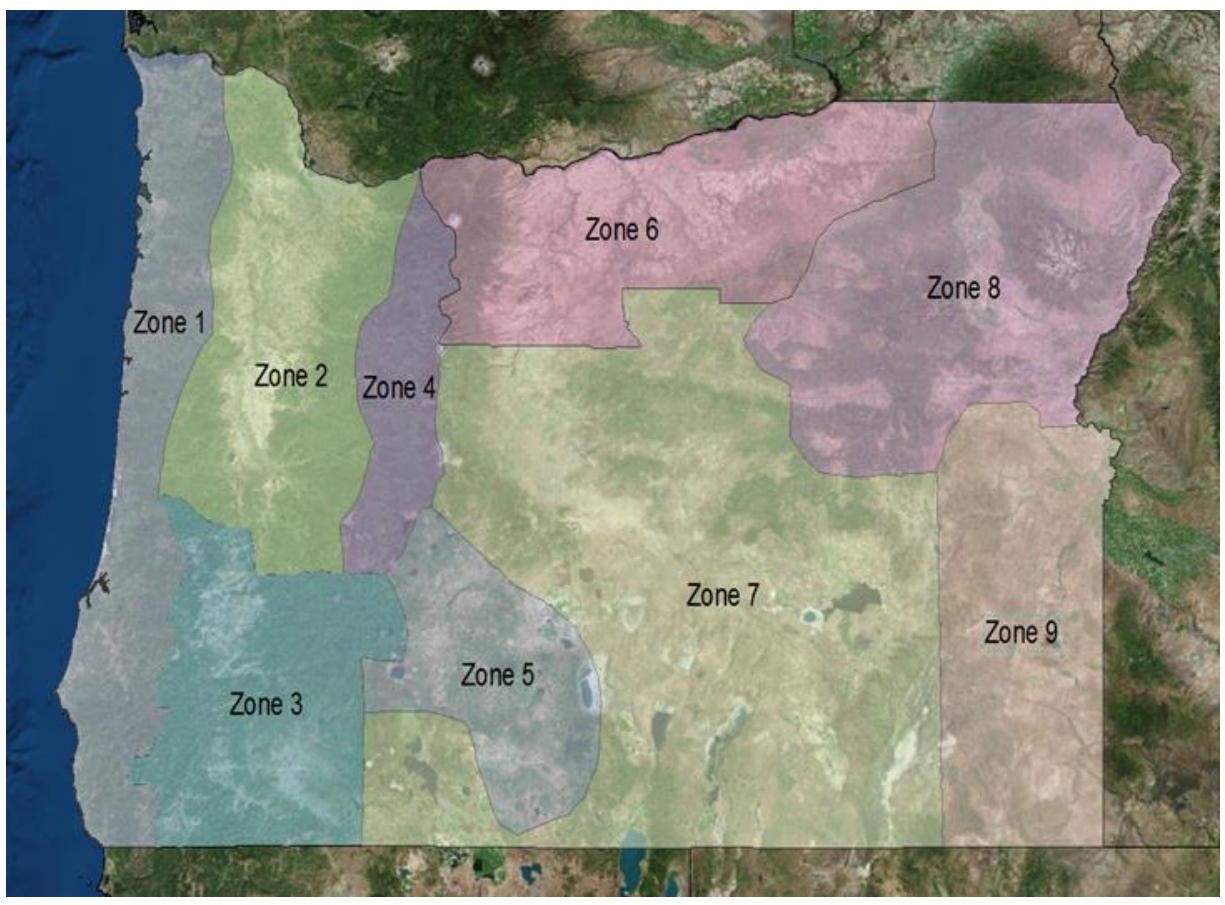

Figure 4-1: Oregon Climate Zones

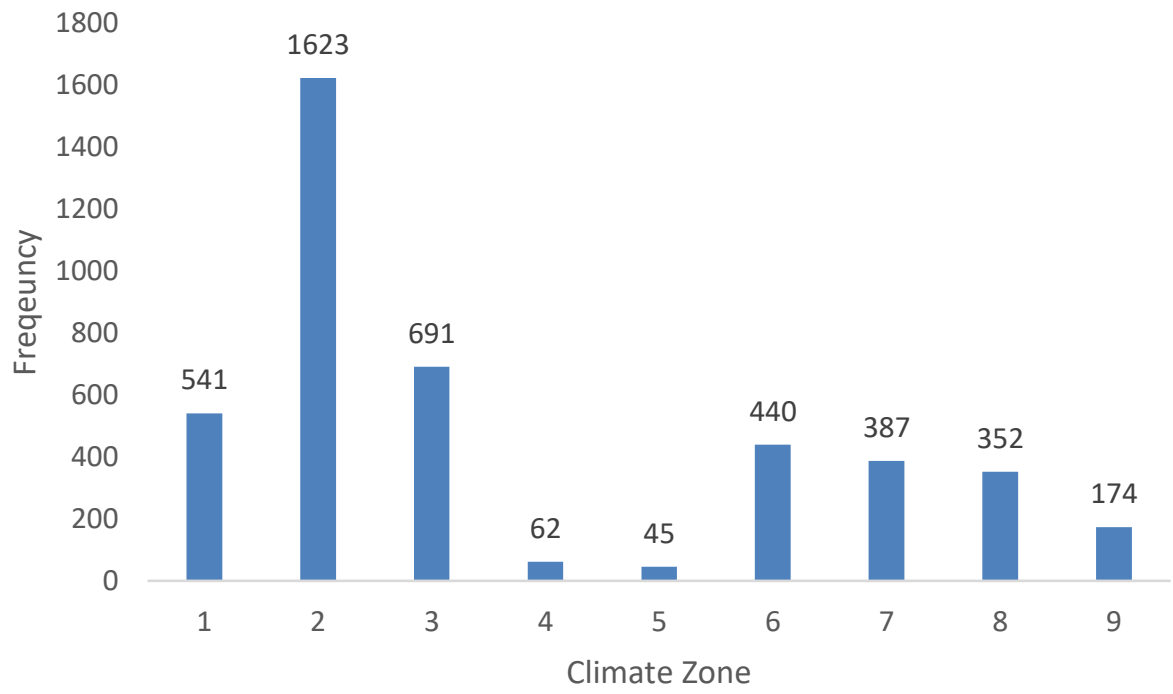

Figure 4-2: Frequency Plot of Climate Zones in NBI Dataset 


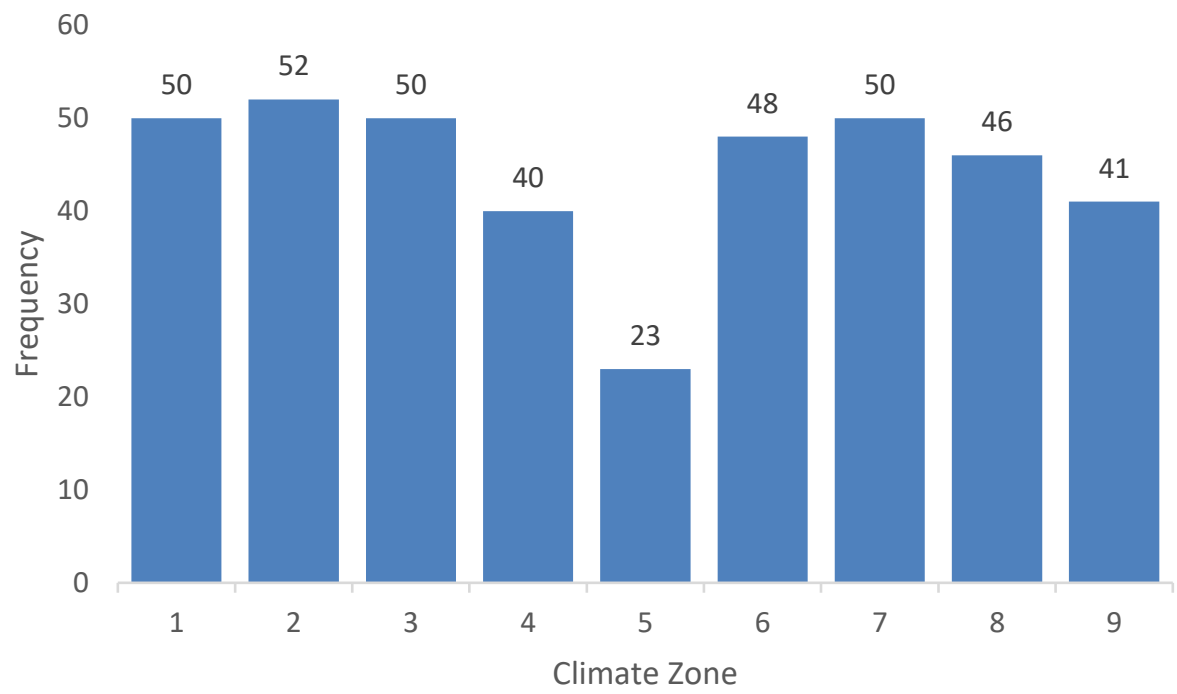

Figure 4-3: Frequency Plot of Climate Zones in Refined Dataset

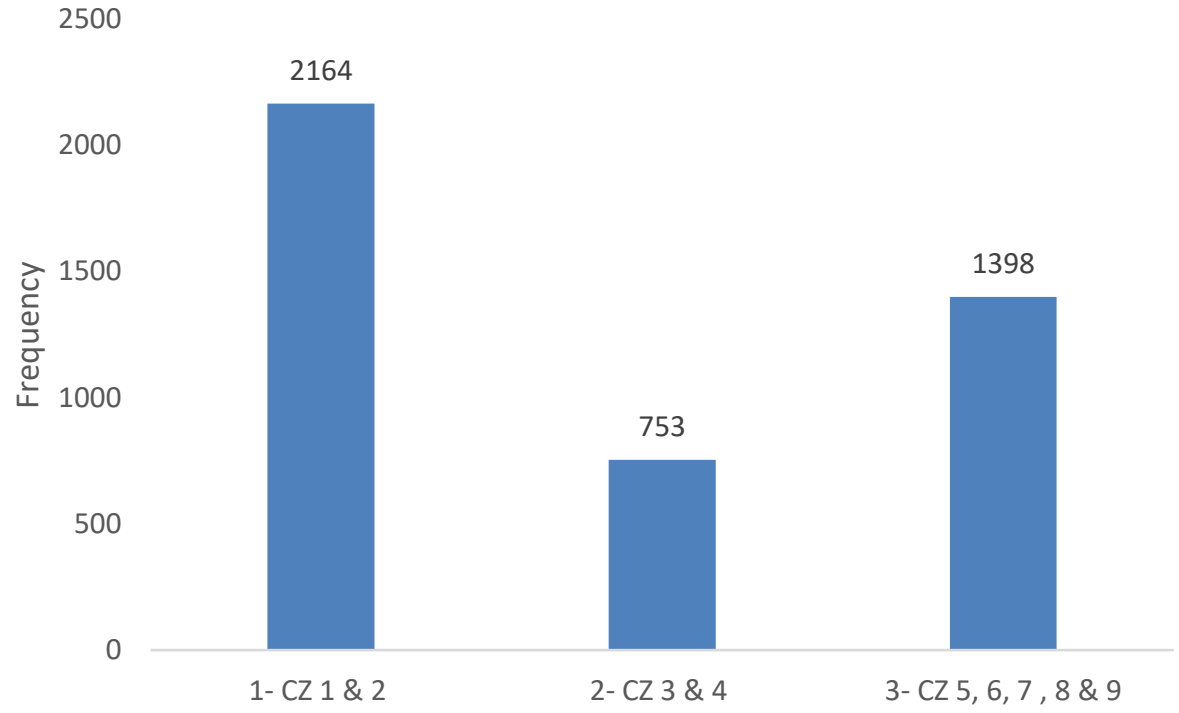

Figure 4-4: Frequency Plot of Climate Groups in NBI Dataset 


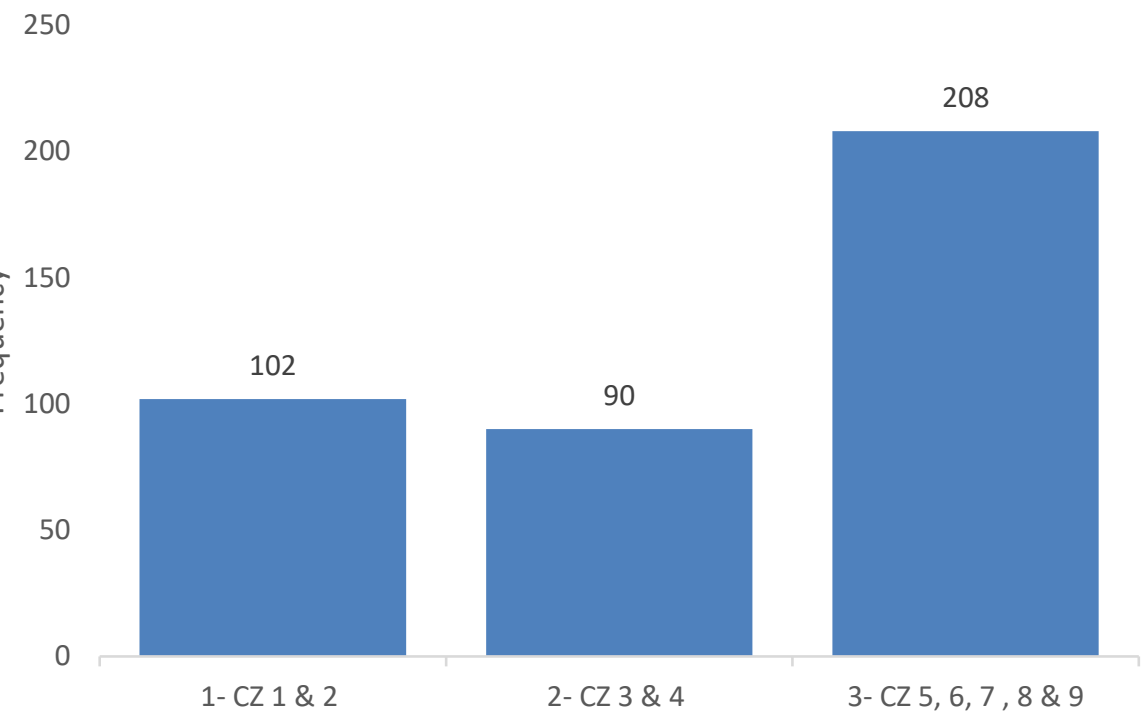

Figure 4-5: Frequency Plot of Climate Groups in Refined Dataset 


\subsection{Design Period}

The design period variable describes the period in which each bridge deck was built in. With the help of ODOT engineers, the design periods of interest were determined to be before 1950, 1950 to 1970, and after 1970. Each one of these design periods reflect changes in deck design practice. However, before bridge decks could be assigned to these periods, the year constructed had to be determined. To do this, the most recent year between the year the bridge deck was constructed and the year the bridge deck was reconstructed was taken to be the effective year the bridge deck was built (Figure 4-6 \& Figure 4-7). Using these dates, the bridge decks were assigned to their respective design period. The resulting frequency plots show that design period 3 has the most information followed by design period 2 and then design period 1 (Figure 4-8 \& Figure 4-9). In addition, the frequency plot for the refined dataset shows the dispersion of available design period information. Only design period 1 does not meet the 120 bridge deck subset that was originally intended. To make up for this shortcoming, bridges deck information was added for the other two design periods. 


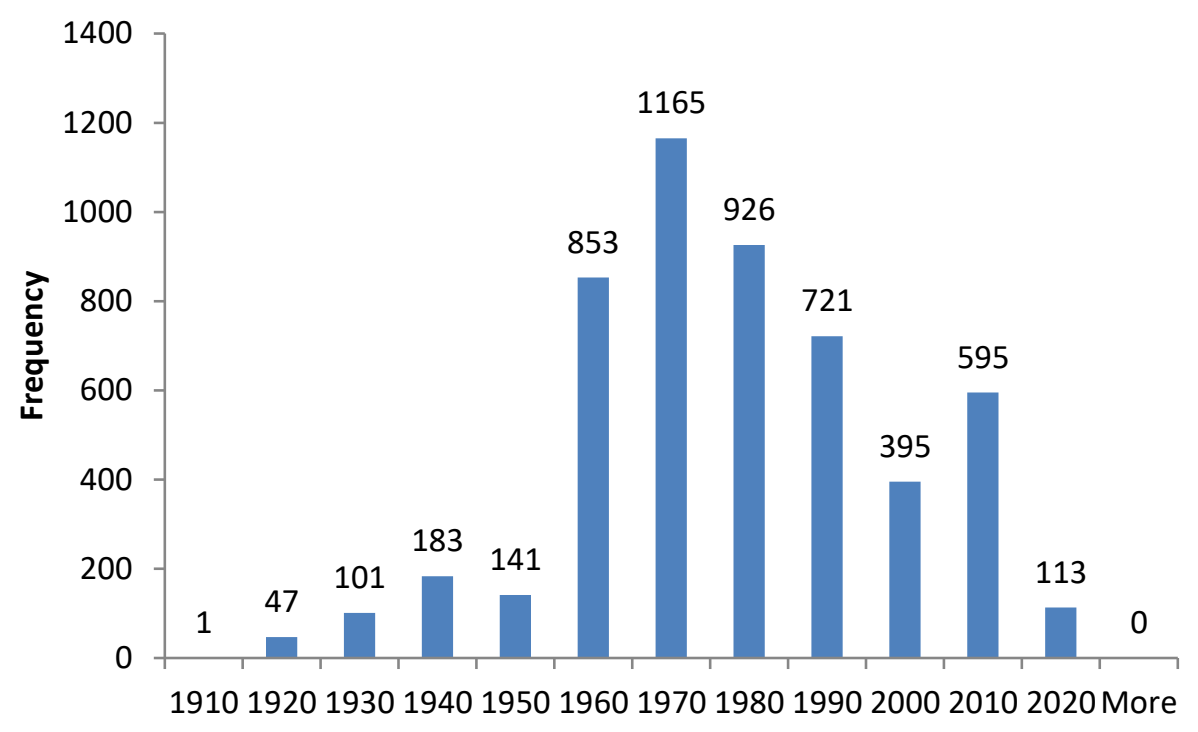

Figure 4-6: Frequency Plot of Bridge Deck Effective Year Built in NBI Dataset

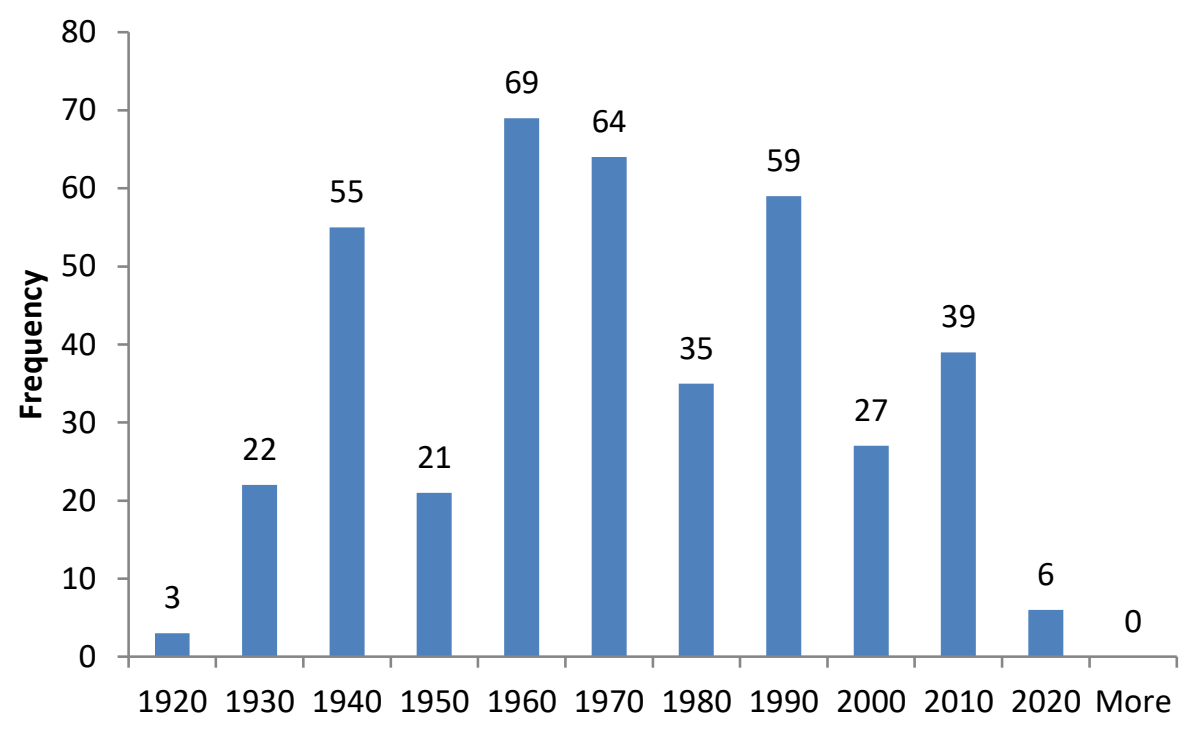

Figure 4-7: Frequency Plot of Bridge Deck Effective Year Built in Refined Dataset 


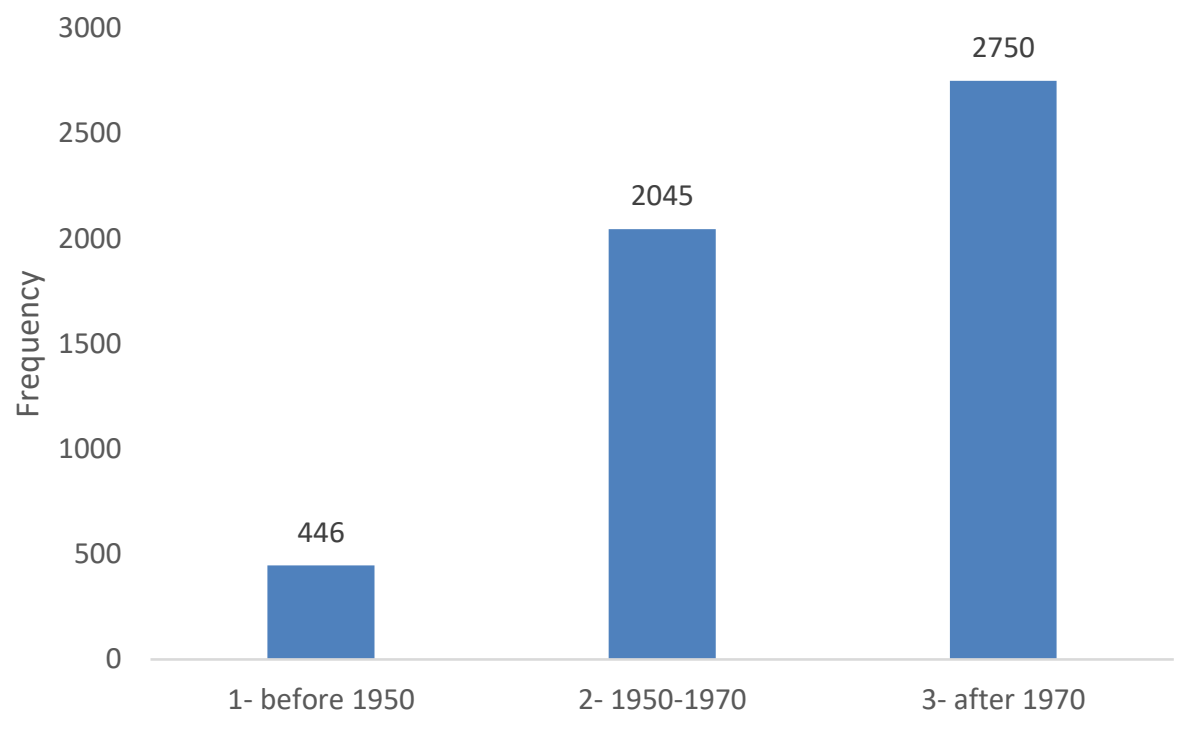

Figure 4-8: Frequency Plot of Design Period in NBI Dataset

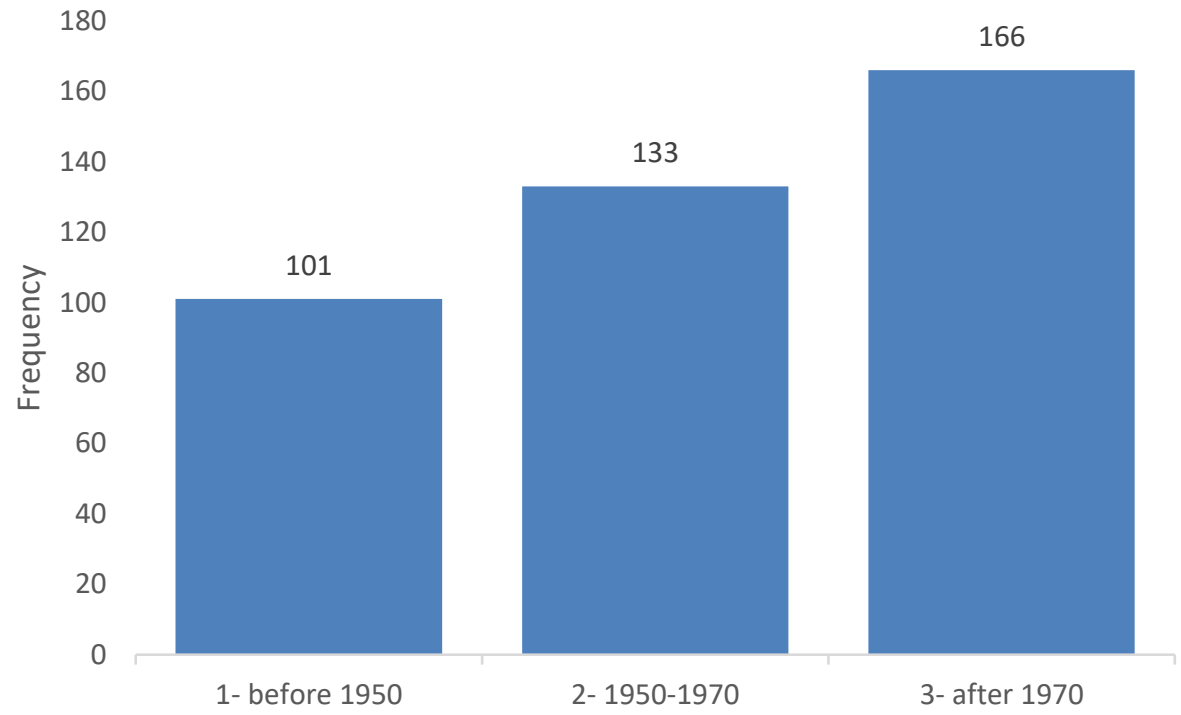

Figure 4-9: Frequency Plot of Design Period in Refined Dataset 


\subsection{Maintenance Responsibility}

Maintenance responsibility describes which agency is responsible for the maintenance of each bridge and is based on NBI Item 21. The resulting frequency plots show that over $95 \%$ of bridges are maintained by either the state highway agency or the county highway agency (Figure 4-10 \& Figure 4-11). However, only $22 \%$ of bridges are maintained by county highway agency in the refined dataset compared to $47 \%$ in NBI dataset.

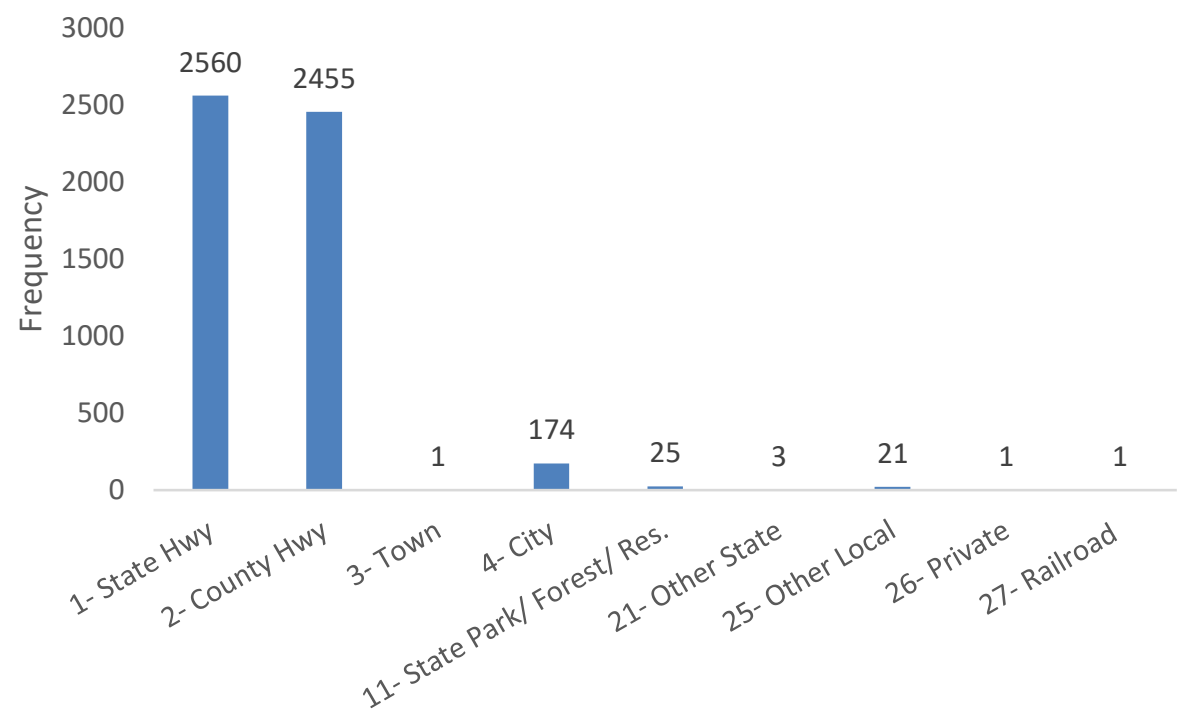

Figure 4-10: Frequency Plot of Maintenance Responsibility in NBI Dataset 


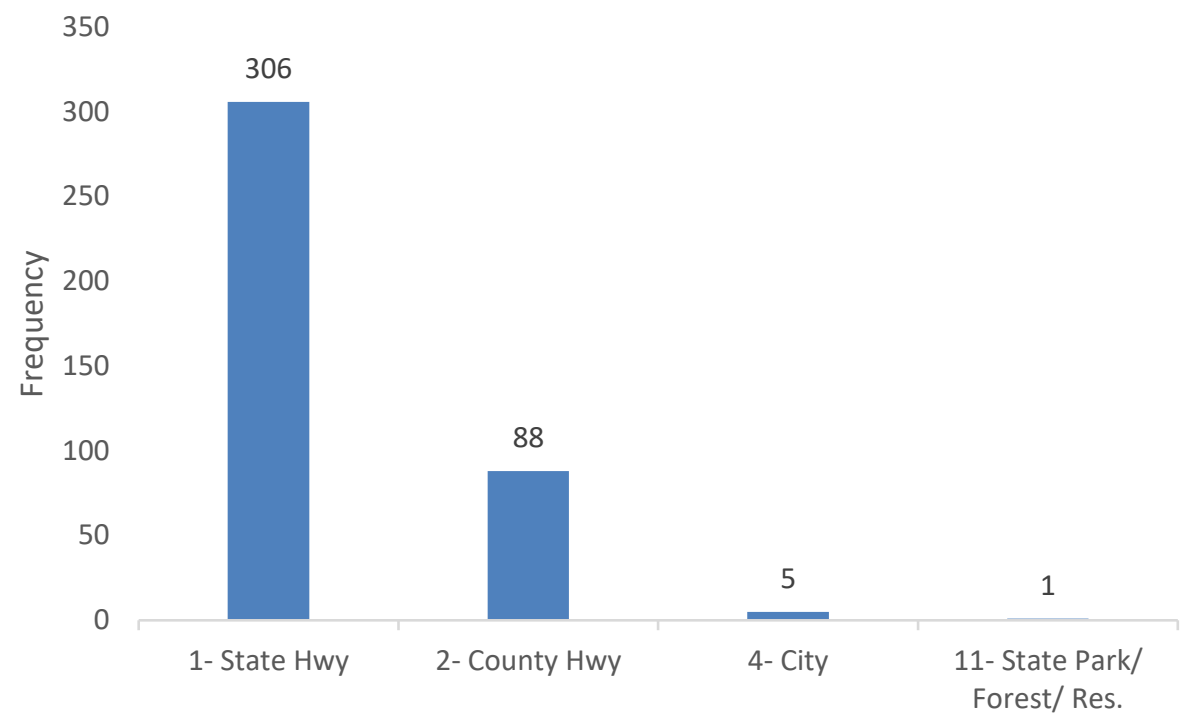

Figure 4-11: Frequency Plot of Maintenance Responsibility in Refined Dataset

\subsection{Kind of Material and/or Design}

This variable provides information on the material and design of each bridge in the database and is based on NBI Item 43a. In total there are seven different material/ design types. The NBI frequency plot shows that concrete bridges are the most common bridges within the dataset, of those bridges the majority are precast concrete (Figure 4-12). In comparison, the refined dataset frequency plot shows that concrete bridges are the most common but there is a higher proportion of concrete, concrete continuous, and steel bridges (Figure 4-13). 


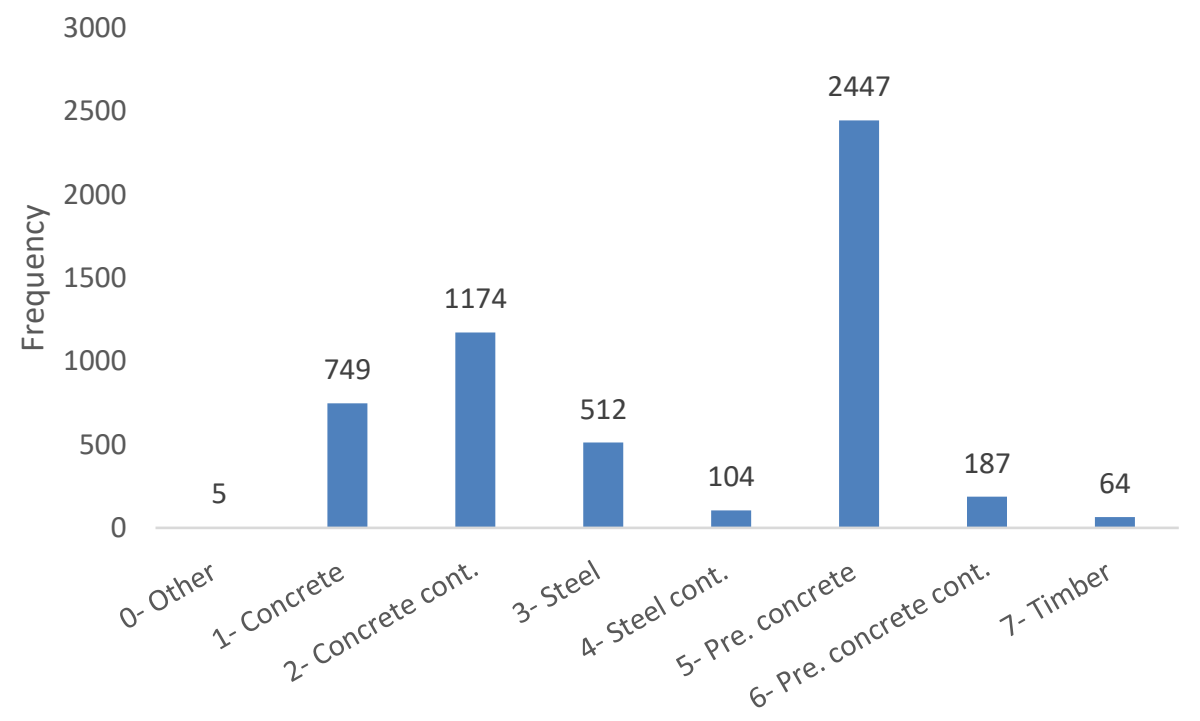

Figure 4-12: Frequency Plot of Bridge Material/Design in NBI Dataset

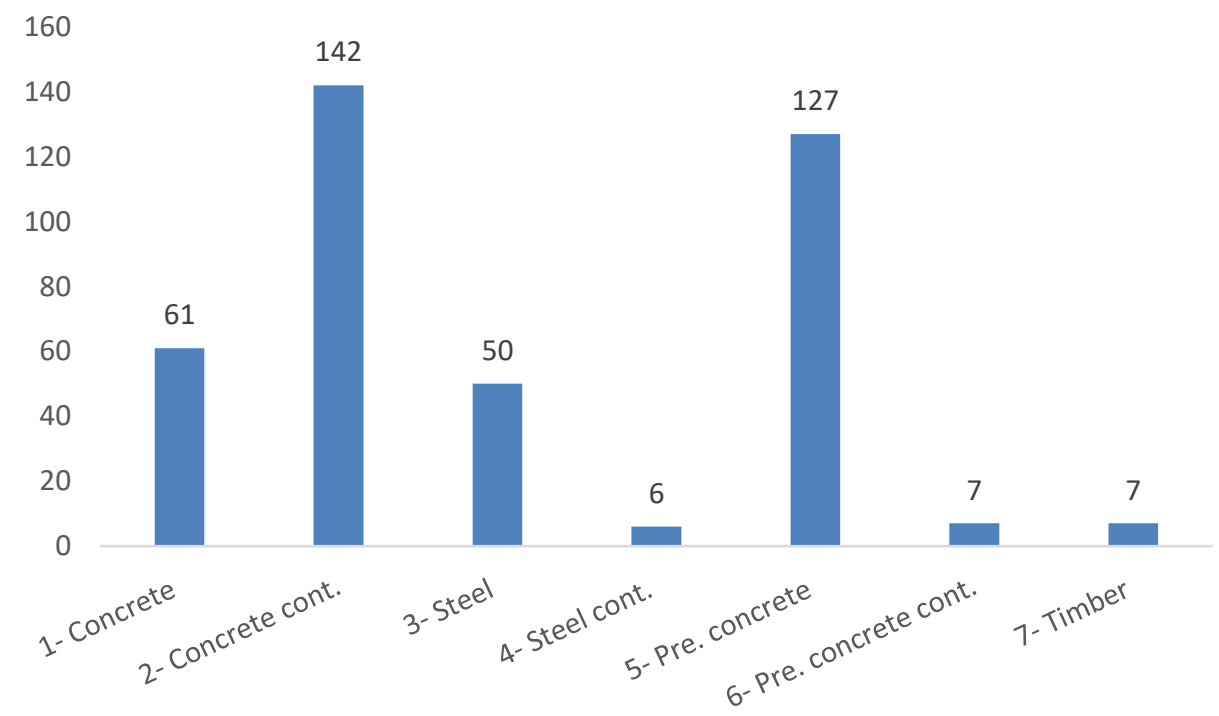

Figure 4-13: Frequency Plot of Bridge Material/Design in Refined Dataset 


\subsection{Type of Design and/or Construction}

This variable provides further information on the design and construction of each bridge and is based on NBI Item $43 \mathrm{~b}$. In total there are 17 different types in the NBI dataset and 12 different types in the refined dataset. Both frequency plots show that over $70 \%$ of bridges are either slab or stringer/ multi-beam/girder (Figure 4-14 \& Figure 4-15).

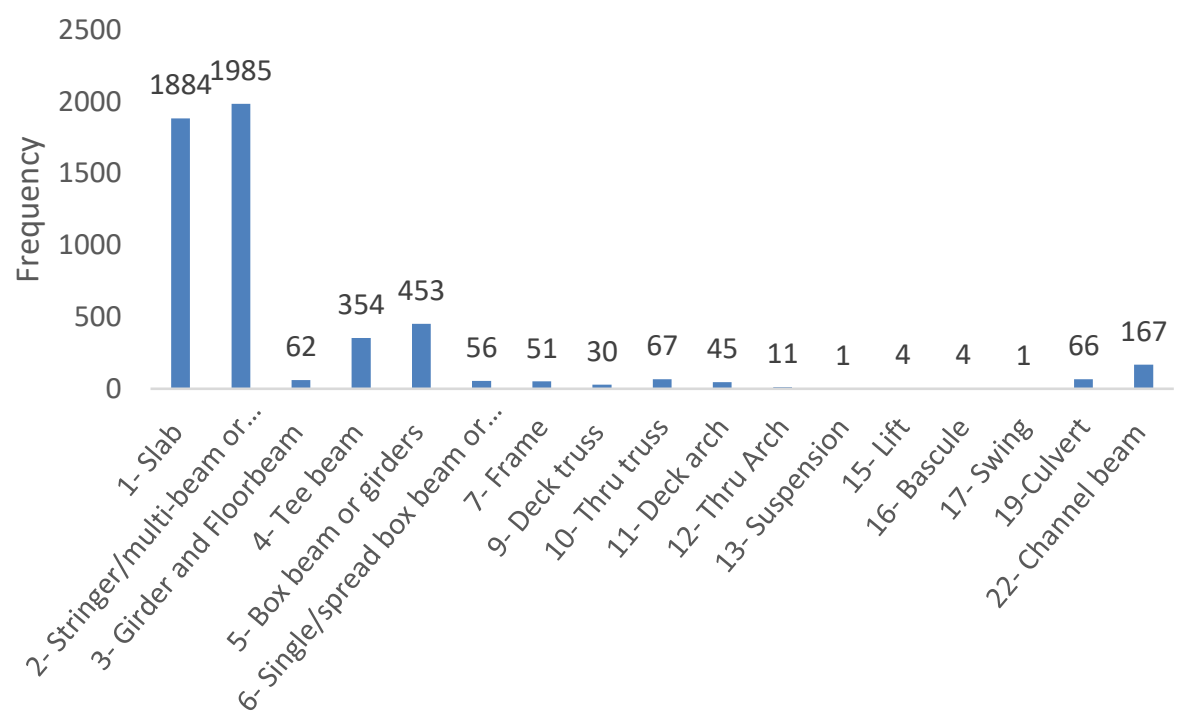

Figure 4-14: Frequency Plot of Bridge Design/Construction in NBI Dataset 


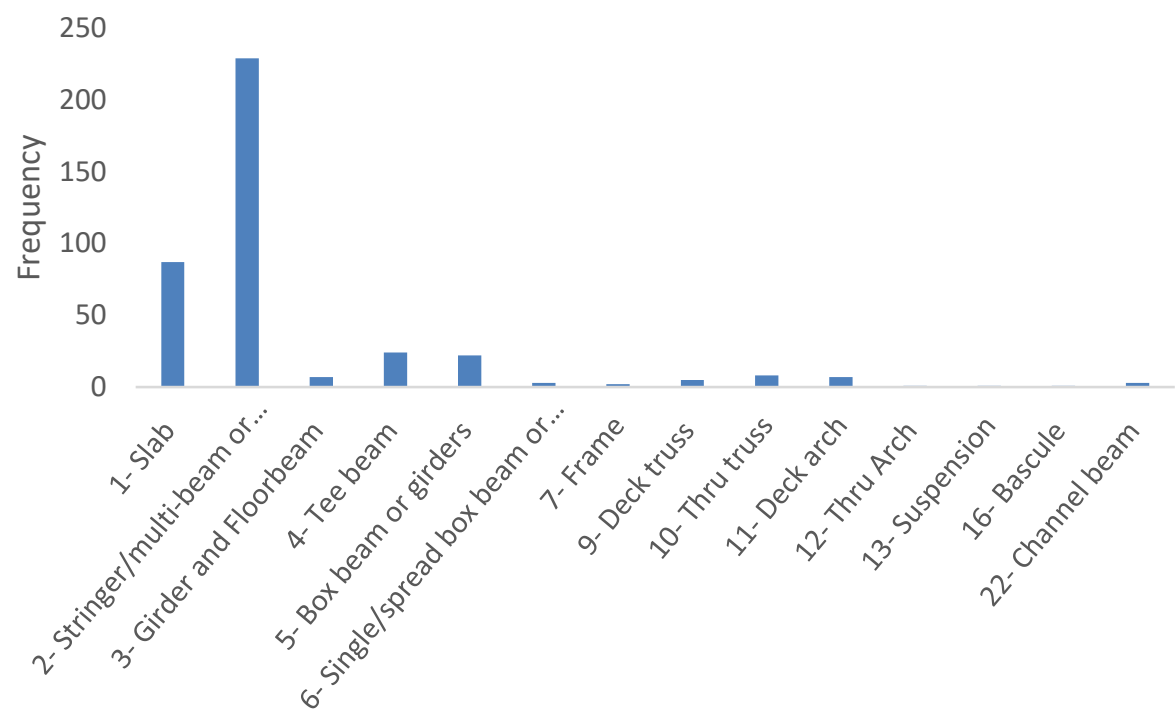

Figure 4-15: Frequency Plot of Bridge Design/Construction in Refined Dataset

\subsection{Deck Structure Type}

This deck structure variable describes the deck of each bridge in the database and is based on NBI Item 107. Since this project focuses specifically on concrete bridge decks, all other types are excluded from the dataset, i.e. this parameter mainly served as a filter. Of the concrete bridge decks in the dataset, there are two different types: 1-cast-in-place, and 2-precast panels. The resulting frequency plots show that there are more cast-in-place to precast bridge decks for both datasets (Figure 4-16 \& Figure 4-17). However, for the refined dataset, the ratio of cast-in-place bridge decks to precast bridge decks is significantly greater than the ratio for the NBI dataset. 


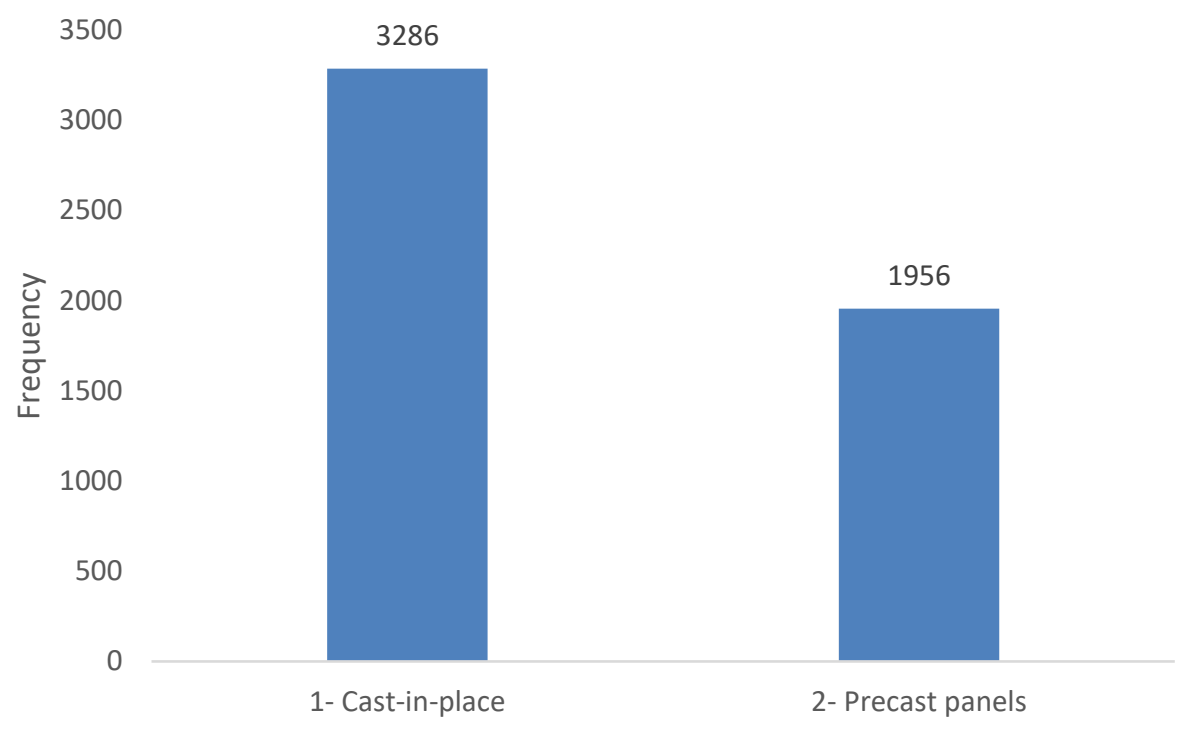

Figure 4-16: Frequency Plot of Deck Structure Type in NBI Dataset

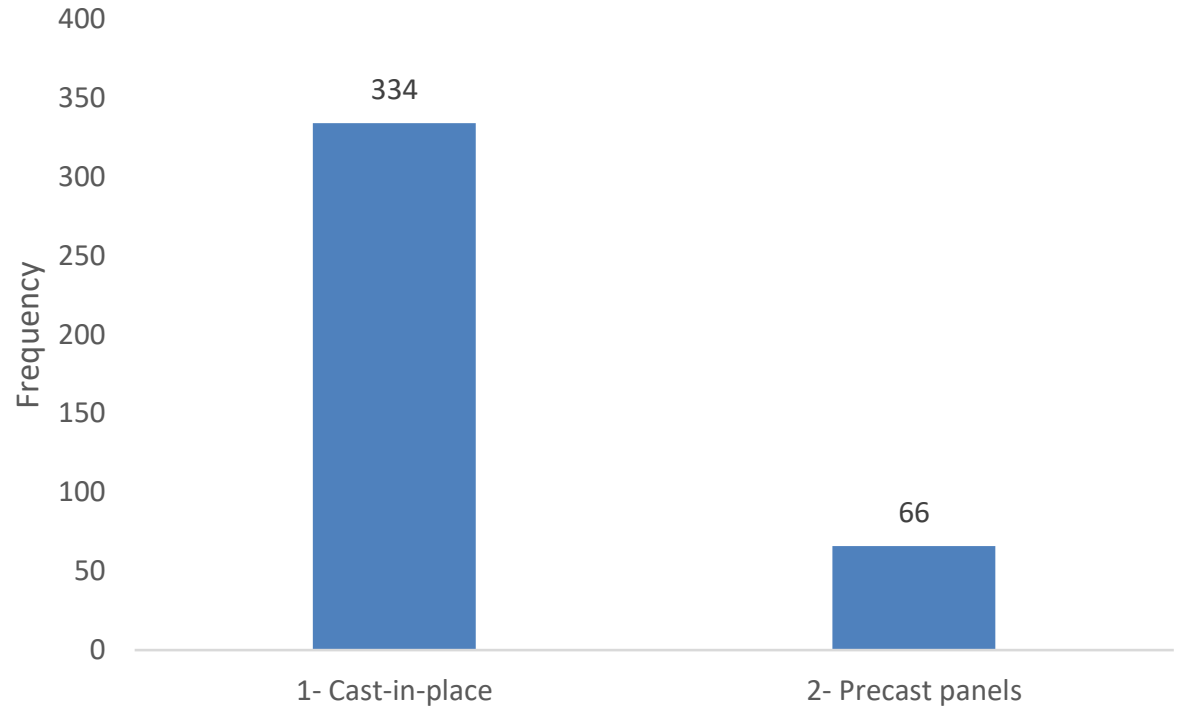

Figure 4-17: Frequency Plot of Deck Structure Type in Refined Dataset 


\subsection{Type of Wearing Surface}

The wearing surface variable describes the type of wearing surface present for each bridge deck and is based on NBI Item 108a. The resulting frequency plots show that over $60 \%$ of bridge decks have a bituminous wearing surface while less than $25 \%$ have a monolithic concrete wearing surface (Figure 4-18 \& Figure 4-19). According to FHWA (1995), a monolithic concrete wearing surface is a layer of concrete concurrently placed with the deck while an integral concrete wearing surface is a separate non-modified layer of concrete added to the deck (FHWA, 1995).

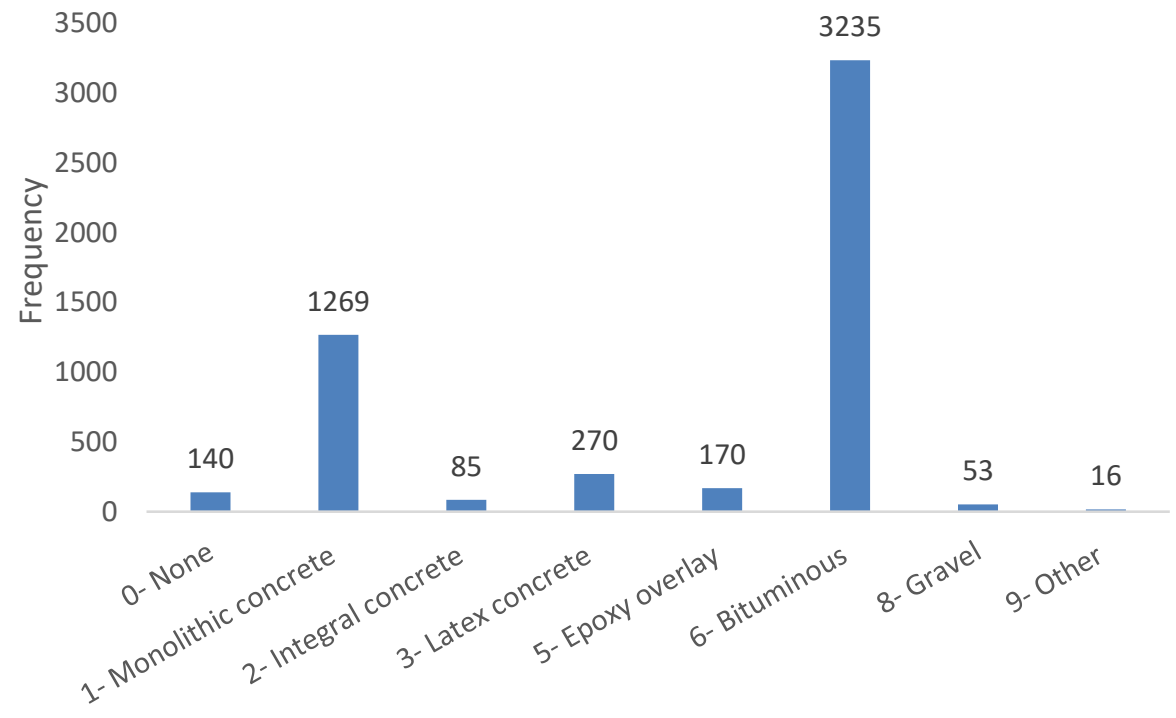

Figure 4-18: Frequency Plot of Wearing Surface Types in NBI Dataset 


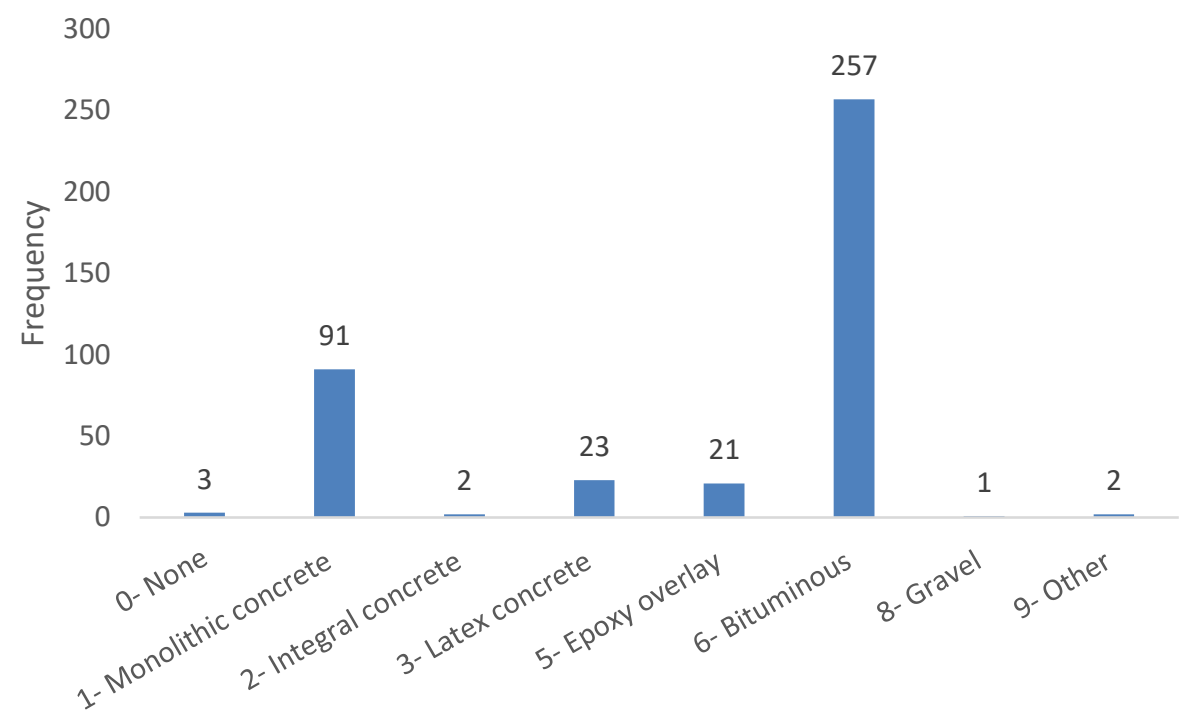

Figure 4-19: Frequency Plot of Wearing Surface Types in Refined Dataset

\subsection{Type of Membrane}

This variable, which is based on NBI Item 108b, describes what type of protective membranes exist on bridge decks with asphalt concrete wearing surfaces. For both datasets, there are 6 different membrane types. The different types are 0-none, 1-built-up, 2-preformed fabric, 3-epoxy, 8-unknown, 9-other. Although rarely used in current practice, built-up membranes consist of a fabric coated with a coal-tar pitch or rubberized asphalt (Kepler, Darwin, \& Locke Jr., 2000). The frequency plots show that over $70 \%$ of bridges do not have protective membranes (Figure 4-20 \& Figure 4-21). However, a small percentage have preformed fabric membranes. 


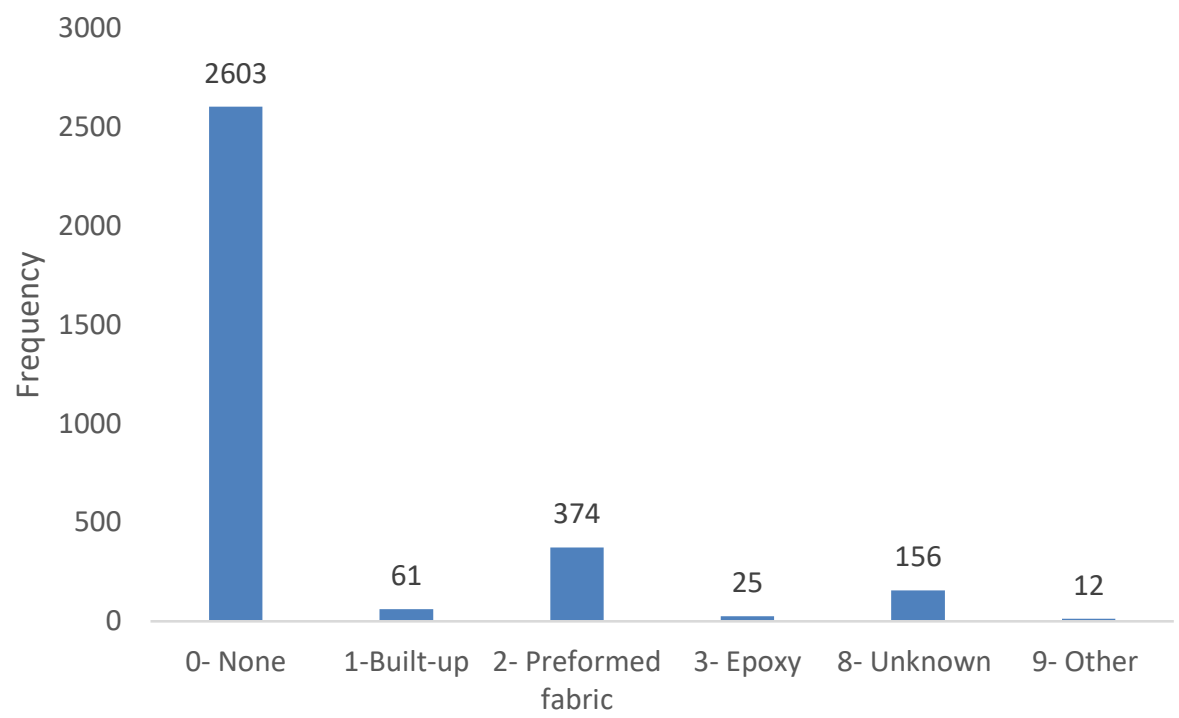

Figure 4-20: Frequency Plot of Membrane Types in NBI Dataset

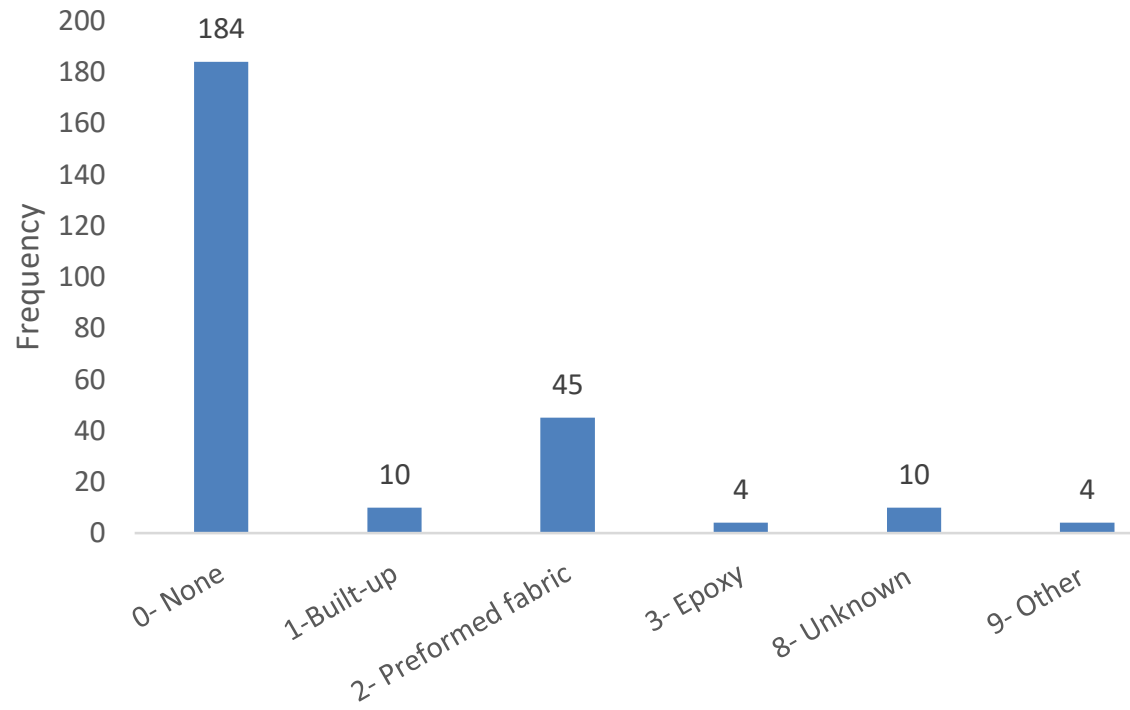

Figure 4-21: Frequency Plot of Membrane Types in Refined Dataset 


\subsection{Deck Protection}

This variable details the different deck protection methods that exist in both datasets and is based on NBI Item 108c. Both frequency plots show that most bridges do not have any deck protection although some have epoxy-coated rebars (Figure 4-22 \& Figure 4-23). Of the bridges with deck protection in the NBI dataset, $81 \%$ have epoxy-coated rebar. In comparison, for bridges in the refined dataset that have deck protection, $90 \%$ have epoxy coated rebar.

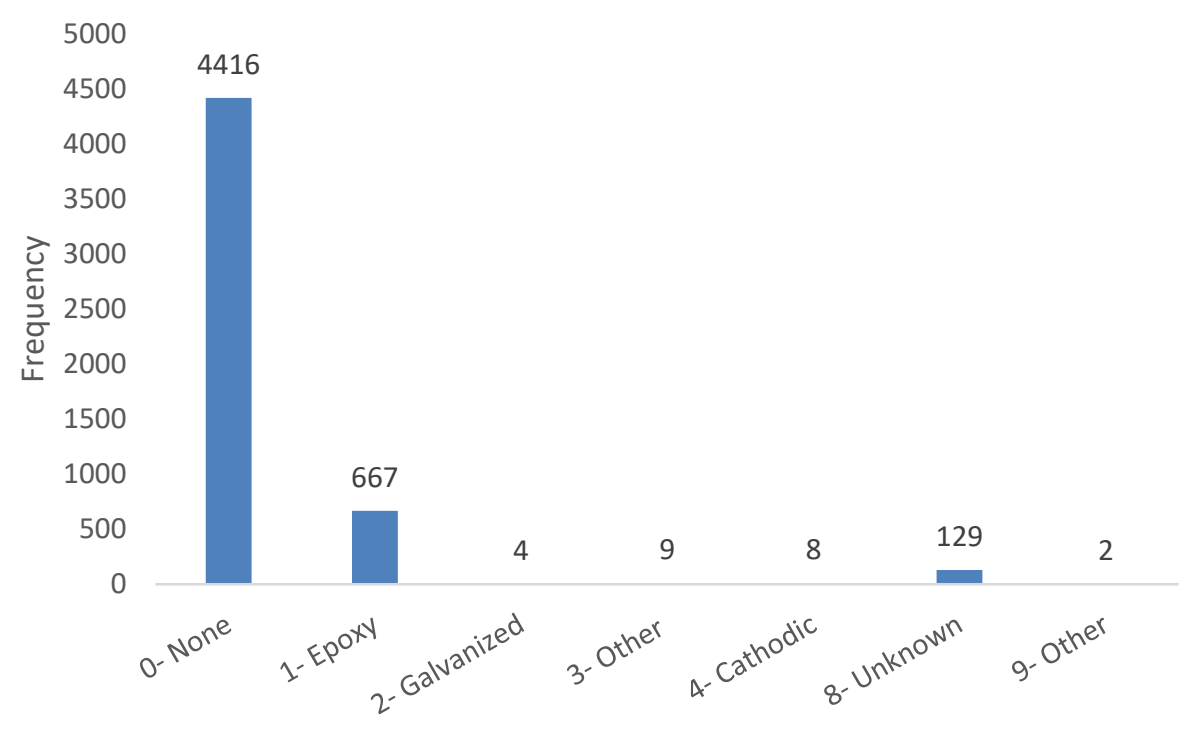

Figure 4-22: Frequency Plot of Deck Protection Method in NBI Dataset 


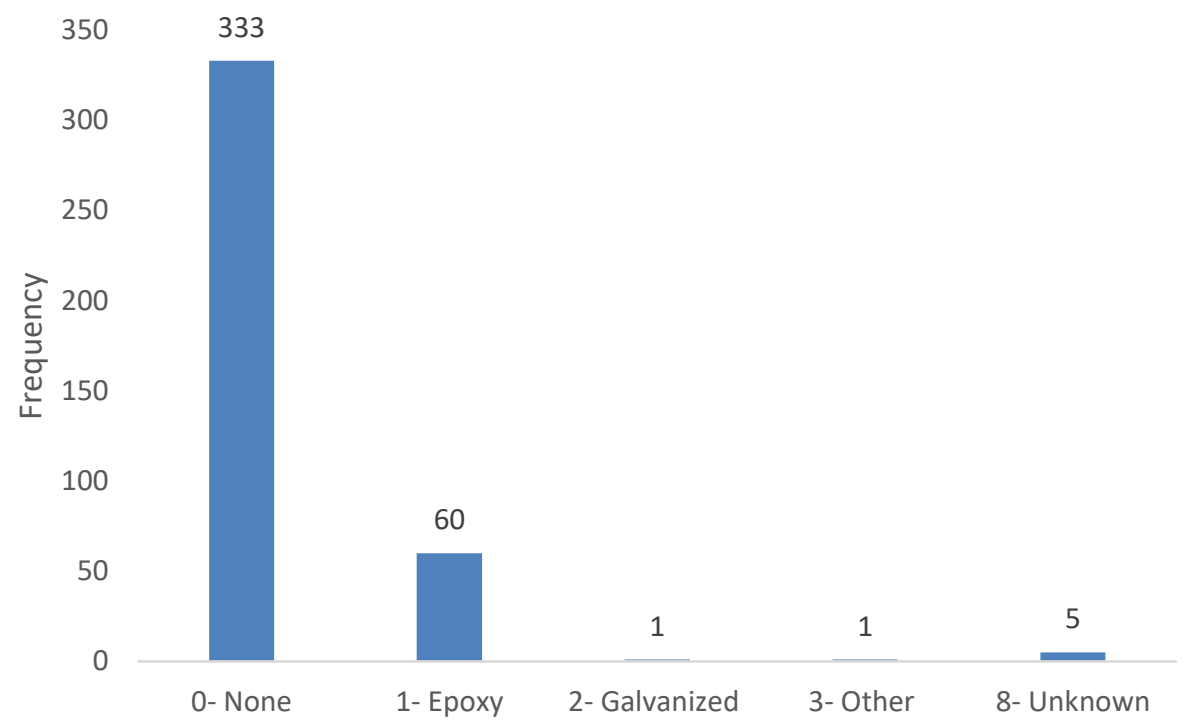

Figure 4-23: Frequency Plot Deck Protection Method in Refined Dataset 


\subsection{ADTT}

This variable was calculated from the percentage of ADT provided in NBI Item 109 and describes the average daily truck traffic bridges throughout Oregon experience. The resulting frequency plots show that over $60 \%$ of bridges in both datasets experience ADTT of 500 or less despite some bridges experiencing greater than 8,000 ADTT (Figure 4-24 \& Figure 4-25). ). For the NBI dataset, ADTT ranges from 0 to 19256 with an average of 927 and a median of 138. For the refined dataset, ADTT ranges from 0 to 8485 with an average of 765 and a median of 290 . In order to simplify this variable and better understand the effects of ADTT, the values presented from the NBI were grouped into three categories signifying low, medium, and high ADTT. Low ADTT (1) corresponds to <100, medium ADTT (2) corresponds to 100-1000, and high ADTT (3) corresponds to $>1000$. The resulting frequency plot for the NBI dataset shows that most bridges experience ADTT in group 1 (Figure 4-26). In comparison, the frequency plot for the refined dataset shows that most bridges experience ADTT in group 2 (Figure 4-27). Both plots show that group 3 contains the smallest number of bridges. 


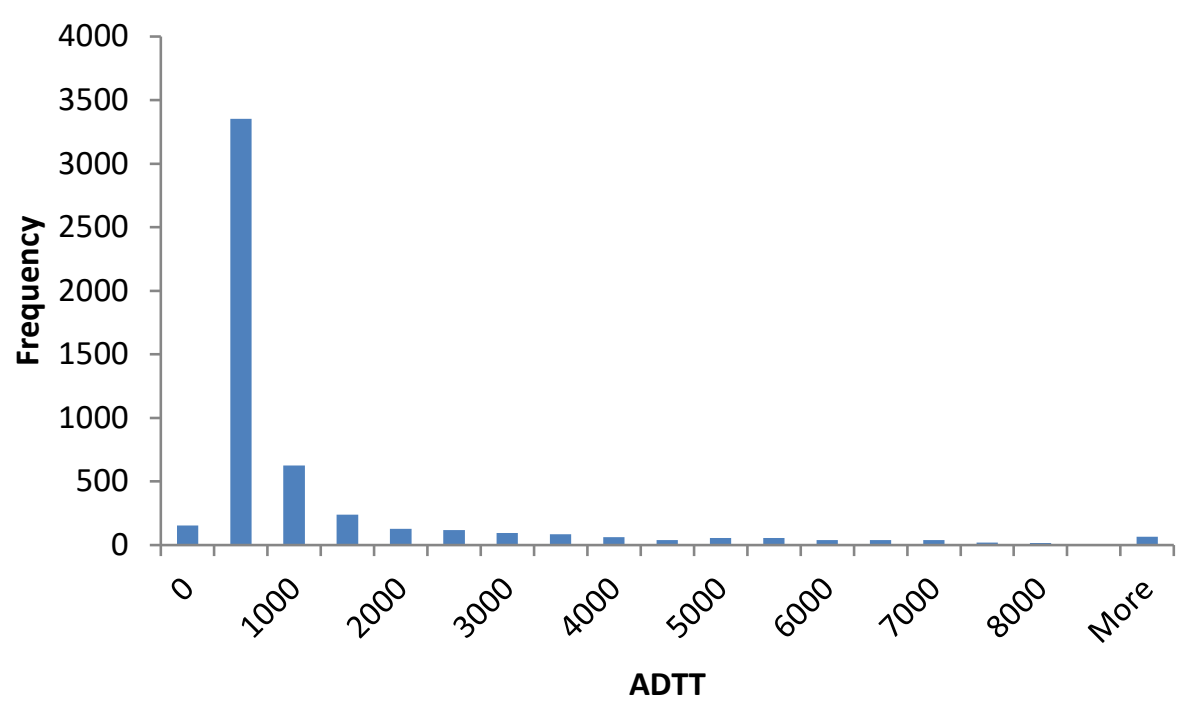

Figure 4-24: Frequency Plot of ADTT in NBI Dataset

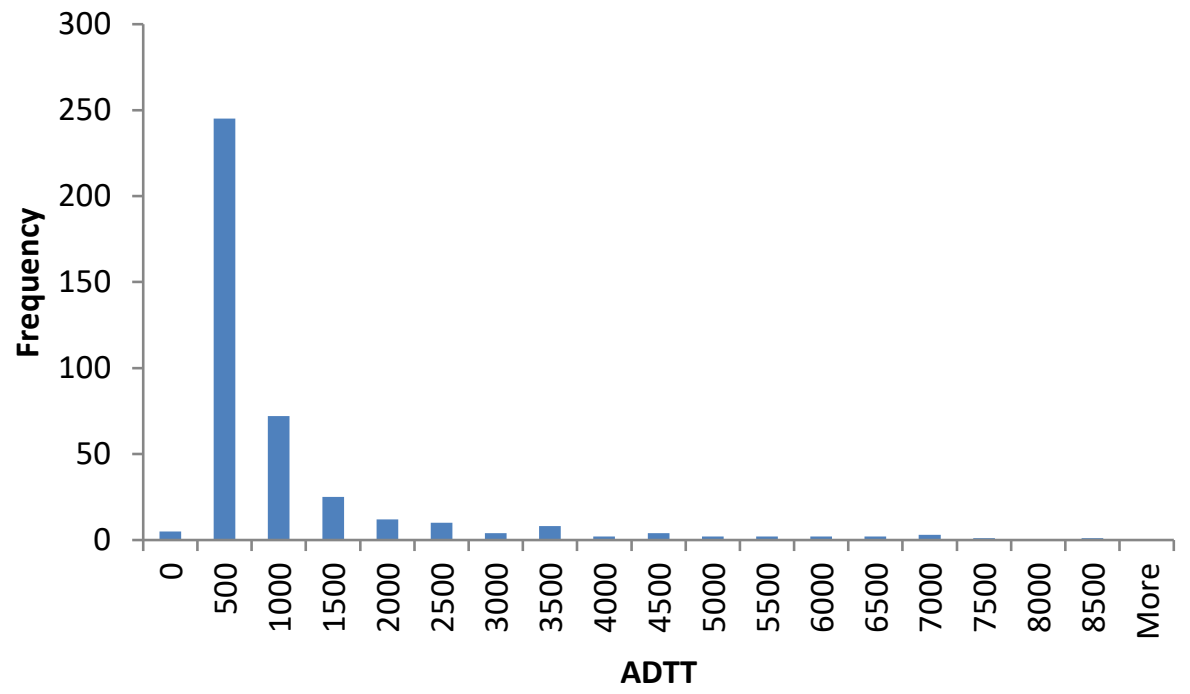

Figure 4-25: Frequency Plot of ADTT in Refined Dataset 


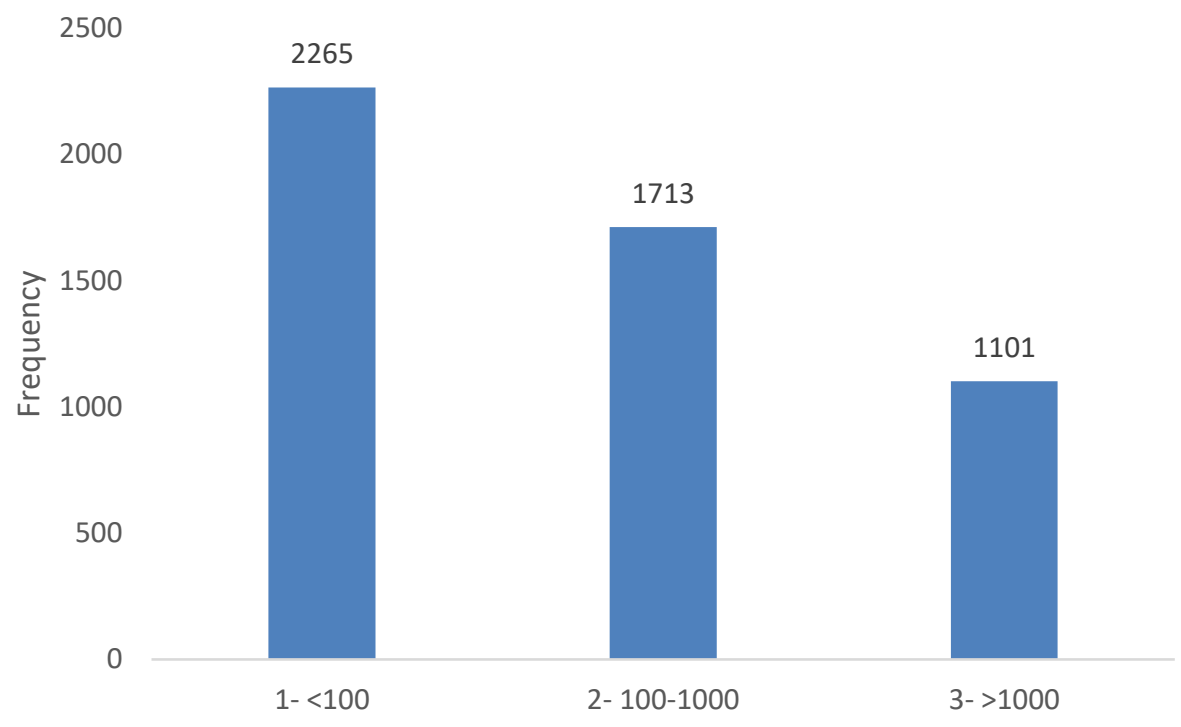

Figure 4-26: Frequency Plot of ADTT Groups in NBI Dataset

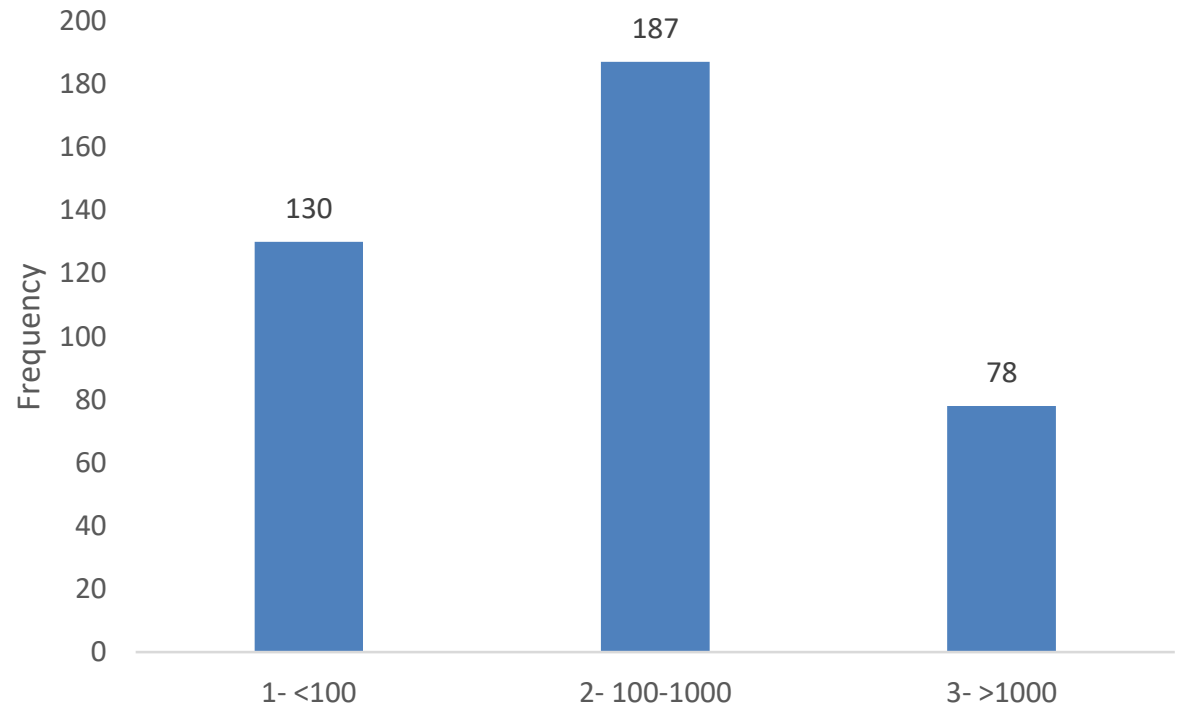

Figure 4-27: Frequency Plot of ADTT Groups in Refined Dataset 


\subsection{Distance to Seawater}

This variable aims to capture the chloride exposure a bridge deck is exposed to by computing the distance in kilometers a bridge is to the ocean. The resulting frequency plots reflect the dispersion of bridges from each dataset throughout the state of Oregon (Figure 4-28 \& Figure 4-29). For the NBI dataset, distances range from $0.003 \mathrm{~km}$ to 614 $\mathrm{km}$ with an average distance of $180 \mathrm{~km}$ and a median distance of $112 \mathrm{~km}$. For the refined dataset, distances range from $0.2 \mathrm{~km}$ to $597 \mathrm{~km}$ with an average distance of $239 \mathrm{~km}$ and a median distance of $190 \mathrm{~km}$. According to the literature, salt spray can travel up to $3 \mathrm{~km}$ and areas within $2 \mathrm{~km}$ of the ocean are considered aggressive chloride environments $(\mathrm{Vu}$ \& Stewart, 2000). In order to simplify this variable, distances were split into two categories, bridges within $1 \mathrm{~km}$ of the ocean, and bridges further than $1 \mathrm{~km}$ from it. The resulting frequency plots show that over $95 \%$ of bridges are located outside of the influence of seawater (Figure 4-30 \& Figure 4-31).

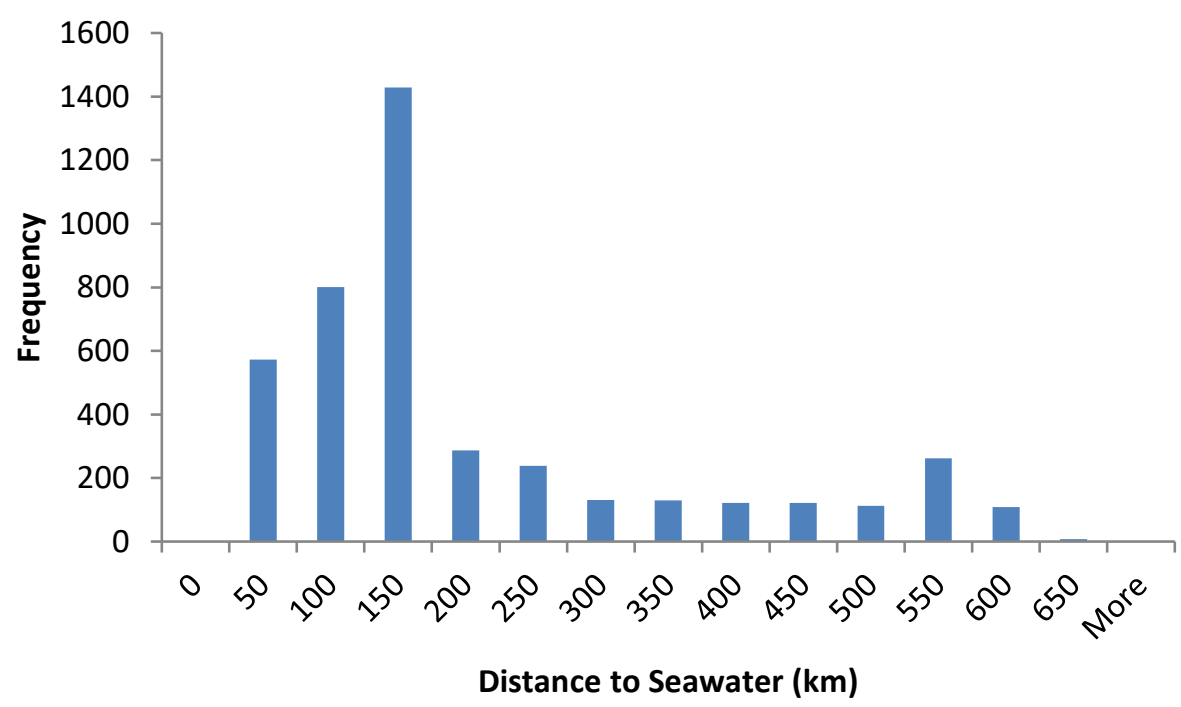

Figure 4-28: Frequency Plot of Distance to Seawater in NBI Dataset 


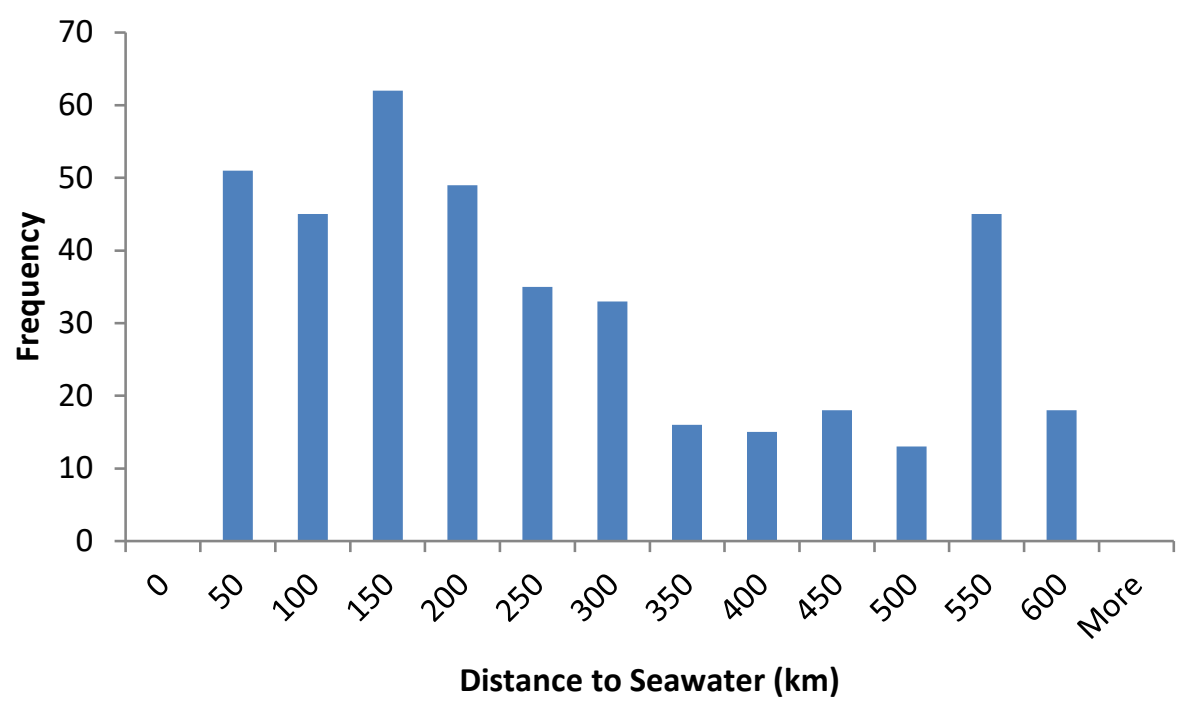

Figure 4-29: Frequency Plot of Distance to Seawater in Refined Dataset

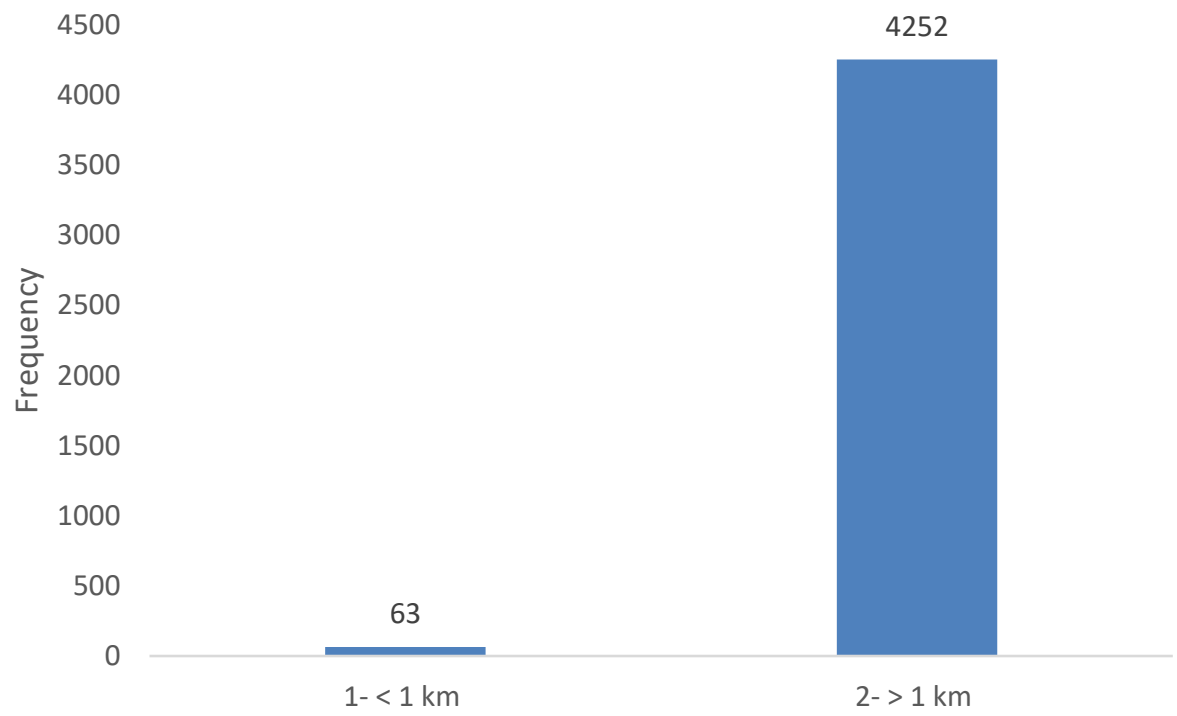

Figure 4-30: Frequency Plot of Distance to Seawater Groups in NBI Dataset 


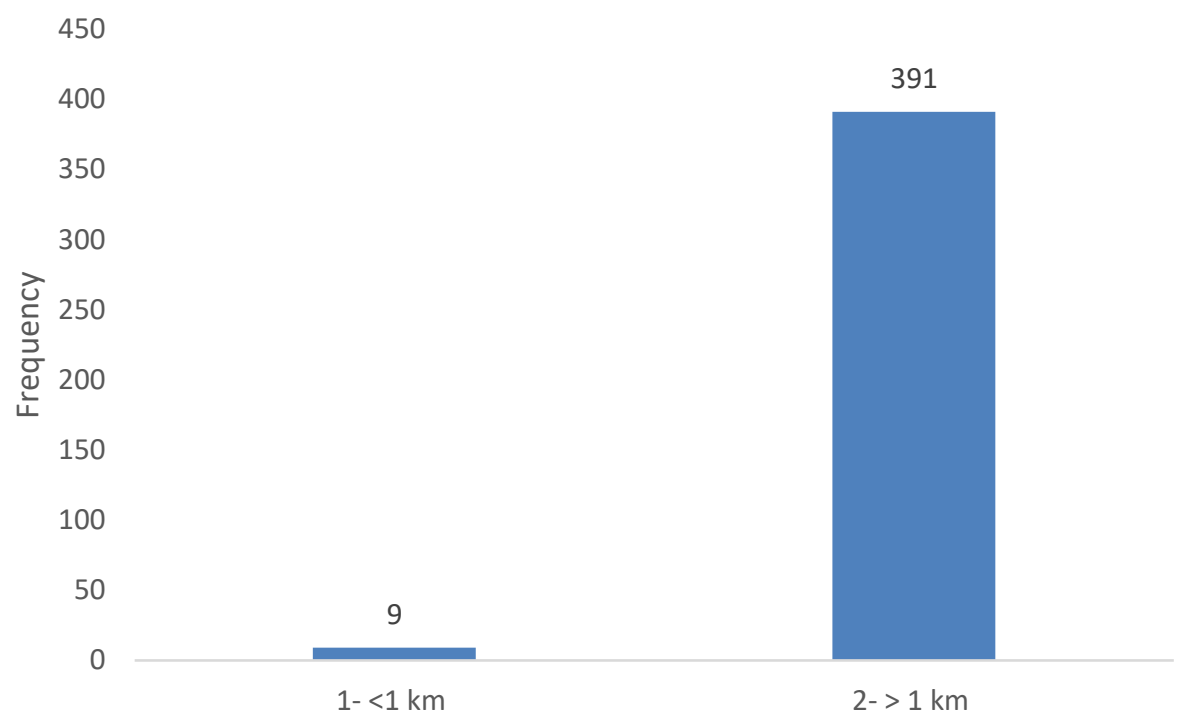

Figure 4-31: Frequency Plot of Distance to Seawater Groups in Refined Dataset

\subsection{Concrete Cover}

This variable shows the specified concrete cover for each bridge deck. The resulting frequency plot shows that there is a range of thicknesses from 0.5 to 3 in (Figure 4-32). In addition, most bridge decks have a specified cover thickness of $1.5 \mathrm{in.}$ In order to simplify this variable, 3 groups were created to show the difference in cover thickness. The first group contains bridges with cover from 0 to $1 \mathrm{in}$, the second 1 to 2 in, and the third 2 to 3 in. The resulting frequency plot shows that most bridges have cover between 1 and 2 in (Figure 4-33). 


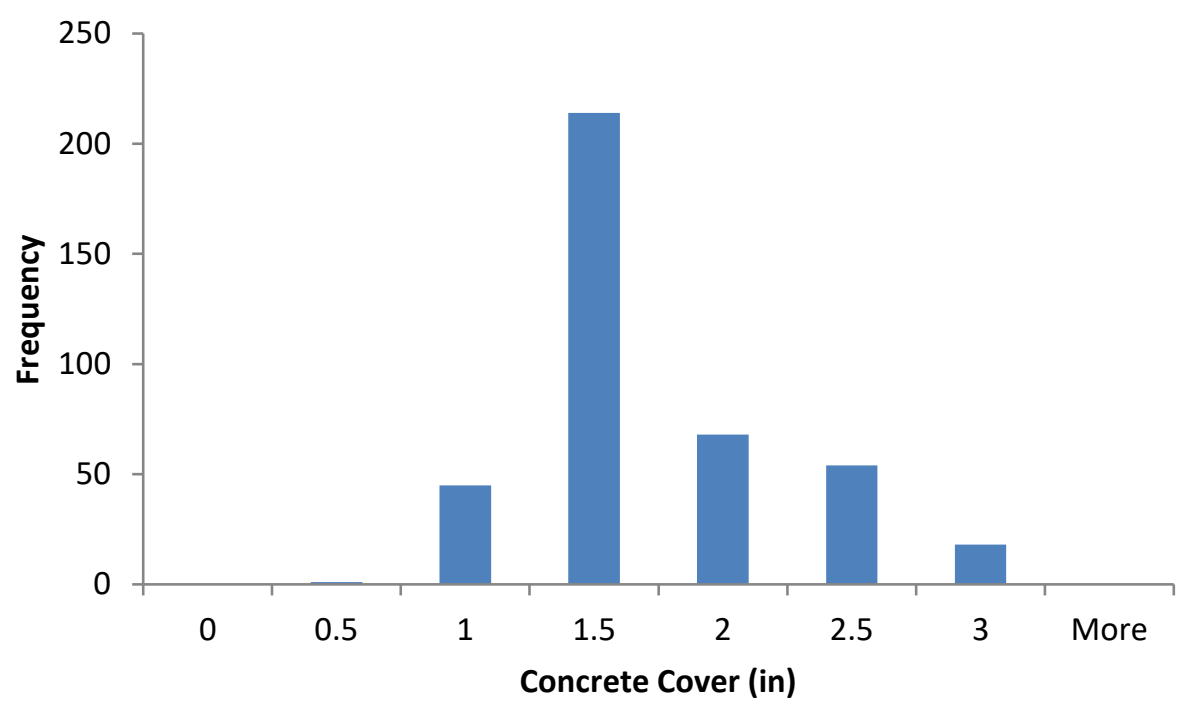

Figure 4-32: Frequency Plot of Bridge Deck Concrete Cover in Refined Dataset

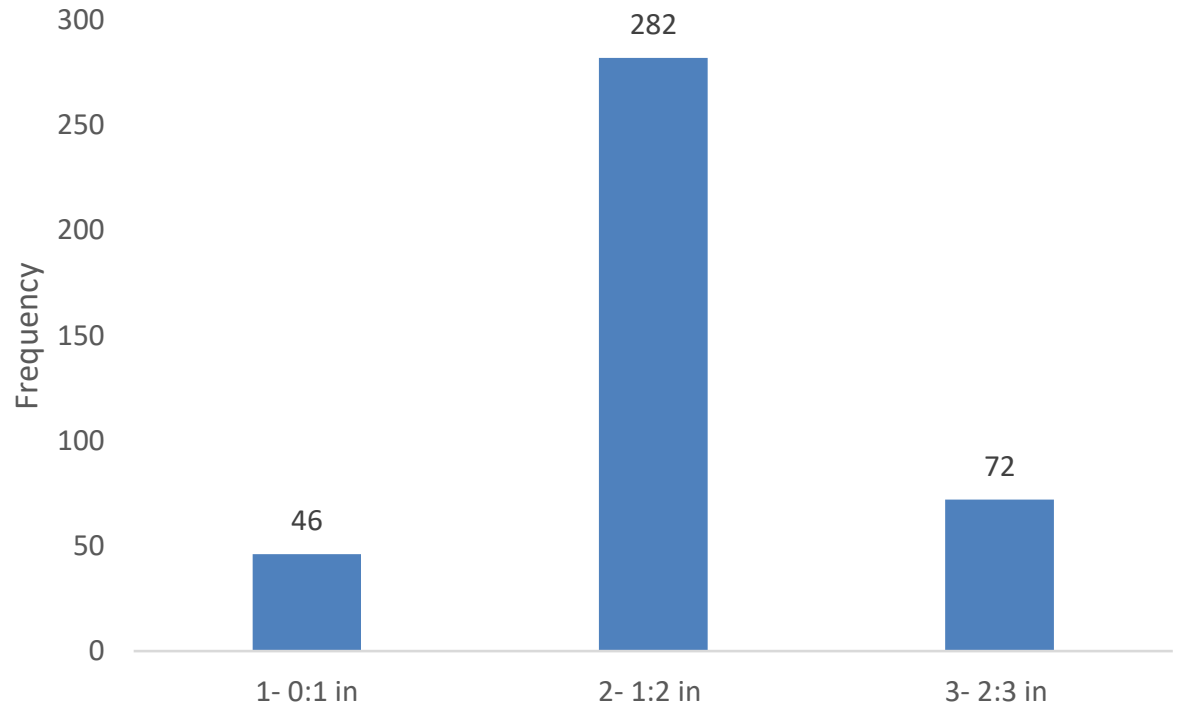

Figure 4-33: Frequency Plot of Concrete Cover Groups in Refined Dataset 


\subsection{Transverse Rebar Spacing}

This variable describes the top transverse rebar spacing of each bridge deck. Looking at the frequency plot, the spacing ranges from 3 to 24 in with a mean of 11.8 in and a median of 12 in (Figure 4-34). In order to simplify this information, the rebar spacing was split into two groups, bridge decks with spacing less than 10 in and bridge decks with spacing greater than $10 \mathrm{in}$. The resulting frequency plot shows that there are almost twice as many bridges in group 2 than in group 1 (Figure 4-35).

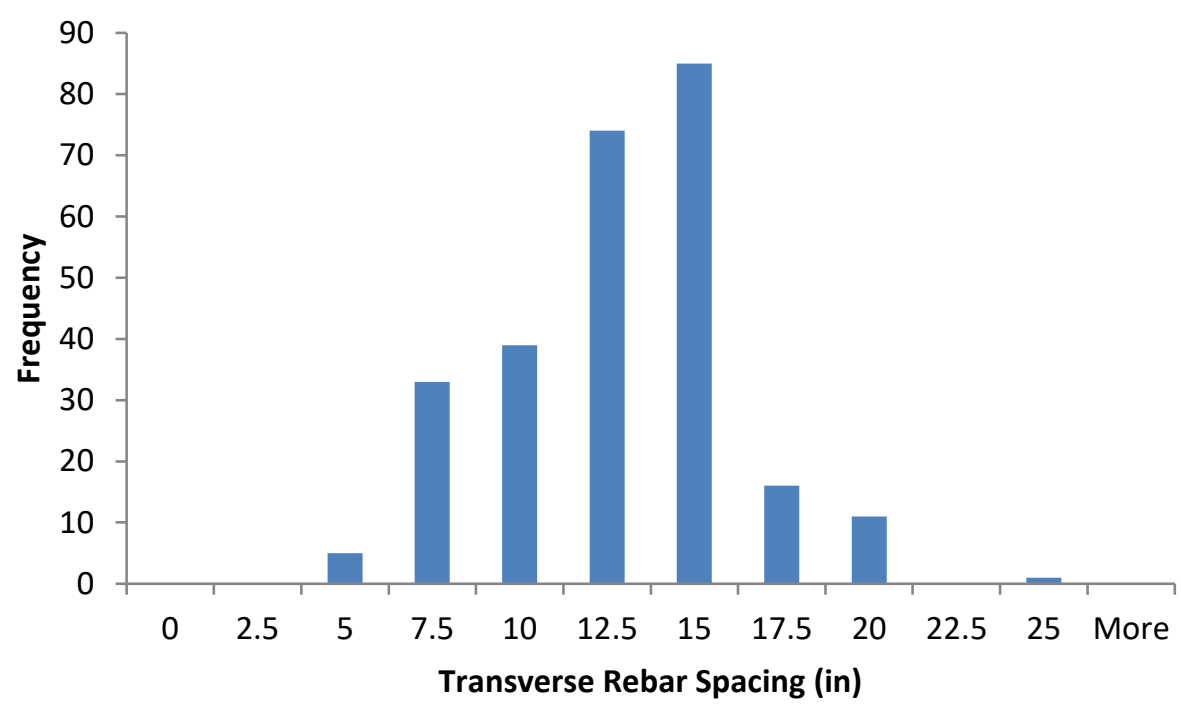

Figure 4-34: Frequency Plot of Rebar Spacing in Refined Dataset 


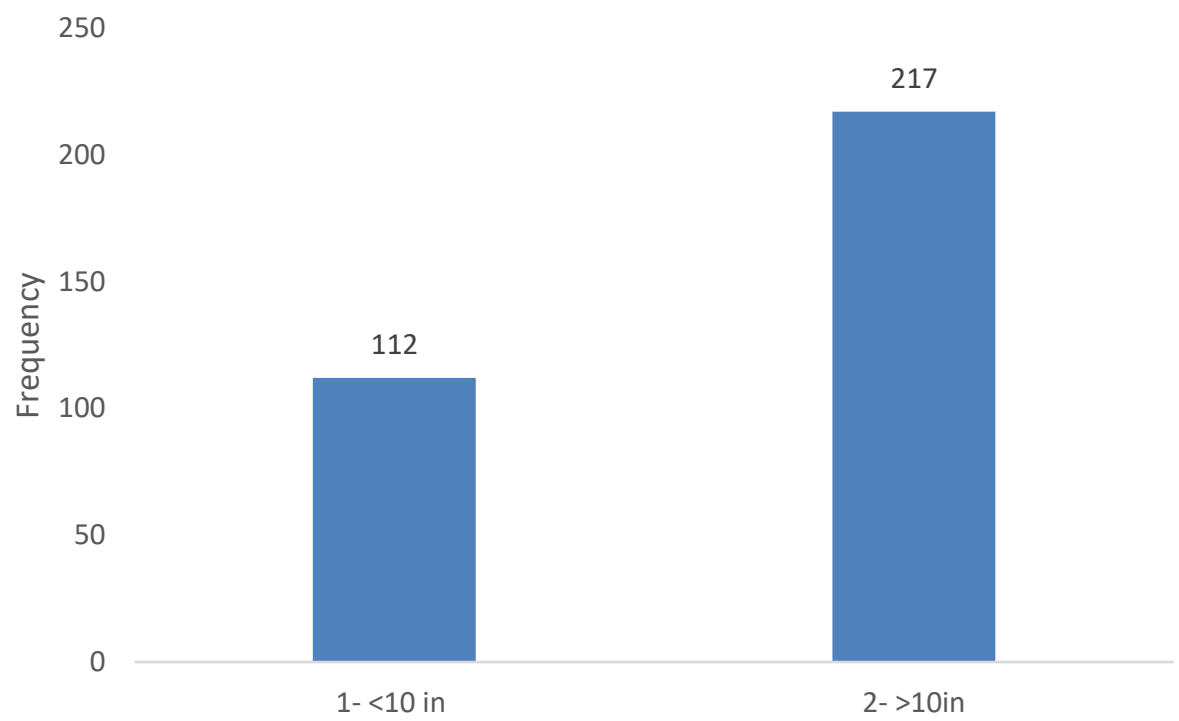

Figure 4-35: Frequency Plot of Rebar Spacing Groups in Refined Dataset

\subsection{Rebar Type}

This variable describes the type of rebar present in the top layer of the bridge deck reinforcement. This variable was gathered directly from the available bridge deck drawings and showed some differences between what is reported in the NBI. In such cases, the information from the drawings was used rather than what is reported in the NBI. The type of steel reinforcement is split into two groups. The first group includes bridge decks with standard black rebars while the second group includes bridges with epoxy-coated rebar. The resulting frequency plot shows the majority of bridges use standard black bar reinforcement steel while about a sixth of bridges have epoxy-coated rebars (Figure 4-36). 


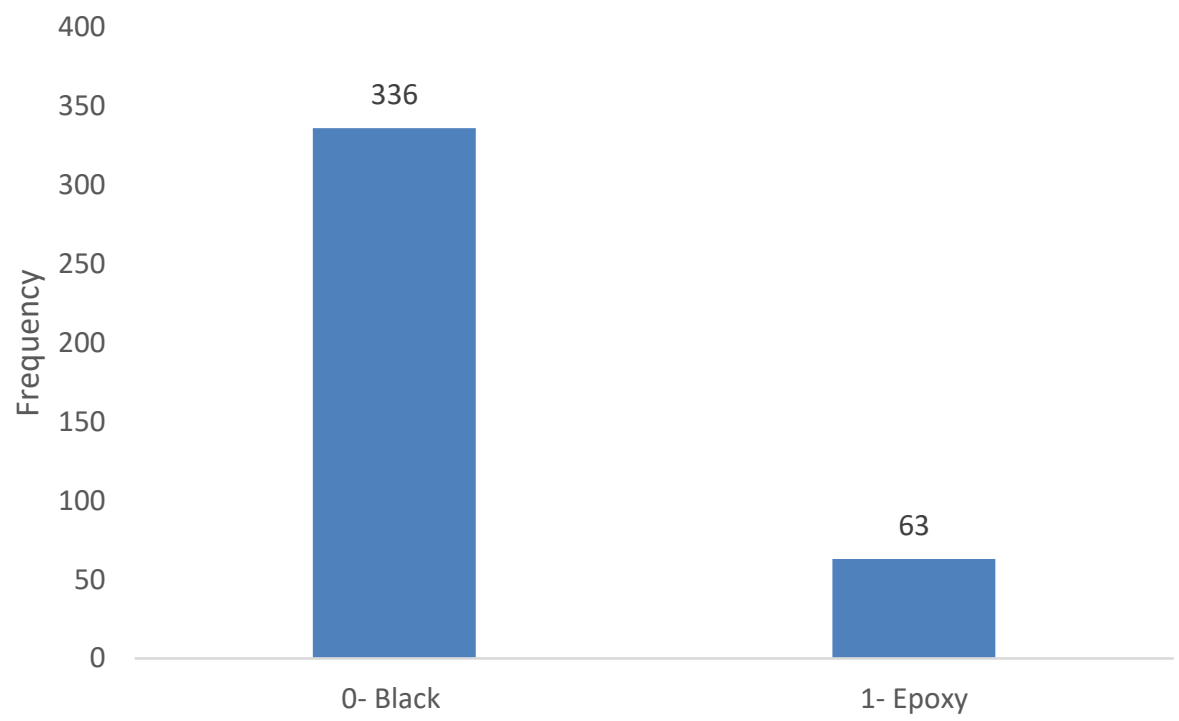

Figure 4-36: Frequency Plot of Rebar Type in Refined Dataset

\subsection{Deck Slenderness}

This variable describes the slenderness of the deck and was determined by dividing the deck thickness by the smaller of the space between beams or the space between bents. The resulting frequency plot shows that the majority of bridges have slenderness less than 0.15 (Figure 4-37). In order to simplify this variable, three groups were created that split up bridges with slenderness less than 0.05 , between 0.05 and 0.15 , and greater than 0.15 . The resulting frequency plot shows that most bridge decks have slenderness in group 2 followed by group 1 and then group 3 (Figure 4-38). 


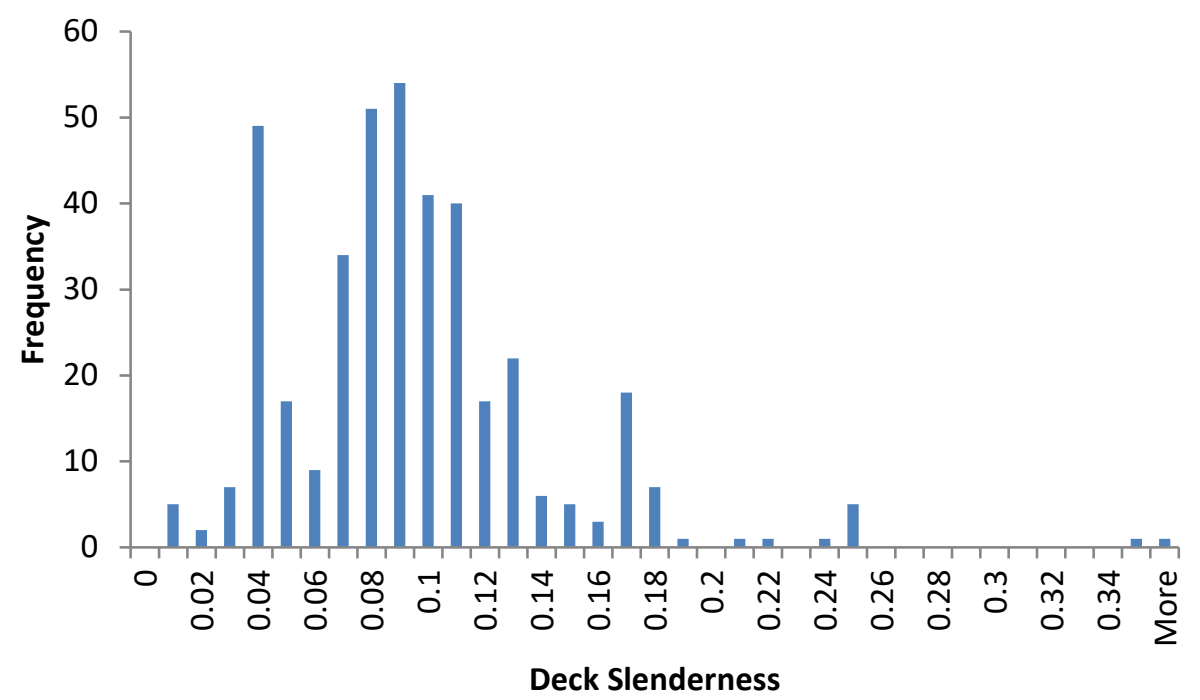

Figure 4-37: Frequency Plot of Deck Slenderness in Refined Dataset

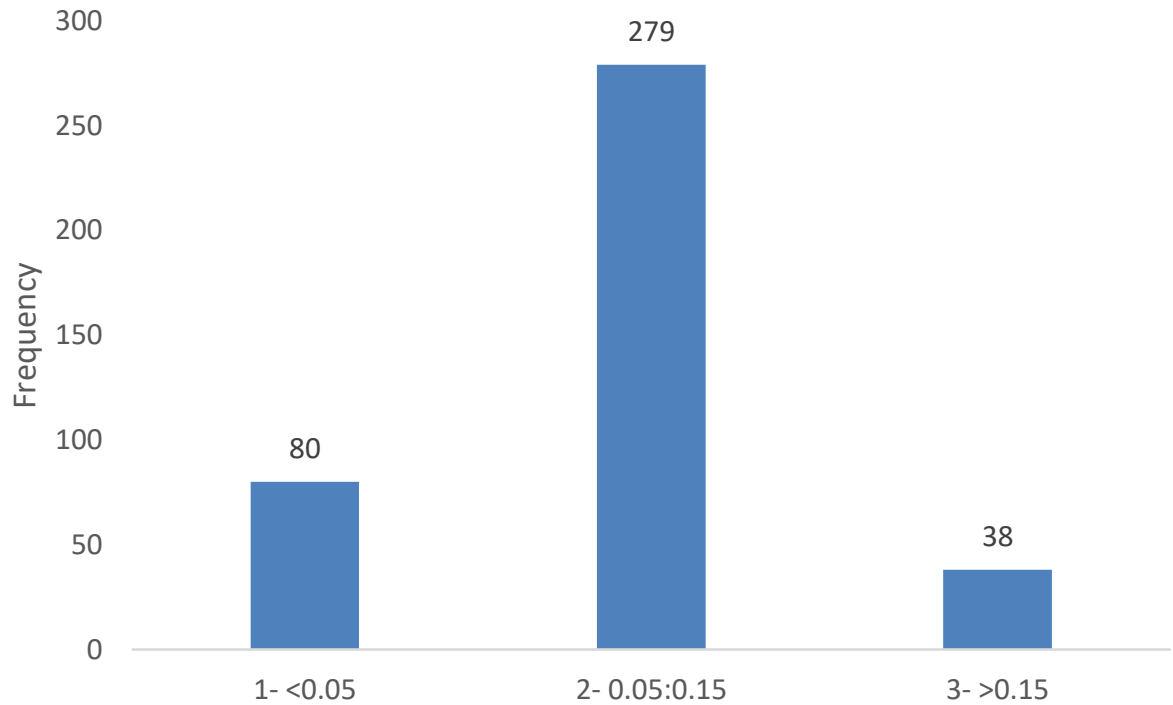

Figure 4-38: Frequency Plot of Deck Slenderness Groups in Refined Dataset 


\subsection{Time-In-Condition Rating (TICR)}

In addition to the independent variables found in the NBI database, the performance metric TICR was calculated from the NBI condition ratings (CR) for the years 1992 through 2016. Since each bridge experiences multiple CRs throughout its life, bridges can have multiple TICR for different CR. For example, if a bridge is observed to be in $\mathrm{CR}=$ 7 for eighteen years and $\mathrm{CR}=6$ for seven years, the bridge has two TICR, the first TICR $=18$ and is associated with $\mathrm{CR}=7$ while the second TICR $=7$ and is associated with CR $=6$. In order to calculate TICR for all bridge decks in the Oregon-specific datasets, some preprocessing was performed. For bridge decks with a large quantity of missing CRs, nothing was done. However, for bridge decks with three years or less of missing data between known CRs, the missing data was interpolated. In the case where missing data existed between two equal CR's, the missing CRs were assigned the known CR. In the case were missing CRs were between two different CR's, two procedures were performed. For an odd number of missing CRs, the middle CR was assigned randomly to either of the known CRs. For an even number of missing CRs, the assignment of CRs was simply split between the known CRs. After preprocessing and calculation, the NBI dataset has 11940 TICRs associated with 5242 bridge decks while the refined dataset has 1035 TICRs associated with 400 bridge decks.

Although the concept of TICR is straightforward, calculating descriptive statistics for this variable is much more complicated. The reason for this difficulty has to do with the presence of censoring. Censoring occurs when the value of an observation is only partially known (Leung, Elashoff, \& Afifi, 1997). In the TICR case, censoring occurs for 
three reasons (1) CR before 1992 and after 2016 are unknown, (2) there are missing CR observations, and (3) CR increase from one year to the next, this is assumed to be maintenance (Ghonima, Schumacher, Unnikrishnan, \& Fleischhacker, 2018). Here, for simplicity, we refer to "maintenance" as any action that increases the CR. In all these cases, a minimum TICR can be computed but it is inaccurate to assume that this TICR is correct because it is only observable partially. As a result of these uncertainties, any statistics attempting to describe TICR without considering censoring will be significant underestimates of the actual values. Three example cases of bridge deck CR records can be seen in Figure 4-39. These examples show how TICR is determined and also the different cases of censoring.

In order to account for censoring in the TICR performance metric, the research team is looking into predicting the TICR of censored observations using the Kaplan-Meier estimator. The Kaplan-Meier estimator is a non-parametric statistical method traditionally used to calculate the summary statistics of censored data in survival analysis (Huston \& Juarez-Colunga, 2009 ). This method calculates survival curves by estimating the probability that an individual object will survive past a given time. By only calculating the survival probability each time an event occurs, censorship is taken into account. In the dataset being analyzed, only uncensored TICRs are considered deterioration events. To show the difference between TICR considering censoring and not considering censoring, the mean TICR for both scenarios was calculated and plotted for the refined dataset for all 400 bridge decks (Figure 4-40). From this plot, it is apparent that the mean TICR is 
significantly larger when considering censoring. It should be noted that the censored TICR values are based on estimates that are affected by the amount of censoring. The TICR data found in our dataset is over $75 \%$ censored, which is above the recommended maximum of 50\% (Huston \& Juarez-Colunga, 2009 ). In addition to affecting the mean TICR of a bridge deck, censoring also affects a bridge deck's survival probability. Survival probability is defined as the probability that a bridge deck is assigned the same CR as a function of TICR (Figure 4-41). The figure shows that survival probability increases when censored data is considered, this is because there are fewer deterioration events to calculate survival probabilities from.

In addition to showing the general difference between censored and uncensored data, the effect of climate zone and design period on TICR can be observed for both cases. When looking at the difference in climate groups, the bar plot and survival curves show that climate group 1 and 3 are similar while climate group 2 has lower average TICR as well as survival probability (Figure 4-42 \& Figure 4-43). Looking at the difference in design periods, the bar plot shows that for the uncensored case, mean TICR stays the same (Figure 4-44). However, for the censored case mean TICR increases with design period, this trend can also be seen with the survival curves. The survival probability increases with design period (Figure 4-45). 


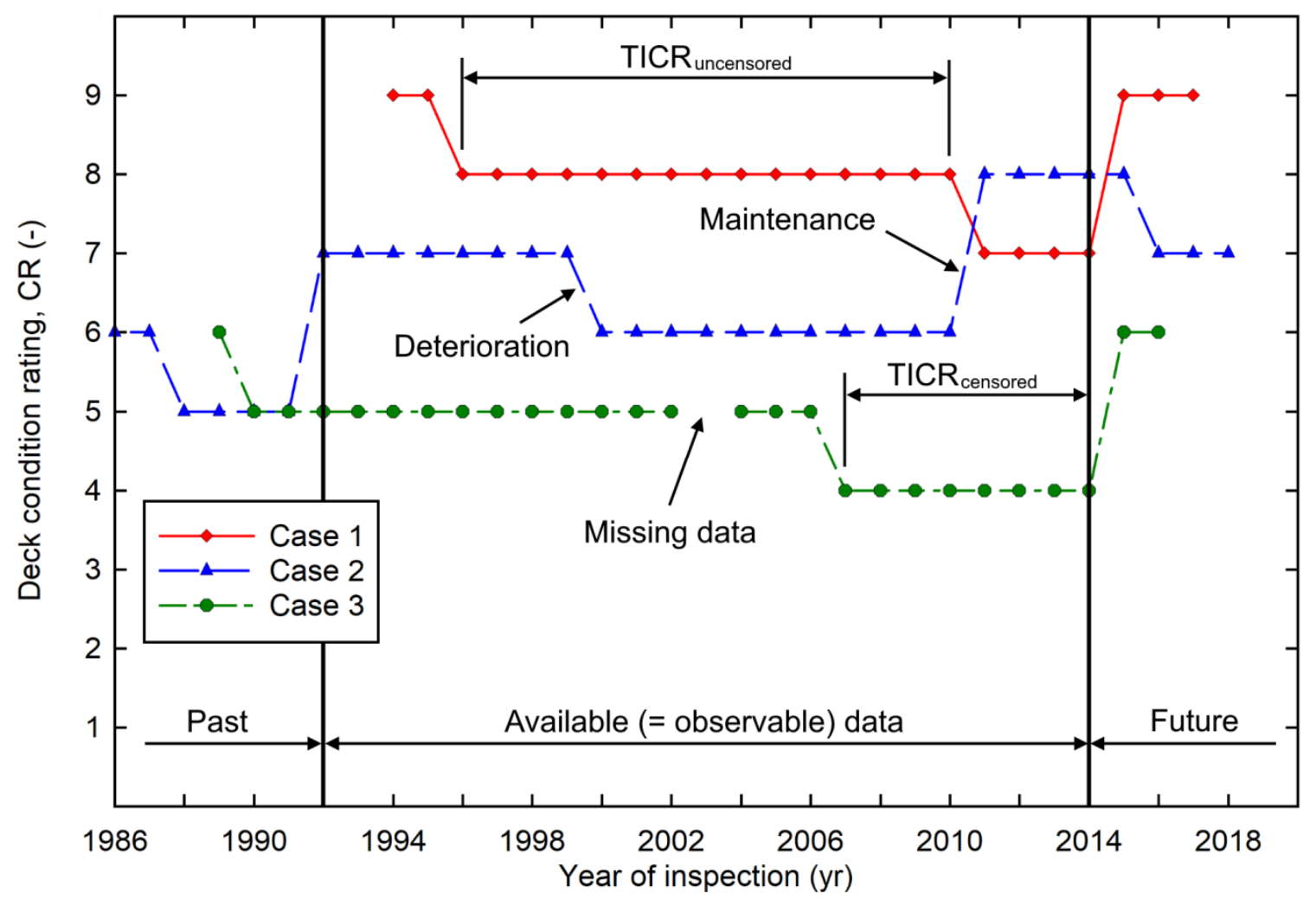

Figure 4-39: Three sample cases of CR records for 23 years of NBI data, 1992-2014.

Source: (Ghonima, Schumacher, Unnikrishnan, \& Fleischhacker, 2018)

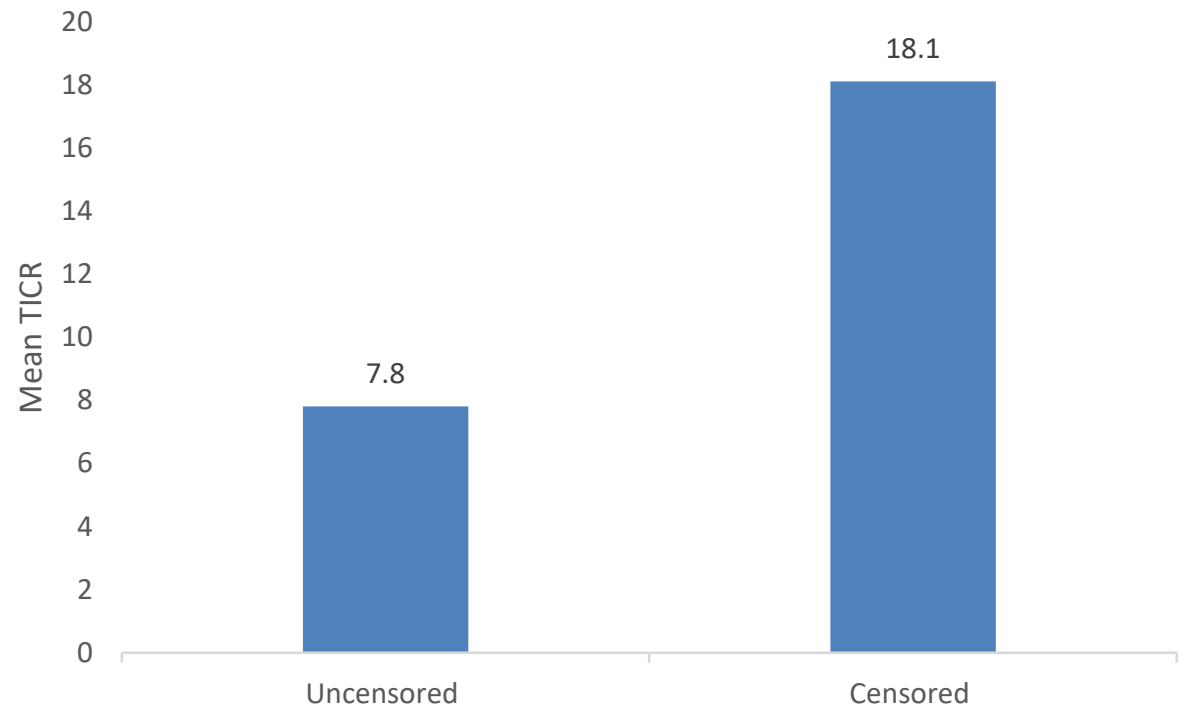

Figure 4-40: Bar Plot of Mean TICR from Refined Dataset 


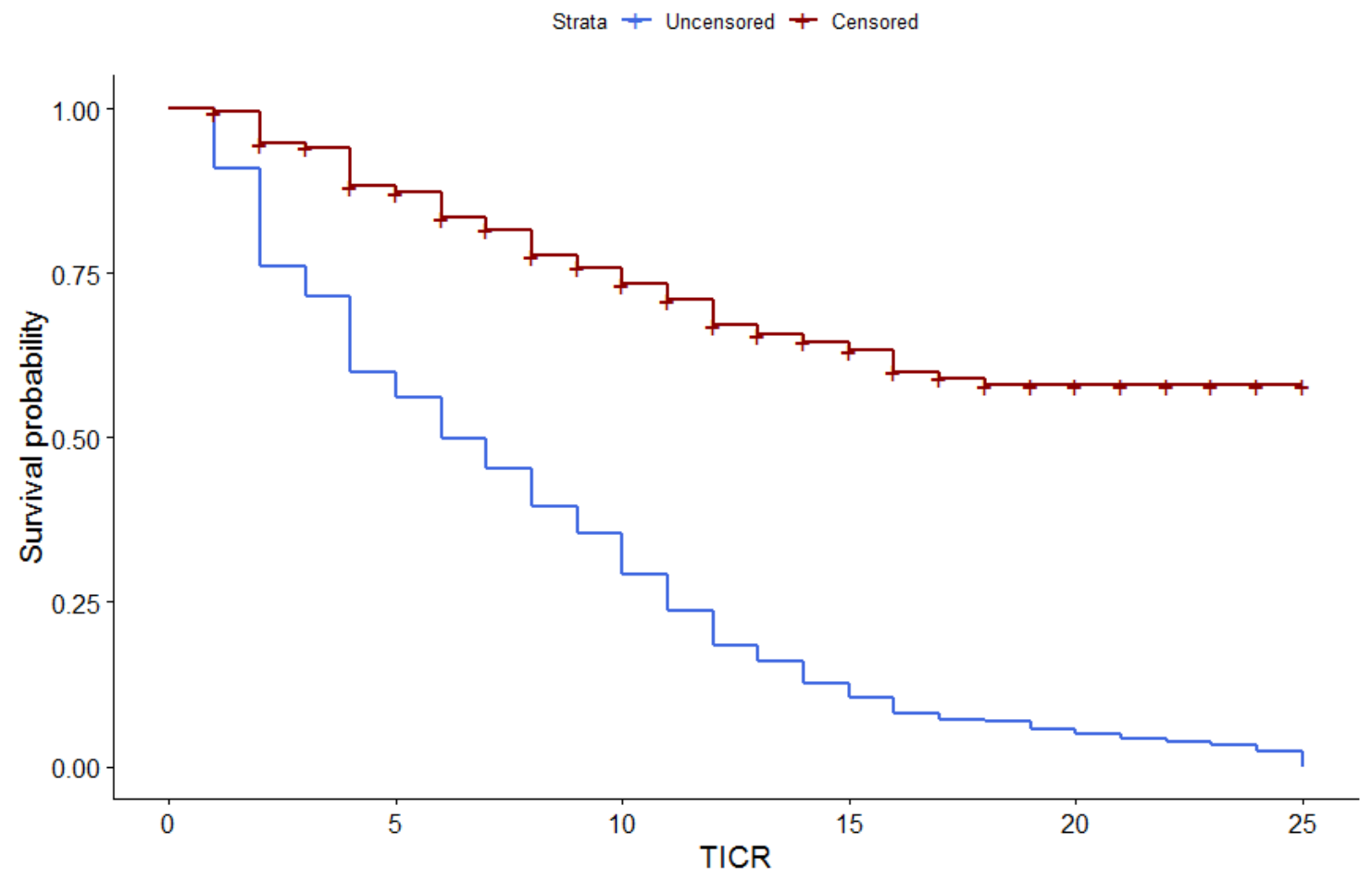

Figure 4-41: Survival Curves of TICR from Refined Dataset

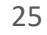

uncensored Censored

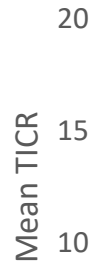

18.5

16.7
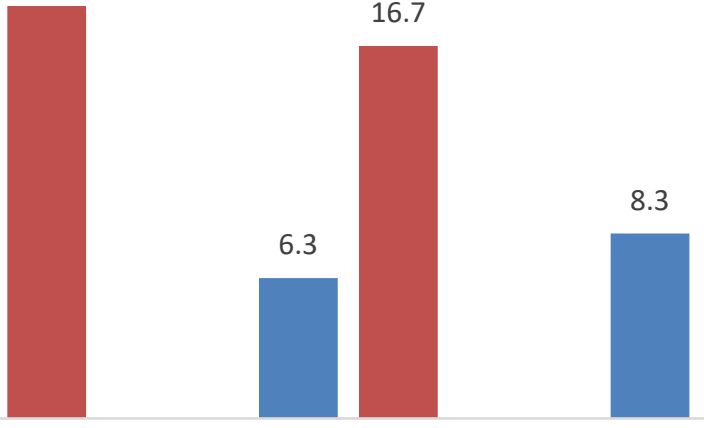

2

18.6

1

Climate Group

Figure 4-42: Bar Plot of Mean TICR from Refined Dataset by Climate Group 


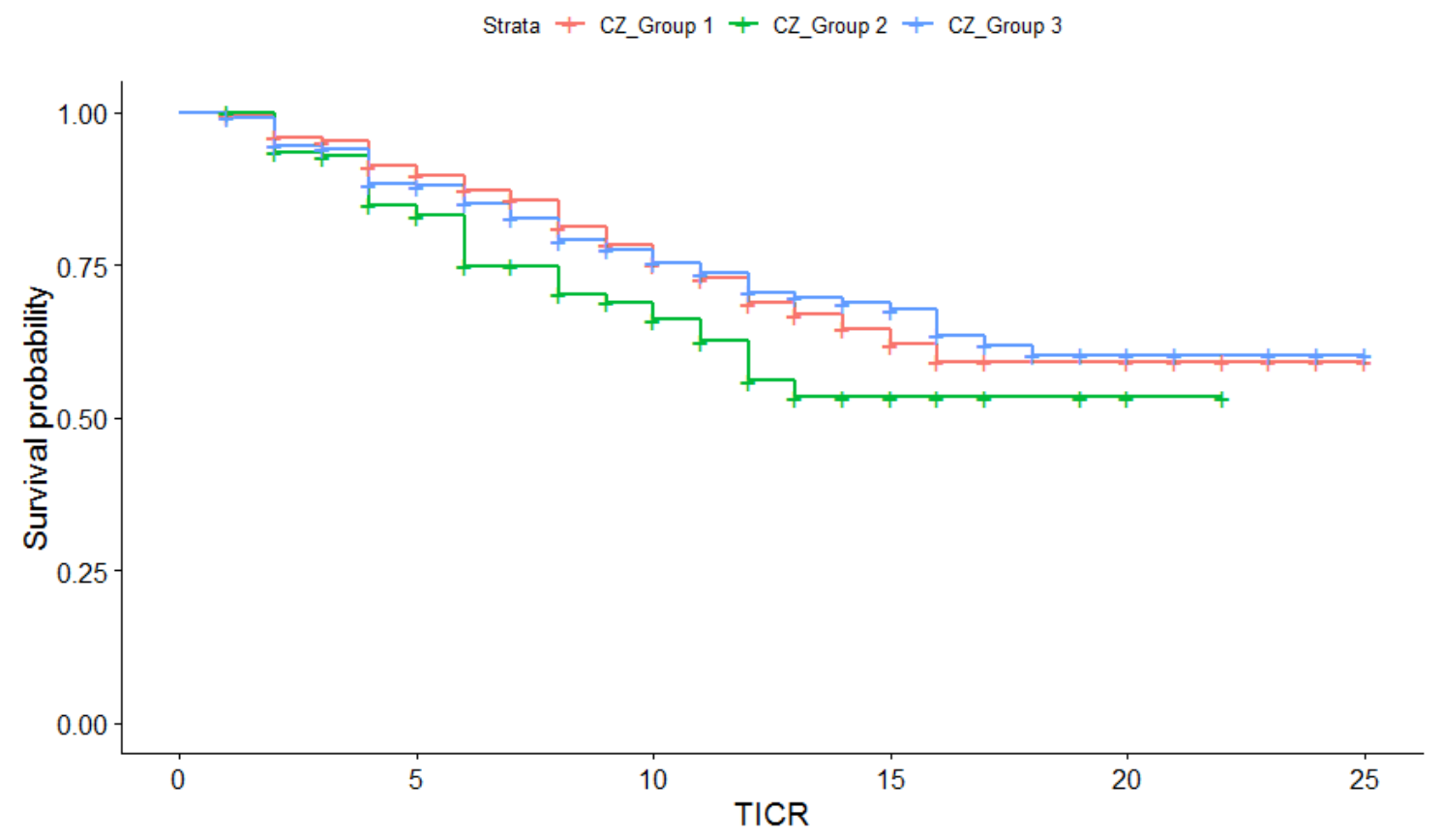

Figure 4-43: Survival Curves of Censored TICR from Refined Dataset by Climate Group

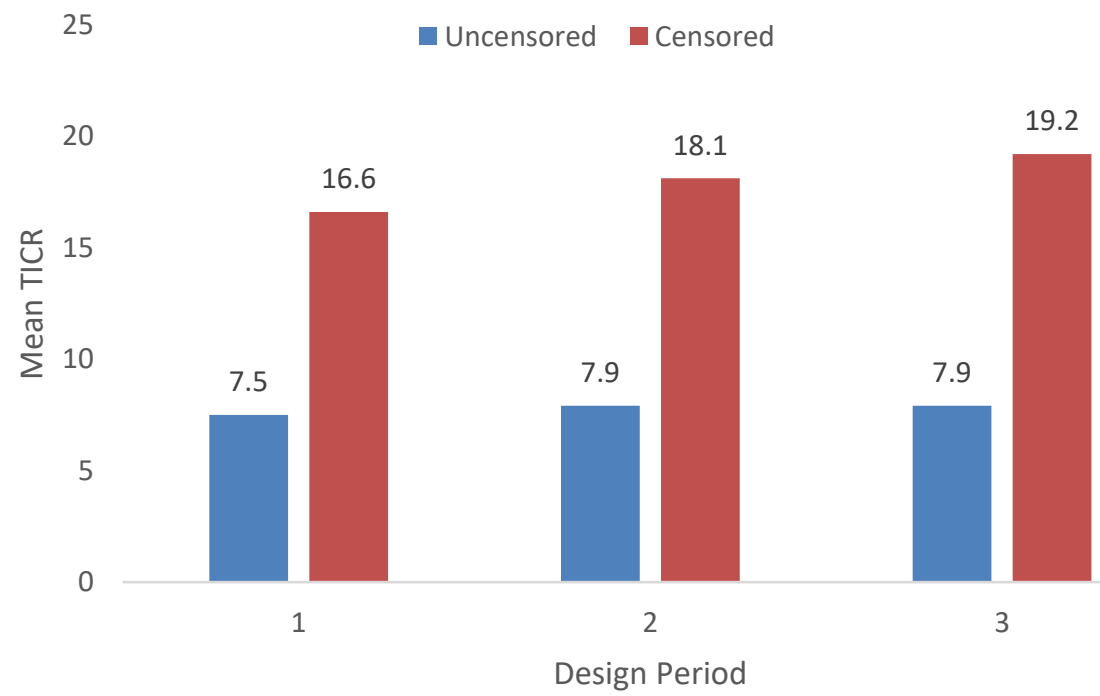

Figure 4-44: Bar Plot of Mean TICR from Refined Dataset by Design Period 


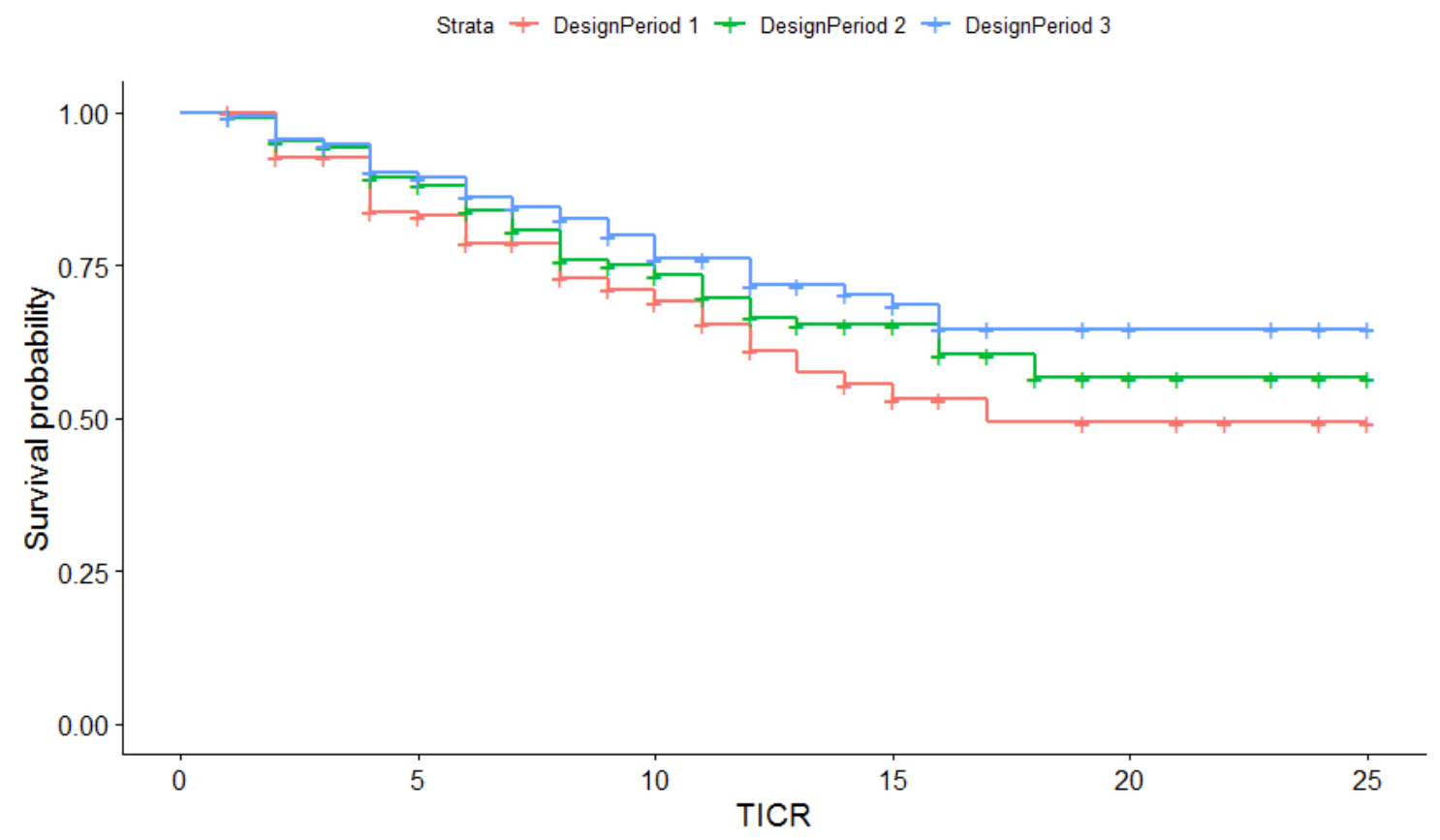

Figure 4-45: Survival Curves of Censored TICR from Refined Dataset by Design Period

\subsection{Conclusions}

Overall, the descriptive statistical analysis between the NBI dataset and the refined dataset shows that most variables have similar distributions of bridge decks. The largest difference between the two datasets is a result of selecting bridge decks in different climate zones for the incorporation of construction data. The research team gained the following insights on the variables gathered and derived from the NBI.

- The climate zones that bridge decks in Oregon are located in are distinctly different based on a variety of characteristics. In general, the majority of bridge decks in Oregon are in climate zone 2 while the fewest bridge decks are in climate zones 4 and 5. This distribution can be seen in the NBI dataset because it includes 
all concrete NBI bridge decks in Oregon. However, the refined dataset selected bridge decks based on climate zone and so there is a relatively even distribution for this dataset. Each climate zone includes at least 40 bridges except for climate zone 5 .

- The design period variable shows that there are more new bridge decks than old bridge decks. For both the NBI dataset and the refined dataset, the frequency of bridge decks increases with design period.

- For both datasets, over $95 \%$ of bridge decks are maintained by either the state highway agency or the county highway agency.

- The material/design variable shows that most bridges are made of concrete. The NBI dataset shows that over $45 \%$ of bridges are made of precast concrete compared to $32 \%$ in the refined dataset.

- According to the frequency plots for both datasets, over $70 \%$ of bridge decks are either slabs or supported by stringer/ multi-beam/girder systems.

- Most bridge decks in both datasets are cast-in-place. However, only $63 \%$ of decks in the NBI dataset are cast-in-place compared to $84 \%$ in the refined dataset.

- The wearing surface variable shows that over $85 \%$ of bridge decks in both datasets have either a monolithic concrete or bituminous wearing surface.

- Over $70 \%$ of bridge decks that have asphalt concrete wearing surfaces do not have protective membranes for both datasets. Of the bridge decks that do, most have preformed fabric membranes. 
- The NBI item deck protection illustrates that for both datasets over $80 \%$ of bridge decks do not have deck protection.

- For this analysis, ADTT was split into three group: low (ADTT < 100), medium $(100<$ ADTT < 1000), and high (ADTT > 1000). In the NBI dataset, most bridge decks experience low ADTT. However, in the refined dataset, most bridges experience medium ADTT.

- The distance to seawater variable aims to capture chloride exposure of a bridge deck. For both datasets, over $95 \%$ of bridge decks are further than $1 \mathrm{~km}$ from the ocean.

In addition to the variables associated with the NBI, the refined dataset includes construction information for 400 bridge decks. Below are some insights into these variables:

- The concrete cover variable describes the thickness of the specified cover for each bridge deck. For the bridge decks in the refined dataset, over $70 \%$ have a cover between 1 and 2 in.

- According to the associated frequency plot, over $60 \%$ of bridge decks have transverse rebar spacing greater than 10 in.

- The frequency plot for the rebar type variable shows that $84 \%$ of bridge decks have black rebar. This is comparable with $80 \%$ for the NBI deck protection variable. However, a closer review shows that these two variables do not match for each bridge deck. 
- The deck slenderness variable ranges from 0 to 0.12 . Over $70 \%$ of bridge decks have slenderness between 0.05 and 0.15 .

The two datasets are supplemented by performance metrics in order to quantify bridge deck performance as a function of the above variables. In order to show how these performance metrics can be used, the first metric, TICR, was calculated for the bridge decks in the refined dataset. Due to missing CR data, the TICR performance metric is subject to censoring. To better understand this dependent variable and the concept of censoring, plots were created that show the effect of censoring on bridge deck average TICR and survival probability. The plots show that when censoring is considered, average TICR almost doubles and the survival probability increases notably. This is because estimates are being calculated that attempt to quantify partially observable TICR values. In addition to explaining the concept of censoring, plots were created that show the influence of climate group and design period on the performance metric. The climate group plots show that climate group 2 has a lower average TICR and decreased survival probability compared to the other groups. In contrast, the design period plots show that average TICR and survival probability increase with design period. 


\subsection{SURVIVAL ANALYSIS}

Two datasets have been created that are composed of parameters gathered from the National Bridge Inventory (NBI) database and ODOT data (see Section 4.0). The first dataset is referred to as the "NBI dataset" (with 5242 bridge decks) made up of data gathered only from the NBI and includes information on bridge characteristics and environmental conditions. The second dataset is referred to as "Refined dataset" and is composed of 400 randomly selected bridge decks throughout the state containing data on bridge construction gathered directly from ODOT's Bridge Data System (BDS). In order to quantify concrete bridge deck performance, a survival analysis was performed to relate TICR to the parameters included in the two datasets. To show and identify the effects of these parameters on bridge deck deterioration, Kaplan-Meier survival curves and Cox proportional hazards regression were used. Both of these methods take into account censored data to estimate the survival of bridge decks in different conditions. In this study, concrete bridge CR for the years 1992 to 2016 were considered.

\subsection{Survival Curves}

In order to begin the survival analysis, survival curves were created to visualize bridge deck survival over time. To do this, the Kaplan-Meier estimator was used, which determines the probability a bridge deck survives (or is assigned the same CR) past each time interval. To create survival curves, survival objects were created which are composed of three key elements. These elements are survival time, status at survival time, and study group (Rich, et al., 2010). For this analysis, the survival time is the performance metric, TICR, which describes how long a bridge stays in any given CR. 
The status at survival time describes whether the performance metric is censored or not censored. Censoring occurs when the value of an observation is only partially known (Leung, Elashoff, \& Afifi, 1997). In the TICR case, censoring occurs for three reasons: (1) CR before 1992 and after 2016 are unknown, (2) there are missing CR observations, and (3) CR increase from one year to the next, which is assumed to be associated with action due to preservation or repair (Ghonima, Schumacher, Unnikrishnan, \& Fleischhacker, 2018). In all these cases, a minimum TICR can be computed but it is inaccurate to assume that this TICR is correct because it is only observable partially. Three examples of hypothetical bridge deck CR records are illustrated in Figure 4-39 to show how TICR is determined and also the different cases of censoring. One example each of a censored and an uncensored TICR is labeled. Longer and shorter TICR are interpreted as lower and higher deterioration, respectively.

The study group element describes how TICR can be grouped. For the data being analyzed in this project, the study group can be based on any of the parameters compiled in the NBI and refined datasets. Once all of these elements are determined, the survival object is sorted from lowest to highest survival time. Using the created survival object, the survival probability at each time interval can be determined through the following equations (Sullivan, 2016): 


$$
\begin{aligned}
& N_{t+1}=N_{t}-D_{t}-C_{t} \\
& S_{t+1}=S_{t} * \frac{N_{t+1}-D_{t+1}}{N_{t+1}}
\end{aligned}
$$

Where $S_{t}$ is the survival probability at time $t, N_{t}$ is the number of TICRs at risk at time $t$, $D_{t}$ is the number of uncensored TICRs at time $t$, and $C_{t}$ is the number of censored TICRs at time $t$. Once these survival probabilities are calculated, the Kaplan-Meier survival curves are generated. For each TICR, survival probability is plotted. Survival times that are uncensored are graphed with a horizontal line while survival times that are censored are indicated with a tick mark. As time increases, only bridge decks that survived the previous time interval are considered, this creates a step function that spans the 25 years of available NBI CR data.

For example, to create a survival curve for bridge decks that are located in climate zone group one (West of the Cascades), a table is created that contains all of the key elements of a survival object (Table 5-1). Once this table is compiled, survival probabilities for each time interval can be determined using equations 1 and 2 (Table 5-1). 
Table 5-1: Survival Object Elements and Survival Probabilities for Bridge Decks in Climate Zone Group 1

\begin{tabular}{|c|c|c|c|c|c|}
\hline \multirow[b]{2}{*}{$\begin{array}{c}\text { GRO } \\
\text { UP }\end{array}$} & \multirow[b]{2}{*}{$\begin{array}{c}\text { TIME } \\
\text { (TICR) }\end{array}$} & \multicolumn{2}{|c|}{ STATUS } & \multirow[b]{2}{*}{$\begin{array}{l}\text { NO. AT } \\
\text { RISK }\end{array}$} & \multirow[b]{2}{*}{$\begin{array}{c}\text { SURVIV } \\
\text { AL } \\
\text { PROB. }\end{array}$} \\
\hline & & $\begin{array}{c}\text { NO. OF } \\
\text { UNCENSORED } \\
\text { TICR }\end{array}$ & $\begin{array}{c}\text { NO. OF } \\
\text { CENSORED } \\
\text { TICR }\end{array}$ & & \\
\hline 1 & 0 & 0 & 0 & 262 & 1.000 \\
\hline 1 & 1 & 1 & 16 & 262 & 0.996 \\
\hline 1 & 2 & 9 & 17 & 245 & 0.960 \\
\hline 1 & 3 & 3 & 14 & 219 & 0.946 \\
\hline 1 & 4 & 9 & 14 & 202 & 0.904 \\
\hline 1 & 5 & 3 & 11 & 179 & 0.889 \\
\hline 1 & 6 & 4 & 5 & 165 & 0.868 \\
\hline 1 & 7 & 3 & 9 & 156 & 0.851 \\
\hline 1 & 8 & 5 & 11 & 144 & 0.821 \\
\hline 1 & 9 & 3 & 9 & 128 & 0.802 \\
\hline 1 & 10 & 5 & 15 & 116 & 0.768 \\
\hline 1 & 11 & 3 & 13 & 96 & 0.744 \\
\hline 1 & 12 & 3 & 16 & 80 & 0.716 \\
\hline 1 & 13 & 1 & 12 & 61 & 0.704 \\
\hline 1 & 14 & 4 & 6 & 48 & 0.645 \\
\hline 1 & 15 & 1 & 8 & 38 & 0.628 \\
\hline 1 & 16 & 1 & 6 & 29 & 0.607 \\
\hline 1 & 17 & 0 & 4 & 22 & 0.607 \\
\hline 1 & 18 & 0 & 3 & 18 & 0.607 \\
\hline 1 & 19 & 0 & 1 & 15 & 0.607 \\
\hline 1 & 20 & 0 & 1 & 14 & 0.607 \\
\hline 1 & 21 & 0 & 2 & 13 & 0.607 \\
\hline 1 & 22 & 0 & 2 & 11 & 0.607 \\
\hline 1 & 23 & 0 & 1 & 9 & 0.607 \\
\hline 1 & 24 & 0 & 3 & 8 & 0.607 \\
\hline 1 & 25 & 0 & 5 & 5 & 0.607 \\
\hline
\end{tabular}

Using these probabilities, a Kaplan-Meier survival curve can be plotted that depicts the change in cumulative probability as time passes. Since there are censored observations for each time increment, each plotted survival probability has a vertical line indicating uncertainty. The survival curve below shows that for a bridge deck west of the Cascades 
there is a $70 \%$ probability that the condition of that bridge deck will survive for 13 years (Figure 5-1).

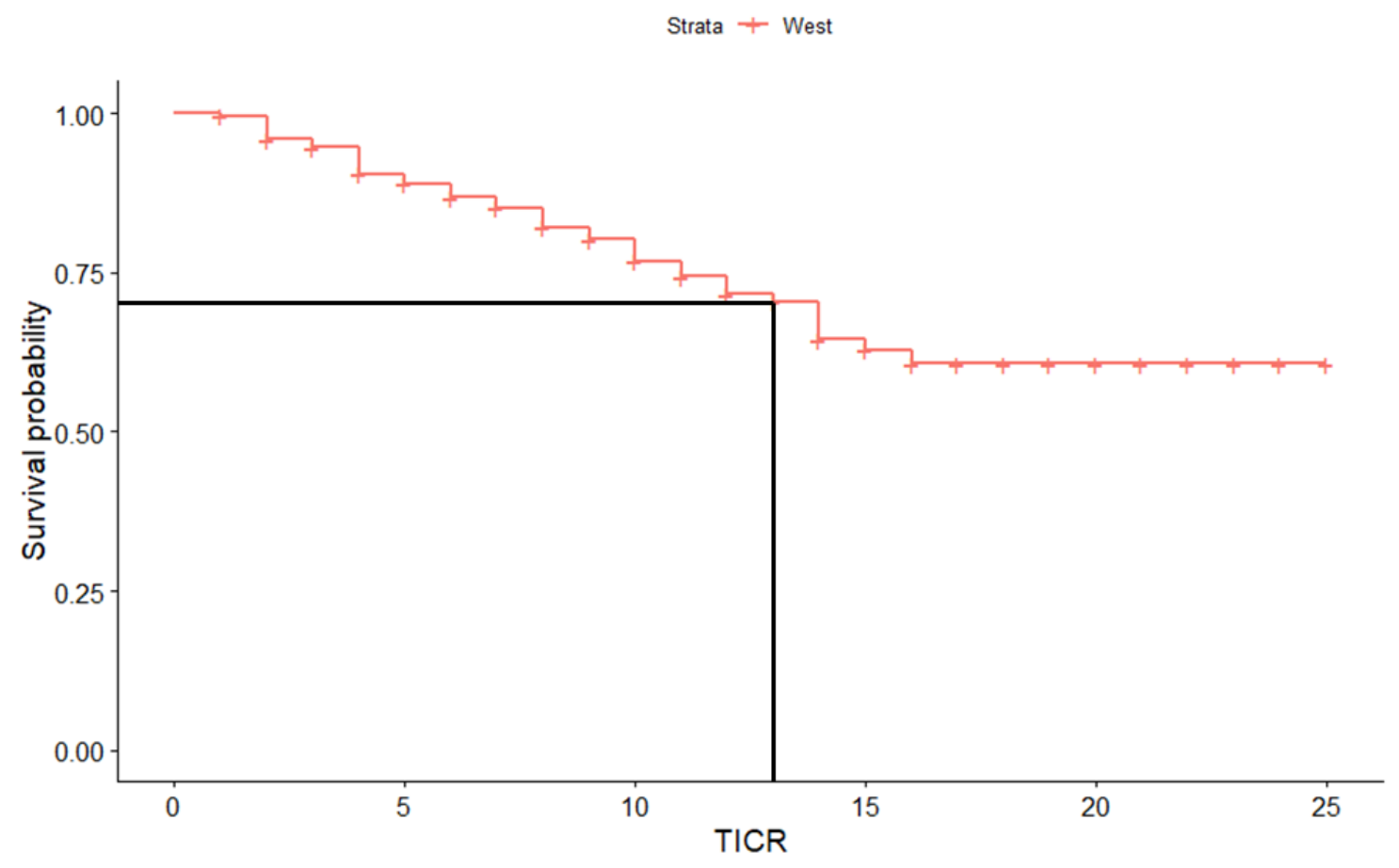

Figure 5-1: Survival Curve for Bridge Decks in Climate Zone Group 1

Survival curves can be generated for different select groups of a variable. By plotting these curves together, the difference in survival probability between groups can be visualized and quantified. For example, Figure 5-2 shows the survival curves for concrete bridge decks west and east of the Cascades. For a bridge deck east of the Cascades there is a $75 \%$ probability that the condition of that bridge deck will survive for 13 years. This is a $5 \%$ increase in survival probability compared to a bridge deck west of the cascades. The shaded band represents the $95 \%$ confidence bounds, which depicts the range within the true population mean can be found with $95 \%$ certainty. The low $p$-value indicates that 
the two survival curves are from different data groups with high probability. A typical threshold value to make this distinction is when $p<0.05$.

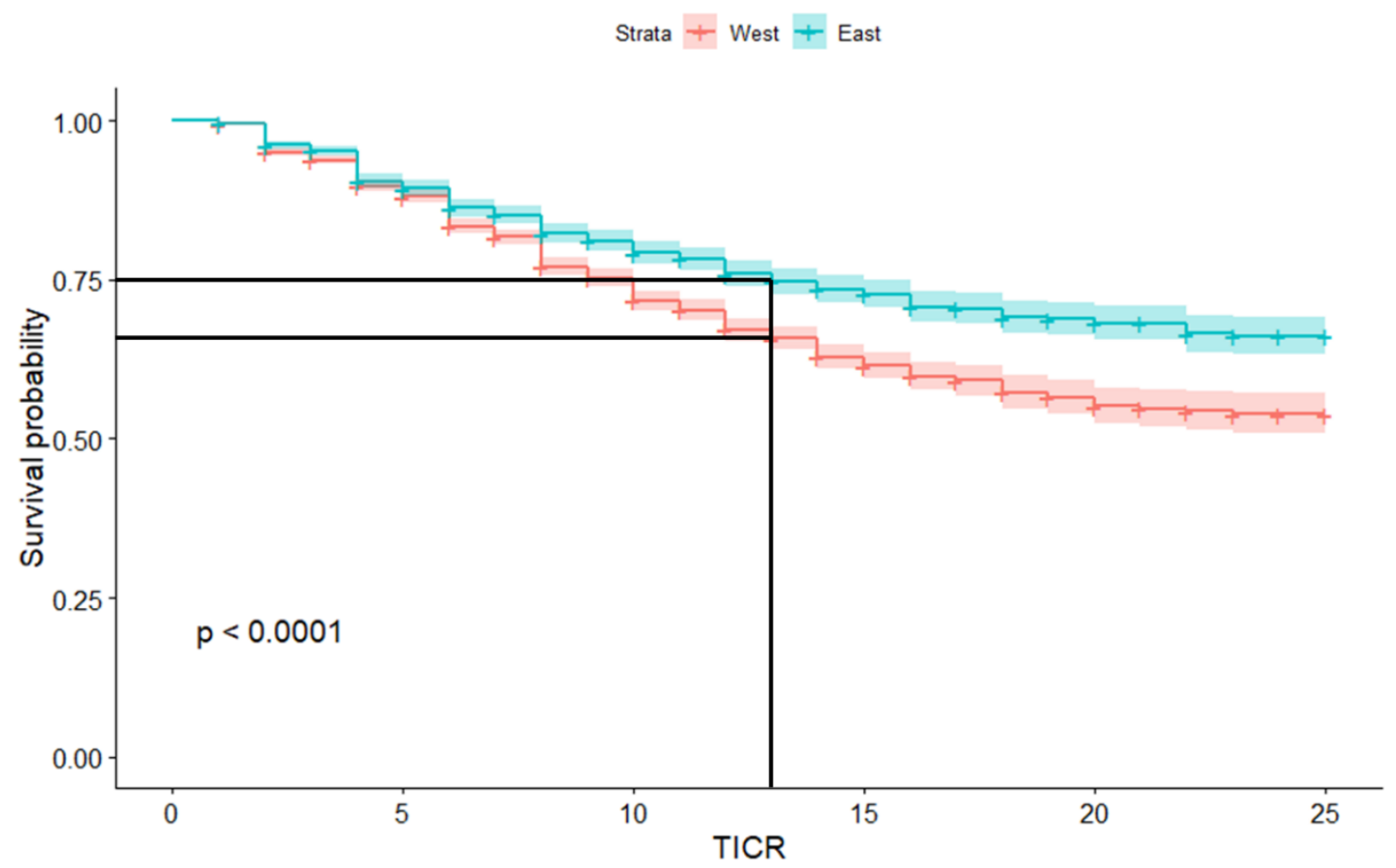

Figure 5-2: Survival Curves for Bridge Decks in Climate Zone Group 1 and 3

In this analysis, survival curves were created for both the NBI dataset and the refined dataset. Since a high percentage of censoring is present in both datasets (over $70 \%$ ), the probability of survival is never far below $50 \%$. In order to determine general trends about bridge deck performance, survival curves were generated for each variable identified in the descriptive analysis. For each variable, survival curves were generated for each study group to compare and contrast their effect on bridge deck survival probability. 


\subsubsection{NBI Dataset}

The NBI dataset used in this research contains information on 5242 concrete highway bridge decks in the state of Oregon. The data included in this dataset are the performance metric TICR and variables suspected of influencing bridge deck deterioration. These variables were either gathered directly or derived from information available in the NBI. In general, since there is more available data in the NBI dataset, the generated survival curves are more informative and precise than survival curves generated from the refined dataset.

\subsubsection{Condition Rating}

The first variable analyzed was the CR variable (Figure 5-3). The survival curves show that CR 3, 4, and 5 have the highest survival probability, this is most likely due to the fact that inspectors are less likely to decrease a condition rating that is already low and bridge decks with these CR are awaiting repair or replacement. The curves also show that CR 9 has the lowest survival probability, which can be explained by the fact that CR 9 is reserved for new bridge decks and are typically downgraded at the presence of even minor signs of deterioration. The log-rank test produces a $p$-value $\leq 0.05$, which suggests that at least two survival curves are significantly different from each other. However, the curves for CR 3, 4, and 9 do not have enough data and should be interpreted with caution. 


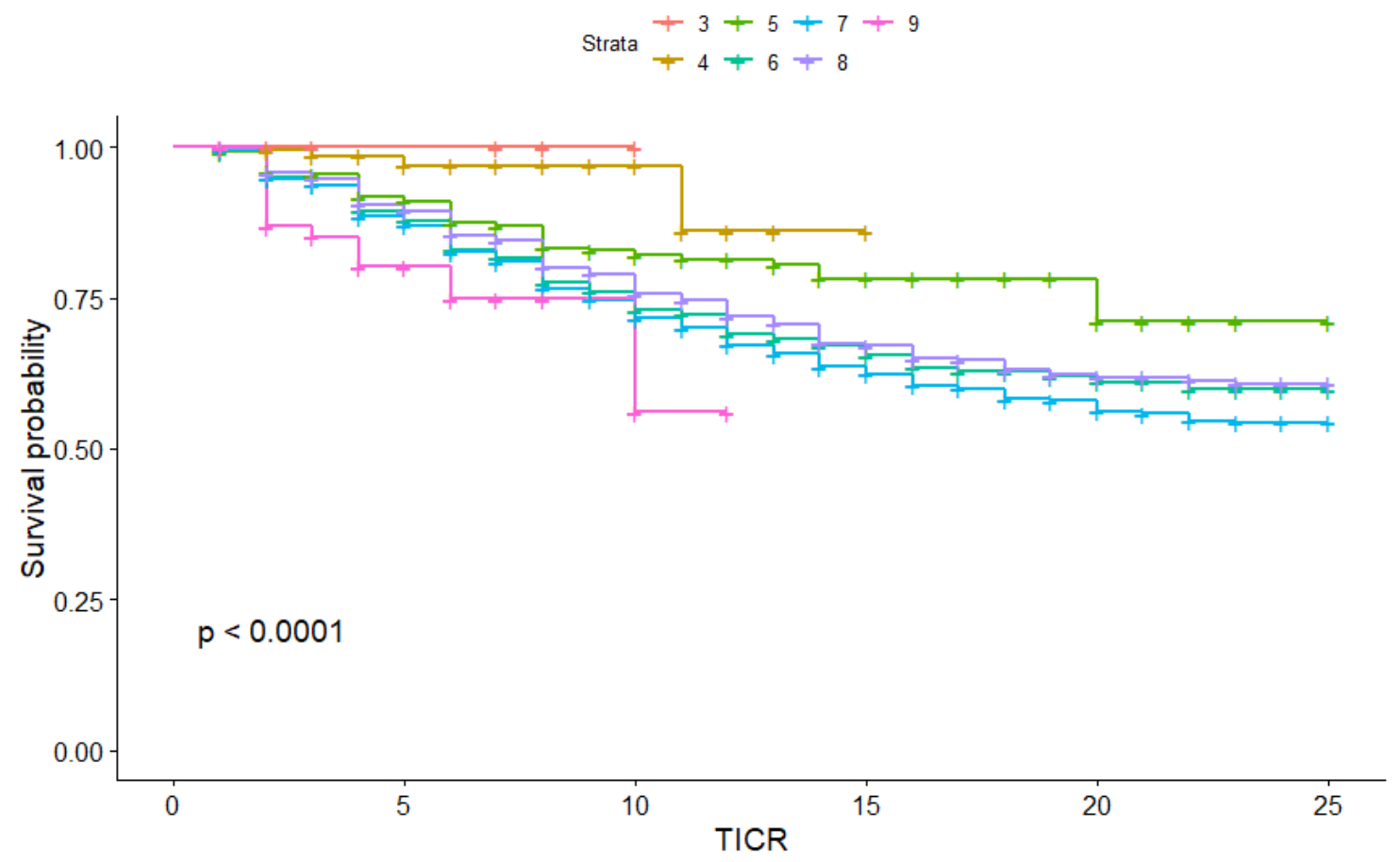

Figure 5-3: Survival Curves of TICR Depending on CR

\subsubsection{Climate Zone}

In order to compare the effect of climate zone on bridge decks, survival curves for the three climate groups outlined in the descriptive analysis were created (Figure 5-4). The resulting plot shows that bridge decks east of the Cascades have a higher survival probability than bridge decks in other locations. This may be a result of its drier climate as well as other factors such as traffic volume and use of deicers. In addition, at least one curve in this plot is significantly different from another one. Note that the $95 \%$ confidence bounds show a small overlap between the survival probability of bridge decks west of the Cascades and along the Cascades. 


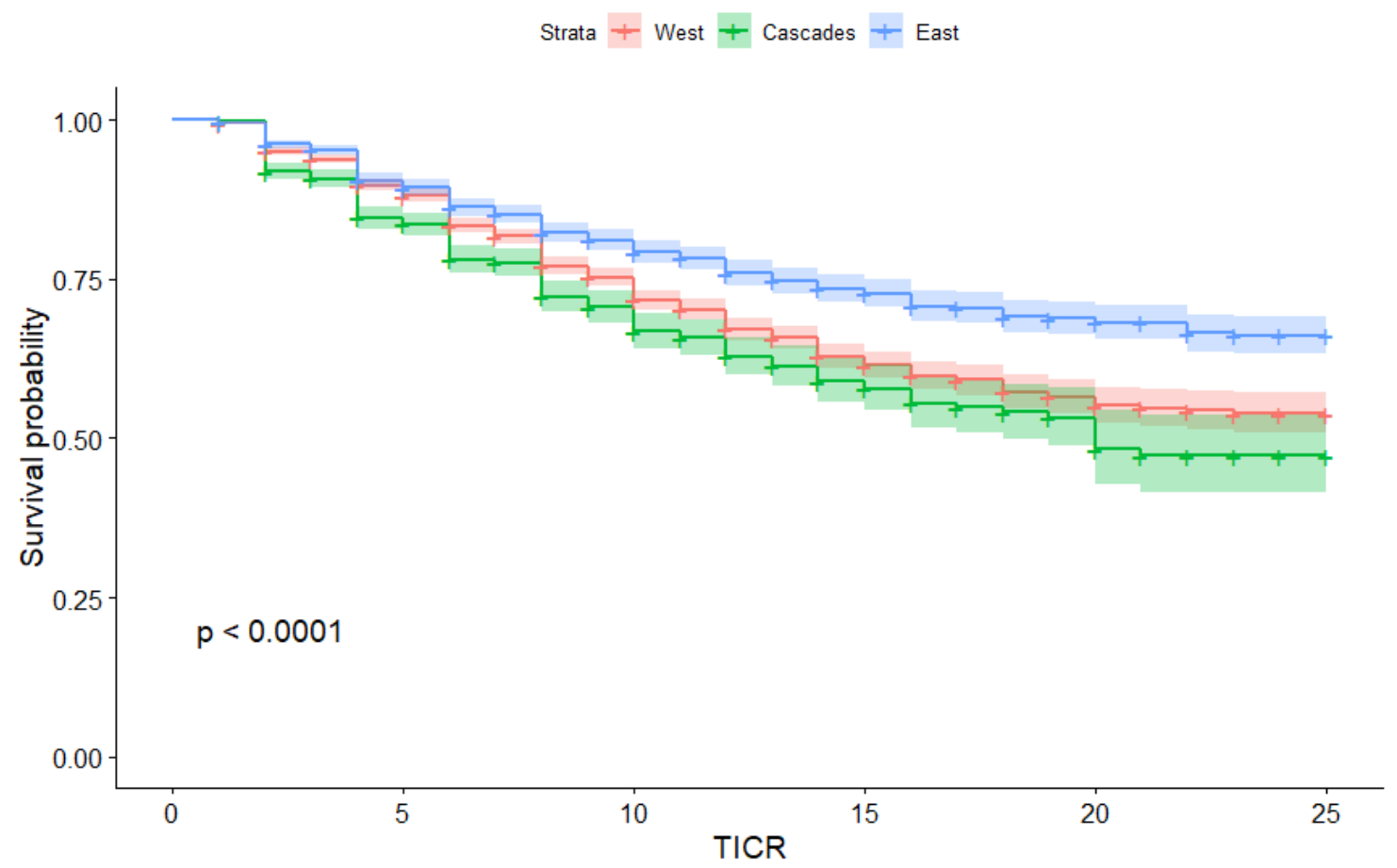

Figure 5-4: Survival Curves of TICR Depending on Grouped Climate Zone

\subsubsection{Design Period}

For the design period variable, survival curves were generated for the three design periods identified in the descriptive analysis (Figure 5-5). The resulting plots show that the bridge decks built between 1970 and 2016 have the highest survival probability and are significantly different. This is most likely because of the improvements made in bridge design and construction. 


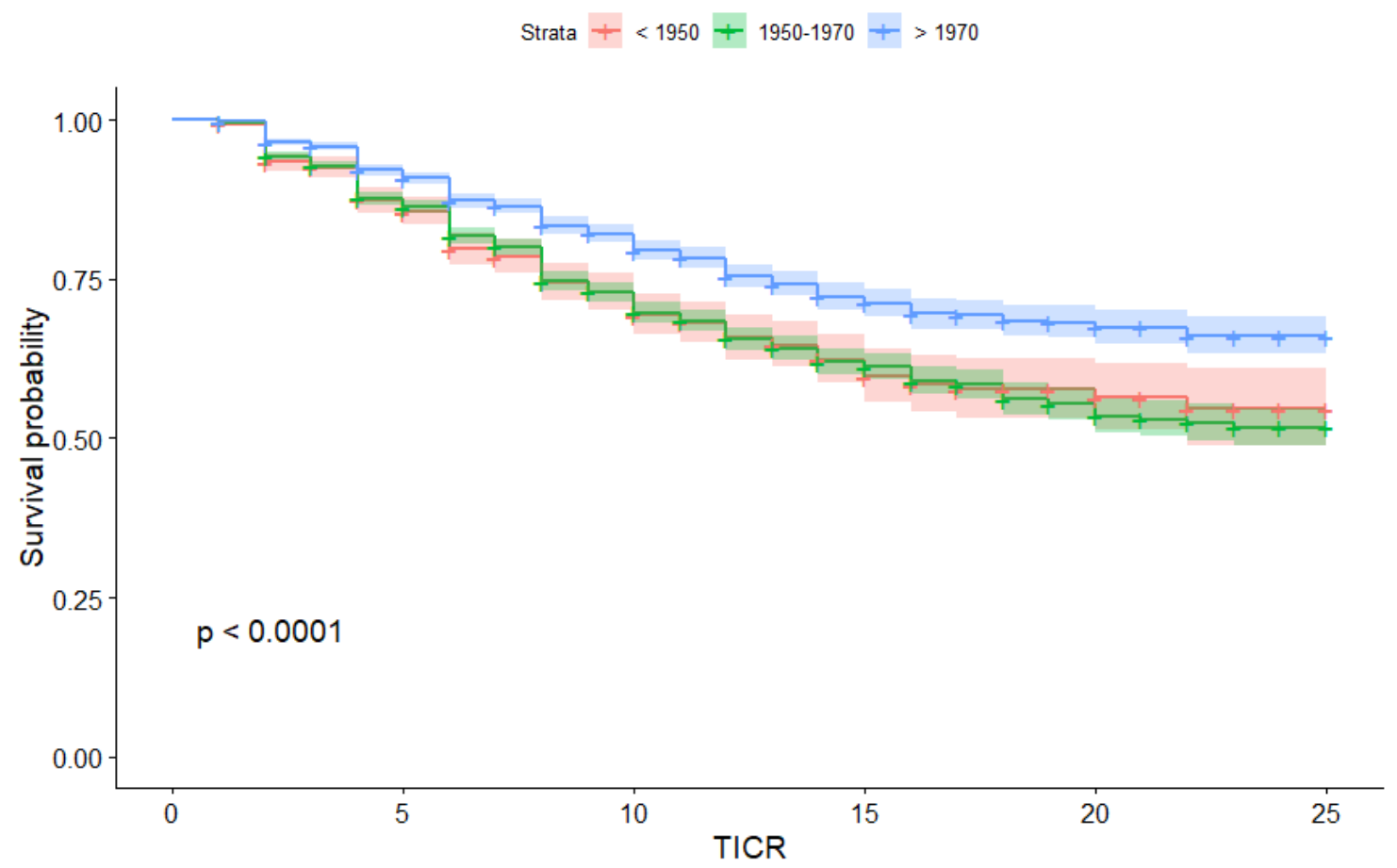

Figure 5-5: Survival Curves of TICR Depending on Design Period

\subsubsection{Maintenance Responsibility}

The maintenance responsibility variable is the first variable gathered directly from the NBI and based on NBI Item 21. Since most NBI variables have more than three groups, a different approach was taken to show the difference in survival probability. To simplify the survival curves, dummy variables were created in which one group acts as the group of interest to which all other groups are compared. To determine which group would act as the group of interest for each dummy variable, a preliminary regression analysis was performed that determined which group had the largest effect on bridge deck survival. For example, for the maintenance responsibility variable, state highway agency was selected and compared to all other agencies. Other agencies include county highway, 
town/township highway, city/municipal highway, state park/forest/reservation, other state, other local, private, railroad. The resulting survival curves show that bridge decks maintained by the state highway agency have a lower survival probability than bridge decks maintained by other agencies (Figure 5-6). This could be because the state highway agency maintains more bridge decks that experience high ADTT that are located either in the Cascades or west of the Cascades. These curves are significantly different according to the log-rank test.

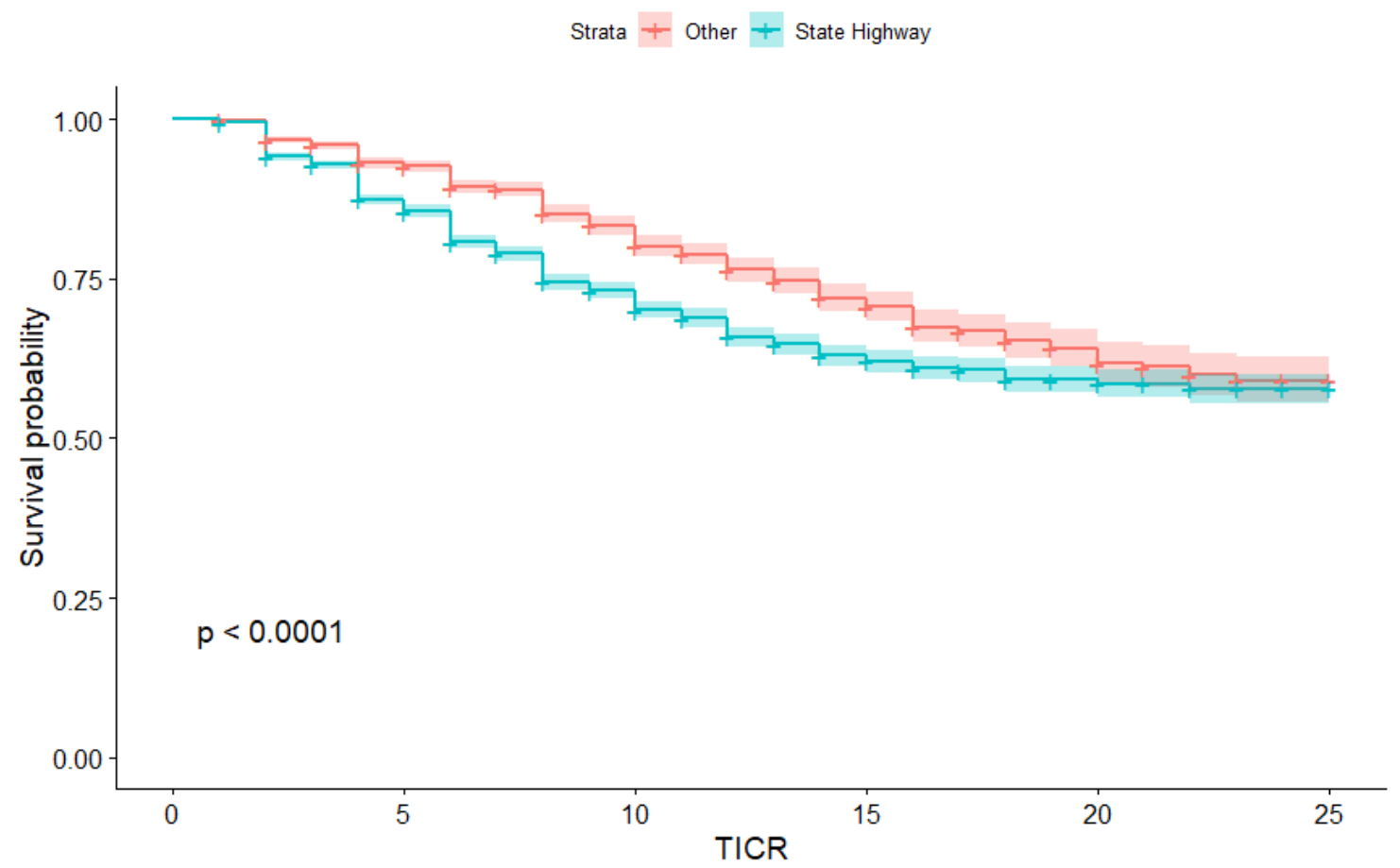

Figure 5-6: Survival Curves of TICR Depending on NBI Item 21 Maintenance Responsibility 


\subsubsection{Kind of Material and/or Design}

For the material/design variable based on NBI Item 43A, two dummy variables were created to analyze bridge decks associated with prestressed concrete bridges and continuous (= multi-span) bridges. For the prestressed concrete dummy variable, other materials/designs include other, concrete, concrete continuous, steel, steel continuous, timber. For the continuous dummy variable, which is comprised of concrete continuous, steel continuous, and prestressed concrete continuous bridges, simple materials/designs include other, concrete, steel, timber. The resulting survival curves for the prestressed concrete dummy variable show that bridge decks on prestressed concrete bridges have a significantly different and higher survival probability than bridge decks on other bridges (Figure 5-7). The survival curves for the continuous dummy variable show that bridge decks on continuous bridges have a significantly different lower survival probability than bridge decks on simple bridges (Figure 5-8). Finally, to show the difference in survival probability between bridge decks on prestressed, steel, and concrete bridges survival curves were generated for these three groups. The resulting plot shows that the survival probability of bridge decks on concrete and steel bridges is less than for bridge decks on prestressed bridges (Figure 5-9). The conclusions for all three of these dummy variables make sense. They show that bridge decks on bridges with the least potential for cracking, which are simple-span prestressed concrete bridges, have greater survival probability. 


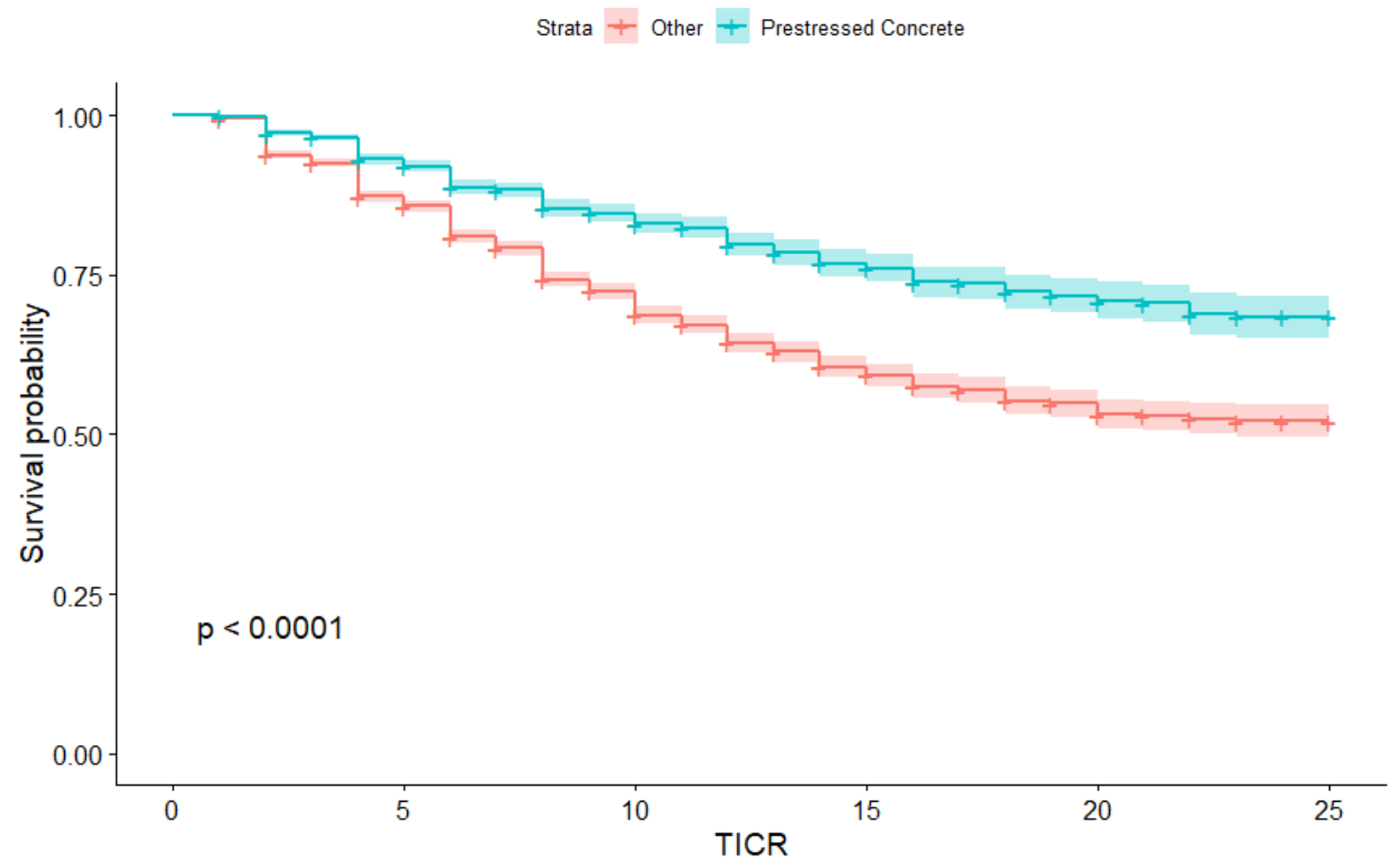

Figure 5-7: Survival Curves of TICR Depending on Prestressed Concrete Bridges from NBI Item 43A Kind of Material and/or Design 


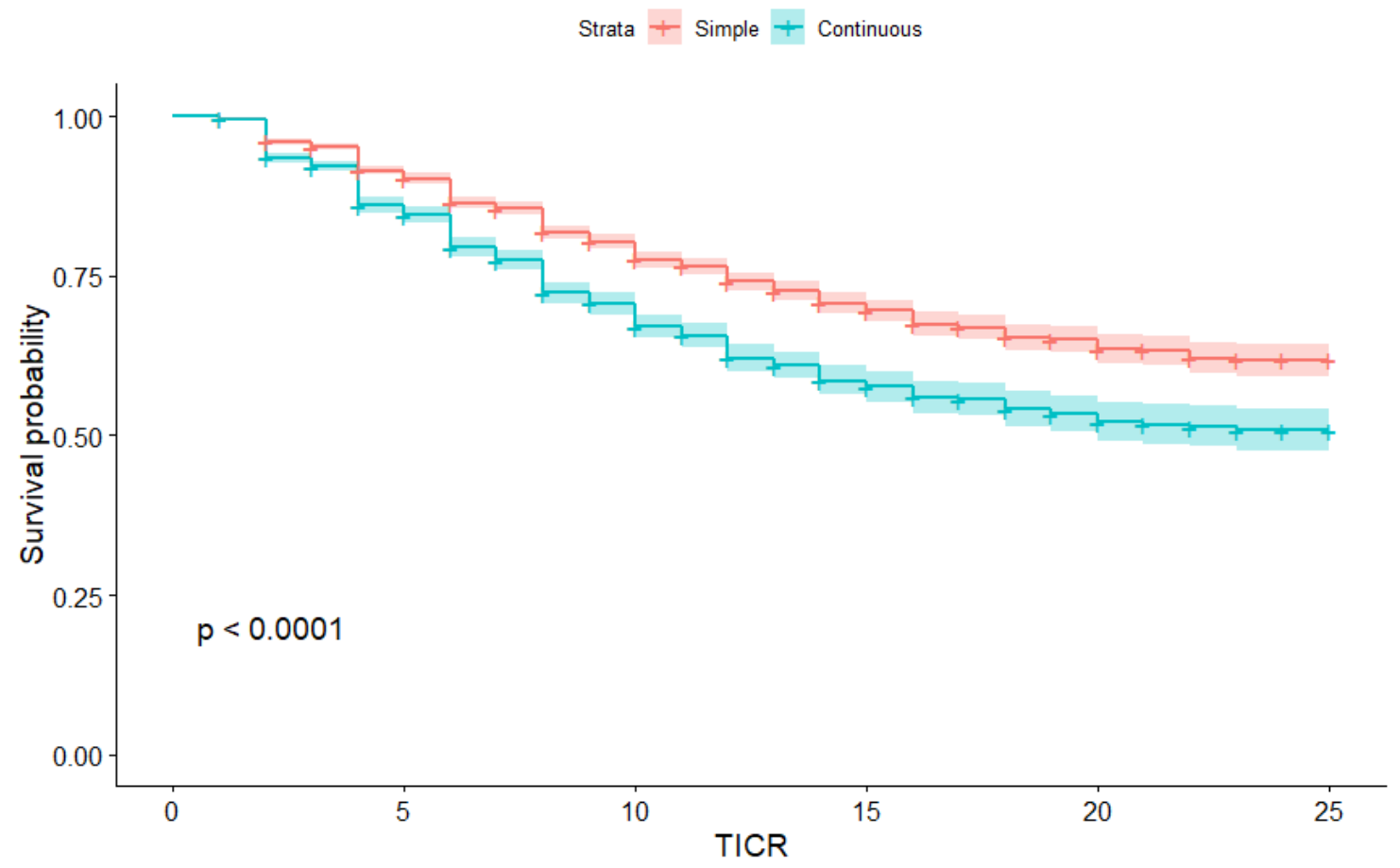

Figure 5-8: Survival Curves of TICR Depending on Continous Bridges from NBI Item 43A Kind of Material and/or Design 


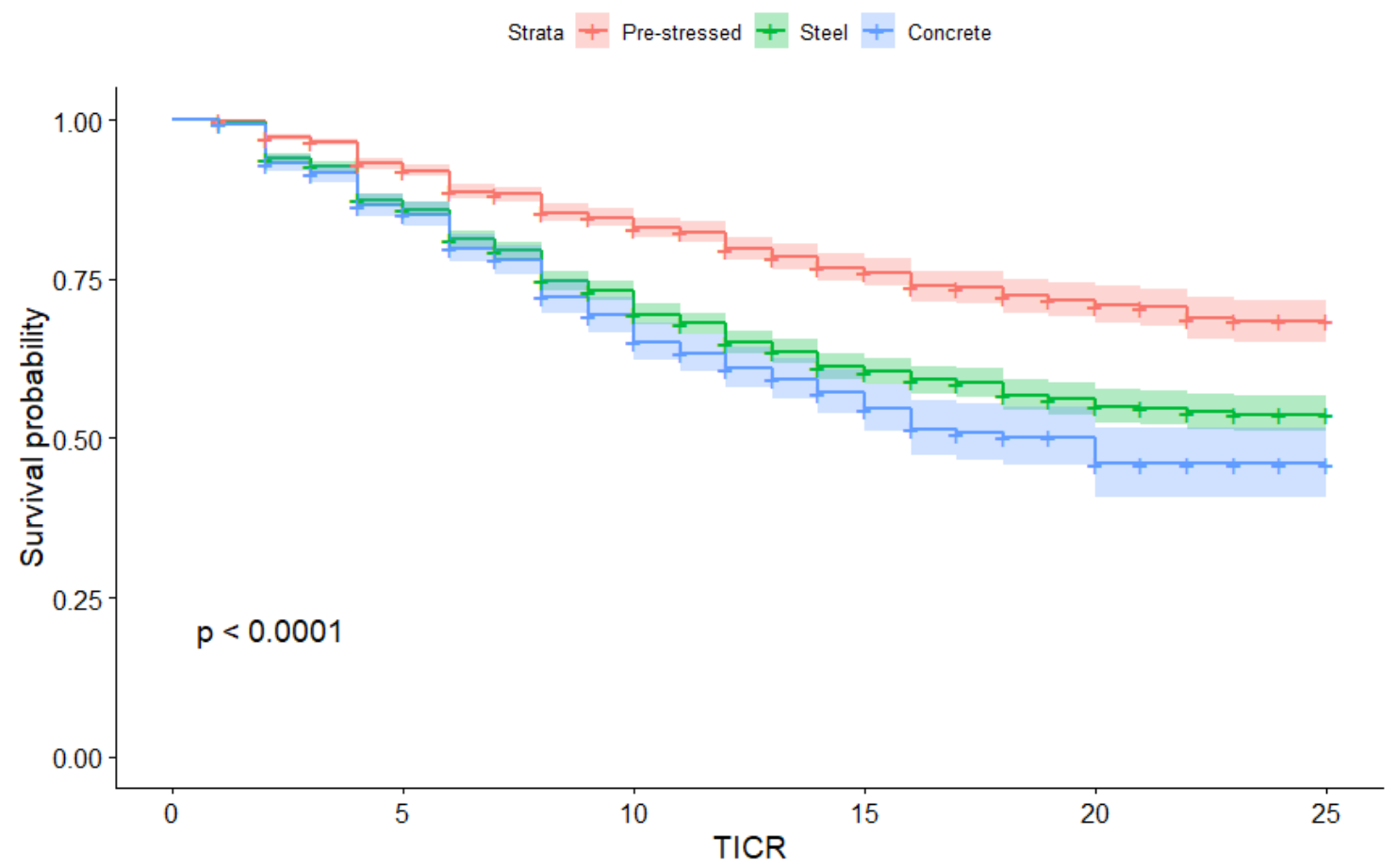

Figure 5-9: Survival Curves of TICR Depending on Prestressed, Steel, and Continuous Bridges from NBI Item 43A Kind of Material and/or Design

\subsubsection{Type of Design and/or Construction}

The type of design/construction variable based on NBI Item 43B has the most groups out of all NBI variables in the NBI dataset. To accommodate for this, a dummy variable was created for which stringer/multi-beam/girder bridges is the group of interest. Other bridge design/construction types include: slab, girder and floorbeam system, tee beam, box beam/girders - multiple, box beam/girders - single or spread, frame, deck truss, thru truss, deck arch, thru arch, suspension, lift, bascule, swing, culvert, channel beam. The resulting significantly different survival curves show that the survival probability for stringer/multi-beam/girder bridges is lower than for other bridges (Figure 5-10). The reason for this might be that decks on stringer/multi-beam/girder bridges are often 
continuous and common on high ADTT highways as opposed to the other types that are more commonly used for short single-span bridges.

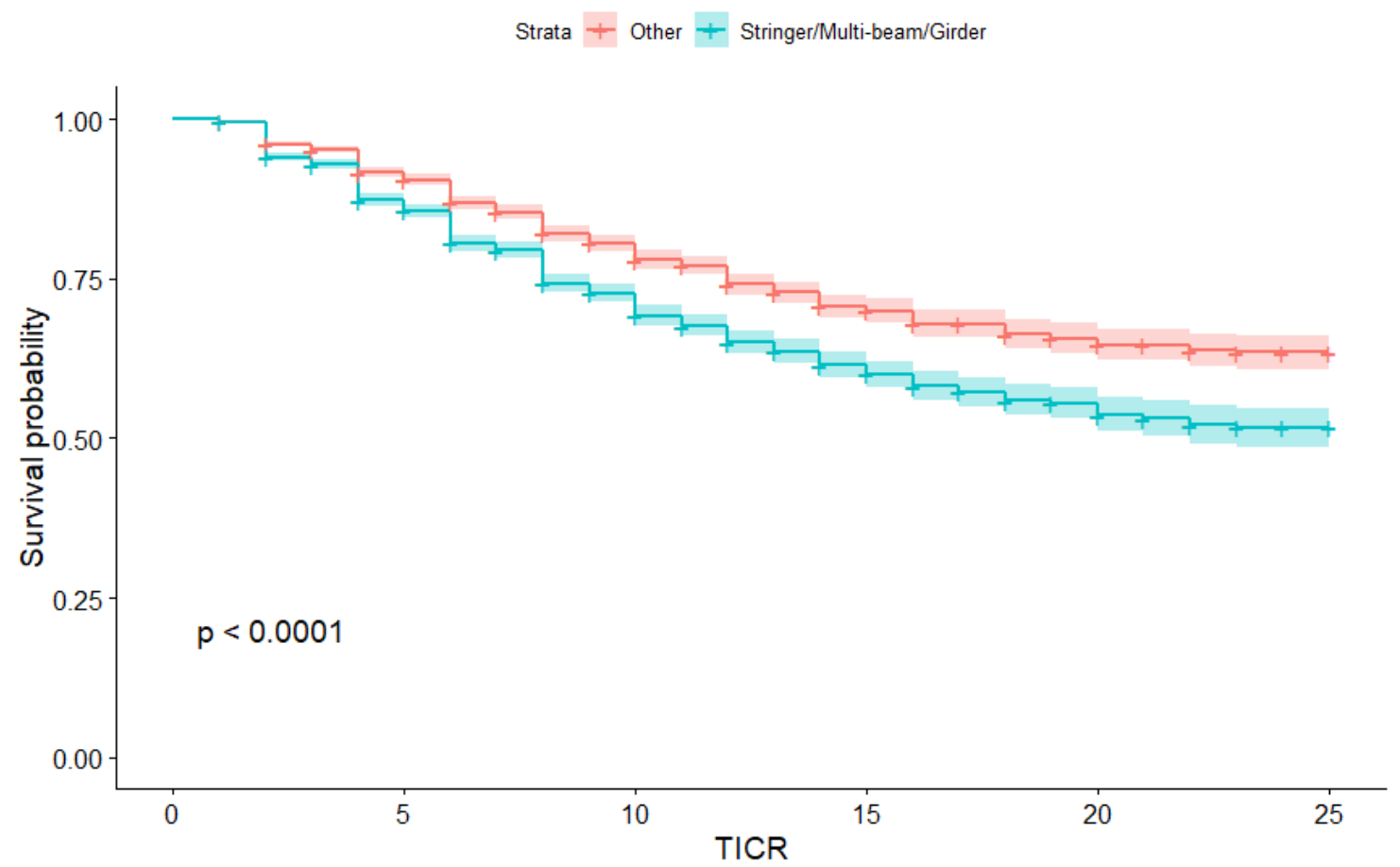

Figure 5-10: Survival Curves of TICR Depending on NBI Item 43B Type of Design and/or Construction

\subsubsection{Deck Structure Type}

For the deck structure type variable based on NBI Item 107, there are only two groups, hence a dummy variable did not need to be created. The generated plot for this variable shows that there is a significant difference between the two survival curves and precast decks have a higher survival probability then cast-in-place decks (Figure 5-11). This makes sense considering that precast decks are made in a controlled environment with 
consistent curing resulting in potentially fewer crack issues. Per ODOT, precast panels are likely overrepresented due to a recording issue in the NBI dataset.

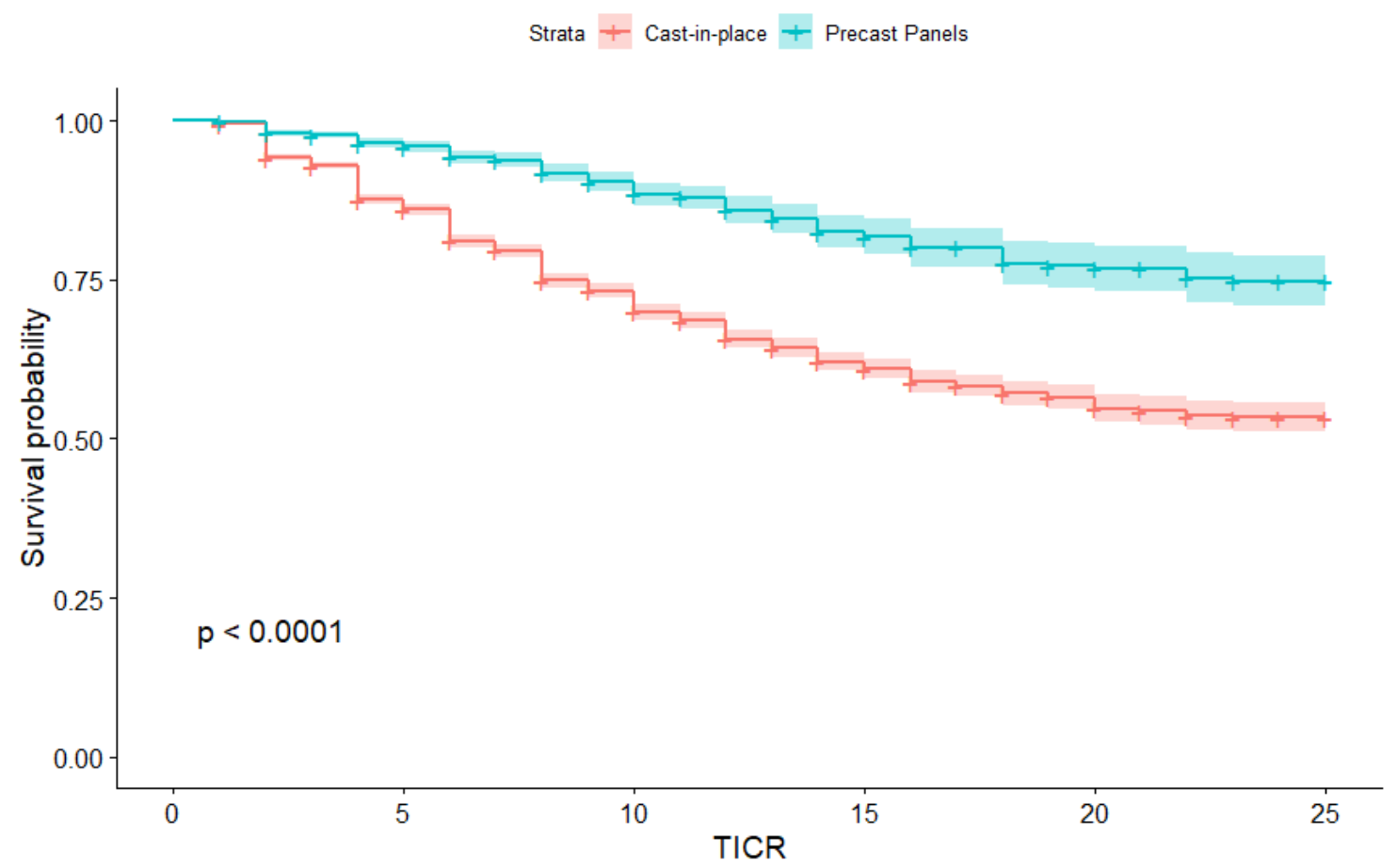

Figure 5-11: Survival Curves of TICR Depending on NBI Item 107 Deck Structure Type

\subsubsection{Type of Wearing Surface}

To create survival curves for the type of wearing surface variable based on NBI Item 108A, a dummy variable was created for which bituminous wearing surface is the group of interest. Other wearing surfaces include none, monolithic concrete, integral concrete, latex concrete, epoxy overlay, gravel, other. The resulting survival curves show that bridge decks with a bituminous wearing surface have higher survival probability than other bridge decks (Figure 5-12). In addition, the log-rank test shows that the curves are 
significantly different. An explanation for this could be that bridge decks with an asphalt overlay are typically associated with low and mid-level ADTT bridges. Also, inspectors simply have to infer deck condition from the pavement and the soffit of the deck and an inspector may not change the CR even if they witness what would be considered normal wear of the asphalt concrete wearing surface (Blower, 2019).

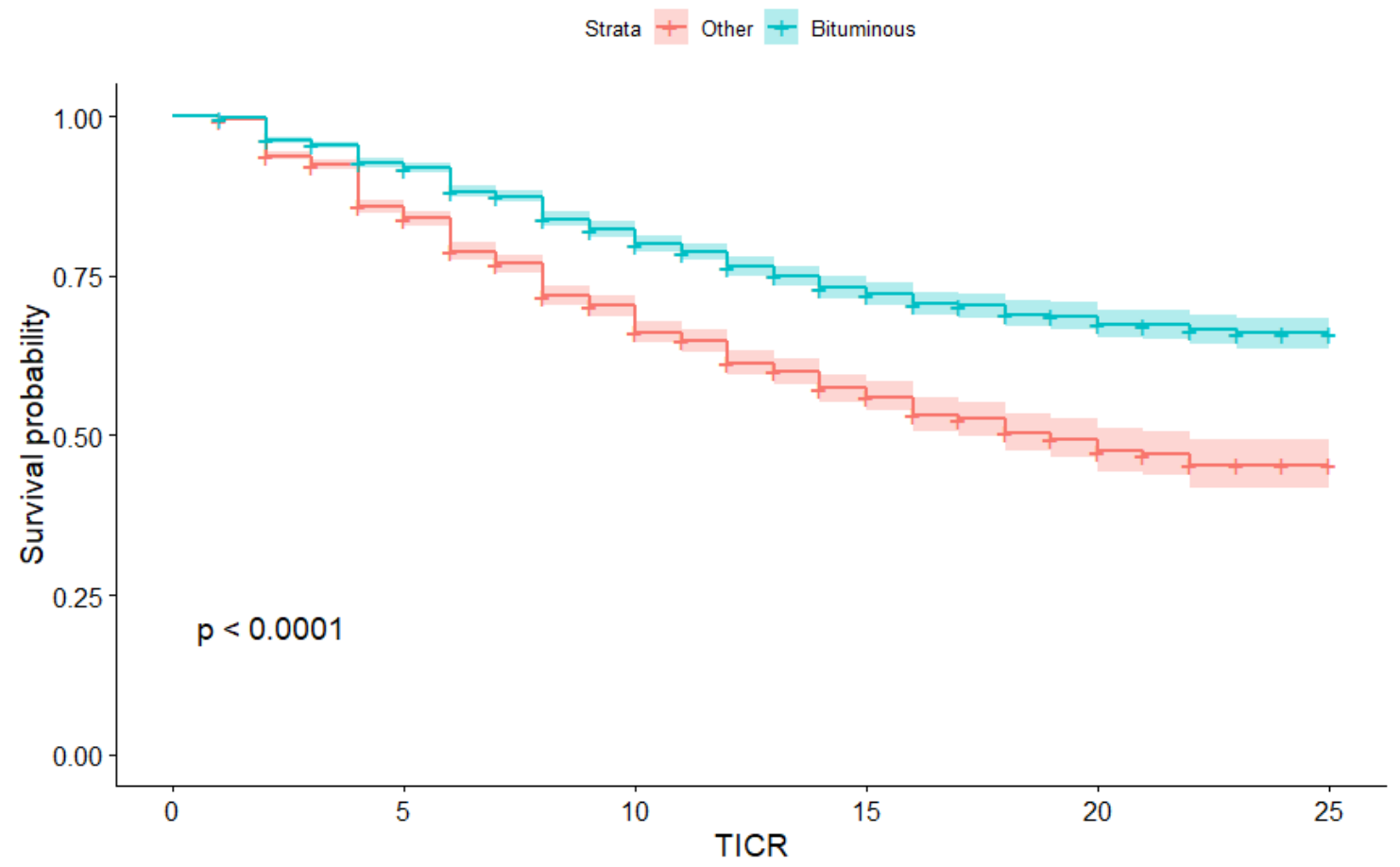

Figure 5-12: Survival Curves of TICR Depending on NBI Item 108A Type of Wearing Surface

\subsubsection{Type of Membrane}

Only bridge decks with an asphalt wearing surface have membranes. Therefore, to create the survival curves for this variable based on NBI Item 108B, a subset had to be created that only included bridge decks with an asphalt wearing surfaces. Once this subset was 
created, a dummy variable was established with the group of interest being bridge decks with no membrane. Other membranes include built-up, preformed fabric, epoxy, unknown, other. The resulting survival curves show that bridge decks without membranes have a lower survival probability than bridge decks with membranes (Figure 5-13). Also, the curves are significantly different. The conclusion that bridge decks with membranes have increased survival probability makes sense because chloride penetration is more difficult when a bridge deck has a membrane.

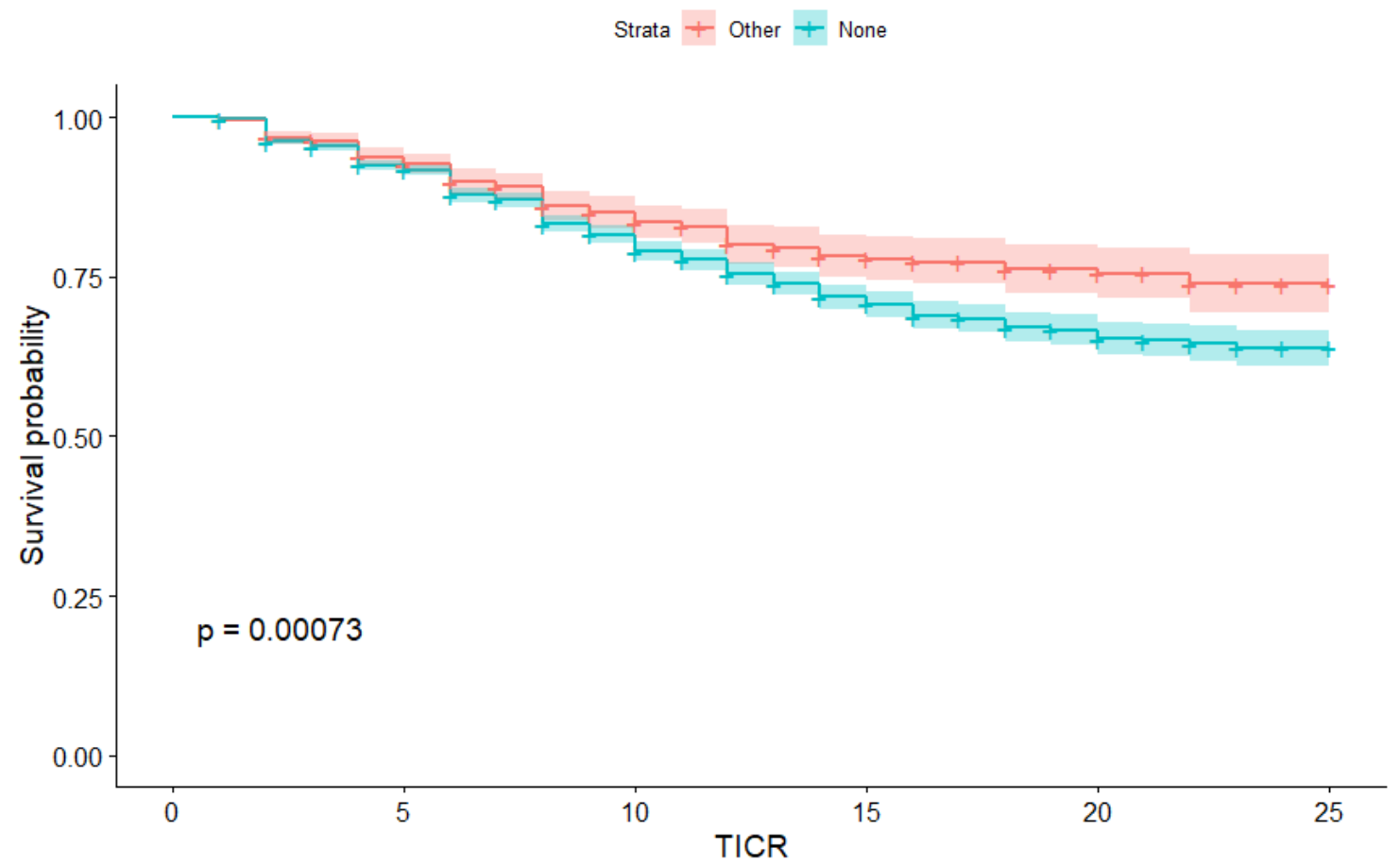

Figure 5-13: Survival Curves of TICR Depending on NBI Item 108B Type of Membrane 


\subsubsection{Deck Protection}

For the deck protection variable based on NBI Item 108C, a dummy variable was created to simplify the seven groups into two groups. To do this, the group of interest was chosen to be bridge decks without any deck protection. Other deck protection types include: epoxy reinforcing, galvanized reinforcing, other coated reinforcing, cathodic protection, unknown, other. From this dummy variable, significantly different survival curves were generated that show that bridge decks without deck protection have lower survival probability than bridge decks with deck protection (Figure 5-14). This is consistent with Ghonima, et al. (2018), which shows that in general, the presence of deck protection improves survival probability.

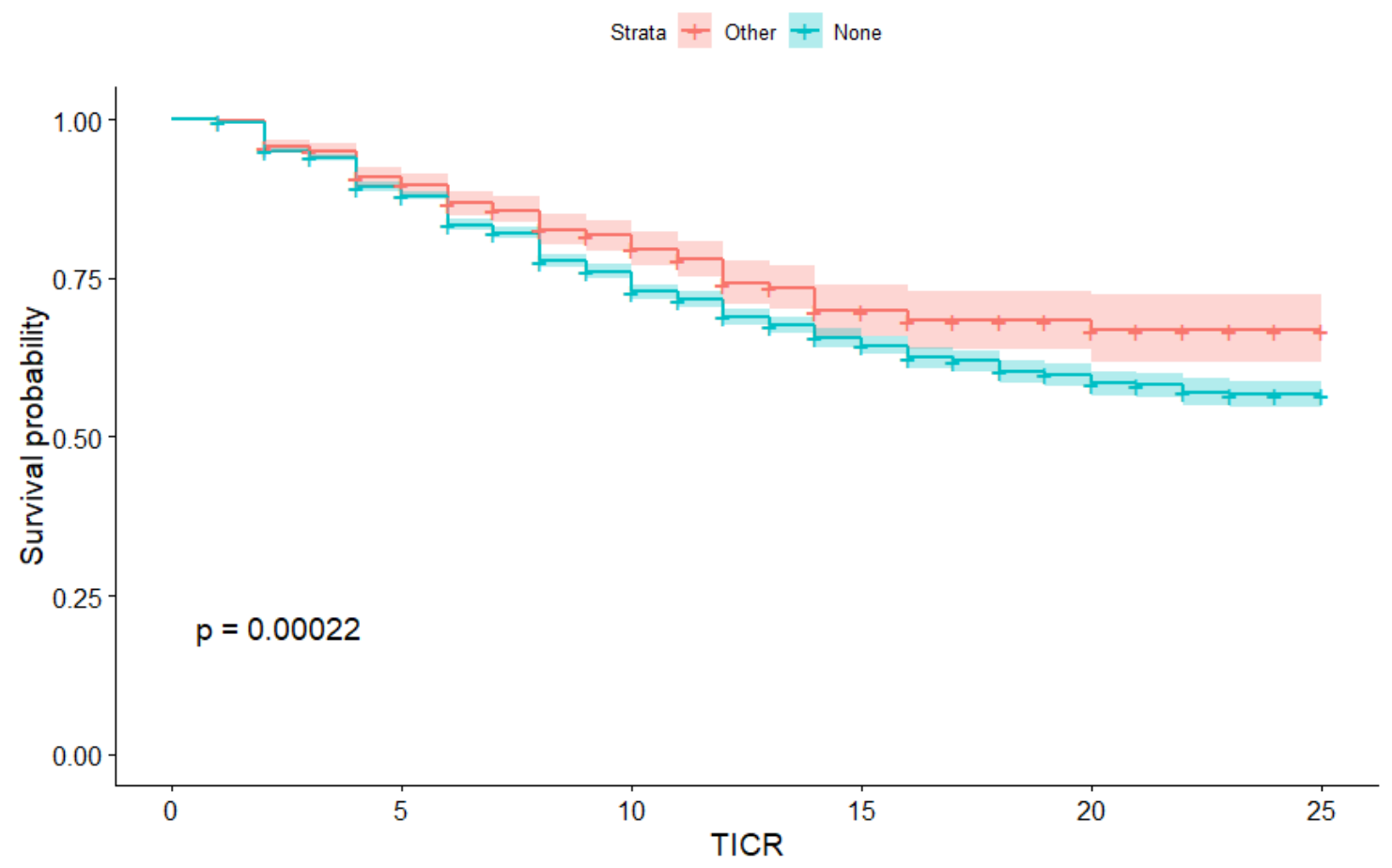

Figure 5-14: Survival Curves of TICR Depending on NBI Item 108C Deck Protection 


\subsubsection{ADTT}

The ADTT variable was divided into three groups, ADTT $<100,100 \leq \mathrm{ADTT} \leq 1000$, and ADTT > 1000, hence no dummy variable needed to be created. The generated survival curves show that bridge decks with high ADTT have a lower survival probably than bridge decks with low and medium ADTT (Figure 5-15). In addition, the log-rank test shows that at least two of these survival curves are significantly different. The conclusion that higher ADTT results in lower survival probability, or higher deterioration, is consistent with Ghonima, et al. (2018), Hatami \& Morcous (2011) Agrawal, Kawaguchi, \& Chen (2008), Kim \& Yoon (2010).

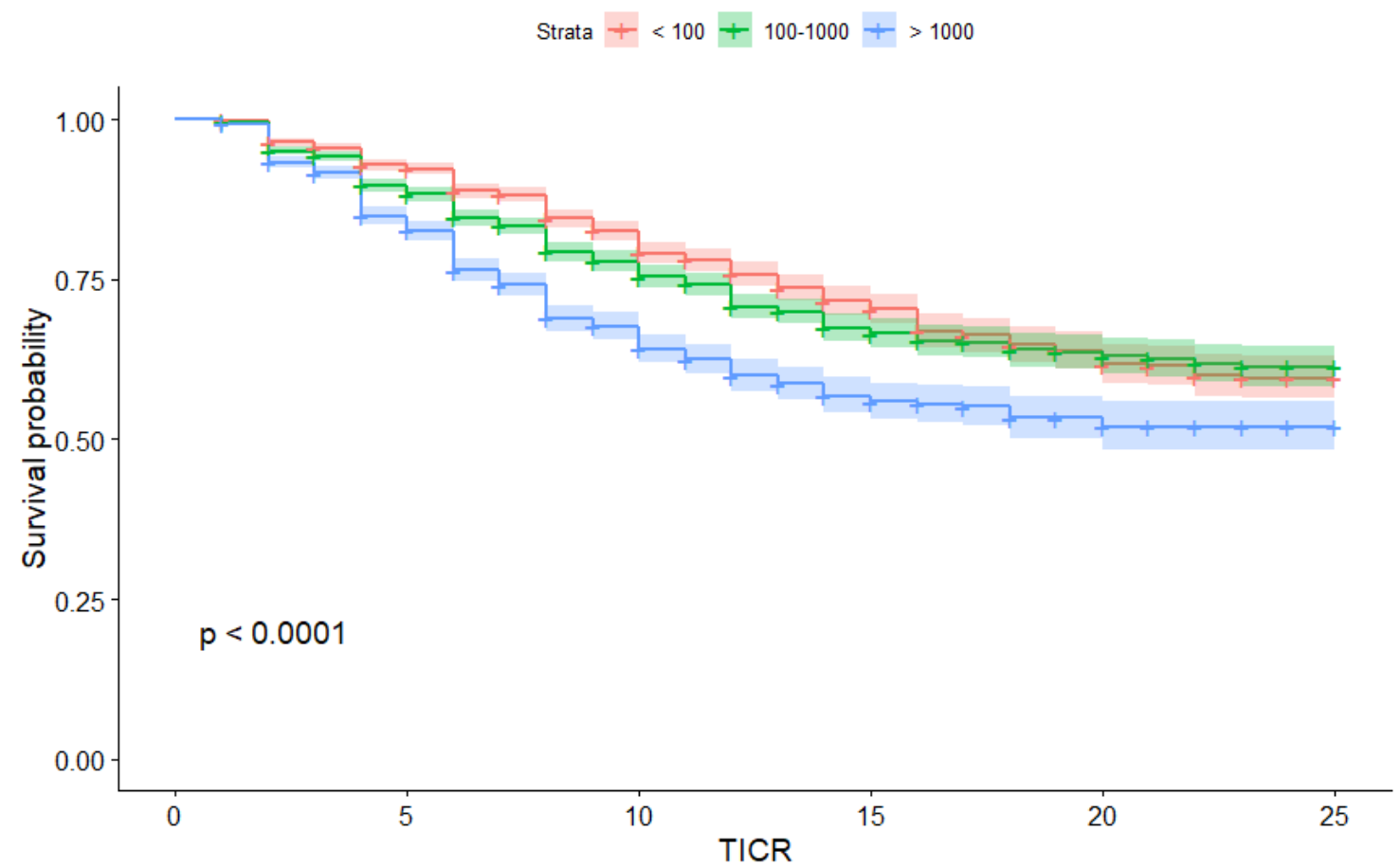

Figure 5-15: Survival Curves of TICR Depending on ADTT 


\subsubsection{Distance to Seawater}

The distance to seawater variable has two groups. However, since there are only 63 bridge decks less than one kilometer to the ocean, predicting survival probability is difficult. The confidence interval for the first group is quite large due to the small dataset. The resulting survival curves show that there is no significant difference between the two groups (Figure 5-16). This could be because frequent rainfall on the Oregon coast washes the top surface of bridge decks, reducing deterioration due to chlorides on the roadway surface. That being said, the trend of the survival curves still indicates that bridge decks within $1 \mathrm{~km}$ of seawater have a lower survival probability. This is consistent with Stewart \& Rosowsky (1998) and Vu \& Stewart (2000).

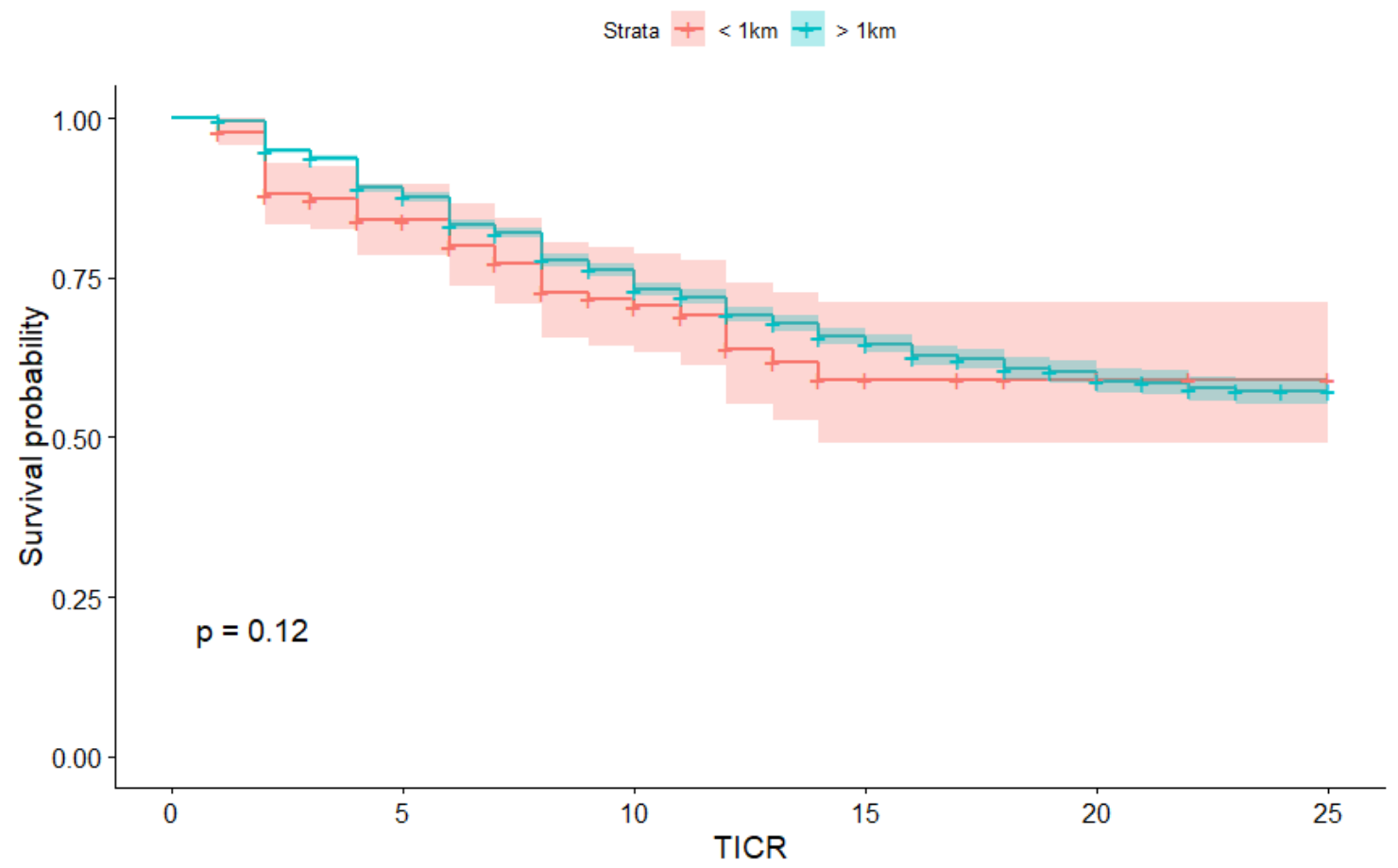

Figure 5-16: Survival Curves of TICR Depending on Distance to Seawater 


\subsubsection{Refined Dataset}

Compared to the NBI dataset, the refined dataset has significantly less information on bridge decks. However, the construction information that is included provides a new look at the potential contributors to bridge deck deterioration. The refined dataset contains construction information gathered for 400 bridge decks across all climate zones and design periods. The process to create survival curves for this dataset follows the same procedure as the NBI dataset. However, since there is less data, not all survival curves are significantly different for each variable. Therefore, the survival curves that are not significant should be interpreted as trends.

\subsubsection{Concrete Cover}

The first variable analyzed from the refined dataset was the concrete cover variable. This variable has three groups, which when plotted as survival curves, have similar survival probabilities (Figure 5-17). Although the curves are not significantly different, on average, bridge decks with concrete cover less than 1 in have a lower survival probability than bridge decks with a higher cover. This is consistent with the literature, which states that increased cover depth reduces chloride ingress, which in turn decreases bridge deck

deterioration (Kirkpatrick, Weyers, Anderson-Cook, \& Sprinkel, 2002; Shi, Xie, Fortune, \& Gong, 2012 ). 


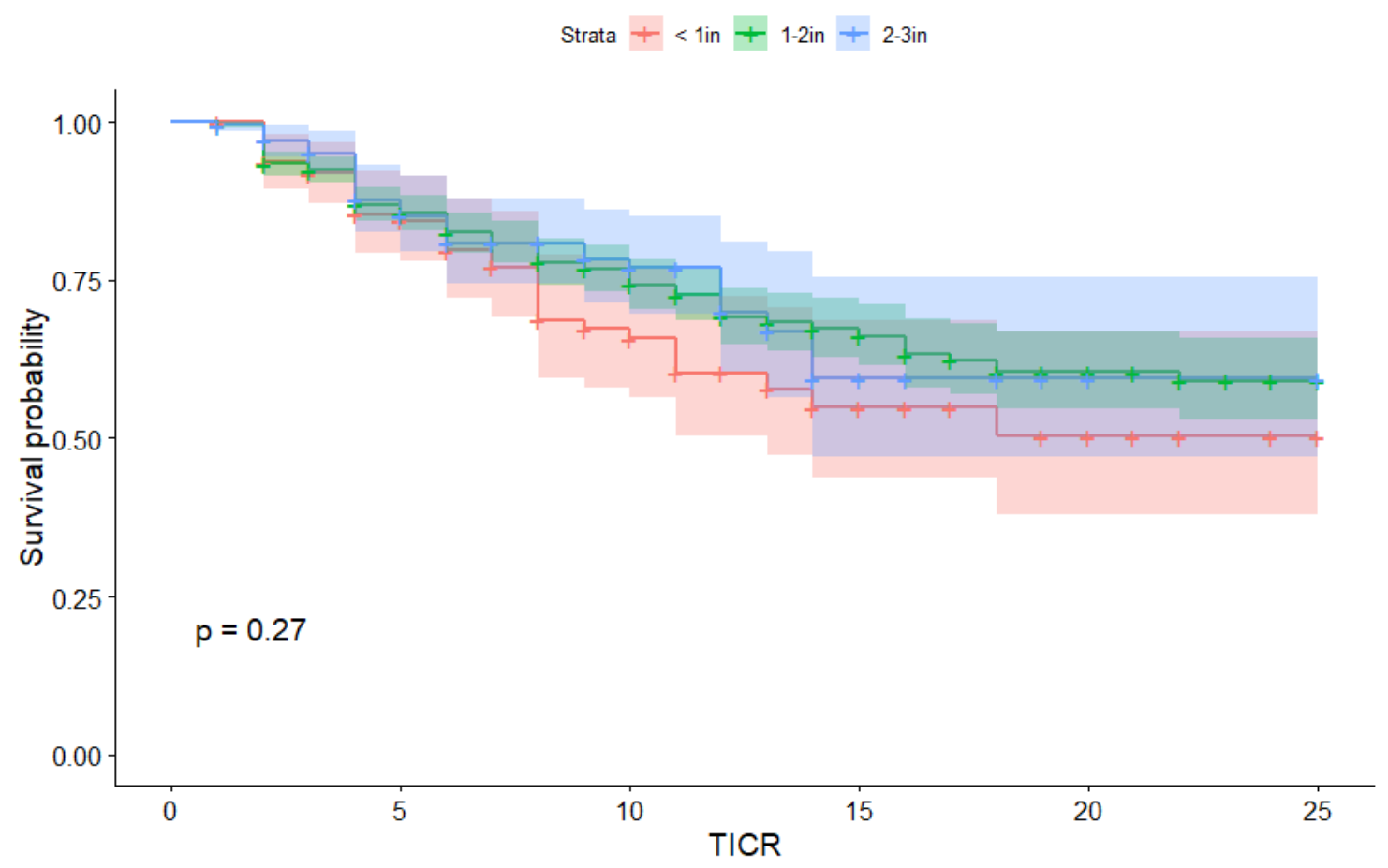

Figure 5-17: Survival Curves of TICR Depending on Concrete Cover

\subsubsection{Transverse Rebar Spacing}

For the transverse rebar spacing variable, there are only two groups, $\leq 10$ in and spacing $>10$ in. The resulting survival curves show that there is no significant difference between the two curves (Figure 5-18). However, on average, bridge decks with rebar spacing $\leq 10$ in have a lower survival probability than bridge decks with rebar spacing $>10$ in. This is reasonable since tighter rebar spacing generally results in more cracks with smaller crack widths. 


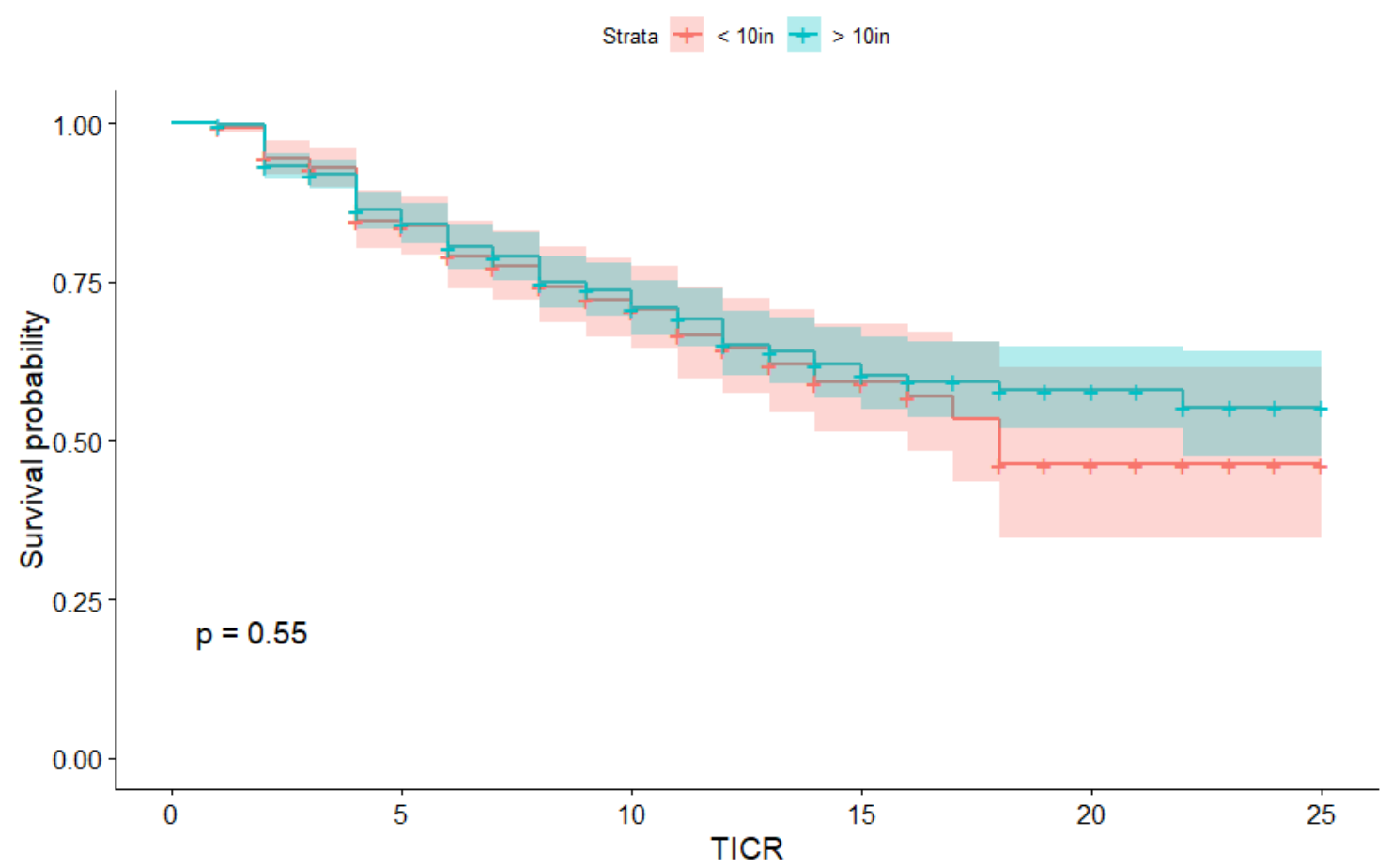

Figure 5-18: Survival Curves of TICR Depending on Transverse Rebar Spacing

\subsubsection{Rebar Type}

Although the rebar type variable is similar to NBI item 108C deck protection, there are some differences between what is reported in the NBI and what is read from the actual bridge drawings. Because of this inconsistency, the results for the two variables do not agree. For the rebar type variable, the generated survival curves show that there is no significant difference between bridge decks with black rebars and bridge decks with epoxy coated rebars (Figure 5-19). 


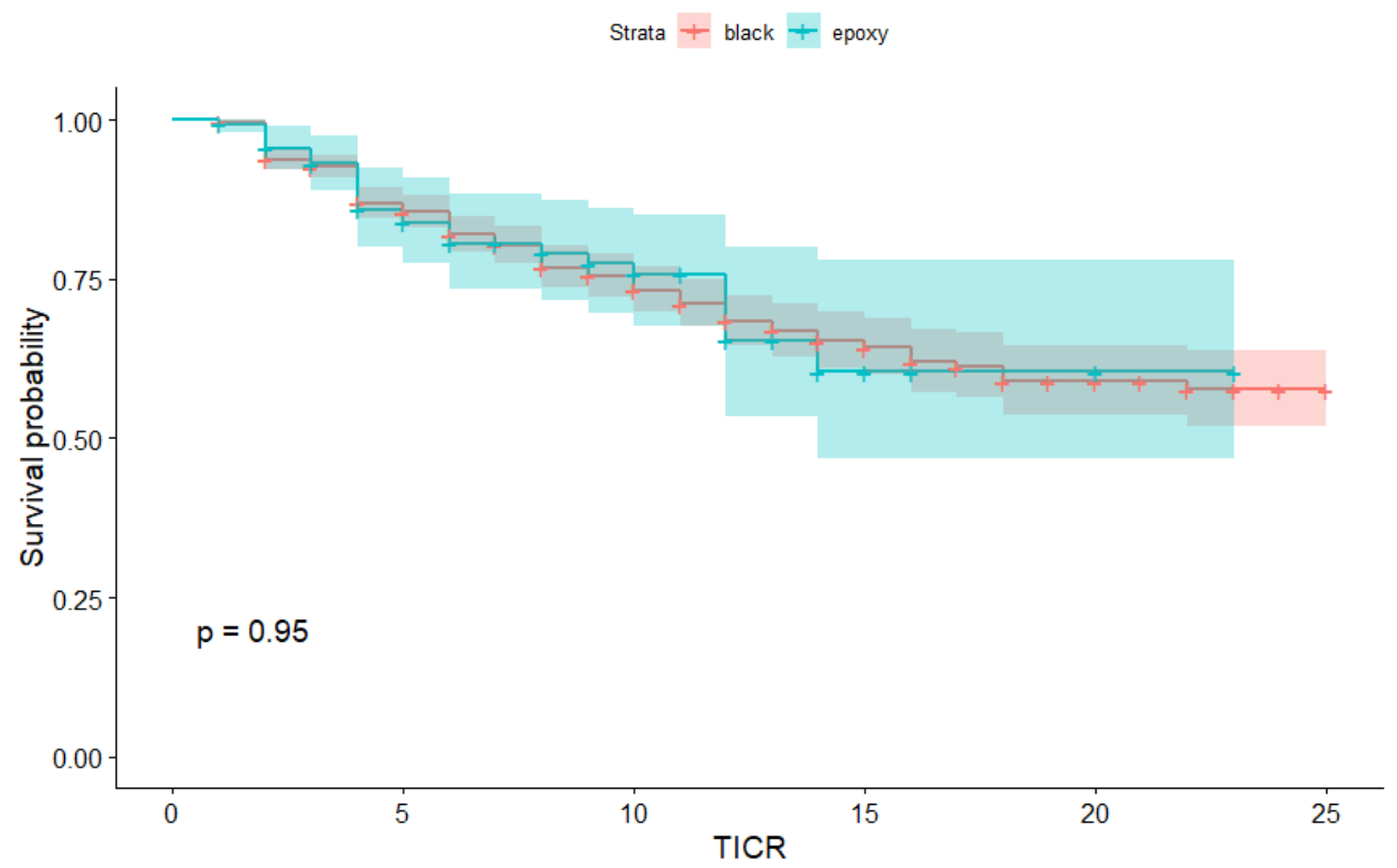

Figure 5-19: Survival Curves of TICR Depending on Rebar Type

\subsubsection{Deck Slenderness}

The slenderness variable has three groups: $\leq 0.05,0.05$ to 0.15 , and $>0.15$. The generated survival curves show that bridge decks with slenderness $\leq 0.05$ have a higher survival probability than other bridge decks (Figure 5-20). This makes sense considering that bridge decks with low slenderness are typically precast/prestressed. In addition, the logrank test shows that at least two of the survival curves are significantly different. 


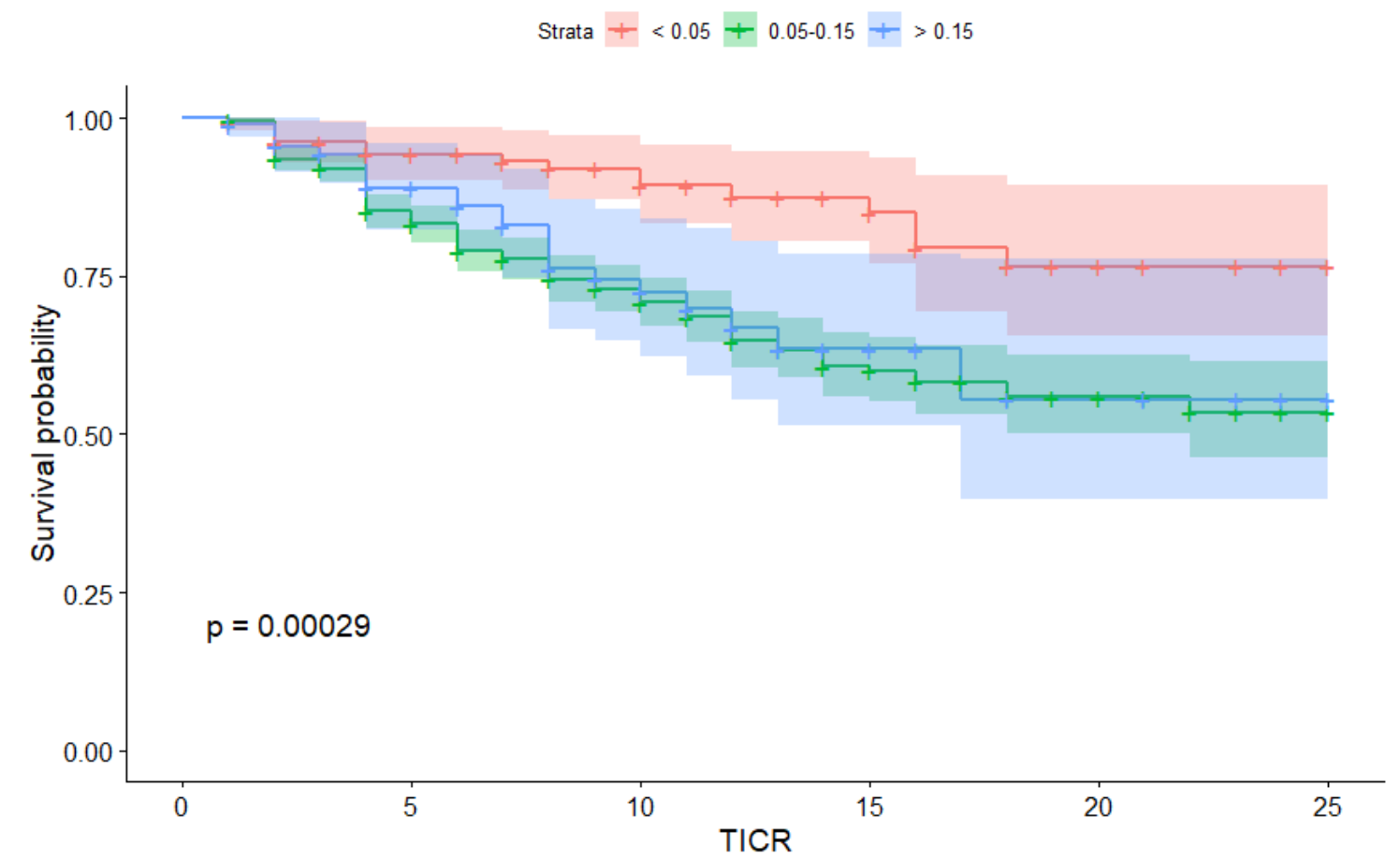

Figure 5-20: Survival Curves of TICR Depending on Deck Slenderness 


\section{$5.2 \quad$ Regression Model}

Although Kaplan-Meier survival curves can be compared to determine the difference in survival probability between groups of a variable, determining the influence of all the independent variables on bridge deck deterioration simultaneously is more complicated. To determine the contribution of covariates on the prediction of bridge deck performance, Cox proportional hazards models were used, which are semiparametric regression models that take into consideration censored data. In Cox regression, coefficients are estimated for each explanatory variable in a hazard function. This hazard function can be written as (Mauch \& Madanat, 2001 ; Cox, 1972):

$$
h(t)=\lambda_{0}(t) * e^{\beta_{1 X_{1}+\ldots+} \beta_{k} X_{k}}
$$

where $t$ is the survival time, $h(t)$ is the hazard function determined by a set of $k$ covariates $\left(\mathrm{X}_{1}, \mathrm{X}_{2}, \ldots, \mathrm{X}_{3}\right)$ and represents the expected number of events per unit of time, $\beta_{1}$ through $\beta_{k}$ are the coefficients that measure the impact of the covariates, and $\lambda_{o}(t)$ is the baseline hazard function that corresponds to the hazard when all covariates are equal to zero. When the logarithm of this hazard function is taken, the Cox model can be written as a linear function of the variables $\mathrm{X}_{\mathrm{i}}$, from which the coefficients $\beta_{i}$ can be determined (Sullivan, 2016). By taking the antilog of the estimated regression coefficients, hazard ratios (HR) can be calculated, which describe the effect of each variable on survival. HR $>1$ indicates an increased risk of deterioration while $\mathrm{HR}<1$ indicates a decreased risk of deterioration. 
In order to begin this regression analysis, the predictive variables included in the model had to be converted to dummy variables. This process of dichotomizing variables with multiple groups was based on the same method used for the survival curves. The group selected to be the group of interest for each variable was determined to be the group with the most significant effect on bridge deck survival. To determine the significance of each group, a model was created with all of the groups of each variable and the Wald statistic was calculated. In almost every case the chosen group of interest was the group with the most available data. After choosing which group would represent each variable, $\mathrm{CR}$ categories were determined to show how TICR is affected when bridge deck condition changes. Based on regression models for each CR, it was determined that hazard ratios for CR 4 and 5 were similar and hazard ratios for CR 7 and 8 were similar. Hazard ratios for CR 6 did not follow the trends for either of these categories. Therefore, the three CR categories were chosen to be: $\mathrm{CR} 4 \& 5$, CR 6 , and CR $7 \& 8$. For simplification, these categories are referred to as low, medium, and high CR, respectively. To perform this regression analysis, missing data had to be removed from the datasets. By removing bridges with missing data, both the NBI dataset and refined dataset were reduced by approximately $11 \%$.

The results from the Cox proportional hazards models are presented in two parts. First, for each CR category, hazard ratios are presented for each variable included in the model. Second, for each hazard ratio, $p$-values are shown based on the Wald statistic. These $p$ values indicate whether the coefficient of a variable is significantly different from zero. 
For simplicity, HR $\leq 1$ are highlighted in green while HR $>1$ are highlighted in red. Significant $p$-values $(<0.05)$ are highlighted in yellow. In addition, each variable is ranked based on their overall influence on the global significance of the model considering all CR. The results of the log-rank test for each CR group are shown at the bottom of the table.

\subsubsection{NBI Dataset}

In general, the results of the Cox proportional hazards model for the NBI dataset agree with the survival curves for the same dataset (Table 5-2). What is different about the regression model is that it simultaneously shows the effect of the predictor variables on bridge deck survival time. In addition, the model also shows that the effect of these variables on bridge deck deterioration changes depending on the CR group. The hazard ratios produced by the model show that for bridge decks in the Cascades there is an increased risk of deterioration for all CR groups. For bridge decks built after 1970, there is a decreased risk of deterioration for all CR groups. For bridge decks maintained by a state highway agency, deterioration risk varies depending on the CR group. However, the only significant hazard ratio for this variable is associated with the high $\mathrm{CR}$, which indicates an increased risk of deterioration. For prestressed concrete bridges, there is a decreased risk of bridge deck deterioration associated with the medium and high CR groups. Bridges with either stringer/multi-beam/girder design have an increased risk of bridge deck deterioration for high CR. Precast bridge decks have a decreased risk of deterioration for medium CR. Bridge decks with a bituminous wearing surface have a decreased risk of deterioration for medium and high CR. For bridge decks with an asphalt 
wearing surface and no membrane, there is an increased risk of deterioration for high CR. Bridges with no deck protection have an increased risk of bridge deck deterioration for medium and high CR. Bridge decks who experience high ADTT have an increased risk of deterioration for medium and high CR. Bridge decks who are further than three kilometers from the ocean have a decreased risk of deterioration for high CR.

Table 5-2: Regression Results for the NBI Dataset

\begin{tabular}{|c|c|c|c|c|c|c|}
\hline VARIABLE (group & \multicolumn{2}{|c|}{ LOW CR } & \multicolumn{2}{c|}{ MEDIUM CR } & \multicolumn{2}{c|}{ HIGH CR } \\
\cline { 2 - 7 } of interest) & HR & Sig. & HR & Sig. & HR & Sig. \\
\hline $\begin{array}{c}\text { Type of Wearing } \\
\text { Surface (Bituminous) }\end{array}$ & 0.77 & 0.310 & 0.40 & $<0.001$ & 0.58 & $<0.001$ \\
\hline $\begin{array}{c}\text { Kind of Material } \\
\text { and/or Design } \\
\text { (Pre-stressed } \\
\text { Concrete) }\end{array}$ & 1.14 & 0.738 & 0.56 & $<0.001$ & 0.64 & $<0.001$ \\
\hline $\begin{array}{c}\text { Climate Zone } \\
\text { (Cascades) }\end{array}$ & 1.78 & 0.013 & 1.44 & 0.001 & 1.31 & $<0.001$ \\
\hline $\begin{array}{c}\text { ADTT (>1000) } \\
\text { Design Period (> } \\
\text { 1970) }\end{array}$ & 1.36 & 0.191 & 1.47 & $<0.001$ & 1.34 & $<0.001$ \\
\hline $\begin{array}{c}\text { Type of Design } \\
\text { and/or Construction } \\
\text { (Stringer/Multi- } \\
\text { beam/Girder) }\end{array}$ & 0.41 & 0.011 & 0.77 & 0.027 & 0.75 & $<0.001$ \\
\hline $\begin{array}{c}\text { Type of Membrane } \\
\text { (None) }\end{array}$ & 0.83 & 0.412 & 1.20 & 0.055 & 1.21 & $<0.001$ \\
\hline $\begin{array}{c}\text { Deck Structure Type } \\
\text { (Precast) }\end{array}$ & $<0.01$ & 0.993 & 0.22 & 0.003 & 0.88 & 0.164 \\
\hline $\begin{array}{c}\text { Deck Protection } \\
\text { (None) }\end{array}$ & 2.33 & 0.257 & 1.44 & 0.061 & 1.17 & 0.072 \\
\hline $\begin{array}{c}\text { Maintenance } \\
\text { Responsibility } \\
\text { (State Hwy) }\end{array}$ & 0.65 & 0.155 & 0.98 & 0.88 & 1.27 & $<0.001$ \\
\hline $\begin{array}{c}\text { Kind of Material } \\
\text { and/or Design } \\
\text { (Continuous) }\end{array}$ & 0.90 & 0.628 & 1.09 & 0.375 & 1.01 & 0.880 \\
\hline $\begin{array}{c}\text { Distance to Seawater } \\
\text { (> 1 km) }\end{array}$ & 0.46 & 0.292 & 1.63 & 0.238 & 0.59 & 0.002 \\
\hline Log-Rank Test & $\mathbf{0 . 0 1}$ & 0.887 & 1.16 & 0.508 & 1.38 & 0.001 \\
\hline
\end{tabular}




\subsubsection{Refined Dataset}

Compared to the regression model for the NBI dataset, the refined dataset regression model is less informative (Table 5-3). Since there are not enough data in the refined dataset, the majority of hazard ratios (HR) determined from the model are not statistically significant. The two hazard ratios that are significant make sense intuitively. The hazard ratio associated with bridge decks in the Cascades and medium CR indicates an increased risk of deterioration. The hazard ratio associated with concrete cover between two and three inches and high CR indicates a decreased risk of deterioration.

Table 5-3: Regression Results for the Refined Dataset

\begin{tabular}{|c|c|c|c|c|c|c|}
\hline \multirow{2}{*}{$\begin{array}{c}\text { VARIABLE } \\
\text { group of interest) }\end{array}$} & \multicolumn{2}{|c|}{ LOW CR } & \multicolumn{2}{c|}{ MEDIUM CR } & \multicolumn{2}{c|}{ HIGH CR } \\
\cline { 2 - 7 } & HR & Sig. & HR & Sig. & HR & Sig. \\
\hline $\begin{array}{c}\text { Climate Zone } \\
\text { (Cascades) }\end{array}$ & 1.00 & 0.995 & 2.24 & 0.012 & 1.34 & 0.083 \\
\hline $\begin{array}{c}\text { Concrete Cover } \\
(2 \text { in }<\mathrm{x} \geq 3 \text { in) }\end{array}$ & $<0.01$ & 0.998 & 0.39 & 0.279 & 0.50 & 0.015 \\
\hline Rebar Type (Epoxy) & $>10.00$ & 0.998 & 0.21 & 0.198 & 1.77 & 0.060 \\
\hline $\begin{array}{c}\text { Design Period (> } \\
1970)\end{array}$ & 0.45 & 0.465 & 1.22 & 0.580 & 1.18 & 0.387 \\
\hline $\begin{array}{c}\text { Deck Slenderness }(\leq \\
0.05)\end{array}$ & $<0.01$ & 0.999 & $\mathbf{1 . 7 6}$ & 0.359 & 0.91 & 0.823 \\
\hline $\begin{array}{c}\text { Rebar Spacing }(>10 \\
\text { in) }\end{array}$ & 0.80 & 0.707 & 0.58 & 0.086 & 0.98 & 0.920 \\
\hline \begin{tabular}{c} 
Log-Rank Test \\
\hline
\end{tabular} & $\mathbf{0 . 7}$ & & $\mathbf{0 . 0 2}$ & & $\mathbf{0 . 2}$ \\
\hline
\end{tabular}




\subsubsection{Ranking of Variables}

The regression results show that the effect of the predictor variables on bridge deck performance varies depending on the condition of the bridge deck. In order to capture the influence of each variable depending on CR group, the variables listed above were ranked based on their significance to each CR group's model. In Table 5-2, the variables were ranked based on their contribution to the model that contained all CRs. To establish this ranking, each CR group model was run containing all of the predictor variables. From the results, the $\mathrm{p}$-values were gathered which illustrate the overall model significance and are determined from the log-rank test. To determine the influence of a variable, the change in the log-rank test was recorded for the model excluding that variable. This process of removing a variable and performing the log-rank test was completed for each variable. Using the gathered $p$-values, each variable was ranked from most influential to least influential for each CR group (Table 5-4 and Table 5-5). To achieve the overall rank of each variable, the rank of each variable for each CR group was summed and then ranked again.

The results show that for different bridge deck conditions, different variables are important. This makes sense considering that in different stages of deterioration, bridge decks will be influenced by different parameters. From the NBI dataset, the top five most influential variables were found to be type of wearing surface (NBI item 108A), climate zone, design period, kind of material and/or design (NBI item 43A), and ADTT. Each of these variables were found to have significant hazard ratios that influence the model. From the refined dataset, the top three most influential variables were found to be 
concrete cover, climate zone, and rebar type. However, although these variables influence the model, only the hazard ratio for climate zone in the medium CR group and the hazard ratio for concrete cover in the high CR group were found to be significant.

Table 5-4: Ranking of Variables Depending on CR Group for the NBI Dataset

\begin{tabular}{|c|c|c|c|c|c|}
\hline $\begin{array}{c}\text { VARIABLE } \\
\text { (group of interest) }\end{array}$ & LOW CR & MEDIUM CR & HIGH CR & $\begin{array}{c}\text { ALL } \\
\text { CR }\end{array}$ & $\begin{array}{c}\text { Overall } \\
\text { Rank }\end{array}$ \\
\hline $\begin{array}{c}\text { Type of Wearing } \\
\text { Surface (Bituminous) }\end{array}$ & 6 & 1 & 1 & 1 & 1 \\
\hline $\begin{array}{l}\text { Climate Zone } \\
\text { (Cascades) }\end{array}$ & 2 & 5 & 4 & 3 & 2 \\
\hline Design Period $(>1970)$ & 1 & 6 & 3 & 5 & 3 \\
\hline $\begin{array}{c}\text { Kind of Material and/or } \\
\text { Design } \\
\text { (Pre-stressed Concrete) }\end{array}$ & 11 & 2 & 2 & 2 & 4 \\
\hline ADTT $(>1000)$ & 3 & 4 & 6 & 4 & 5 \\
\hline $\begin{array}{l}\text { Deck Structure Type } \\
\text { (Precast) }\end{array}$ & 5 & 3 & 11 & 8 & 6 \\
\hline $\begin{array}{c}\text { Type of Design and/or } \\
\text { Construction } \\
\text { (Stringer/Multi- } \\
\text { beam/Girder) }\end{array}$ & 9 & 8 & 7 & 6 & 7 \\
\hline $\begin{array}{c}\text { Maintenance } \\
\text { Responsibility } \\
\text { (State Hwy) }\end{array}$ & 4 & 12 & 5 & 10 & 8 \\
\hline Deck Protection (None) & 8 & 7 & 10 & 9 & 9 \\
\hline $\begin{array}{c}\text { Distance to Seawater (> } \\
1 \mathrm{~km})\end{array}$ & 7 & 9 & 9 & 12 & 10 \\
\hline $\begin{array}{l}\text { Type of Membrane } \\
\text { (None) }\end{array}$ & 12 & 11 & 8 & 7 & 11 \\
\hline $\begin{array}{c}\text { Kind of Material and/or } \\
\text { Design } \\
\text { (Continuous) }\end{array}$ & 10 & 10 & 12 & 11 & 12 \\
\hline
\end{tabular}


Table 5-5: Ranking of Variables Depending on CR Group for the Refined Dataset

\begin{tabular}{|c|c|c|c|c|c|}
\hline $\begin{array}{c}\text { VARIABLE } \\
\text { group of interest) }\end{array}$ & LOW CR & MEDIUM CR & HIGH CR & ALL CR & $\begin{array}{c}\text { Overall } \\
\text { Rank }\end{array}$ \\
\hline $\begin{array}{c}\text { Concrete Cover } \\
(2 \text { in }<\mathrm{x} \geq 3 \text { in) }\end{array}$ & 3 & 3 & 1 & 2 & 1 \\
\hline $\begin{array}{c}\text { Climate Zone } \\
\text { (Cascades) }\end{array}$ & 5 & 1 & 3 & 1 & 2 \\
\hline Rebar Type (Epoxy) & 1 & 4 & 2 & 3 & 3 \\
\hline Design Period (> 1970) & 2 & 6 & 4 & 4 & 4 \\
\hline $\begin{array}{c}\text { Deck Slenderness ( } \leq \\
\text { 0.05) }\end{array}$ & 4 & 5 & 5 & 5 & 5 \\
\hline Rebar Spacing (> 10 in) & 6 & 2 & 6 & 6 & 6 \\
\hline
\end{tabular}




\subsection{Case Study}

To better understand the influence of the selected variables on bridge deck deterioration, a case study was created that identifies which bridge decks have the most and least deterioration risk. As a semi-parametric model, the Cox proportional hazards model estimates the influence of the selected variables on bridge deck deterioration without knowing the distribution function associated with the baseline hazard. Because the baseline hazard is unknown, it is difficult to determine the overall hazard function accurately. Instead of determining the hazard at each time interval, the relative hazard can be determined by dividing the hazard function by the baseline hazard (Sullivan, 2016). By expressing the Cox model in this way, the relative hazard of each bridge deck can be calculated as a function of the predictive variables:

$$
\frac{h(t)}{h_{0(t)}}=e^{\beta_{1 X_{1}+\ldots+} \beta_{k} X_{k}}
$$

This equation can be simplified even further to include just the predictive variables and their associated hazard ratios:

$$
\frac{h(t)}{h_{0(t)}}=H R_{1}^{X_{1}} * H R_{2}^{X_{2}} * \ldots * H R_{k}^{X_{k}}
$$

Using this equation, the relative hazard of any bridge deck can be determined as long as the CR and predictive variables of the bridge are known. It should be noted that the relative hazard is a ratio that describes the hazard of any bridge deck to the hazard of a reference bridge deck. This reference bridge deck can be any bridge deck for which each 
predictive variable's hazard ratio is equal to 0 . In other words, the reference bridge deck is a bridge deck for which all predictive variables are equal to the reference group. For the NBI dataset, this type of bridge may not exist due to the conflicting nature of certain variables such as the type of wearing surface and type of membrane. For the refined dataset, the reference bridge deck is a bridge deck with less than 2 in of cover, black rebar, slenderness greater than 0.05 rebar, spacing less than 10 in, built before 1970, and not located in the Cascades.

Although it is straight forward to compare relative hazard to the reference value of 1 , this might not be practical due to the small number of bridges that meet the reference group requirements. Instead, comparing a bridge deck's relative hazard to the minimum and maximum possible relative hazard is a more effective way of determining a bridge's risk of deterioration. To determine the minimum and maximum relative hazard, Equation 5 was used with the hazard ratios for the best and worst cases. Best case hazard ratios are less than 1 while worst case hazard ratios are greater than 1 . Only hazard ratios that were found to be significant were included in these calculations. Since the significance of hazard ratios changes depending on the $\mathrm{CR}$ group, the minimum and maximum relative hazard is different for each CR group. The minimum and maximum relative hazard for each CR group can be seen in Table 5-6 and Table 5-7. Since there are so few significant hazard ratios for the refined dataset, only two of the relative hazard ratios are different from the reference ratio. Therefore, this case study should not be used with the refined dataset. 
Table 5-6: Relative Hazard Ratios for the NBI Dataset

\begin{tabular}{|c|c|c|c|}
\hline RELATIVE HAZARD TYPE & LOW CR & MEDIUM CR & HIGH CR \\
\hline Minimum (Good Bridge) & 0.41 & 0.04 & 0.16 \\
\hline Maximum (Bad Bridge) & 1.78 & 3.05 & 3.74 \\
\hline
\end{tabular}

Table 5-7: Relative Hazard Ratios for the Refined Dataset

\begin{tabular}{|c|c|c|c|}
\hline RELATIVE HAZARD TYPE & LOW CR & MEDIUM CR & HIGH CR \\
\hline Minimum (Good Bridge) & 1.00 & 1.00 & 0.50 \\
\hline Maximum (Bad Bridge) & 1.00 & 2.24 & 1.00 \\
\hline
\end{tabular}

In order to determine the deterioration risk of a bridge deck, the relative hazard of that bridge deck should be compared to the minimum and maximum values. To showcase this procedure, a bridge was selected at random from the NBI dataset. The bridge deck that was selected is on the bridge with ODOT ID 00511 and has a CR = 6 as of 2016 and its characteristics are listed in Table 5-8.

Table 5-8: Characteristics of Concrete Bridge Deck on Bridge 00511

\begin{tabular}{|l|c|}
\hline VARIABLE (group of interest) & STATUS \\
\hline Type of Wearing Surface (Bituminous) & YES \\
\hline Kind of Material and/or Design (Pre-stressed Concrete) & NO \\
\hline Climate Zone (Cascades) & NO \\
\hline ADTT (> 1000) & YES \\
\hline Design Period (> 1970) & NO \\
\hline Type of Design and/or Construction (Stringer/Multi-beam/Girder) & NO \\
\hline Type of Membrane (None) & NO \\
\hline Deck Structure Type (Precast) & NO \\
\hline Deck Protection (None) & NO \\
\hline Maintenance Responsibility (State Hwy) & NO \\
\hline Kind of Material and/or Design (Continuous) & NO \\
\hline Distance to Seawater (>3km) & YES \\
\hline
\end{tabular}

Using these characteristics and Equation 5, the relative hazard for the concrete bridge deck of Bridge 00511 can be calculated as follows: 


$$
0.40^{1} * 0.56^{0} * 1.44^{0} * 1.47^{1} * 0.77^{0} * 0.22^{0} * 1.44^{0}=0.59
$$

Compared to the minimum and maximum relative hazard for bridge decks in a medium $\mathrm{CR}$, this bridge deck has a risk of deterioration 15 times higher than the best bridge deck but also 5 times lower than the worst bridge deck (Figure 5-21). The relative hazard for Bridge 00511's bridge deck can be ranked by dividing the calculated relative hazard by the range of potential relative hazard values for bridge decks in a medium CR. In this case, Bridge 00511's deterioration risk is within the best $20 \%$ of possible relative hazards.

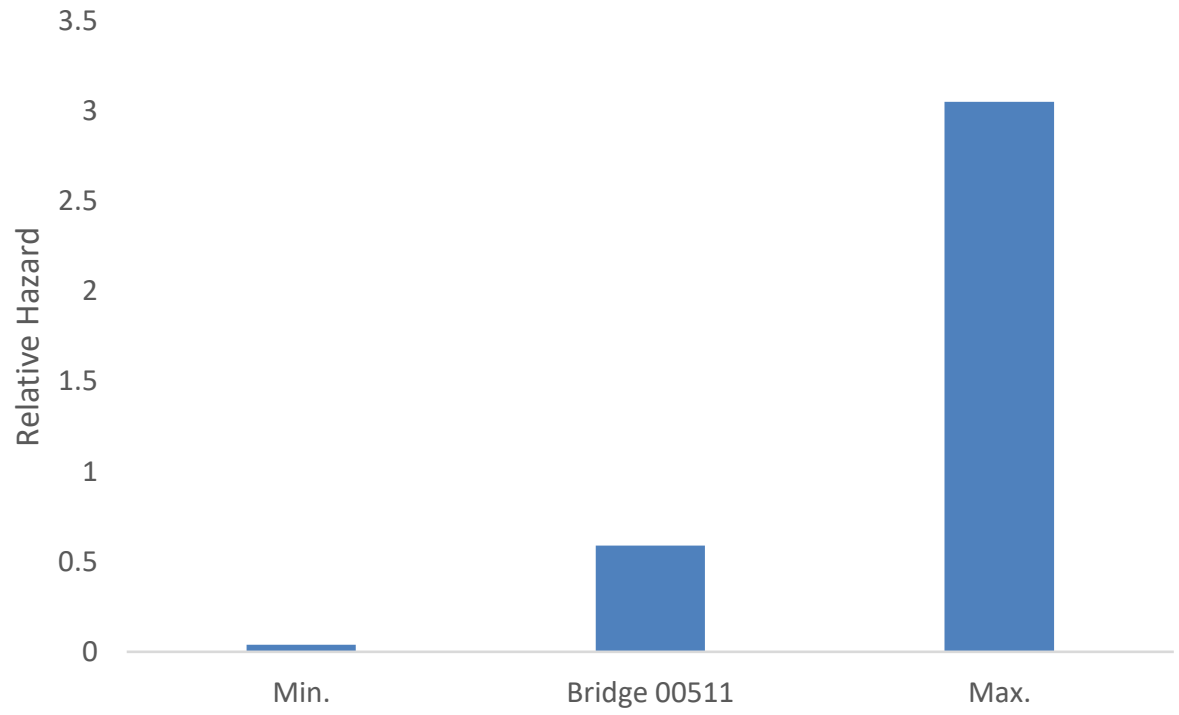

Figure 5-21: Relative Hazard of Bridge 00511

Using this method of determining deterioration risk, bridge decks that need the most attention can be identified and managed. In order to compare the deterioration risk of 
different bridge decks, the calculated relative hazard of each bridge deck needs to be normalized by the maximum and minimum relative hazard associated with that bridge decks current condition. For example, by calculating and normalizing the relative hazard of each NBI bridge deck in Oregon, the deterioration risk of bridge decks was mapped (Figure 5-22). This map shows the relative hazard of bridge decks grouped by quartiles from green to yellow to orange to red. Green bridge decks have a lower risk of deterioration while red bridge decks have a higher risk of deterioration. It should be noted that since the calculation of relative hazard requires complete data, only 4160 of the 5242 NBI bridges were plotted. Also, the method used in this case study is not rigorous and should only be used as a guideline.

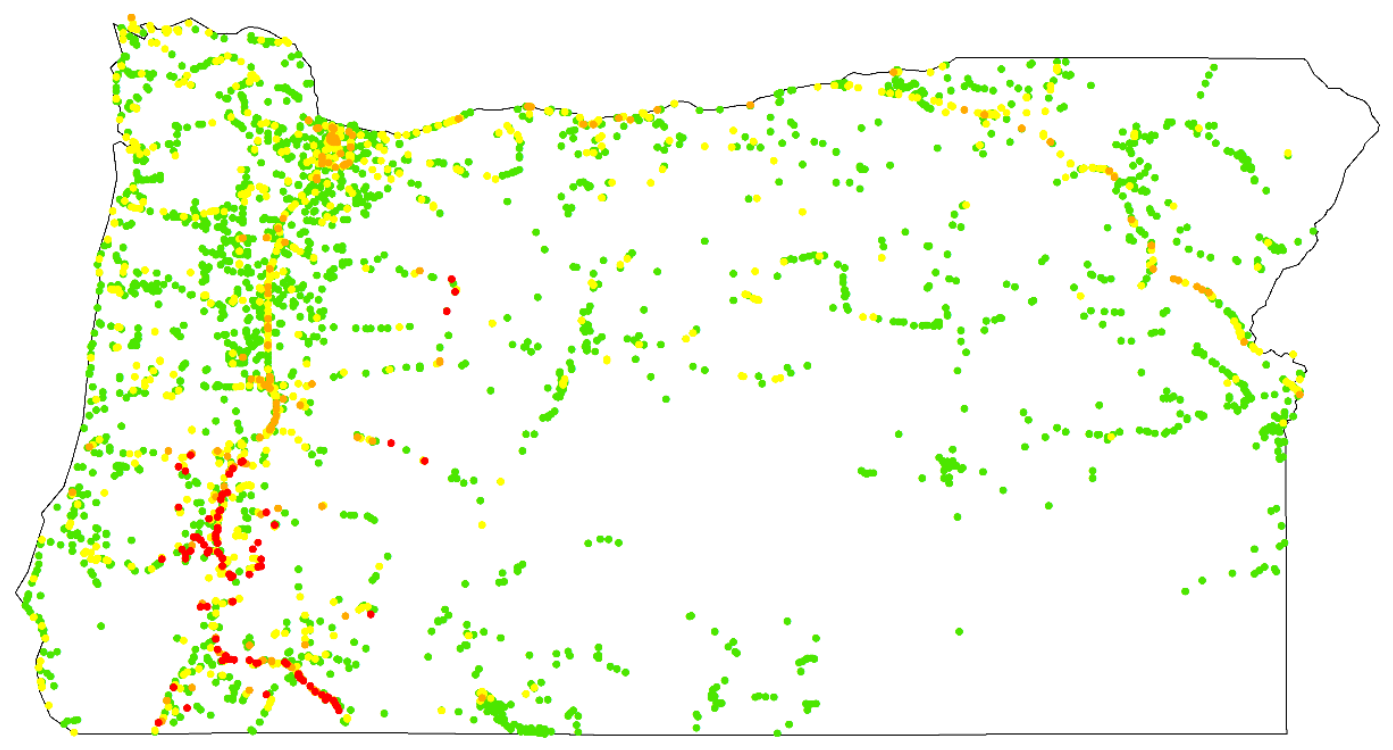

Figure 5-22: Normalized Relative Hazards of Bridge Decks in Oregon 


\subsection{Conclusions}

To quantify bridge deck deterioration and determine the effect of select variables on bridge deck performance, a survival analysis was performed. First, survival curves were created that visualize the change in survival probability of bridge decks depending on groups of a variable. Almost all of the survival curves generated from variables in the NBI dataset were statically significant. In comparison, all but one of the survival curves generated for the refined dataset were statistically insignificant. This lack of significance is a result of less available data in the refined dataset. Although no concrete conclusions about the variables in the refined dataset can be made, the survival curves can be interpreted as trends in survival probability. Second, Cox proportional hazards regression was used to determine the contribution of all the variables on the prediction of bridge deck performance. From the Cox proportional hazards models, the effect of each variable on survival was determined through hazard ratios. Using these hazard ratios and their overall contribution to the models, variables that have the largest effect on concrete bridge deck performance were identified. From the NBI dataset, the top five most influential variables were found to be type of wearing surface (NBI item 108A), climate zone, design period, kind of material and/or design (NBI item 43A), and ADTT. Each of these variables were found to have significant hazard ratios that influence the models. From the refined dataset, the top three most influential variables were found to be concrete cover, climate zone, and rebar type. However, although these variables influence the models, only the hazard ratio for climate zone in the medium CR group and the hazard ratio for concrete cover in the high CR group were found to be significant. 
Using the hazard ratios from the regression models, a case study was performed to show how deterioration risk of a randomly selected bridge can be determined. To determine this risk, the relative hazard of the random bridge deck was calculated using the characteristics of the bridge deck and the associated hazard ratios. This relative hazard was then compared to the minimum and maximum possible values. The relative hazard of the random bridge deck was found to be 15 times higher than the best possible bridge but also 5 times lower than the worst possible bridge. In addition, a map showing the normalized relative hazard of NBI bridge decks in Oregon was created to visualize how bridge deck deterioration risk can be compared. 


\subsection{SURVEY}

In addition to the results of the survival analysis, a survey was developed to identify information that should be collected on concrete bridge decks to improve performance monitoring. This survey was distributed to all Departments of Transportation's (DOTs) in the United States as well as to a few select non-destructive evaluation (NDE) contractors. In total there were 32 responses, of which 3 were from contractors and 29 were from DOTs across the country (States highlighted in blue in Figure 6-1). The 6 questions included in this survey were designed to explore the knowledge and experience of the different agencies regarding bridge deck performance and data collection (Table 6-1).

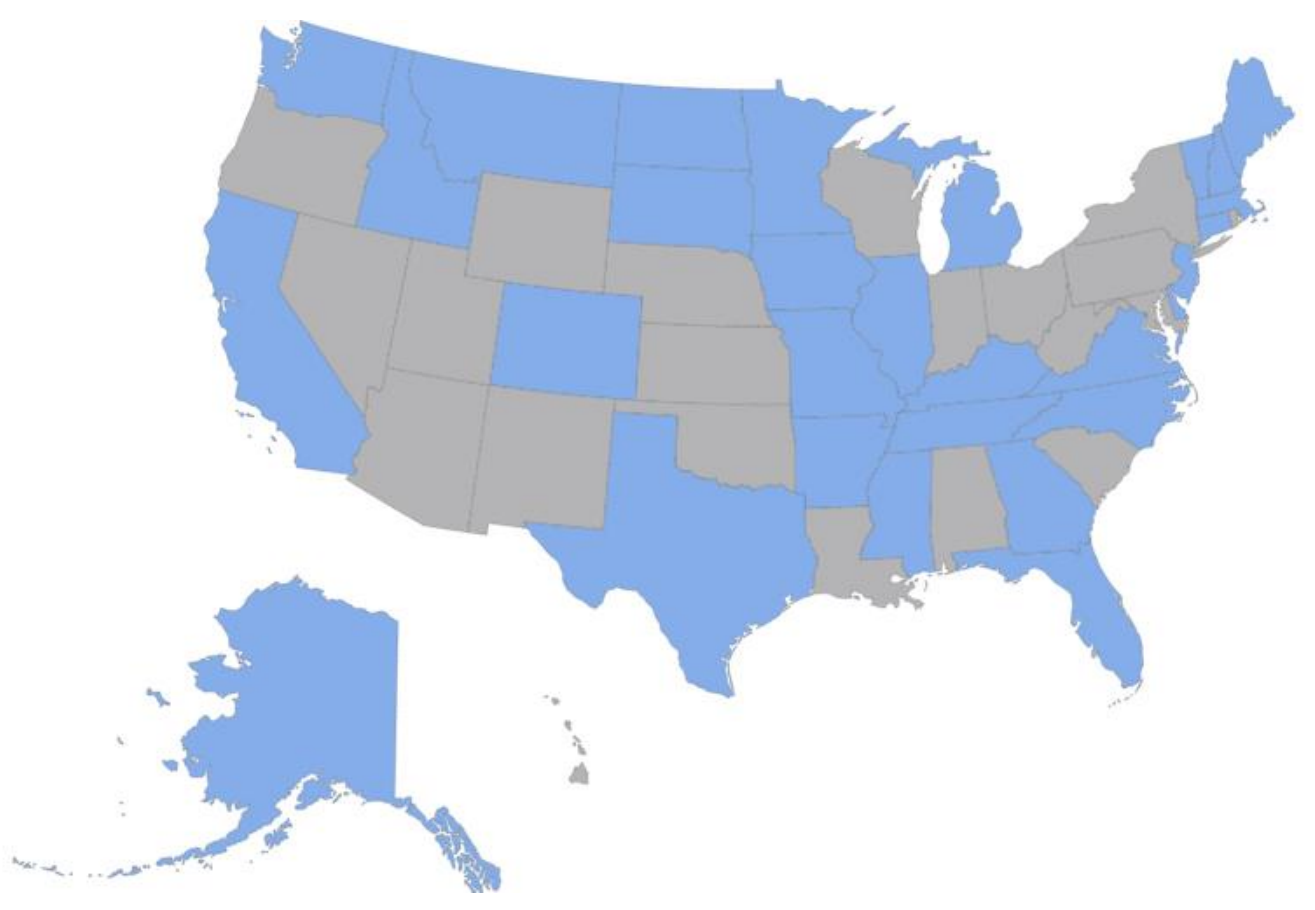

Figure 6-1: State DOT Responses 
Table 6-1 Survey Questions

Question 1: In your experience, what are the three most important parameters controlling concrete bridge deck performance (e.g. specific design details, construction practice, environmental conditions, use of deicers, etc.)?

Question 2: What data does your agency currently collect in addition to the minimum requirements to satisfy concrete bridge deck inspections?

Question 3: If you could, what three additional information/measurements/tests would you collect/perform as part of every concrete bridge deck inspection in order to improve future asset management practice?

Question 4: Do you have any additional recommendations or thoughts?

Question 5: What is your area of responsibility in your agency (e.g. design, maintenance, programming, etc.)?

Question 6: What is your job title?

\subsection{Summary of Responses}

Responses to the first question resulted in a collection of parameters that DOTs believe control concrete bridge deck performance. For simplicity, these responses were condensed into the following groups: use of deicers, ADTT, construction practices, preservation policies, maintenance actions, construction practice, and design details. For the most important parameter, 34\% of responders answered "use of deicers", $28 \%$ answered "construction practices", and 25\% answered "design details" (Figure 6-2). Of the DOTs that answered "use of deicers", the majority are from the Midwest. For the second most important parameter, 31\% answered "design details", 19\% answered "construction practices", "use of deicers", and "environmental conditions" (Figure 6-3). Of the DOTs that answered "design details", the majority are from the South. For the third most important parameter, 31\% answered "design details", $19 \%$ answered "construction practices", and 16\% answered "use of deicers" (Figure 6-4). Again, of the DOTs that answered "design details", the majority are from the South. 


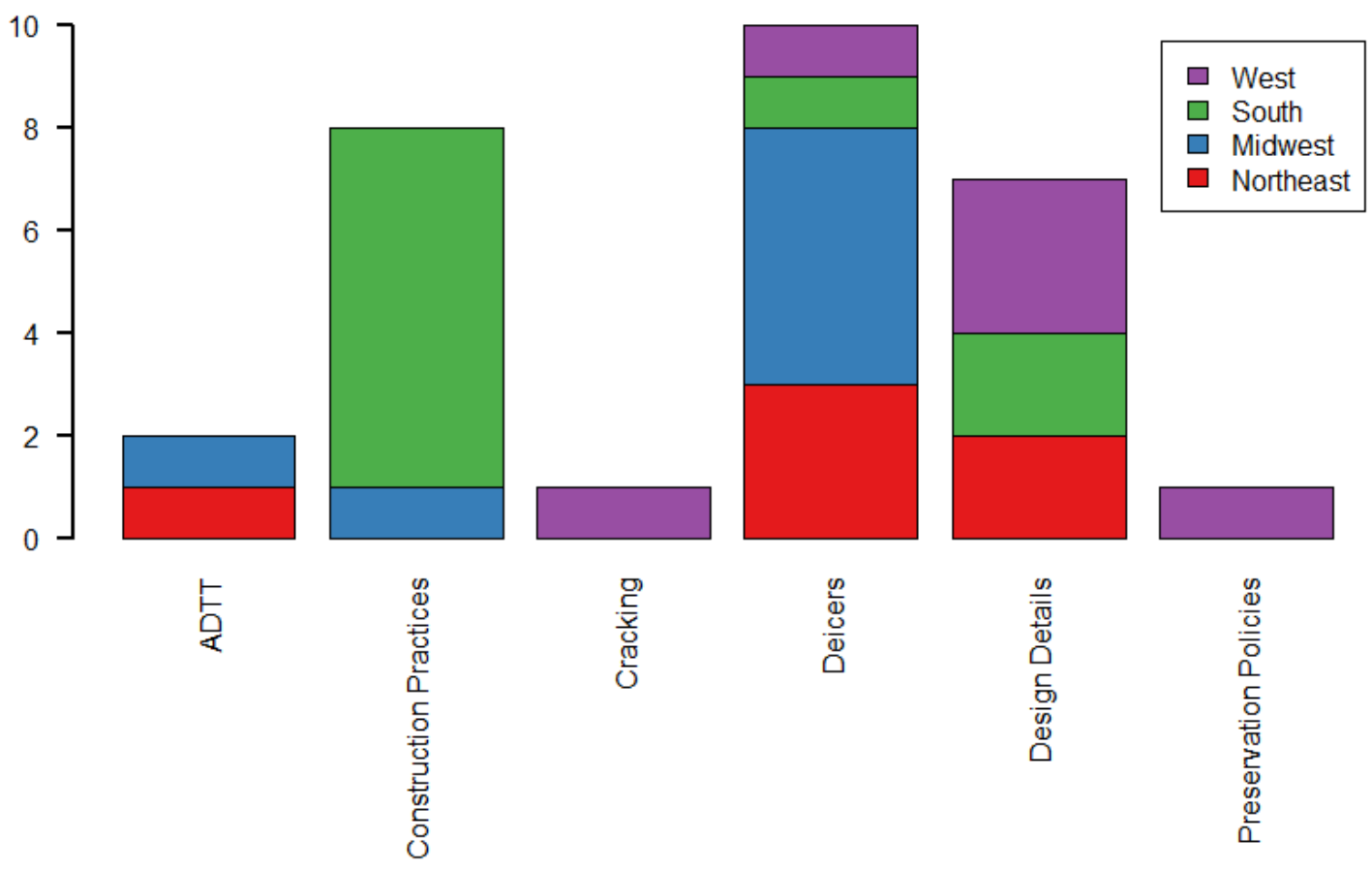

Figure 6-2: DOT Responses to Question 1.1 (Most Important Parameter Controlling Concrete Bridge Deck Performance) Grouped by Region in the United States 


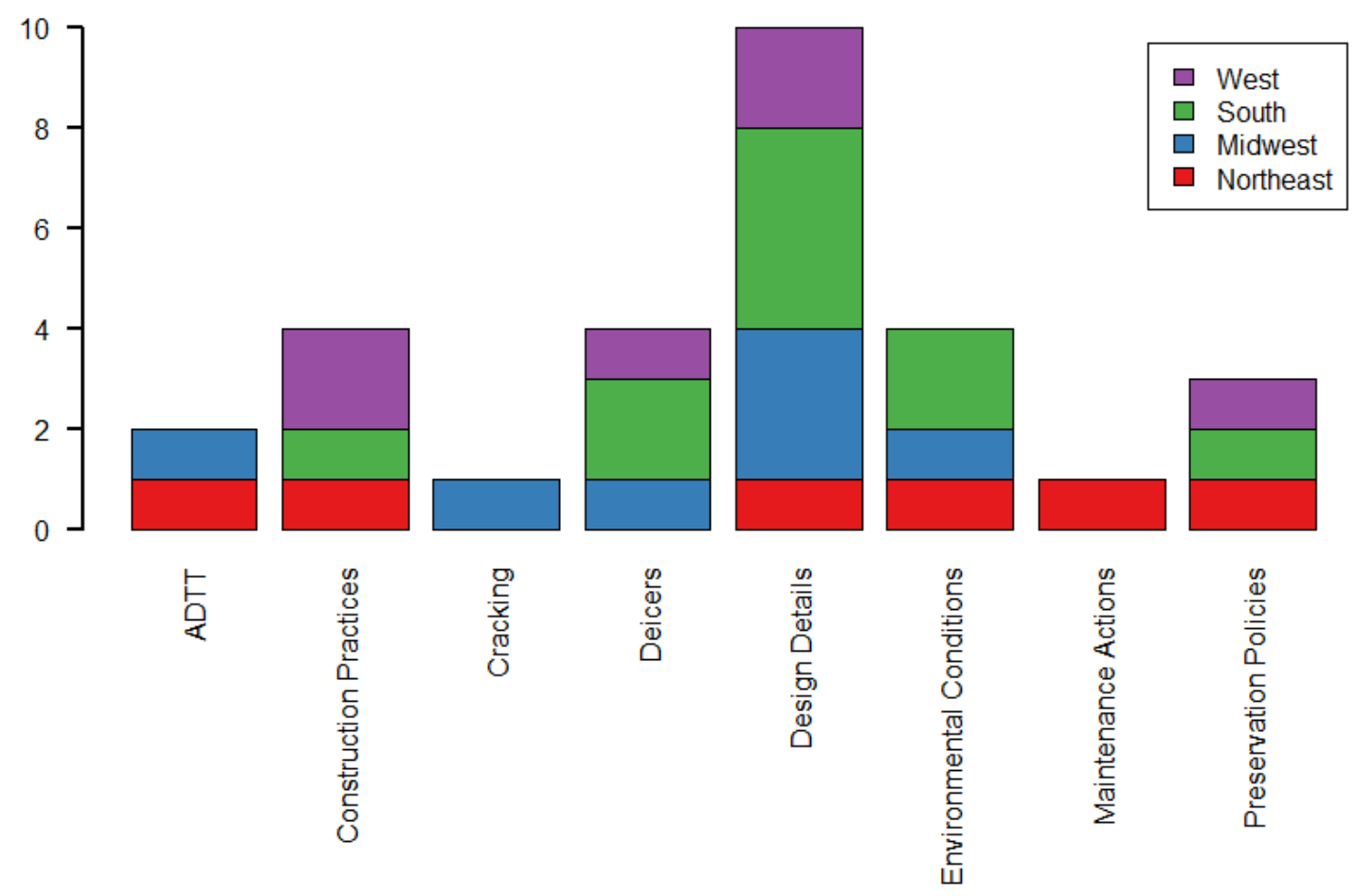

Figure 6-3: DOT Responses to Question 1.2 (Second Most Important Parameter Controlling Concrete Bridge Deck Performance) Grouped by Region in the United States 


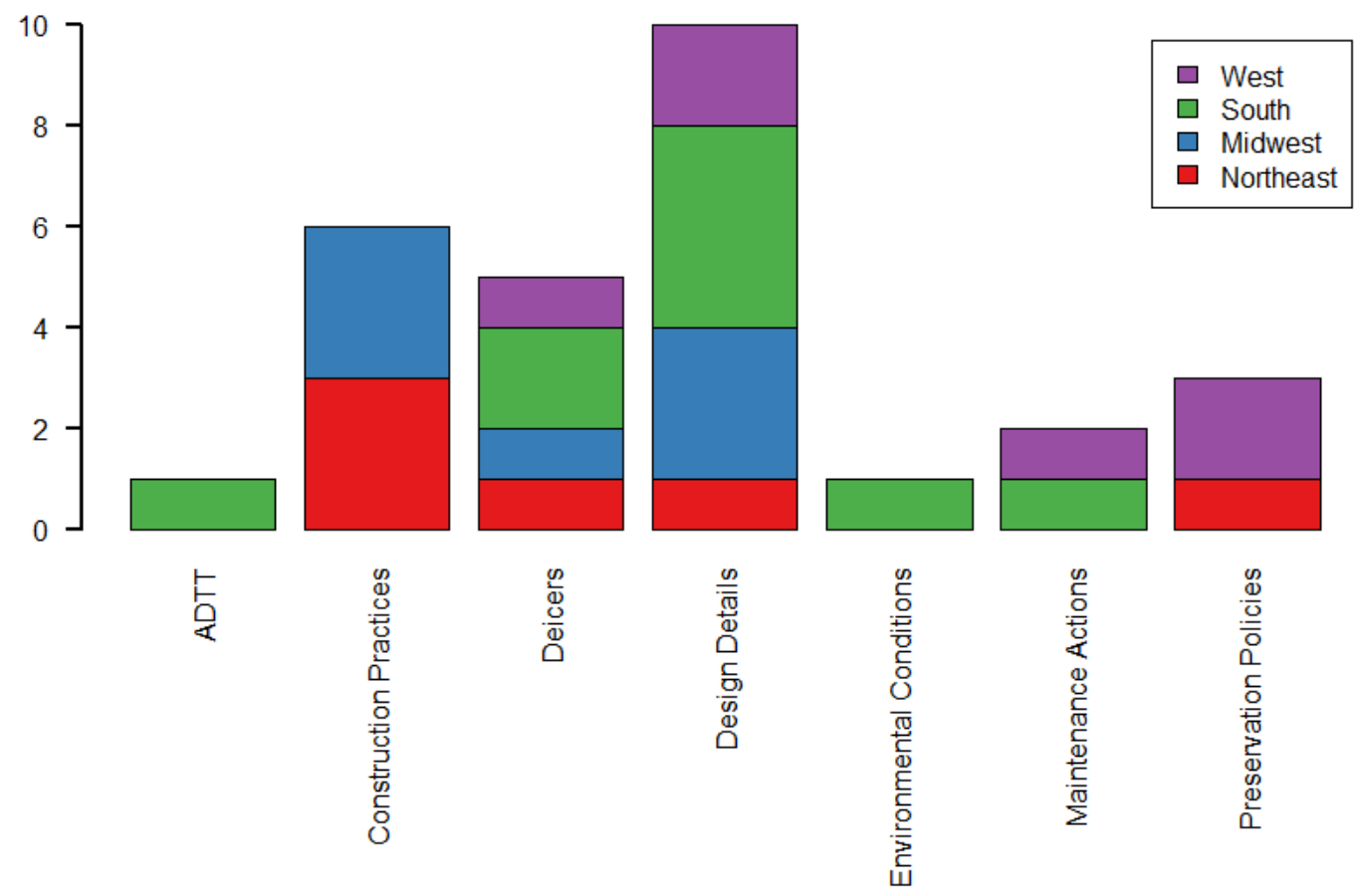

Figure 6-4: DOT Responses to Question 1.3 (Third Most Important Parameter Controlling Concrete Bridge Deck Performance) Grouped by Region in the United States

Because each agency has different data needs and opinions on data collection, the responses to Question 2 varied significantly. Of all the DOTs that responded, 28\% do not collect any additional data for concrete bridge deck inspections. The remaining DOTs collect additional information in various quantities and for different reasons. For most DOTs, additional information is gathered on a case-by-case basis. Out of the responses to Question 2, 3 DOTs reported collecting additional construction data on rebar cover depth, rebar clearance, concrete strength, concrete air entrainment, concrete slump, and deck thickness. For repair or preservation projects, 4 DOTs reported using GPR and/or IR while 9 DOTs reported taking cores to determine chloride content and concrete strength. For routine inspection or select projects, 11 DOTs utilize sounding and 5 DOTs map 
cracking on the bridge deck. Other data that are occasionally collected by DOTs include deck saturation, half-cell potential, atmospheric evaporation, impact echo, bar condition, and deck leakage.

Similar to the responses for Questions 1 and 2, responses to Question 3 had a lot of variation. In general, if agencies had the opportunity they would like to see the use of multiple NDE methods to acquire more information for bridge deck inspection. The responses include 30 different types of information or methods for collecting data that agencies would like to measure, collect, or perform (Figure 6-5). The most prominent answers were: chloride penetration (15\%), crack profile (8\%), IR (8\%), and GPR (7\%). It should be noted that NDE methods such as GPR can be used to gather information on multiple parameters such as concrete cover and concrete delamination area. 


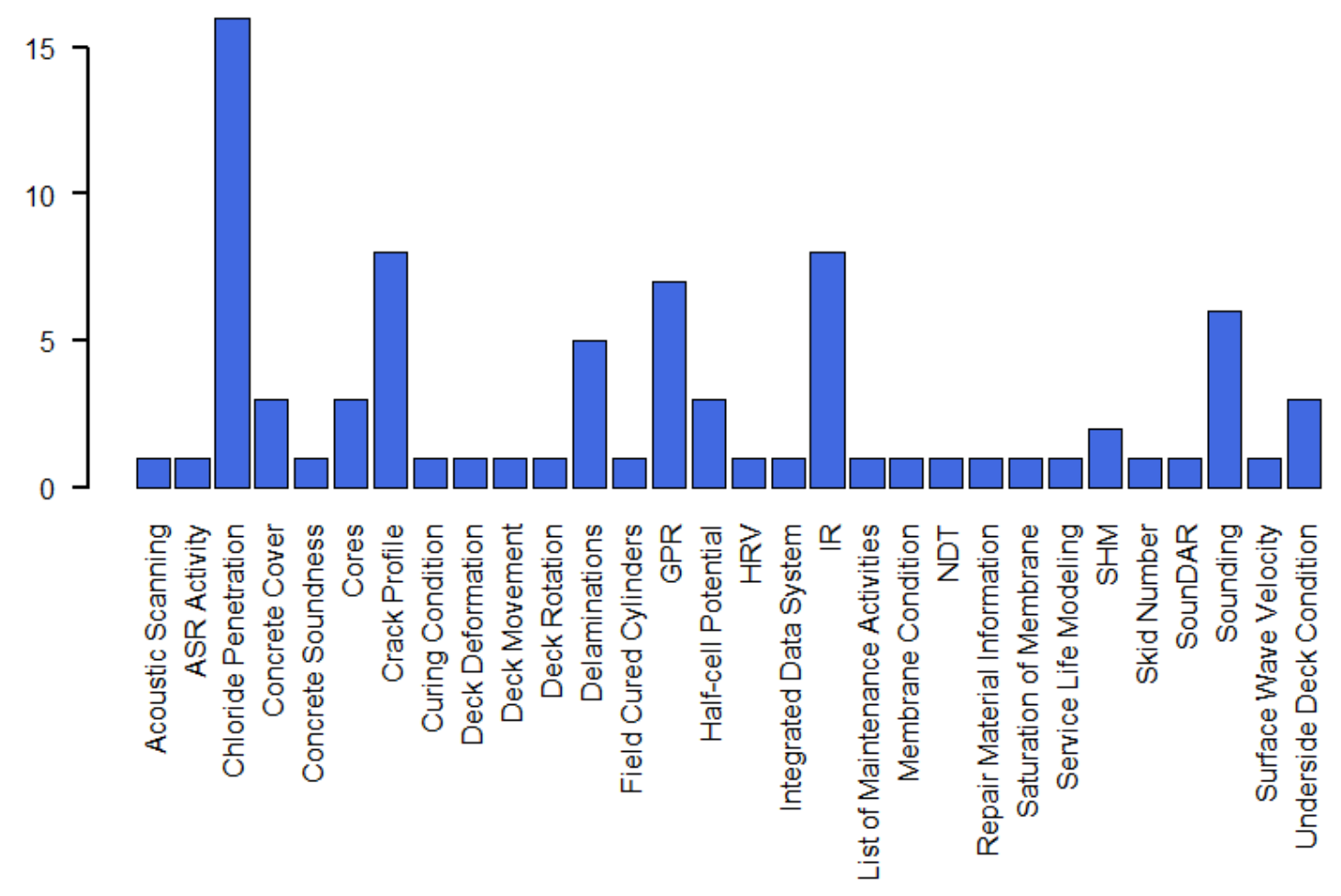

Figure 6-5: Agency Responses to Question 3

Question 4 asked the agencies what recommendations or thoughts they have on bridge deck performance. The responses to this question span multiple topics and vary in detail. Therefore, in order to convey the information in the best possible manner, the responses for each state are included in Appendix A. The responses to Question 4 include nondestructive evaluation (NDE) advice, asset management suggestions, comments on what works well for DOTs with an emphasis on design and construction practice, notes on specific problems with bridges and testing, and suggestions for future research. The responses for Questions 5 and 6, which include the area of responsibility and job title of each responder, can also be found in Appendix A. 
In order to provide more detailed information relevant to Oregon, the responses from the Idaho, California, and Washington DOTs were analyzed in further detail. For Question 1, Idaho responded that use of deicers, preservation policies, and maintenance actions are the most important parameters influencing concrete bridge deck performance. California responded that mix design, design details, and preventative measures are the most important. Washington responded with design details, construction practice, and deck protection. For Question 2, Idaho occasionally collects chain drag, GPR, thermal imaging, and coring, California has access to detailed crack information, and Washington collects chain drag, crack, bar condition, and underside condition information. For Question 3, Idaho responded that they would like to have sounding, GPR, and IR information. California responded that they would like to have concrete soundness, chloride penetration, and crack information. Washington responded that they would like to have deck deformation, rotation, and movement data. For Question 4, Idaho mentioned that the availability of maintenance resources is important. California explained that they provide extra rebar clearance, utilize crack free deck specifications, and use epoxy-coated rebars for their decks. They also use polyester concrete overlays with methacrylate treatment to seal and protect decks. Washington suggested that concrete bridge deck performance could be improved with performance specifications, use of fiber and increased solid to paste ratio in concrete mixes, the avoidance of high strength concrete mixes and large pier skews, proper sequencing of deck casting, and proper rebar placement. 


\subsection{Conclusions}

To complement the findings from the survival analysis, a survey was created and distributed to all DOTs in the United States as well as to a few select NDE contractors. The survey found that the most important parameters that control concrete bridge deck performance are thought to be use of deicers, construction practices, and design details. The survey also found that some DOTs collect additional construction data, use GPR and/or IR, collect cores, utilize sounding, and map cracking in addition to minimum inspection requirements. In addition, agencies would like to have more information from GPR and IR and on chloride penetration and crack profiles. To capture more relevant information for Oregon, the responses from Idaho, Washington, and California DOTs were explored in more detail. 


\subsection{SUMMARY AND CONCLUSIONS}

This research analyzed data currently available through ODOT and the NBI to evaluate the performance of concrete bridge decks throughout the state of Oregon. From this analysis, the parameters that influence concrete bridge deck performance the most were identified. In addition, a list of parameters that ODOT can use to improve concrete bridge deck performance monitoring in the future was compiled.

\subsection{Literature Review}

The literature review found that the deterioration of concrete bridge decks is a complex topic that requires an understanding of the processes and parameters that drive deterioration. Of the many ways deterioration occurs, corrosion of the reinforcing steel and cracking of the concrete were found to be the two governing processes affecting bridge deck performance. These two processes interact with each other making deterioration more damaging and costly as time progresses. In this review, the parameters that influence these processes were identified to advise what information could help inform asset management decisions in the future. The parameters that past studies have found to drive bridge deck deterioration are concrete cover, concrete permeability, type of reinforcement, chloride exposure, climate, and truck traffic. The review also researched methodologies for data collection and asset management practices for different states and countries. In addition, to outline the important inputs in deterioration modeling, the main service life prediction models were identified and explored. 


\subsection{Data Assembly and Descriptive Analysis}

Through consultation with ODOT personnel, the research team determined that two datasets would need to be created that combine construction data with NBI data. The two datasets were named "NBI dataset" and "Refined dataset". The NBI dataset is composed of all NBI concrete highway bridge decks in Oregon and contains variables gathered and calculated from the NBI database. The refined dataset is a subset of 400 bridge decks in which NBI related variables are supplemented by construction data gathered from ODOT's BDS. In addition to the independent variables included in the datasets, both datasets contain performance metrics used to quantify concrete bridge deck deterioration. The first performance metric is TICR, which is based on NBI CRs for the years 19922016. The second performance metric is bridge deck health index, which is determined from element-level data for the years 1997-2018. The element-level data was queried through ODOT's bridge inspection database. To complete the survival analysis, only TICR was used because of data availability and consistency.

In order to better understand the Oregon-specific datasets, descriptive statistical analysis was performed on the parameters assumed of affecting concrete bridge deck performance. Overall, the descriptive statistical analysis between the NBI dataset and the refined dataset shows that both datasets have similar distributions of bridge decks for most variables. Differences between the two datasets are a result of the selection of bridge decks based on climate zone and design period. The variables that are different between the two datasets are climate zone, kind of material/design, deck structure type, 
and ADTT. Also, the refined dataset also contains the construction variables concrete cover, transverse rebar spacing, rebar type, and deck slenderness.

In addition to the independent variables present in the Oregon-specific datasets, the first performance metric, TICR, was reviewed. TICR was calculated for the bridge decks in the refined dataset and plots were created that show how climate group and design period affect average TICR and survival probability. However, before these plots could be explained, the concept of censoship was introduced and plots were created that show how censored data increases average TICR and survival probability. In summary, average TICR and survival probability vary depending upon which climate group or design period bridge decks are in.

\subsection{Survival Analysis}

To better understand the relationship between concrete bridge deck performance and the data in the Oregon-specific datasets, a survival analysis was performed using the performance metric TICR as the dependent variable. First, survival curves were created that visualize the change in survival probability of bridge decks depending on each independent variable. Second, Cox proportional hazards regression was used to determine the contribution of all the variables on the prediction of bridge deck performance. From the survival analysis, the influence of each parameter on concrete bridge deck performance was identified.

- From the NBI dataset, the top five most influential variables were found to be type of wearing surface (NBI item 108A), climate zone, design period, kind of 
material and/or design (NBI item 43A), and ADTT. Each of these variables were found to have significant hazard ratios that influence the model.

- From the refined dataset, the top three most influential variables were found to be concrete cover, climate zone, and rebar type. However, although these variables influence the model, only the hazard ratio for climate zone in the medium CR group and the hazard ratio for concrete cover in the high CR group were found to be statistically significant.

In order to show how the deterioration risk of a randomly selected bridge deck can be determined, a case study was performed. By comparing the relative hazard of the bridge deck with the maximum and minimum relative hazards, the deterioration risk of the bridge deck was determined. In summary, the randomly selected bridge deck has a deterioration risk 15 times higher than the best bridge deck but also a deterioration risk 5 times lower than the worst bridge deck.

\subsection{Survey}

To complement the findings from the survival analysis, a survey was created and sent out to DOTs all over the United States. The results of the survey found that the most important parameters that control concrete bridge deck performance are thought to be use of deicers, construction practices, and design details. In addition, the survey also found that although some DOTs collect additional information for inspections, agencies would like to have more information from GPR and IR and on chloride penetration and crack profiles. 


\subsection{Recommendations}

The second objective of this study was to develop a list of additional data that can be collected by ODOT to improve future concrete bridge deck performance monitoring. To create this list, the results of the survival analysis and survey were reviewed to determine which variables influence concrete bridge deck performance the most.

Although the variables included in the NBI dataset are already collected by ODOT, the research team believes it is important to identify and include the most important of these variables for completeness. The results of the survival analysis for the NBI dataset show that most influential variables are type of wearing surface (NBI item 108A), kind of material and/or design (NBI item 43A), climate zone, ADTT, and design period.

The variables included in the refined dataset were collected from bridge deck drawings gathered from ODOT's BDS. Because the data collection process of these variables was very time consuming the research team believes it would be beneficial to record the variables identified in the refined dataset for every bridge. Of all the variables that are unique to the refined dataset, the most influential variable is concrete cover. Despite not showing significance in the survival analysis, the other unique variables (rebar type, deck slenderness, rebar spacing) show trends of influencing concrete bridge deck performance and should be included.

In addition to the selected variables from the NBI dataset and the refined dataset, the concrete bridge deck performance survey identified variables that agencies believe should 
be collected. The most prominent variables identified in the survey are deicer quantity, chloride concentration, crack area, and delamination area. In addition to these variables, some agencies reported collecting information on the in situ concrete cover and deck thickness of newly constructed bridge decks. Since the variables included in the refined dataset are only specified quantities, having the actual quantities after construction would be extremely valuable in improving concrete bridge deck performance monitoring. A complete list of recommended variables can be seen in Table 7-1. 
Table 7-1: Recommended Factors to Be Collected by ODOT

\begin{tabular}{|c|c|}
\hline VARIABLE & DESCRIPTION \\
\hline $\begin{array}{l}\text { Type of Wearing Surface (NBI item } \\
\text { 108A) }\end{array}$ & $\begin{array}{l}\text { The type of wearing surface placed over } \\
\text { the bridge deck. None, monolithic } \\
\text { concrete, integral concrete, latex } \\
\text { concrete, epoxy overlay, bituminous, } \\
\text { gravel, other. }\end{array}$ \\
\hline $\begin{array}{l}\text { Kind of Material and/or Design (NBI } \\
\text { item 43A) }\end{array}$ & $\begin{array}{l}\text { The type of material the bridge is made } \\
\text { of. Other, concrete, concrete continuous, } \\
\text { steel, steel continuous, prestressed } \\
\text { concrete, prestressed concrete } \\
\text { continuous, timber. }\end{array}$ \\
\hline Climate Zone & $\begin{array}{l}\text { The climate zone in which the bridge } \\
\text { deck exists (see section } 0 \text { ). }\end{array}$ \\
\hline ADTT & $\begin{array}{l}\text { The average daily truck traffic the } \\
\text { bridge deck experiences. }\end{array}$ \\
\hline Design Period & $\begin{array}{l}\text { The design period in which the bridge } \\
\text { deck was built. Either before } 1950, \\
1950-1970, \text { or after } 1970 .\end{array}$ \\
\hline Concrete Cover & $\begin{array}{l}\text { The specified and/or in situ rebar } \\
\text { concrete cover for the bridge deck. }\end{array}$ \\
\hline Rebar Type & $\begin{array}{l}\text { The specified and/or in situ rebar type } \\
\text { for the bridge deck. Black or epoxy } \\
\text { coated. }\end{array}$ \\
\hline Deck Slenderness & $\begin{array}{l}\text { The slenderness of the deck determined } \\
\text { by dividing the specified in situ and/or } \\
\text { deck thickness by the smaller of the } \\
\text { space between beams or the space } \\
\text { between bents. }\end{array}$ \\
\hline Transverse Rebar Spacing & $\begin{array}{l}\text { The specified and/or in situ transverse } \\
\text { rebar spacing for the bridge deck. }\end{array}$ \\
\hline Deicer Quantity & $\begin{array}{l}\text { The quantity of deicers applied on the } \\
\text { bridge deck. }\end{array}$ \\
\hline Chloride Concentration & $\begin{array}{l}\text { The concentration of chlorides within } \\
\text { the bridge deck. }\end{array}$ \\
\hline Crack Area & $\begin{array}{l}\text { The area of cracks present in the bridge } \\
\text { deck. }\end{array}$ \\
\hline Delamination Area & $\begin{array}{l}\text { The area of delamination's present in } \\
\text { the bridge deck. }\end{array}$ \\
\hline
\end{tabular}




\section{REFERENCES}

AASHTO. (2011). Manual for Bridge Evaluation. Washington, DC : American Association of State Highway and Transportation Officials .

AASHTO. (2018). Retrieved from AASHTOWare Bridge Management : http://aashtowarebridge.com/

Achal, V., Mukherjee, A., \& Reddy, M. S. (2011). Effect of Calcifying Bacteria on Permeation Properties of Concrete Structures . Journal of Industrial Microbiology and Biotechnology, 1229-1234.

Agrawal, A. K., Kawaguchi, A., \& Chen, Z. (2008). Bridge Element Deterioration Rates. Albany, New York: NYS Department of Transporatation.

Anderson, D., \& DiBrito, B. (2012). Self Curing Admixture Performance Report . Salem, OR : Oregon Department of Transportation .

Angst, U., Elsener, B., Larsen, C. K., \& Vennesland, Ø. (2009). Critical Chloride Content in Reinforced Concrete - A Review. Cement and Concrete Research , 1122-1138.

ASCE. (2017). 2017 Infrastructure Report Card. American Society of Civil Engineers (ASCE). Retrieved from https://www.infrastructurereportcard.org/

Azizinamini, A., Power, E. H., Myers, G. F., \& Ozyildirim, H. C. (2014). SHRP2 Renewal Project R19A: Design Guide for Bridges for Service Life . Washington, D.C.: Transportation Research Board .

Beuth Verlag. (1999). DIN 1076 Ingenieurbauwerke im Zuge von Straßen und Wegen; Überwachung und Prüfung. Berlin, Germany: Beuth Verlag.

Blower, A. (2019, May 30). Personal Communication .

BMVBS. (2004). ASB Anweisung Straßeninformationsbank, Teilsystem Bauwerksdaten. 150 
Chase, S., Adu-Gyamfi, Y., Aktan, A., \& Minaie, E. (2016). Synthesis of National and International Methodologies Used for Bridge Health Indices. McLean, VA: FHWA.

Clifton, J. R., Naus, J., D., Amey, S. L., Archibald, J. P., Buenfeld, N. R., . . Weyers, R. E. (2000). Service-Life Prediction: State-of-the-Art Report. Farmington Hills, MI: American Concrete Institute (ACI).

Covino Jr., B. S., Cramer, S. D., Bullard, S. J., Holcomb, G. R., Russell, J. H., Collins, W. K., . . Cryer, C. B. (2002). Performance of Zinc Anodes for Cathodic Protection of Reinforced Concrete Bridges . Salem, OR : Oregon Department of Transportation .

DIN. (2011). DIN 1076 Highway Structure - Testing and Inspection . German Institute for Standardization .

Dong, B., Fang, G., Wang, Y., Liu, Y., Hong, S., Zhang, J., . . Xing, F. (2017). Performance Recovery Concerning the Permeability of Concrete by Means of a Microcapsule Self-healing System. Cement and Concrete Composites , 84-96.

Eamon, C. D., Jensen, E. A., Grace, N. F., \& Shi, X. (2012). Life-cycle Cost Analysis of Alternative Reinforcement Materials for Bridge Superstructures Considering Cost and Maintenance Uncertainties. Journal of Materials in Civil Engineering, 373380.

Ehlen, M. A., Bentz, E. C., \& Thomas, M. D. (2008 ). Life-365 Service Life Prediction Model and Computer Program for Predicting the Service Life and Life-Cycle Costs of Reinforced Concrete Exposed to Chlorides . Life-365 Consortium 2 . 
Everett, T. D., Wekamp, P., Capers, H. A., Cox, W. R., Drda, T. S., Hummel, L., . . Washer, G. A. (2008). Bridge Evaluation Quality Assurance in Europe . Washington, D.C. : Federal Highway Administration, U.S. Department of Transportation .

FHWA. (1995). Recording and Coding Guide for the Structure Inventory and Appraisal of the Nation's Bridges. Report No. FHWA-PD-96-001. Washington, DC: Federal Highway Administration .

FHWA. (2005). Transportation Asset Managment Case Studies: Bridge Management Experiences of California, Florida, and South Dakota. Washington, DC: U.S. Department of Transportation Federal Highway Administration.

FHWA. (2011). Bridge Preservation Guide: Maintaining a State of Good Repair Using Cost Effective Investment Strategies. Federal Highway Administration (FHWA). FHWA. (2012). Bridge Inspectors Referance Manual . Washington, DC: Federal Highway Administration .

FHWA. (2012). Transportation Asset Management Case Studies: Bridge Management Practices in Idaho, Michigan, and Virginia . Washington, DC : U.S. Department of Transportation Federal Highway Administration .

FHWA. (2018, July 26). National Bridge Inventory (NBI). Retrieved from Bridges \& Structures : https://www.fhwa.dot.gov/bridge/nbi.cfm

Fleischhacker, A., Ghonima, O., \& Schumacher, T. ((In review)). Bayesian Survival Analysis for US Concrete Highway Bridge Decks. Submitted to the ASCE Journal of Infrastructure Systems. 
Ghonima, O., Schumacher, T., \& Unnikrishnan, A. (In review). A Nationwide Enhanced National Bridge Inventory Database to Study Concrete Highway Bridge Deck Performance. Submitted to the Journal of Risk and Uncertainty in Engineering Systems, Part A: Civil Engineering.

Ghonima, O., Schumacher, T., Unnikrishnan, A., \& Fleischhacker, A. (2018). Advancing Bridge Technology, Task 10: Statistical Analysis and Modeling of US Concrete Highway Brdige Deck Performance. McLean, VA: FHWA.

Gucunski, N., Imani, A., Romero, F., Nazarian, S., Yuan, D., Wiggenhauser, H., . . Kutrubes, D. (2013). SHRP2 Report S2-R06A-RR-1: Nondestructive Testing to Identify Concrete Bridge Deck Deterioration. Washington, D.C.: Transporation Research Board (TRB).

Guthrie, W. S., \& Tuttle, R. S. (2006). Condition Analyses of Concrete Bridge Decks in Utah . Taylorsville, UT: Utah Department of Transportation Research and Development Division .

Guthrie, W. S., Waters, T., \& Reese, G. B. (2015). Comparison of Moisture Content and Electrical Conductivity of Lightweight and Normal-Weight Concrete Bridge Decks: Instrumentation and Monitoring. 16th International Conference on Cold Regions Engineering . Salt Lake City, UT : American Society of Civil Engineers . Haardt, P., \& Holst, R. (2008). The German Approach to Bridge Management: Current Status and Future Development . Transportation Research Circular: International Bridge and Structure Managment (pp. 3-15). Buffalo, NY: Transportation Research Board . 
Hatami, A., \& Morcous, G. (2011). Developing Deterioration Models for Nebraska Bridges . Lincoln, NE: Nebraska Department of Roads .

Houska, C. (2007). Deicing Salt-Recognizing the Corrosion Threat. International Molybdenum Association, 1-10.

Huston, C., \& Juarez-Colunga, E. (2009 ). Guidelines for Computing Summary Statistics for Data-sets Containing Non-detects . Bulkley Valley Research Center .

Ideker, J. H., \& Banuelos, J. (2014). The Use of Synthetic Blended Fibers to Reduce Cracking Risk In High Performance Concrete. Salem, OR: Oregon Department of Transportation (ODOT).

Ideker, J. H., Deboodt, T., \& Fu, T. (2013). Internal Curing of High-Performance Concrete for Bridge Decks . Salem, OR: Oregon Department of Transportation . Isgor, O. B., Ideker, J. H., Trejo, D., Jafari-Azad, V., Rodriguez, D. A., Shields, S., \& Husseini, P. (2017). Strategies to Increase the Service Life of Concrete Bridge Decks. Salem, OR: Oregon Department of Transportation (ODOT).

ITD. (2016). Idaho Manual for Bridge Evaluation . Boise, ID: Idaho Transportation Department .

Kassir, M. K., \& Ghosn, M. (2001). Chloride-induced Corrosion of Reinforced Concrete Bridge Decks. Cement and Concrete Research, 139-143.

Kepler, J. L., Darwin, D., \& Locke Jr., C. E. (2000). Evaluation of Corrosion Protection Methods for Reinforced Concrete Highway Structures. Lawrence, Kansas: University of Kansas Center for Research, Inc. 
Kim, Y. J., \& Yoon, D. K. (2010). Identifying Critical Sources of Bridge Deterioration in Cold Regions Through the Constructed Bridges in North Dakota. Journal of Bridge Engineering, 542-552.

Kirkpatrick, T. J., Weyers, R. E., Anderson-Cook, C. M., \& Sprinkel, M. M. (2002). Probabilistic Model for the Chloride-induced Corrosion Service Life of Bridge Decks. Cement and Concrete Research, 1943-1960.

Koch, G. H., Brongers, M., Thompson, N. G., Virmani, Y. P., \& Payer, J. H. (2003). Corrosion Cost and Preventive Strategies in the United States. Washington, D.C.: Transportation Research Board (TRB).

Leung, K.-M., Elashoff, R. M., \& Afifi, A. A. (1997). Censoring Issues in Survival Analysis . Annual Review Public Health, 83-104.

Li, V. C., \& Zhang, J. (2001). Approaches to Enhancing Concrete Bridge Deck Durability. Long Term Durability of Structural Materials, 11-22.

Lin, Z., Zhao, J., \& Tabatabai, H. (2012). Impact of Overweight Vehicles (with Heavy Axle Loads) on Bridge Deck Deterioration. Washington, D.C.: Research and Innovative Technology Administration.

Liu, D., Zhao, W., Liu, S., Cen, Q., \& Xue, Q. (2016). Comparative Tribological and Corrosion Resistance Properties of Epoxy Composite Coatings Reinforced with Functionalized Fullerene C60 and Graphene . Surface and Caotings Technology, 354-364.

Marchand, J. (2001). Modeling the Behavior of Unsaturated Cement Systems Exposed to Aggressive Chemical Environments . Materials and Structures , 195-200. 
Mauch, M., \& Madanat, S. (2001 ). Semiparametric Hazard Rate Models of Reinforced Concrete Bridge Deck Deterioration . Journal of Infrastructure Systems , 49-57. McConnell, J. R., Shenton, H. W., \& Mertz, D. R. (2016). Performance of Uncoated Weathering Steel Bridge Inventories: Methodology and Gulf Coast Region Evaluation. Journal of Bridge Engineering, 1-16.

Mitchell, D., \& Frohnsdorff, G. (2004). Service-Modeling and Design of Concrete Structures for Durability. Concrete International , 57-63.

Moomen, M., Qiao, Y., Agbelie, B. R., Labi, S., \& Sinha, K. C. (2016 ). Bridge Deterioration Models to Support Indians's Bridge Managment System . West Lafayette, IN : Indiana Department of Transporation .

Morcous, G., Lounis, Z., \& Mirza, M. S. (2003). Identification of Enviromental Categories for Markovian Deterioration Models of Bridge Decks. Journal of Bridge Engineering, 353-361.

Morris, W., Vico, A., \& Vazquez, M. (2004). Chloride Induced Corrosion of Reinforcing Steel Evaluated by Concrete Resistivity Measurments . Electrochimica Acta, 4447-4453.

Norwegian Public Roads Administration . (2014, July 25). Bridges . Retrieved from Statens vegvesen: https://www.vegvesen.no/en/roads/Roads+and+bridges/Bridges Norwegian Public Roads Administration. (1997). Handbook R211 - Field Surveys. Norwegian Public Roads Administration. (1997). Handbook R411 - Bridge Managment. Norwegian Public Roads Administration. (2000). Handbook V441 - Inspection Manual for Bridges. 
Norwegian Public Roads Administration. (2012). Handbook R610 - Standard for Operation and Maintenance of National Roads.

Norwegian Public Roads Administration. (2017). Handbook N401 - Bridge Managment for County Roads.

ODOT. (2017). 2017 Bridge Condition Report and Tunnel Data. Salem, OR : Oregon Department of Transportation .

PCA. (2002). Types and Cause of Concrete Deterioration. Skokie, IL: Portland Cement Association.

PCA. (2017 ). Corrosion of Embedded Metals . Retrieved from Portland Cement Association : http://www.cement.org/learn/concretetechnology/durability/corrosion-of-embedded-materials

Phares, B. M., Fanous, F. S., Wipf, T. J., Lee, Y.-S., \& Jolley, M. J. (2006). Evaluation of Corrosion Resistance of Different Steel Reinforcement Types . Center for Transportation Research and Education (CTRE).

Rich, J. T., Neely, J. G., Paniello, R. C., Voelker, C. C., Nussenbaum, B., \& Wang, E. W. (2010). A Practical guide to understanding Kaplan-Meier Curves . Offical Journal of American Academy of Otolaryngol-Head Neck Surgery, 331-336.

Ruck, G., \& Francis, K. (2017). Bridge Model Validation at Indiana Department of Transportation . Transporation Research Circular: Eleventh International Bridge and Structures Management Conference (pp. 21-29). Mesa, AZ : Transportation Research Board (TRB). 
Russell, H. G., Capers, H., Darwin, D., Hanna, A. N., Kaslan, E., Lenzini, J., . . Lwin, M. (2004). NCHRP Synthesis 333: Concrete Bridge Deck Performance. Washington, D.C.: Transportation Research Board (TRB).

Shepard, R. W., \& Johnson, M. B. (2001). California Bridge Health Index: A Diagnostic tool to Maximize Bridge Longevity, Investment . TR News , 6-11.

Shi, X., Akin, M., Pan, T., Fay, L., Liu, Y., \& Yang, Z. (2009). Deicer Impacts on Pavement Materials: Introduction and Recent Developments . The Open Civil Engineering Journal , 16-27.

Shi, X., Cross, J. D., Liu, Y., Fortune, K., \& Ewan, L. (2011). Replacing Thermal Sprayed Zinc Anodes on Cathodically Protected Steel Reinforced Concrete Bridges . Salem, OR : Oregon Department of Transporation .

Shi, X., Xie, N., Fortune, K., \& Gong, J. (2012 ). Durability of Steel Reinforced Concrete in Chloride Environments: An Overview . Construction and Building Materials, $125-138$.

Shi, X., Ye, Z., Muthumani, A., Zhang, Y., Dante, J. F., \& Yu, H. (2015). A Corrosion Monitoring System for Existing Reinforced Concrete Structures. Salem, OR: Oregon Department of Transporation (ODOT).

Song, H.-W., \& Saraswathy, V. (2006). Corrosion Monitoring of Reinforced Concrete Structures. International Journal of Electrochemical Science, 1-28.

Stewart, M. G., \& Rosowsky, D. V. (1998). Structural Safety and Serviceability of Concrete Bridges Subject to Corrosion. Journal of Infrastructure Systems, 146155. 
Stewart, M. G., \& Rosowsky, D. V. (1998). Time-dependent Reliability of Deteriorating Reinforced Concrete Bridge Decks. Structural Safety, 91-109.

Sullivan, L. (2016, June 3 ). Survival Analysis . Retrieved from Boston University School of Public Health Website : http://sphweb.bumc.bu.edu/ottt/MPHModules/BS/BS704_Survival/BS704_Survival_print.html

Taylor, G. H., \& Hannan, C. (1999). The Climate of Oregon: from Rain Forest to Desert . Corvallis, OR : Oregon State University Press .

Thomas, M. (1996). Chloride Thresholds in Marine Concrete . Cement and Concrete Research , 513-519.

TRB. (2001). Evaluating Bridge Health: California's Diagnostic Tool. TR News, 6-11.

Vu, K. A., \& Stewart, M. G. (2000). Structural Reliability of Concrete Bridges Including Improved Chloride-induced Corrosion Models. Structural Safety, 313-333.

Williamson, G., Weyers, R. E., Brown, M. C., \& Sprinkel, M. M. (2007). Bridge Deck Service Life Prediction and Costs. Richmond, Virginia: Virginia Department of Transportation.

WSDOT. (2018 ). Washington State Bridge Inspection Manual . Olympia, WA: Washington State Department of Transportation .

WSDOT. (2018). BridgeWorks.NET - Bridge Inspection and Reporting Software. Retrieved from Washington State Department of Transportation : https://www.wsdot.wa.gov/LocalPrograms/Bridge/BridgeWorks.htm

Yu, L., Francois, R., Dang, V. H., L'Hostis, V., \& Gagne, R. (2015). Development of Chloride-induced Corrosion in Pre-cracked RC Beams Under Sustained Loading: 
Effect of Load-induced Cracks, Concrete Cover, and Exposure Conditions.

Cement and Concrete Research , 246-258. 
APPENDIX A: SURVEY RESPONSES 


\section{A.1 Survey Response from BDI}

1) In your experience, what are the three most important parameters controlling concrete bridge deck performance (e.g. specific design details, construction practice, environmental conditions, use of deicers, etc.)? Please order according to importance (most important to least important).

- Icing salts (deicers)

- Environmental (freeze/thaw)

- Loading / ADTT

2) What data does your agency currently collect in addition to the minimum requirements to satisfy concrete bridge deck inspections?

BDI is not an agency, but we typically see states only collecting visual data. The few states that are collecting NDE data are collecting GPR, IR, HRV, and SounDAR.

3) If you could, what three additional information/measurements/tests would you collect/perform as part of every concrete bridge deck inspection in order to improve future asset management practice?

•NDE Measurements - GPR/IR/HRV/SounDAR

-Chloride sampling

-Cores

4) Do you have any additional recommendations or thoughts? 
In general, from our experience, agencies have a misconception that the deployment of NDE is more expensive than typical NBIS visual bridge deck inspection. While this may be true for smaller bridges where traffic control is minimal, the implementation of mobile NDE techniques such as high speed GPR, IR, and HRV and methods such as SounDAR that require a mobile closure provides a much quicker data collection process with less traffic control cost. For larger structures, this process ends up being of similar or smaller cost than traditional sounding or chloride extraction procedures and provides a quantitative set of data for the deck.

5) What is your area of responsibility in your agency (e.g. design, maintenance, programming, etc.)?

N/A

6) What is your job title?

Vice President of NDE 


\section{A.2 Survey Response from E2CHEM}

1) In your experience, what are the three most important parameters controlling concrete bridge deck performance (e.g. specific design details, construction practice, environmental conditions, use of deicers, etc.)? Please order according to importance (most important to least important).

- Design Details

- Environmental Conditions

- Repair options chosen overtime for maintenance

2) What data does your agency currently collect in addition to the minimum requirements to satisfy concrete bridge deck inspections?

Currently we collect: Concrete Cover, Half-Cell Potential and Corrosion Activity and Moisture Mapping. We extract concrete cores for Petrographic Analysis, Chloride profiles and for Chloride Permeability [ASTM 1202] Testing.

3) If you could, what three additional information/measurements/tests would you collect/perform as part of every concrete bridge deck inspection in order to improve future asset management practice?

-Inspect the underside of the concrete deck and structure [Often we only look at the deck] -Long term monitoring including environmental, corrosion, etc to see seasonal changes

-Ask a concrete material specialist what material to use for repair

4) Do you have any additional recommendations or thoughts? 
Looking at the underside: We recently found very important to look at the underside of a concrete deck as the deck had been coating for so many years. Clearly all trapped chlorides are moving to the other end of the deck.

As material specialist, we feel that if we could be asked to assess the condition of a bridge prior to when they start doing repair it would be very beneficial. Bad repair choices can accelerate the deterioration of the deck.

Transportation Authority are often unaware of good practice - More awareness could improve the condition of bridges in USA: DOT'S around the country should be more aware of the problems with the use of EPOXY coating rebar [very very bad], possibly start applying asphalt on top of the concrete deck etc.

5) What is your area of responsibility in your agency (e.g. design, maintenance, programming, etc.)?

Field Operations

6) What is your job title?

Operation Manager 


\section{A.3Survey Response from AIDPE}

1) In your experience, what are the three most important parameters controlling concrete bridge deck performance (e.g. specific design details, construction practice, environmental conditions, use of deicers, etc.)? Please order according to importance (most important to least important).

- Construction Practices

- Traffic Load

- Environmental Conditions, specifically on the Northeast, freeze-thaw cycles, use of deicers

2) What data does your agency currently collect in addition to the minimum requirements to satisfy concrete bridge deck inspections?

Typically, we always conduct deck deterioration evaluation using nondestructive testing (NDT), such as Ground Penetrating Radar (GPR) as per ASTM D6087, Half-cell potential, or chain drag/hammer sounding. To complement that, cores are retrieved for measure compressive strength, chloride content or petrographic analysis. Visual distress surveys are sometimes carried out as well.

3) If you could, what three additional information/measurements/tests would you collect/perform as part of every concrete bridge deck inspection in order to improve future asset management practice?

- Collect surface distresses using laser images and automated crack detection programs -Improve infrared cameras/analysis methods to measure delamination 
$\cdot \mathrm{NA}$

4) Do you have any additional recommendations or thoughts?

Rapid NDT methods (GPR, Infrared, laser cameras, other) that do not require lane closure should be included in DOT's specifications as current screening practices for deck evaluation. This initial screening should be used to determine more in depth test methods for detailed deck evaluation (coring, chain drag, others).

5) What is your area of responsibility in your agency (e.g. design, maintenance, programming, etc.)?

Supervise the NDT department

6) What is your job title?

NDT/NDE practice lead 


\section{A.4Survey Response from Idaho DOT}

1) In your experience, what are the three most important parameters controlling concrete bridge deck performance (e.g. specific design details, construction practice, environmental conditions, use of deicers, etc.)? Please order according to importance (most important to least important).

- State's salt policies

- Preservation policies such as epoxy overlays and sealers

- Maintenance actions such as sweeping or washing decks

2) What data does your agency currently collect in addition to the minimum requirements to satisfy concrete bridge deck inspections?

At times we will perform chain drag (sounding) evaluations, GPR, Thermal Imaging, coring, or other testing/evaluation methods.

3) If you could, what three additional information/measurements/tests would you collect/perform as part of every concrete bridge deck inspection in order to improve future asset management practice?

- Soundings for delamination's

- GPR

- Thermal Imaging

4) Do you have any additional recommendations or thoughts? 
Sometimes managing the assets and collecting data is not an area that needs

improvement. Obtaining resources to properly maintain the asset such as maintenance funding and preservation funding might be helpful.

5) What is your area of responsibility in your agency (e.g. design, maintenance, programming, etc.)?

Bridge Operations/Program Manager

6) What is your job title?

Bridge Asset Management Engineer 


\section{A.5Survey Response from Kentucky DOT}

1) In your experience, what are the three most important parameters controlling concrete bridge deck performance (e.g. specific design details, construction practice, environmental conditions, use of deicers, etc.)? Please order according to importance (most important to least important).

- Use of Deicers

- Construction practices (inadequate rebar cover, contractor deficiencies, phase const.) - Environmental Conditions

2) What data does your agency currently collect in addition to the minimum requirements to satisfy concrete bridge deck inspections?

Construction collects rebar cover depth and concrete strength with new construction. Bridge inspectors collect NBI data and bridge element level data as well as photographs and soundings during visual inspections. GPR data is also sometimes collected to assist with potential overlay projects.

3) If you could, what three additional information/measurements/tests would you collect/perform as part of every concrete bridge deck inspection in order to improve future asset management practice?

- Non Destructive Testing (GPR, IR, Soundings)

- Chloride Tests (Cores)

- Removal of an SIP form to assess deck underside condition 
4) Do you have any additional recommendations or thoughts?

In regards to asset management, element level deterioration rates are needed for deterioration modeling which most states do not have.

5) What is your area of responsibility in your agency (e.g. design, maintenance, programming, etc.)?

Bridge Maintenance

6) What is your job title?

Transportation Engineering Branch Manager for Bridge Preservation 


\section{A.6Survey Response from Missouri DOT}

1) In your experience, what are the three most important parameters controlling concrete bridge deck performance (e.g. specific design details, construction practice, environmental conditions, use of deicers, etc.)? Please order according to importance (most important to least important).

- Use of deicing compounds

- Type superstructure (does it result in reflective cracking of deck)

- Construction Practice

2) What data does your agency currently collect in addition to the minimum requirements to satisfy concrete bridge deck inspections?

Deck saturation

3) If you could, what three additional information/measurements/tests would you collect/perform as part of every concrete bridge deck inspection in order to improve future asset management practice?

- Chloride Penetration Test

- IR survey to determine delamination not found during routine inspections

- Coring cracks to determine effectiveness of crack sealers

4) Do you have any additional recommendations or thoughts?

None 
5) What is your area of responsibility in your agency (e.g. design, maintenance, programming, etc.)?

Bridge Inspection

6) What is your job title?

Supervising Bridge Inspection Engineer 


\section{A.7Survey Response from New Hampshire DOT}

1) In your experience, what are the three most important parameters controlling concrete bridge deck performance (e.g. specific design details, construction practice, environmental conditions, use of deicers, etc.)? Please order according to importance (most important to least important).

- Design Details

- Construction Practices

- Deicers

2) What data does your agency currently collect in addition to the minimum requirements to satisfy concrete bridge deck inspections?

None

3) If you could, what three additional information/measurements/tests would you collect/perform as part of every concrete bridge deck inspection in order to improve future asset management practice?

- Condition of membrane

- If water is between membrane and deck

- Chloride in concrete deck

4) Do you have any additional recommendations or thoughts?

None 
5) What is your area of responsibility in your agency (e.g. design, maintenance,

programming, etc.)?

Design

6) What is your job title?

Bridge Design Administrator 


\section{A.8Survey Response from Iowa DOT}

1) In your experience, what are the three most important parameters controlling concrete bridge deck performance (e.g. specific design details, construction practice, environmental conditions, use of deicers, etc.)? Please order according to importance (most important to least important).

- Deicers

- Truck traffic volume

- Concrete type and quality at time of placement

2) What data does your agency currently collect in addition to the minimum requirements to satisfy concrete bridge deck inspections?

Sketches of cracks greater than or equal to 1/16". Sketches of hollow areas found during deck sounding. Sketches of spalled areas. Yes/No determination of delaminated areas on the bottom of the deck over traffic.

3) If you could, what three additional information/measurements/tests would you collect/perform as part of every concrete bridge deck inspection in order to improve future asset management practice?

- Chloride concentration levels at top mat of rebar.

- Delamination Depth

- crack depth

4) Do you have any additional recommendations or thoughts? 
Overlapping Element defects are difficult to document and prevents proper deterioration modeling.

5) What is your area of responsibility in your agency (e.g. design, maintenance, programming, etc.)?

Bridge Maintenance and Inspection

6) What is your job title?

Bridge Maintenance and Inspection Engineer 


\section{A.9Survey Response from Mississippi DOT}

1) In your experience, what are the three most important parameters controlling concrete bridge deck performance (e.g. specific design details, construction practice, environmental conditions, use of deicers, etc.)? Please order according to importance (most important to least important).

- Construction Quality

- Use of salts

- Design Details

2) What data does your agency currently collect in addition to the minimum requirements to satisfy concrete bridge deck inspections?

None

3) If you could, what three additional information/measurements/tests would you collect/perform as part of every concrete bridge deck inspection in order to improve future asset management practice?

- NA

- NA

- NA

4) Do you have any additional recommendations or thoughts?

In Mississippi, a good quality cured deck with the reinforcing placed at the correct location and a reduction in the misuse of salt will allow a deck to last near $100 \mathrm{yrs}$. We 178 
gather chloride content and do IR and thermal scanning when a deck become severely deteriorated.

5) What is your area of responsibility in your agency (e.g. design, maintenance, programming, etc.)?

Design, maintenance, construction, and programming

6) What is your job title?

State Bridge Engineer 


\section{A.10 Survey Response from Tennessee DOT}

1) In your experience, what are the three most important parameters controlling concrete bridge deck performance (e.g. specific design details, construction practice, environmental conditions, use of deicers, etc.)? Please order according to importance (most important to least important).

- Initial corrosion protection (epoxy coated rebar \& adequate concrete cover)

- Preventive maintenance (thin epoxy deck seal)

- Jointless design philosophy

2) What data does your agency currently collect in addition to the minimum requirements to satisfy concrete bridge deck inspections?

We currently will chain drag all of our bare deck bridges as part of our routine biannual inspections. If we are looking to complete a repair or preservation project, we will take samples of the deck concrete and investigate to chloride content of the material.

3) If you could, what three additional information/measurements/tests would you collect/perform as part of every concrete bridge deck inspection in order to improve future asset management practice?

- NA

$\cdot \mathrm{NA}$

- NA

4) Do you have any additional recommendations or thoughts? 
TDOT currently uses design details (epoxy steel $\&$ added cover) to enhance the performance of our bridge decks. We also add deck seals (thin epoxy or sheet or spray applied with an asphalt overlay) to extend the performance of our good rated decks.

5) What is your area of responsibility in your agency (e.g. design, maintenance, programming, etc.)?

Design, preservation, and maintenance

6) What is your job title?

Civil Engineering Director - Structures 


\section{A.11 Survey Response from Vermont DOT}

1) In your experience, what are the three most important parameters controlling concrete bridge deck performance (e.g. specific design details, construction practice, environmental conditions, use of deicers, etc.)? Please order according to importance (most important to least important).

-Vermont's extensive use of deicers. Surface distress leads to porosity issues.

- Lack of a deck protection measure (i.e., fabric or epoxy membrane or other).

- Concrete cracking, material quality, ASR, expansion joints, drainage issues, etc.

2) What data does your agency currently collect in addition to the minimum requirements to satisfy concrete bridge deck inspections?

Typical NBIS data inspections, element level inspections to track deterioration. Also, implementing/developing tracking system using deterioration models to determine performance based measures; though only a recent inception.

Aside from typical field testing like sounding or coring, half-cell, chloride concentration, etc. is done on a case by case basis

3) If you could, what three additional information/measurements/tests would you collect/perform as part of every concrete bridge deck inspection in order to improve future asset management practice?

- A simplified test to accurately gauge chloride contamination.

- A simplified test to determine ASR activity. 
- NA

4) Do you have any additional recommendations or thoughts?

Unfortunately, most if not all testing requires substantial prep work, restriction of traffic, and time to perform and analyze data results. Certain NDT techniques can be beneficial as a scoping for repair work, quality control practice or possibly some benefit of potential deterioration modeling. However, determining deterioration of or within a bridge deck after the fact; especially over years of service, has no preventative application, as the damage is already done. Innovative materials/design, initial protection measures and preventive maintenance, are paramount.

5) What is your area of responsibility in your agency (e.g. design, maintenance, programming, etc.)?

Asset Manager

6) What is your job title?

Lead Bridge Inspector 


\section{A.12 Survey Response from Florida DOT}

1) In your experience, what are the three most important parameters controlling concrete bridge deck performance (e.g. specific design details, construction practice, environmental conditions, use of deicers, etc.)? Please order according to importance (most important to least important).

- Quality of Construction

- Environmental Conditions

- Level of Traffic

2) What data does your agency currently collect in addition to the minimum requirements to satisfy concrete bridge deck inspections?

We do element inspections including the coding of the predominant defect.

3) If you could, what three additional information/measurements/tests would you collect/perform as part of every concrete bridge deck inspection in order to improve future asset management practice?

- NA

- NA

- NA

4) Do you have any additional recommendations or thoughts?

None 
5) What is your area of responsibility in your agency (e.g. design, maintenance, programming, etc.)?

Bridge Inspection and Maintenance

6) What is your job title?

Bridge Management Inspection Engineer 


\section{A.13 Survey Response from Texas DOT}

1) In your experience, what are the three most important parameters controlling concrete bridge deck performance (e.g. specific design details, construction practice, environmental conditions, use of deicers, etc.)? Please order according to importance (most important to least important).

- Proper construction including curing (mix design, surface prep, placement, curing)

- Environmental conditions and heavy use of de-icing chemicals significantly reduce the service life of a bridge deck.

- Bridge deck thickness. Thin bridge decks have become more problematic with age compared to thicker bridge decks

2) What data does your agency currently collect in addition to the minimum requirements to satisfy concrete bridge deck inspections?

TxDOT does not regularly collect additional information beyond the minimum requirements for a safety inspection of in-service bridge decks. In highly congested areas and on bridges with high traffic volumes, deck inspections may be very limited as TxDOT does not regularly set up traffic control with lane closures for routine inspections.

3) If you could, what three additional information/measurements/tests would you collect/perform as part of every concrete bridge deck inspection in order to improve future asset management practice?

- Deck delamination survey

- Laser crack measurements 
- Concrete chloride profiles

4) Do you have any additional recommendations or thoughts?

Responses to question 3 are not necessary for safety inspection of bridges. Visual inspection of a bridge deck is sufficient for a safety inspection of a bridge.

To start tracking the progression of deterioration, the additional tests in question 3 would help develop trends and could eventually lead to an assessment method to determine remaining useful life.

5) What is your area of responsibility in your agency (e.g. design, maintenance, programming, etc.)?

Bridge inspection and construction support

6) What is your job title?

Field Operations Section Director 


\section{A.14 Survey Response from Maine DOT}

1) In your experience, what are the three most important parameters controlling concrete bridge deck performance (e.g. specific design details, construction practice, environmental conditions, use of deicers, etc.)? Please order according to importance (most important to least important).

- Truck traffic

- Preventive maintenance practices

- Construction practice

2) What data does your agency currently collect in addition to the minimum requirements to satisfy concrete bridge deck inspections?

Perform a chain drag to verify and quantify delamination's.

3) If you could, what three additional information/measurements/tests would you collect/perform as part of every concrete bridge deck inspection in order to improve future asset management practice?

- List of Maintenance activities since last inspection (including deicer applications)

- Half-cell Potentials

- GPR

4) Do you have any additional recommendations or thoughts?

None 
5) What is your area of responsibility in your agency (e.g. design, maintenance, programming, etc.)?

Asset management

6) What is your job title?

Bridge Management Engineer 


\section{A.15 Survey Response from Arkansas DOT}

1) In your experience, what are the three most important parameters controlling concrete bridge deck performance (e.g. specific design details, construction practice, environmental conditions, use of deicers, etc.)? Please order according to importance (most important to least important).

- Construction practices (placement, curing)

- Design details (flexure/deflection, pouring sequence(s), stage construction) - mix design properties

2) What data does your agency currently collect in addition to the minimum requirements to satisfy concrete bridge deck inspections?

Reinforcing steel clearances, air entrainment, slump, reinforcing steel coverage during placement of concrete, bridge deck thickness during placement of concrete

3) If you could, what three additional information/measurements/tests would you collect/perform as part of every concrete bridge deck inspection in order to improve future asset management practice?

- Field cured cylinders in lieu of lab cylinders for acceptance and greater freq. of sampling

- Emphasis on consistent curing methods for the entire 7 days after placement of concrete

- Use in-place, nondestructive instrumentation for present (and future) monitoring of bridges 
4) Do you have any additional recommendations or thoughts?

We allow contractors to submit requests to modify pouring sequences from those specified in the plans. I believe our Bridge Division is revisiting their stance on allowing pouring sequence modifications for certain bridge designs.

5) What is your area of responsibility in your agency (e.g. design, maintenance, programming, etc.)?

Construction

6) What is your job title?

Staff Construction Engineer 


\section{A.16 Survey Response from Massachusetts DOT}

1) In your experience, what are the three most important parameters controlling concrete bridge deck performance (e.g. specific design details, construction practice, environmental conditions, use of deicers, etc.)? Please order according to importance (most important to least important).

- De-icing Agents

- Truck ADT

- Deck Waterproofing

2) What data does your agency currently collect in addition to the minimum requirements to satisfy concrete bridge deck inspections?

None

3) If you could, what three additional information/measurements/tests would you collect/perform as part of every concrete bridge deck inspection in order to improve future asset management practice?

$\cdot$ NA

-NA

- NA

4) Do you have any additional recommendations or thoughts?

We have used some GPR surveys in advance of bridge rehab projects to assist with project scoping. 
5) What is your area of responsibility in your agency (e.g. design, maintenance, programming, etc.)?

Bridge Inspection Program Manager

6) What is your job title?

State Bridge Inspection Engineer 


\section{A.17 Survey Response from North Carolina}

1) In your experience, what are the three most important parameters controlling concrete bridge deck performance (e.g. specific design details, construction practice, environmental conditions, use of deicers, etc.)? Please order according to importance (most important to least important).

- Built to specifications particularly ensuring clear cover to reinforcement.

- Use of concrete mineral admixtures (i.e. Fly Ash).

- Routine maintenance program for cleaning \& treating.

2) What data does your agency currently collect in addition to the minimum requirements to satisfy concrete bridge deck inspections?

Priority Maintenance List (Description of defects that may require corrective actions found during NBIS inspections)

Deck Evaluations: Chain drag, crack mapping, chloride sampling, and coring.

3) If you could, what three additional information/measurements/tests would you collect/perform as part of every concrete bridge deck inspection in order to improve future asset management practice?

- Chloride Content

- Cycle for IR, Acoustic Scanning, \& GPR.

- Integrated system to collect all construction, inspection and maintenance documents. 
4) Do you have any additional recommendations or thoughts?

Collection of extra data would likely be too costly for our full inventory.

5) What is your area of responsibility in your agency (e.g. design, maintenance, programming, etc.)?

Policy Development

6) What is your job title?

Policy Development Engineer - Preservation and Rehabilitation 


\section{A.18 Survey Response from Michigan DOT}

1) In your experience, what are the three most important parameters controlling concrete bridge deck performance (e.g. specific design details, construction practice, environmental conditions, use of deicers, etc.)? Please order according to importance (most important to least important).

- Use of deicers

- Environmental Condition - Freeze/Thaw

- Reinforcement Material - (uncoated, epoxy, stainless)

2) What data does your agency currently collect in addition to the minimum requirements to satisfy concrete bridge deck inspections?

MDOT collects the deck deficiencies for the top and bottom surface (Item 58a, 58b).

Agency defined elements (i.e. bridge deck - black bar vs epoxy coated bar).

Michigan Bridge Element Inspection Manual https://www.michigan.gov/documents/mdot/MiBEIM_2017-10-24_Final_606687_7.pdf

3) If you could, what three additional information/measurements/tests would you collect/perform as part of every concrete bridge deck inspection in order to improve future asset management practice?

- Deck Surface Sounding (detect for delamination)

- Deck Bottom Sounding (detect for delamination) 
- Chloride Testing

4) Do you have any additional recommendations or thoughts?

None

5) What is your area of responsibility in your agency (e.g. design, maintenance, programming, etc.)?

Scoping and Inspection

6) What is your job title?

Bridge Scoping Engineer \& Bridge Inspection Program Manager 


\section{A.19 Survey Response from Connecticut}

1) In your experience, what are the three most important parameters controlling concrete bridge deck performance (e.g. specific design details, construction practice, environmental conditions, use of deicers, etc.)? Please order according to importance (most important to least important).

- Use of Deicers

- Type of concrete (high performance-low permeability concrete better)

- Type of reinforcing bars used (i.e. less corroding such as galvanizing better)

2) What data does your agency currently collect in addition to the minimum requirements to satisfy concrete bridge deck inspections?

For specific requests in the past for rehabilitation projects we collected GPR but did not find the results to be conclusive and not always match the condition or location in the field.

To aid Designers, concrete cores, as well as chloride content, may be taken

3) If you could, what three additional information/measurements/tests would you collect/perform as part of every concrete bridge deck inspection in order to improve future asset management practice?

- Chloride content testing

- Half-Cell potential testing

- Thermography 
4) Do you have any additional recommendations or thoughts?

We have very few exposed concrete decks (102 bridges). The majority of our concrete bridge decks have a bituminous concrete overlay. Therefore, the selection of a concrete deck membrane can be critical to minimize chlorides making their way to the bridge deck's reinforcing bars.

5) What is your area of responsibility in your agency (e.g. design, maintenance, programming, etc.)?

Asset Management

6) What is your job title?

Transportation Supervising Engineer 


\section{A.20 Surey Response from Georgia DOT}

1) In your experience, what are the three most important parameters controlling concrete bridge deck performance (e.g. specific design details, construction practice, environmental conditions, use of deicers, etc.)? Please order according to importance (most important to least important).

- Deck thickness, minimum of 7.5"

- Cover to top mat of reinforcement 2.5" minimum

$\cdot$ N/A

2) What data does your agency currently collect in addition to the minimum requirements to satisfy concrete bridge deck inspections?

Minimum requirements of NBIS condition rating and Element Level data are collected. Only additional information are written text by the inspector and supplemental photos.

3) If you could, what three additional information/measurements/tests would you collect/perform as part of every concrete bridge deck inspection in order to improve future asset management practice?

$\cdot$ NA

- NA

$\cdot \mathrm{NA}$

4) Do you have any additional recommendations or thoughts? 
Testing chloride penetration may be useful but not every inspection. Possibly something that could be done every 5 to 10 years.

5) What is your area of responsibility in your agency (e.g. design, maintenance, programming, etc.)?

Design

6) What is your job title?

State Bridge Engineer 


\section{A.21 Survey Response from North Dakota DOT}

1) In your experience, what are the three most important parameters controlling concrete bridge deck performance (e.g. specific design details, construction practice, environmental conditions, use of deicers, etc.)? Please order according to importance (most important to least important).

- Construction Practice-proper curing, saline treatment

- Design Details - use of epoxy, cover requirements

- Use of Deicers, proper crack sealing

2) What data does your agency currently collect in addition to the minimum requirements to satisfy concrete bridge deck inspections?

Chaining data on select bridges

3) If you could, what three additional information/measurements/tests would you collect/perform as part of every concrete bridge deck inspection in order to improve future asset management practice?

- Underside condition

- crack spacing/density and crack width

- Chloride content

4) Do you have any additional recommendations or thoughts?

None 
5) What is your area of responsibility in your agency (e.g. design, maintenance, programming, etc.)?

Bridge Design and Programming

6) What is your job title?

State Bridge Engineer - ND 


\section{A.22 Survey Response from Alaska}

1) In your experience, what are the three most important parameters controlling concrete bridge deck performance (e.g. specific design details, construction practice, environmental conditions, use of deicers, etc.)? Please order according to importance (most important to least important).

- Proper bar placement and concrete cover

- Proper concrete mix design, placement, consolidation, finish and curing

- Wear related issues (e.g., studded tires and chains) and use of deicing chemicals

2) What data does your agency currently collect in addition to the minimum requirements to satisfy concrete bridge deck inspections?

Although decreasing in recent years, Alaska DOT\&PF collect chloride ion information for surface concrete.

On a case-by-case basis, we collect bond strength measurements of delaminated concrete regions.

3) If you could, what three additional information/measurements/tests would you collect/perform as part of every concrete bridge deck inspection in order to improve future asset management practice?

- Real (reliable) concrete cover and as-built data especially in older bridge decks

- Additional sounding data for quantifying delaminated deck area (traffic control)

- Concrete material samples with focus on deterioration parameters 
4) Do you have any additional recommendations or thoughts?

More than half of new bridges built by the Alaska DOT\&PF incorporate precast deck elements (e.g., decked bulb-T girders). These elements have high-quality concrete (low w/c ratio and compressive strength over 10,000 psi) that have performed very well. Perhaps increasing the use of factory-produced, high-performance concrete decks could help extend the service life of bridge decks.

For bridge decks that are to receive asphalt overlays, the use of spray-applied waterproofing membrane may also be a cost-effective feature in regions where traffic control would result in a significant future rehabilitation costs.

5) What is your area of responsibility in your agency (e.g. design, maintenance, programming, etc.)?

Bridge design squad leader

6) What is your job title?

Technical Engineer II (senior bridge design engineer) 


\section{A.23 Survey Response from Californai DOT}

1) In your experience, what are the three most important parameters controlling concrete bridge deck performance (e.g. specific design details, construction practice, environmental conditions, use of deicers, etc.)? Please order according to importance (most important to least important).

- Mix design - including measures to prevent initial cracking

- Design details such as additional clearance to top mat of rebar, epoxy coated rebar - Long-term preventive measures such as polyester concrete overlay and methacrylate treatment

2) What data does your agency currently collect in addition to the minimum requirements to satisfy concrete bridge deck inspections?

We have access to APCS data for all roadways in the state that allows us to see Condition State 3 deck cracking relatively closely to supplement inspections on roadways where lane closures are difficult or impossible.

3) If you could, what three additional information/measurements/tests would you collect/perform as part of every concrete bridge deck inspection in order to improve future asset management practice?

- Concrete soundness tests (such as those ABI Pros perform) on 100\% of every deck

- Cores taken to test salt intrusion/corrosion severity

- Crack width measurements in all lanes 
4) Do you have any additional recommendations or thoughts?

A large part of the bridge deck maintenance philosophy of our office is being proactive instead of reactive. We put additional clearance to the reinforcing, we've worked extensively on a crack-free deck specification, we use epoxy coated reinforcing where needed. We also place polyester concrete overlays in conjunction with methacrylate treatment in order to seal and protect the deck from salt intrusion and provide a wearing surface.

5) What is your area of responsibility in your agency (e.g. design, maintenance, programming, etc.)?

Structure Maintenance \& Investigations, and Chair, Bridge Preservation Committee

6) What is your job title?

Senior Bridge Engineer 


\section{A.24 Survey Response from New Jersey DOT}

1) In your experience, what are the three most important parameters controlling concrete bridge deck performance (e.g. specific design details, construction practice, environmental conditions, use of deicers, etc.)? Please order according to importance (most important to least important).

- Concrete mix design

- Environmental conditions

- Cracking

2) What data does your agency currently collect in addition to the minimum requirements to satisfy concrete bridge deck inspections?

Check atmospheric evaporation rate.

3) If you could, what three additional information/measurements/tests would you collect/perform as part of every concrete bridge deck inspection in order to improve future asset management practice?

- NDT

- NA

- NA

4) Do you have any additional recommendations or thoughts?

Research needed to figure out how to reduce / eliminate cracking of HPC decks 
5) What is your area of responsibility in your agency (e.g. design, maintenance, programming, etc.)?

Construction

6) What is your job title?

Project Engineer, Construction 


\section{A.25 Survey Response from Delaware DOT}

1) In your experience, what are the three most important parameters controlling concrete bridge deck performance (e.g. specific design details, construction practice, environmental conditions, use of deicers, etc.)? Please order according to importance (most important to least important).

- Construction Quality Control

- Deicing agents

- Material Specification: uncoated (black rebar) versus epoxy rebar

2) What data does your agency currently collect in addition to the minimum requirements to satisfy concrete bridge deck inspections?

- Deck soundings (when required)

- Impact Echo (IE) Survey: Used once decks reach a certain age ( 25 years). After initial IE, bridge is placed on a 48 month freq.

- Chloride sampling: typically used for older decks to help evaluate deck replacement versus deck rehab.

- Coring: typically used to identify concrete strength for older decks to help evaluate deck replacement versus deck rehab.

3) If you could, what three additional information/measurements/tests would you collect/perform as part of every concrete bridge deck inspection in order to improve future asset management practice?

- NA

- NA 
- NA

4) Do you have any additional recommendations or thoughts?

None

5) What is your area of responsibility in your agency (e.g. design, maintenance,

programming, etc.)?

Bridge Management: Inspection, Maintenance, Asset/Performance Management, Load

Ratings, Hauling Permits

6) What is your job title?

Bridge Management Engineer 


\section{A.26 Survey Response from Colorado DOT}

1) In your experience, what are the three most important parameters controlling concrete bridge deck performance (e.g. specific design details, construction practice, environmental conditions, use of deicers, etc.)? Please order according to importance (most important to least important).

- Placing an effective overlay

- Concrete cover

- Mix design

2) What data does your agency currently collect in addition to the minimum requirements to satisfy concrete bridge deck inspections?

Cores for chloride content, Visual Inspections

3) If you could, what three additional information/measurements/tests would you collect/perform as part of every concrete bridge deck inspection in order to improve future asset management practice?

- Chloride content measurement

- Chain drag if bare deck

- Perform A surface wave velocity analysis for deterioration limits \& delamination's

4) Do you have any additional recommendations or thoughts?

None 
5) What is your area of responsibility in your agency (e.g. design, maintenance, programming, etc.)?

Design. Corrosion protection Subject matter expert.

6) What is your job title?

Professional Engineer II/ Bridge Design Unit manager 


\section{A.27 Survey Response from Virginia DOT}

1) In your experience, what are the three most important parameters controlling concrete bridge deck performance (e.g. specific design details, construction practice, environmental conditions, use of deicers, etc.)? Please order according to importance (most important to least important).

- Construction practice

- Specific design details

- Use of deicers

2) What data does your agency currently collect in addition to the minimum requirements to satisfy concrete bridge deck inspections?

For acceptance of new decks: concrete strength, deck thickness, rebar cover, surface profile, surface texture, joint construction.

For 2 year inspections: the minimum requirements including surface rating, spalling, cracking, patches, drainage issues, joint condition.

3) If you could, what three additional information/measurements/tests would you collect/perform as part of every concrete bridge deck inspection in order to improve future asset management practice?

- Delamination's

- Electrical half-cell potentials

- Skid number 
4) Do you have any additional recommendations or thoughts?

Good management includes being able to plan for rehab 10 to 20 years later. Currently used visual inspections don't provide much information except when the results are compared to previous inspections and differences in the condition are seen. Once change is seen deterioration is rapid and rehab must be soon and long term planning is not practical. The most common cause of deck deterioration is corrosion of rebar. The best indicator of the area where corrosion is occurring is the electrical half-cell potentials. The deck must be closed to make the measurements is the reason it often not done. Maybe they should be done every 10 years. The potential data can be used for planning rehab 10 to 15 years later. Delamination's and spalling are an indication that immediate rehab is needed. Chloride data is not as useful as half-cell potential data because many factors (concrete quality, rebar quality, moisture, chloride differentials, etc.) influence the effect of chlorides on corrosion.

5) What is your area of responsibility in your agency (e.g. design, maintenance, programming, etc.)?

Design. Corrosion protection Subject matter expert.

6) What is your job title?

Professional Engineer II/ Bridge Design Unit manager 


\section{A.28 Survey Response from Montana DOT}

1) In your experience, what are the three most important parameters controlling concrete bridge deck performance (e.g. specific design details, construction practice, environmental conditions, use of deicers, etc.)? Please order according to importance (most important to least important).

- Concrete crack frequency and depth

- Intensity of deicer / anti-icer application (MT uses $\mathrm{MgCl}$ )

- Use of corrosion-resistant reinforcing

2) What data does your agency currently collect in addition to the minimum requirements to satisfy concrete bridge deck inspections?

For regular in-service inspections, we do not collect any additional data above the minimum requirements.

For deck rehabilitation / preservation project screening and scoping, we perform chaindrag mapping and a visual inspection at a minimum. For decks with a large percentage of delamination's, or those with obvious visual signs of distress, a full deck evaluation is performed. This includes chain dragging with delamination / crack / spall mapping, core samples for compressive strength testing, chloride analysis, and use of a pachometer to record reinforcement cover depths.

3) If you could, what three additional information/measurements/tests would you collect/perform as part of every concrete bridge deck inspection in order to improve future asset management practice? 
- Delamination percentage

- Crack frequency

- Reinforcement cover

4) Do you have any additional recommendations or thoughts?

We have been dealing with early-age full-depth cracking of our concrete decks for a while. We have had some recent success by modifying our curing requirements in an attempt to better control internal temperatures during curing. We are also experimenting with larger aggregate size and different types of corrosion-resistant reinforcing.

5) What is your area of responsibility in your agency (e.g. design, maintenance, programming, etc.)?

Bridge design

6) What is your job title?

Bridge Design Engineer (Design Section Supervisor) 


\section{A.29 Survey Response from Illinois DOT}

1) In your experience, what are the three most important parameters controlling concrete bridge deck performance (e.g. specific design details, construction practice, environmental conditions, use of deicers, etc.)? Please order according to importance (most important to least important).

- Superstructure flexibility and how the deck bounces under traffic loads

- Application of deicing chemicals and whether the deck is sealed to prevent chloride ingress.

- Thickness of deck and chloride resistant reinforcing steel.

2) What data does your agency currently collect in addition to the minimum requirements to satisfy concrete bridge deck inspections?

We collect routine NBIS deck condition ratings and Element Level deck condition states and environments along with the presence and condition of overlays and expansion joints.

3) If you could, what three additional information/measurements/tests would you collect/perform as part of every concrete bridge deck inspection in order to improve future asset management practice?

- Chloride penetration depth and infrared thermography to identify spall locations.

- Depth of cover to the top mat of reinforcing steel

- Concrete deck cracking and depth of cracks 
4) Do you have any additional recommendations or thoughts?

Thicker decks with less flexible superstructures should help with long term deck durability. Superstructures with a large live load deflection seem to have more extensive cracking. Employing more corrosion resistant reinforcing steel will go a long way to extending deck life and preventing spalls and delamination's. I would like to see more stainless steel reinforcement used.

5) What is your area of responsibility in your agency (e.g. design, maintenance, programming, etc.)?

Bridge Management and Inspection

6) What is your job title?

Bridge Management and Inspection Unit Chief - Bridges and Structures 


\section{A.30 Survey Response from Minnesota DOT}

1) In your experience, what are the three most important parameters controlling concrete bridge deck performance (e.g. specific design details, construction practice, environmental conditions, use of deicers, etc.)? Please order according to importance (most important to least important).

- Use of deicing chemicals (especially mag chloride prewetting)

- design details with 3" of cover and epoxy bars in both mats

- Construction practice to limit deck cracking (wet cure, fibers, HPC mix)

2) What data does your agency currently collect in addition to the minimum requirements to satisfy concrete bridge deck inspections?

We collect feet of deck cracking as an ADE. We use this for our bridge maintenance to capture quantity of future preventative crack sealing work. Element \#810 per our BSIPM manual.(page B-40 http://www.dot.state.mn.us/bridge/pdf/insp/bridge-and-structureinspection-program-manual.pdf)

Also we collect deck delamination quantity if there is a future project scheduled.

Also for high traffic areas sometimes we get GPR/IR data

3) If you could, what three additional information/measurements/tests would you collect/perform as part of every concrete bridge deck inspection in order to improve future asset management practice? 
- Chloride profile

- Concrete cover profiles from GPR

- Remaining service life modeling

4) Do you have any additional recommendations or thoughts?

Deck condition drives all of our bridge projects. We have 6 deterioration curves we use for planning and programming and all of them are based on deck. Sometimes it is difficult to assess condition of deck with overlays. The deck condition can rapidly deteriorate so we need to have proactive programming.

5) What is your area of responsibility in your agency (e.g. design, maintenance, programming, etc.)?

Operations, scoping, construction

6) What is your job title?

Bridge Construction and Maintenance Engineer 


\section{A.31 Survey Response from South Dakota DOT}

1) In your experience, what are the three most important parameters controlling concrete bridge deck performance (e.g. specific design details, construction practice, environmental conditions, use of deicers, etc.)? Please order according to importance (most important to least important).

- Deicers

- Deck cracking

- Type of resteel

2) What data does your agency currently collect in addition to the minimum requirements to satisfy concrete bridge deck inspections?

On select cases, we'll do chloride levels, GPR, Infrared and just normal chain drag to identify deck decontamination areas.

3) If you could, what three additional information/measurements/tests would you collect/perform as part of every concrete bridge deck inspection in order to improve future asset management practice?

- Chloride Levels

- Infrared/GPR

- Map of deck delamination's

4) Do you have any additional recommendations or thoughts?

None 
5) What is your area of responsibility in your agency (e.g. design, maintenance, programming, etc.)?

Bridge Inspection, Bridge Maintenance/Rehab/Preservation, programming bridge projects

6) What is your job title?

Bridge Maintenance Engineer 


\section{A.32 Survey Response from Washington DOT}

1) In your experience, what are the three most important parameters controlling concrete bridge deck performance (e.g. specific design details, construction practice, environmental conditions, use of deicers, etc.)? Please order according to importance (most important to least important).

- Adequate design and details, epoxy coated bars, etc.

- Adequate construction practice, extended curing, finishing

- Deck protection including corrosion protection, sealant

2) What data does your agency currently collect in addition to the minimum requirements to satisfy concrete bridge deck inspections?

Deck condition, spalling using chain drag, deck cracks and crack orientation, bar corrosion and any rust discoloration, deck leaking from bottom side

3) If you could, what three additional information/measurements/tests would you collect/perform as part of every concrete bridge deck inspection in order to improve future asset management practice?

- Deck deformation and settlement

- Deck rotation by inspecting the expansion joint opening

- Deck movement in longitudinal direction affecting joint performance

4) Do you have any additional recommendations or thoughts? 
Concrete deck performance and longevity could be improved requiring: 1) performance specifications rather than prescriptive mixes 2) use of fiber in the mix 3) avoid high strength concrete mixes above 5ksi 4) avoid large pier skews if possible 5) impose proper sequence of deck casting to minimize cracking 6) Increase the solid to paste ratio in the concrete mix 7) Proper bar placement allowing free flow of concrete through the bar grids

5) What is your area of responsibility in your agency (e.g. design, maintenance, programming, etc.)?

Bridge Design

6) What is your job title?

WSDOT State Bridge Design Engineer 